Melanie U. Pooch

DiverCity - Global Cities as a Literary Phenomenon 
Melanie U. Pooch received her doctoral degree at the University of Mannheim, Germany. Her research interests include Corporate Responsibility and North American cultural, urban, and literary studies in a globalizing age. 
Melanie U. Pooch

\section{DiverCity -}

Global Cities as a Literary Phenomenon

Toronto, New York, and Los Angeles in a Globalizing Age 
The original version of this manuscript was submitted as a doctoral dissertation to the University of Mannheim.

An electronic version of this book is freely available, thanks to the support of libraries working with Knowledge Unlatched. KU is a collaborative initiative designed to make high quality books Open Access for the public good. The Open Access ISBN for this book is 978-3-8394-3541-0.

More information about the initiative and links to the Open Access version can be found at www.knowledgeunlatched.org.

\section{(c) $(\mathcal{\infty} \Theta \Theta$}

This work is licensed under the Creative Commons Attribution-NonCommercial-NoDerivs 4.0 (BY-NC-ND) which means that the text may be used for noncommercial purposes, provided credit is given to the author. For details go to http://creativecommons.org/licenses/by-nc-nd/4.o/.

To create an adaptation, translation, or derivative of the original work and for commercial use, further permission is required and can be obtained by contacting rights@transcript-verlag.de

\section{(C) 2016 transcript Verlag, Bielefeld}

\section{Bibliographic information published by the Deutsche Nationalbibliothek}

The Deutsche Nationalbibliothek lists this publication in the Deutsche Nationalbibliografie; detailed bibliographic data are available in the Internet at http://dnb.d-nb.de

Cover layout: Kordula Röckenhaus, Bielefeld

Cover illustration: New York City 2007 by Michela Zangiacomi Busch, Sulzburg; (C) Pooch

Printed by Majuskel Medienproduktion $\mathrm{GmbH}$, Wetzlar

Print-ISBN 978-3-8376-3541-6

PDF-ISBN 978-3-8394-3541-0 


\section{Contents}

\section{Acknowledgements |7}

1 Introduction |9

2 Globalization and Its Effects | 15

2.1 Mapping Globalization | 15

2.2 Global Consensus | 18

2.3 Global Controversies | 23

3 Global Cities as Cultural Nodal Points | 27

3.1 Urban Studies | 28

3.2 Cultural Nodal Points | 31

3.3 Toronto, New York, and Los Angeles |33

4 Cultural Diversity in a Globalizing Age | 37

4.1 Concepts of Identity | 40

4.2 Postcolonial Discourse 42

4.3 Intra, Inter, Multi, and Trans 49

4.4 The Melting Pot, Salad Bowl, and Canadian Mosaic | 53

$5 \quad$ The Poetics of diverCity | 57

5.1 The Poetics of Narrative | 63

5.2 The Poetics of Place | 67

5.3 The Poetics of Code-Switching | 73

6 Dionne Brand's Toronto, What We All Long For | 79

6.1 The Global City of Toronto 179

6.2 Toronto Imagined: The World in a City $\mid 86$

6.2.1 Polyphonic Murmuring | 88

6.2.2 Converging Threads 94

6.2.3 Mapping the World in a City $\mid 98$

6.2.4 Counter-Cartographies | 103

6.2.5 Time-Space Discrepancy | 109

6.2.6 Longing and Belonging | 113

6.3 Interim Conclusion | 120 
7 Chang-rae Lee's New York, Native Speaker | 123

7.1 The Global City of New York | 123

7.2 New York Imagined: A City of Wor(l)ds | 132

7.2.1 The Strangest Chorale | 135

7.2.2 False Speaker of Language | 138

7.2.3 Amiable Man | 142

7.2.4 The Immigrant City | 149

7.2.5 Interethnic Imagination $\mid 156$

7.3 Interim Conclusion | 162

8 Karen Tei Yamashita's Los Angeles, Tropic of Orange | 165

8.1 The Global City of Los Angeles | 165

8.2 Los Angeles Imagined: The World City | 175

8.2.1 HyperContexts | 177

8.2.2 The Polyglot | 184

8.2.3 The Global | 187

8.2.4 ElastiCity | 192

8.2.5 These Lines | 198

8.3 Interim Conclusion | 203

9 Conclusion | 205

Works Cited | 211 


\section{Acknowledgements}

First and foremost, I want to thank my advisors and mentors Prof. Dr. Ulfried Reichardt and Prof. Dr. Christa Grewe-Volpp. It has been an honor to be your Ph.D. student.

Thank you, Prof. Dr. Roger Keil, Prof. Dr. Jens Martin Gurr, Prof. Dr. Wilfried Raussert, and Prof. Karen Tei Yamashita for your generous support and inspiration with your knowledge and expertise. Thank you my friends for many insightful comments regarding my interdisciplinary project.

I highly appreciate the Ph.D. scholarships I received by the Graduate Program "Formations of the Global" at the University of Mannheim and the Graduate Scholarship Program of the state of Baden-Württemberg. The German Academic Exchange Service (DAAD), the FAZIT Foundation, and the University of Mannheim supported my research abroad in the U.S. and Canada as well as my presentations at conferences in the U.S., Canada, Brazil, and Germany.

Finally, I would like to thank my family, in particular my mom and my sister. My special thanks goes to my partner and his family. I cannot thank you and my family enough for encouraging me throughout this experience. 



\section{Introduction}

The two decades after the beginning of the 1990s saw a paradigm shift across various academic fields, one that also sustainably changed literary and cultural studies. During this time, as a result of the interdisciplinary research of the socioeconomic phenomenon of globalization, North American literary and cultural studies were increasingly denationalizing, reflecting the world-wide globalization process with its increased connectivity and convergence, the erosion of borders, and a growing multidirectional migration. At the same time, interethnic writing was gaining significance, particularly in Canadian multicultural literature and Asian American literature, and established schools of urbanism were performing in-depth studies of global cities as global cultural nodal points in a global network of flows and as major points of intersection for different ethnicities. This co-existence of the rising significance of interethnic writing and the greater understanding of global urbanism has meant that the urban literature of the time illustrates and reflects the multiplicity of cultural diversity in a globalizing age.

As this work's title 'DiverCity - Global Cities as a Literary Phenomenon' expresses, the literary representation of cultural diversity in a globalizing age is analyzed by focusing on the North American global cities of Toronto, New York, and Los Angeles. The neologism 'diverCity,' a compound blend of 'diversity' and 'city,' stresses this study's emphasis of the impact of cultural diversity in a globalizing age on global cities as a literary phenomenon. Thus, globalization functions as the temporal frame, global cities as the spatial frame, and cultural diversity as the topical frame. The common aesthetics of global literature, urban fiction, and ethnic writing identified in this literary analysis are 'the poetics of narrative,' 'the poetics of place,' and 'the poetics of code-switching.' Thus, the three selected contemporary North American novels serve as examples of how an analysis by a 'poetics of diverCity' provides the opportunity to analyze ethnic urban literature in a globalizing age in a structured way. 
This analysis aims to identify and distinguish specifics and synchronies of global cities as a literary phenomenon. Whereas the term 'specifiCity' explains the specific particularities of each global city as a result of its individual economic, geo-political, and socio-cultural present and past, the concept of 'synchroniCity' describes parallel phenomena in a global context, in particular for globalization and its worldwide effects. Using a structured literary analysis involving a poetics of narrative, place, and code-switching allows common as well as individual aspects of global cities as a literary phenomenon to crystallize. As a prerequisite, however, the key terms and particular aesthetics of this analysis need to be introduced.

This work begins in chapter 2 with a brief definition of globalization and its effects. The term 'globalization' has been used in literature since the 1980s, soon being applied all-pervasively across different disciplines. Although globalization is claimed to have started as early as around the discovery of the Americas and was accelerated by the nineteenth century's globe-encompassing transportation and communication, the term gained stronger momentum with the growing global economy in the 1990s. In this globalizing age, increased connectivity, improved technologies, and perceived convergence lead to growing global interdependence, the slow erosion of geo-political borders, and multi-directional migrations. These forces and innovations have triggered global economic, cultural, and media exchange. In this work, homogenization and hybridization, which describe a form of standardization and heterogeneity, are presented as the main departure points within the discussion of globalization.

Chapter 3 places the emphasis on global cities as cultural nodal points, while exploring the interactional relationship of globalization, cultural diversity, and urban space. After introducing the two rivaling movements of urban studies, the traditional Chicago school and the more recent L.A. school, and the main characteristics, functions, and qualities of global cities, attention is shifted to the cultural significance of urban centers in a global network of flows. In this study, the global cities of interest are Toronto, New York, and Los Angeles, three of the largest, most culturally diverse, and globally connected metropolis in North America. While Los Angeles and New York are the American global cities, the preeminent Canadian global city of Toronto is included to show how different regional and national discourses impact cultural diversity in global cities in a globalizing age.

In chapter 4, the concept of 'cultural diversity' and the wide array of neighboring terms are explored. Due to the acceleration of cultural flows and the porosity of borders, cultural exchange in a globalizing age is increasingly understood and practiced multidirectionally. As a consequence, constructions such as 
'national identity' are progressively questioned because cultural identity is being understood more flexibly and dynamically. Emerging in American discourse in the late 1970s, the term 'diversity' describes the process of individual and group identity formation, involving a range of different cultures. In literary and cultural studies, 'diversity' is connected to a multitude of neighboring concepts, such as 'postcolonial hybridity,' 'transnationalism,' or 'the melting pot,' each indicating topics of integration, immigration, adaption, cultural dominance, or assimilation. To analyze the type or degree of integration of specific ethnicities, minorities, or immigrants in a particular global city, the different forms and conceptualizations of diversity need to be examined.

Chapter 5 then focuses on the particular aesthetics of the subsequent literary analysis - the poetics of diverCity - a main component of this work. The combination of the three aesthetics of analysis, 'the poetics of narrative,' 'the poetics of place,' and 'the poetics of code-switching' forms the basis for identifying and interpreting ethnic diversity in global city literature. The text here explores how the novels illustrate and translate the multiplicity, complexity, and heterogeneity of the interaction and negotiation of different ethnic influences in the cultural contact zone of North American urban settings in a time of globalization. Concepts of identity and space, movement and loss, and border experiences are recurring subjects in global literature, ethnic literatures, or both, while hybrid text forms, intertextuality, and polyglossia are recurring elements of style. The 'narrative,' 'place' and 'code-switching' aesthetics allow the literary (re)presentation of 'diverCity' to be grasped through the common features of the selected novels. This analysis provides the connecting link required to show how a literary analysis can fill the gap when examining the triad of globalization and its effects, global cities as cultural nodal points, and cultural diversity in a globalizing age as a literary phenomenon.

In chapters 6,7 , and 8 , the 'poetics of diverCity' will then be applied to the literary analysis of the three selected ethnic global city novels, examining and comparing the synchronic impact of globalization, the specific characteristics of global cities, and the multiplicity of cultural diversity. Each selected novel, Dionne Brand's Toronto, What We All Long For (2005), ${ }^{1}$ Chang-rae Lee's New York, Native Speaker (1995), ${ }^{2}$ and Karen Tei Yamashita's Los Angeles, Tropic of Orange $(1997)^{3}$, constitutes all of the three types of literature: global, urban, and ethnic. Furthermore, they encompass the common characteristics of having

1 Hereafter referred to as ' $W H A$.'

2 Hereafter referred to as ' $N A S$.'

3 Hereafter referred to as 'TRO.' 
been published within the last two centuries, of being mainly set in a North American global city and of incorporating themes of globalization and its effects. The three selected contemporary novels are written in English by authors with an immigrant background. Each novel features a multi-ethnic cast of characters in which a variety of ethnicities are incorporated, each trespassing the ethnic background of the respective author. While each novel features different forms of socio-cultural integration and self-definition, different forms of an 'interethnic imagination' represent a recurring theme. Moreover, since the 'real' and the 'literary' city have an intrinsic relationship, each global city and its particular development and unique composition of cultures is briefly introduced preceding the respective novel's analysis. It is these chapters that provide the detail to tackling the challenge of comparing global cities in a globalizing age: the challenge arising from being as influenced by global process as by national or regional particularities.

In chapter 6, Dionne Brand's Toronto, What We All Long For (2005) can be described as 'the world in a city' because the diversity of the world becomes visible in one city, illustrating the coexistence and overlap of the different worlds. The novel rewrites the formerly anglicized city of Toronto by focusing on a selection of characters that forms an interethnic coalition across the boundaries of the different worlds within the city. The new ethnic diversity of Toronto's formerly anglicized society is made audible with a new vocabulary and reveals the multiple meaning and associations inscribed in a certain place. Brand's Toronto is an urban cultural contact zone where people of different ethnicity, class, or gender encounter each other and intermingle peacefully, while others still struggle for the integration, equality, and social acceptance promoted by the political ideal of Canadian multiculturalism. The novel thus manages to combine the two contradictory discourses of how the integration of the first generation, African Canadians, or illegal immigrants failed and how Toronto offers a space of diversity and tolerance to culturally diverse second-generation immigrants who identify themselves with a new collective form of global urban citizenship that circumvents cultural categorizations.

In chapter 7, Chang-rae Lee's New York, Native Speaker (1995) becomes 'a city of wor(l)ds' (NAS 319) because the poetics of code-switching is the novel's dominating strategy for the visualization, exploration, and translation of urban immigrant life and the integration of the different ethnic groups into society. The novel's depiction of the linguistic distinctiveness of the diverse immigrant groups is achieved without drawing on voicing vernacular in a written form. As the novel's title illustrates, language and conventions have the power to both marginalize and integrate because, even if an immigrant speaks English fluently, 
recognition as a well-integrated American citizen is difficult. By comparing the particular experiences of the two Korean Americans, Henry Park and John Kwang, the general opportunities and limitations of immigration and integration are explored in a 1990s 'Giuliani time' New York. With the application of different narrative strategies that go beyond Asian American literary traditions, globality and diversity manifest themselves in the novel's structure and form, reconciling Asian and African Americans and creating an interethnic vision beyond the two groups.

In chapter 8, Karen Tei Yamashita's Los Angeles, Tropic of Orange (1997) is presented as 'the world city' in which different worlds, such as the 'First World' and the 'Third World,' converge, collide, and cooperate. In the novel, the poetics of narrative, place, and code-switching are equally important. Thus, whereas Brand's Toronto is expressed as a city with many different, overlapping worlds and Lee's New York as a city in which language is the governing structure, Yamashita's Los Angeles captures both and the complexity, diversity, and multiplicity of the globe, virtually representing the world. Yamashita's Los Angeles is a fragmented urban complex in terms of geography, politics, ethnicity, and class, while the novel's mixing of genres paves the road for a new ethnic literature in a globalizing age. Set in a 1990s post-riot Los Angeles, each character is presented with an individually tailored narrative voice and the same number of chapters, thus coming as close as possible to grasping the global. When the whole geography is moved and everything converges in Los Angeles and its neighboring border zone, the global city, its appearance, and cultural identity are altered. In the end, the interethnic collaboration of the seven culturally diverse characters advocates globalization as a process of hybridization and global mélange, challenging the insistence on borders in physical-geographic, literarygeneric, ethnic-categorical, and socio-political terms.

Based on the structured analysis of the three selected North American novels - Dionne Brand's Toronto, What We All Long For (2005), Chang-rae Lee's New York, Native Speaker (1995), and Karen Tei Yamashita's Los Angeles, Tropic of Orange (1997) - this work examines the cultural diversity of global cities as a literary phenomenon ('diverCity') by applying 'the poetics of narrative,' 'the poetics of place,' and 'the poetics of code-switching' to illustrate specific occurrences ('specifiCity') and common developments ('synchroniCity') in a globalizing age. However, before this can be accomplished, the three key terms of this work - globalization, global cities, and cultural diversity - must be explained, beginning with a brief definition of globalization and its effects. 



\section{Globalization and Its Effects}

A great amount of information and material is provided with regard to the study of globalization. In general, research in this field of study is mainly focused on economic, technological, or information systems. This work, however, puts the spotlight on the interplay of the very cohesive concepts of globalization and culture. Tomlinson and Nederveen Pieterse, in particular, successfully connect the dots between the two. Globalization carries many different conceptualizations and interpretations, resulting in a plethora of information and arguments. A concise definition of globalization and its accompanying themes and forces constitutes a difficult task.

This chapter aims at preparing the groundwork for a stable discussion on a 'global turn' in literary and cultural studies for the analysis of cultural diversity and the contemporary North American global city novel. This is accomplished by a brief introduction to the major themes of globalization in Section 2.1. In Section 2.2 on 'Global Consensus,' the recurring characteristics that trigger globalization will be presented. Using the three main approaches to the effects of globalization, the different opinions on globalization theory will be presented in Section 2.3.

\subsection{Mapping Globalization}

Global phenomena continue to entertain the world, including economic issues such as the global financial crisis, ecological issues such as global warming, sport events such as the soccer World Cup or the Olympics, and internationally successful celebrities such as Lady Gaga. Globalization is all-embracing and so is its critique. This work refrains from a more detailed description as 'globalization' is a multi-faceted term, used throughout a wide range of fields of studies. In this chapter, however, a brief definition of globalization is provided. Starting 
with the pinning down of a global time frame, globalization as a possible result of modernity as well as the coordinates and the population of the topic are laid out.

Due to its all-pervasiveness and easy application, every subject can be linked to and is affected by globalization. In the field of cultural studies, advocates include Tomlinson 2001; Nederveen Pieterse 1995, 2004; Stuart Hall 1992; Featherstone 1995; Kraidy 2002, 2005; Appadurai 1990, and Huntington 1996. In international politics, one advocate among many is McGrew 1992. Thomas L. Friedman (2005) claims that for the best or worst, the world has changed economically. Moreover, Jeffrey D. Sachs argues in favor of globalization in his 2005 book The End of Poverty. In sociology, critics include Lash et al 1994; Castells 1996, 1997, 1998; and Robertson 1992. Friedman (1994; 1999) writes about globalization with regard to anthropology. Critics as well as opponents include, among many others, Hirst and Thomson. In Globalization in Question (1996), the two critics argue against a solely economically induced and influenced globalization.

The term 'globalization' itself was coined by the economist Levitt in 1983. It was used in literature beginning in the mid-1980s and gained strong momentum in the 1990s. Since the beginning of the 1990s (Schnell 2000: 189), the use of the term has been propelled by a growing global economy. The name is derived from the globe, encompassing the entire world on Earth. Different versions of the term are used. Whereas the most frequently employed term 'globalization' describes a continuous transnational process of interconnectedness, 'globalism' refers to an economically-driven development (Beck 1997) and 'globality' refers to an 'actual condition' (Stockhammer 2010: 336). Depending on the discipline and the particular national discourse, concepts like 'mondialisation' and 'planetarity' are discussed occasionally. These notions are not derived from the globe but from similar 'unifying' concepts such as the world or the planet. The French term 'mondialisation' describes the economic process of globalization, the rather ecological function of 'planetary awareness,' and the social consciousness of an increasing economic inequality in the world (Augé 2008: x [1995]). The plural form 'mondialisations' describes the plurality of the different cultural phenomena of globalization and how we think about the world in different disciplines (Badura 2006). The term 'planetarity' also functions as a 'counter concept' to globalization, thereby highlighting social responsibility. With regard to this concept, unity is conveyed because humankind inhabits one shared planet (Spivak 2003). Nevertheless, 'globalization' remains the outstanding term across the disciplines. Moreover, the global city is derived from the term and functions as a 
strategic node, both hub, and contact zone of the various processes of globalization. Therefore, 'globalization' will be the leading term of this analysis.

Critics argue about the emergence of globalization. Some claim it occurred within the last thirty years, whereas others see a connection between globalization and modernity (Nederveen Pieterse 2004: 15f.). This sociological approach, which contemplates whether globalization is a consequence of modernity (Giddens 1990) or not, is fiercely disputed. Some critics claim that the 'Global Age' replaced the 'Modern Age' (Albrow 1997: 6), while others draw the line between the revisit of modernity and capitalism (Nederveen Pieterse 2004: 1). Thus, due to its similar economic settings, globalization is occasionally regarded as the disguised successor to imperialism (Nederveen Pieterse 2004; Tomlinson 2001).

Since globalization is viewed as a result of modernity that originated in Western Europe, heavy critique about its Euro-centrism, or the only one kind of modernity, that of the West, arises because it implies the 'Westernization' approach to globalization. Some critics claim that globalization started as early as around 1500 (Reichardt 2010: 31) with the voyages of Christopher Columbus and his discovery of the Americas. This timeframe functions as the first stimulus of globalization, followed by the second stimulus of globe-encompassing transportation and communication in the nineteenth century, and the third and more recent stage of supranational economics and transnational cultures (Ette 2004: 29). With the end of the Cold War and the reunification of Eastern and Western Germany in 1990, physical and symbolic walls became translucent, supporting and accelerating our steadily globalizing and seemingly borderless world (Ohmae 1992).

Locating the global population seems to be an easy task since globalization encompasses the entire globe. Hence, every citizen in the world is affected. However, its global reach is also disputed because globalization affects some regions of the world more than others due to its unbalanced impact. The erosion of boundaries furthers transactions of every kind so that the globe is increasingly connected, disregarding national boundaries, e.g. through the flow of people, capital, or crimes. This phenomenon is taking place simultaneously with a trend towards a demise of the nation-state (McGrew 1992: 65). Hence, to some critics, the term 'transnational' is outdated. ${ }^{4}$ However, critics agree that globalization is not a balanced but rather an uneven force. The process is very selective, as it af-

4 For more information about the term 'transnational' and other expressions used with regard to (cultural) exchange across national borders, see Chapter 4 on 'Cultural Diversity in a Globalizing Age.' 
fects some areas of the world more than others. Nederveen Pieterse calls this effect a 'selective globalization' (2004: 13). According to this approach, globalization started in Europe and other Western countries, whereas remote cultures have not been as affected or not as immediately affected. Moreover, not everyone in the world's population has equal access to markets and technologies (Augé 2008: xi [1995]).

The question of global geography is interrelated with the mapping of a global population. For the first time in history, almost every world citizen is involved. This is the revelation of the globe-encompassing phenomenon. However, each individual is affected on a different scale. These uneven proportions are mainly dependent on the individual's location. Whereas Western or the most developed countries are more globalized, the so-called 'Third World' or less-developed countries are not as much in touch with globalization. The stage of globalization is dependent on active and passive elements of a country, region, or ethnic group. Active elements can be influenced by the individual, for instance the opportunity to travel or the opportunity to use the Internet. In Germany, for example, almost everyone can afford Internet access; however, not many can afford a transatlantic flight. Passive elements restrict those active possibilities for individuals and are mostly determined by political, economic, and geographical restrictions slowing down the globalization process. China's restrictions on the Internet are a good example with entire domains being banned, isolating their inhabitants from world news, as in the struggle for Tibet's independence. Thus, the individual globalization is limited by the political or passive elements of the country.

Pinning down the effects of globalization remains a double-edged sword. Due to the enormity of the material on globalization, fixed and inclusive categories of parallels and controversies of the concept remain a difficult task. Nevertheless, the following two sections will show, on the one hand, parallel opinions and, on the other, disputes in the approach to the topic of globalization and its effects.

\subsection{Global Consensus}

Most critics from various fields, such as economy, sociology, and cultural studies, agree on the following assumptions. The three forces of globalization, namely increased connectivity, improved technologies, and perceived convergence, lead to three innovations. These include the growing global interdependence, a growing numbers of multi-directional migrations around the world, and the slow 
erosion of (national) politics. The forces and innovations trigger international or even global exchange with regard to economic, cultural, and media background. Five types of transnational flows can be identified in a global context: ethnoscapes, technoscapes, financescapes, mediascapes, and ideoscapes, (Appadurai 1996: 33). Moreover, the effects of globalization become driving forces themselves, enriching a circular process of forces and effects. This section will briefly introduce the different forces and effects that accelerate global flows and connectedness. The section will be concluded with a short glimpse at the cultural meaning of globalization.

Increased connectivity translates into fast, almost immediate exchange of information with regard to politics, security, and media. Globalization, as a process, constantly pushes for more connectivity (Hannerz 1990: 237), resulting in increased networking around the globe. Anthony Giddens calls this effect a 'local-global dialect' (1990) in which individual actions on a local level have a global impact, e.g. in the clothing industry: buying a T-shirt has an effect on a Filipino worker thousands of miles away from the purchase. Similarly, news is spread around the world in an instant. One recent example is the Islam-critical You Tube movie from an independent American director, which caused uproar in Pakistan and then quickly spread to further Muslim countries within days. The awareness of this interconnectedness shifts the attention to the so-called butterfly effect ${ }^{5}$ or chaos theory (Kiel et al 1996: 58) in which local events can trigger global actions, problems, disputes, or even catastrophes. ${ }^{6}$ Thus, in a global context, "the world has become one network of social relationships" (Hannerz 1990: 237) in which the different cultural flows interconnect the different localities. Castells calls this effect a 'network society.' The global network society is characterized by both its common features and its diversity. It is conceived as a system of different network societies communicating with each other, forming a global network of information (Castells 2004).

Technological advances are accompanied by an increase in connectivity and experienced convergence. The entire globe seems to be connected by new or better means of infrastructure, transportation, information, or digital devices. Ac-

5 The 'butterfly effect' is a popular term that describes the 'chaos theory' originating in mathematics. This approach explains how a minor error can grow into a tremendous consequence.

6 Albert-László Barabási's Linked: How Everything Is Connected to Everything Else and What It Means for Business, Science, and Everyday Life (2002) provides an entertaining book with regard to the matter of global connectedness as well as the emergence of world-wide events, such as trends or diseases. 
cording to Alfonso de Toro, new Internet technology has "transformed the world into an ever-growing virtual surface that, on the one hand, expands the world in an almost infinite way and, on the other hand, compresses it radically so that we live in a permanent implosion" (2006: 20). New technology leads to faster information services and growing global networks of people, capitalism, and ideologies. While global-encompassing instant messaging devices such as Twitter rapidly change information technology and the entertainment industry, social networks such as Facebook have an increasing impact on the world's youth, forming transnational and translingual 'imagined communities' (Anderson 1983). Thus, technology becomes the capitalist vehicle of culture in which different cultural elements are transported via different transportation systems, the mass media, or alternative electronic devices.

The perceived convergence is first and foremost a product of an individual's consciousness of a global world and its interconnectedness. This awareness of the wholeness of the world (Robertson 1992: 8) or the feeling of more intimacy emerges because remote images are transported to us, e.g. via electronic devices (Tomlinson 2001). An increasing global proximity of places is one possible result. Everything is closer or easier to reach in a certain time frame, e.g. through infrastructure, or it appears closer through the transportation of information and images via electronic or wireless connections. Thus, the image of a 'shrinking world' is created by the illusion of a 'time-space compression' (Harvey 1989) or an 'annihilation of space by time' (Marx 1973).

The first of the three innovations of globalization is the growing interdependence. The global marketplace, for instance, is ruled by global competition (Schnell 2000: 189) and global players in business. This economy-induced globalization interconnects the world economy. However, the process is not a balanced one because economic globalization is mainly influenced by Western countries. Nevertheless, this economically-driven globalization is continuously networking beyond geographical, political, and ethnic boundaries. Free market zones in specific regions of the globe, e.g. NAFTA ${ }^{7}$, are established. Finance and banking have been internationalized. Several good examples include the transna-

7 NAFTA, or the North American Free Trade Agreement, is a treaty that facilitates the transaction of money and other goods between the United States, Mexico, and Canada. Please forward to Section 8.2 'Los Angeles Imagined: The World City' to read more about globalization and NAFTA in Karen Tei Yamashita's Tropic of Orange (1997). 
tional economy of institutions, such as $\mathrm{IMF}^{8}$ or the World Bank and the interdependence of Wall Street with other stock markets. Marx and Engels claimed a long time ago that, economically speaking, "the need for a constantly expanding market for its goods chases the bourgeoisie over the whole surface of the globe. It must nestle everywhere, settle everywhere, establish connections everywhere" (1967: 83 [1848]). This interconnectedness results in extreme competition when it comes to the positioning of headquarters, production facilities, call center services or to economic strategies, such as off-shoring or outsourcing due to cheaper labor, taxes, and other cost cuts. Hence, to some extent, the "acceleration of time-space compression [is] propelled by transnational companies" (Barker 2004: 76).

The second innovation of globalization is a growing multidirectional migration. Jan Nederveen Pieterse argues that "we are all migrants" (2004: 32) and that migration furthers the "interethnic mingling and crisscrossing of gene pools and physiological features" (2004: 26). He claims that there has been a process of 'hybridization' going on all along because "“national' identities are mélange identities, combinations of peoples that have been conventionally amalgamated under a political heading" (2004: 33 ) that has been constructed to create this national identity. There is no question that migration and colonialism, whether boon or bane, have propelled cultural exchange. Newly industrializing countries are longing for an improvement of their standard of living, whereas Western people nowadays strive to go back to their roots or long for an experience of 'exotic' lifestyles abroad. People now migrate to every corner of the globe, and this migration has thus led and contributed to a transfer of knowhow and global technological and economic progress (Griffin 2000).

The third innovation of globalization is the gradual erosion of politics. This may either include the decreasing number of voters and less trust in national politics or, it may signify an erosion of boundaries (Scholte 2000), to a so-called borderless world (Ohmae 1992). In globalization, the demise of the nation-state "involves a paradigm shift from the era of the nation state and international politics to planetary scope" (Nederveen Pieterse 2004: 7). Moreover, transportation and even more so Internet traffic cross boundaries and face even fewer borders or no limits at all, creating an illusion of a world without borders. Hence, the terms 'transnational' and 'international' fail to capture the global process of exchange, in particular with regard to cultural studies, because they refer to interac-

8 IMF stands for International Monetary Fund, an organization that watches world-wide financial transactions. 
tions between two or more nations, whereas globalization goes beyond nations or countries by referring to the entire globe.

Jan Nederveen Pieterse argues that the nation-state has been receding; instead, there emerged an 'age of ethnicity' (2004: 33). This leads us to the cultural meaning of globalization, which is the most important issue with regard to this study on cultural diversity of the literary global city. John Tomlinson explains the reciprocal relationship between culture and globalization as the following: whereas the latter lies "at the heart of modern culture; cultural practices lie at the heart of globalization" (2001: 1). Thus, the understanding of culture is altered in the process of globalization due to the intrinsic relationship between culture and globalization.

As mentioned before, another effect of globalization is the compression of the world (Barker 2004: 76). This all-encompassing act of imagining 'one world' raises awareness and consciousness of the compression process, shrinking the Earth metaphorically, and steadily increasing connectedness. With regard to cultural studies, a compression of the world is beneficial (Barker 2004: 76) because "globalization disturbs the way we conceptualize "culture"" (Tomlinson 2001: 27). Due to the formerly prevailing locality concept, culture was seen as a local phenomenon, shaped by specific local influences. Nowadays, culture is no longer restricted to a certain country or region. It breaks through local cultures and breaks off the immobility of the concept. Globalization provides the opportunity for a 'moving together' of all human kind beyond constructions such as race, class, and nations by celebrating multiculturalism in the media, fashion, and sports (Schnell 2000: 189). Signs of transcultural relations are transported via our television and shopping centers, giving remote cultures a voice and providing access to other or mainstream cultures. According to Ohmae, this resembles "the new melting pot of today's cross-border civilization" (1995: 39). Therefore, tastes, styles, and other economically-induced phenomena circumvent or even blur physical or political borders.

Nevertheless, globalization is not a phenomenon that creates opportunity and equality for all. As a matter of fact, apart from the three forces and the three innovations of globalization, there are many controversies inherent in the topic of globalization. Some critics speak of a 'homogenization', while some argue for a 'differentiation' of cultures. The next section consequently provides an overview of the main approaches to defining globalization and tackling its main directions. 


\subsection{Global Controversies}

There are many departure points within the discussion of globalization, its effects, and repercussions. In this study, three main directions of the topic are identified, namely both westernization and standardization as a process of homogenization as well as hybridization as a concept of heterogeneity. This section aims at featuring an overview of the main directions and several different but nevertheless related approaches to globalization within these directions, providing the perfect cradle for an analysis of cultural diversity in an urban global context.

Globalization can be distinguished in two forms prevailing in literature: uniformity with regard to consumerism (or homogenization) or differentiation as cultural fragmentation (Nederveen Pieterse 2004: 1). Within the concept of 'homogenization', there are two approaches to global uniformity: Westernization, coined by Serge Latouche's The Westernization of the World (1996: 3), and standardization. The two approaches go hand in hand, both featuring the assumption that globalization is a type of modernization. However, due to this study's focus on North America, the question needs to be raised with respect to how the United States fits in. Americanization is the latest variety of the Westernization approach (Nederveen Pieterse 2004: 49). According to this concept, "hegemony is prepackaged in Los Angeles, shipped out to the global village, and unwrapped in innocent minds" (Liebes et al 1993: xi, quoted in Tomlinson 2001). Therein, cultural icons and values, being predominantly American, are transported beyond borders and continents. The impact of international businesses, rooted foremost in the United States, changes the whole world. Since the 1970s, terms like Coca-colonization (Howes 1996), McWorld (Barber 1995), and Disneyfication (Zukin 1995) have been used in exchange for a standardized Westernization perspective of globalization. McDonaldization, for instance, is "the process whereby the principles of the fast-food restaurant are coming to dominate more and more sectors of American society as well as the rest of the world" (Ritzer 1993: 19). All forms stand for a variety of American influence that, together with the power of the American media, lead to 'global cultural synchronization' (Nederveen Pieterse 2004: 49).

Hence, Americanization can be translated as neo-colonialism due to its focus on consumerism, commercials, mass media, mass production, and sales. Essentially, everything is money-focused. The settling and colonization are no longer performed in a physical manner but rather via the transportation of trends, values, and legends like the 'American dream.' Critically speaking, a country in which self-determination, self-development, and self-making are the highest values teaches the world about 'right' or 'wrong' by means of TV shows, Holly- 
wood movies, and hip hop videos. This is not only a transfer of lifestyle but, taken to the extreme, a claim of manifest destiny and superiority in disguise of a civilizing mission to bring the world democracy, wealth, and consumerism. Therefore, Americanization, a double-edged sword, is feared to be cultural imperialism in which the hegemonic culture imposes power over non-Western cultures. Critical conceptions include a nightmare scenario in which "the hierarchical nature of imperialism, that is the increasing hegemony of particular central cultures, the diffusion of American values, consumer goods and lifestyles" (Friedman 1994: 195) constitute the focus. Of course, some critics argue against the homogenization effects of economic influence (Lowe et al 1997). Nevertheless, most view the Westernization force as a trend towards a so-called capitalist monoculture (Tomlinson 2001: 83).

In line with cultural homogenization, globalization as standardization is a process of "synchronization to the demands of standardized consumer culture, making everywhere seem more or less the same" (Tomlinson 2001: 6). This is established by a "commodification of culture" (Tomlinson 2001: 85f), which can be translated into global uniform ways of shopping, fast food, television, Internet, and travel. The most controversial questions raised in that matter are whether the world is becoming a single cultural setting or not and whether cultural convergence leads to unity or uniformity of cultures (Tomlinson 2001: 11). Furthermore, the crucial question is whether time-space compression equals cultural compression.

The standardization process is driven by the most developed countries pushing modern elements, e.g. the increased need for convenience or entertainment, to the less modernized areas. Samuel P. Huntington calls this worldwide phenomenon the 'third wave' of democratization (1991; Nederveen Pieterse 2004: 48). Since the United States has continually appeared to resemble the most developed country in the past, this wave of consumerism can be described as McDonaldization or one of its many variations presented earlier, all of which are closely related to the concept of 'Americanization' or 'Westernization'. However, the so-called 'BRICS' countries consisting of Brazil, Russia, India, China, and South Africa are expected to take over the lead in the long run.

The third position with regard to globalization is that of a global mélange or hybridization of culture. In this position, the previous two approaches of uniformity or modernization are opposed because "hegemony is not merely reproduced but refigured in the process of hybridization" (Nederveen Pieterse 1995: 57). This focus on diversity in a globalizing age argues in favor of a rhizome of culture that captures the multiple approaches to and the multidirectional way of cultural definition (Deleuze et al 1987). Thus, with regard to diversity, globaliza- 
tion as hybridization and global mélange is promoted while arguing against the homogenization approach of globalization (Nederveen Pieterse 2004).

The global homogenization theory is feared and doubted. García Canclini (1995) and Jesus-Martin Barbero (1993) argue for hybridization rather than cultural imposition, giving the example of Latin America. John Tomlinson also argues against a sole homogenization theme (2001: 97). Standardization and Westernization (Americanization) are questioned because there is always translation, adaption, or 'indigenization' of the receiving culture (Appadurai 1990; Tomlinson 2001). Jan Nederveen Pieterse goes a step further and points out that whereas Westernization or standardization appearing in the form of "cultural convergence translates into a politics of assimilation with the dominant group at the cultural center of gravity" (2004: 56), the process of cultural hybridization is influenced by all hierarchical, political, or ethnic directions. In contrast to the 'Westernization' approach, cultural mixing or cultural hybridity refer "to a politics of integration without the need to give up cultural identity while cohabitation is expected to yield new cross-cultural patterns of difference" (Nederveen Pieterse 2004: 56).

In contrast to the economic-focused approach, globalization on a cultural studies level is not entirely 'westernized' because the process is not organized but rather is chaotically induced and influenced by more than one force (Barker 2004: 77). Cultural hybridity in a time of globalization can be regarded as a positive outcome of colonization because "population movement and settlement established during colonialism and its aftermath, combined with the more recent acceleration of globalization, particularly of electronic communications, have enabled increased cultural juxtapositioning, meeting and mixing" (Barker 2004: 77). Hence, contemporary culture is highly influenced by hybridization processes (Gómez Peña 1996; Kraidy 2002: 322).

Globalization is an 'age of boundary crossing'; however, those boundaries are not completely erased (Nederveen Pieterse 2004: 82). Globalization is the engine that accelerates the process of hybridization, raising awareness of the multidimensional process (Nederveen Pieterse 2004: 14) because "it captures the spirit of our times with its obligatory celebration of cultural difference and fusion" (Kraidy 2005: 1). Critics, such as Salman Rushdie and Marwan M. Kraidy, promote hybridity and the fusion of different cultural elements: "Mélange, hotchpotch, a bit of this and a bit of that is how newness enters the world. It is the great possibility that mass migration gives the world" (Rushdie 1991: 394; emphasis original).

The idea of deterritorialization is directly linked to cultural hybridity and increasing global migration because "complex connectivity weakens the ties of 
culture to place" (Tomlinson 2001: 29). Thus, cultural diversity in a globalizing age is characterized by high mobility. Global migration and deterritorialization lead to a process of hybridization in which cultural elements are mixed and different cultural elements are re-embedded. Moreover, global mélange is the perfect playground for diversity in a global environment.

In a globalizing age, intracultural, intercultural, and transcultural exchange has become a global experience. Cultural diversity, as in the sense of intermingling, mixing, and mélange, has conquered the entire globe (Tomlinson 2001: 142). Migration is leading to hybridization and the fusion of cultural difference. In a famous everyday example, migration and fusion of difference cultural inspirations can sound like the following: "Thai boxing by Moroccan girls in Amsterdam, Asian rap in London, Irish Bagels, Chinese tacos..." (Nederveen Pieterse 1995: 53). Therefore, in a global context, hybridity and hybridization have shifted from the biological meaning, carrying the inherited shadow of implied racism, to a transcultural exchange, or, as Renato Rosaldo refers to it, a "two-way borrowing and lending between cultures" (1995: xv). This borrowing from both sides does not recognize prejudices but instead celebrates the exotic elements of not only two but multiple influences. On the other hand, there are also critics of the 'differentiation' approach because "cultures may well travel and move around the world, but ethnicity is still about the maintenance of social boundaries, something which remains a powerful force in the current phase of globalization" (Featherstone et al 1999: 12).

The standardization, westernization, and hybridization approaches to globalization are valid, each successfully capturing a piece of the globalization pie. To some extent, each approach has its truth and reach. However, the most interesting approach with regard to cultural studies and identity formation is globalization as a process of hybridization or global mélange. All three perspectives form the ideal base for an analysis of diversity and the North American global city in a globalizing age because culture is no longer as restricted to a certain region or place. It breaks through local cultures and breaks off the immobility of the concept. Therefore, the effects of globalization become particularly visible in global cities. As Saskia Sassen, one of the most renown urban critics, explains, "an immense array of cultures from around the world, each rooted in a particular country or village, now are reterritorialized in a few single places, places such as New York, Los Angeles, Paris, London (...)" (2000: 89). How global cities function as cultural nodes in a network of world-encompassing flows will be the focal point of the following chapter. 


\title{
3 Global Cities as Cultural Nodal Points
}

\begin{abstract}
Global cities around the world are the terrain where a multiplicity of globalization processes assume concrete, localized forms. These localized forms are, in good part, what globalization is about. (...) The large city of today has emerged as a strategic site for a whole range of new types of operations-political, economic, 'cultural,' subjective. It is one of the nexi where the formation of new claims, by both the powerful and the disadvantaged, materializes and assumes concrete forms.
\end{abstract}

(SASSEN 2005: 40)

In the above-mentioned quote, the American sociologist and urban critic Saskia Sassen highlights the intrinsic relationship of globalization and global cities. The effects of economic globalization processes manifest themselves in global cities, as can be seen in the interconnectedness of the world's economy revealed by e.g. urban-based transnational corporations, international institutions, the labor market, fiscal centers, or stock markets. Additionally, global cities function as organizational nodes (Friedmann 1986) of different types. Global cities also operate as informational nodes for national and global communication and transportation as well as organizational centers for social infrastructure and cultural networking. As stressed in Sassen's quote, this intersection of different flows, individuals, and ideas leads to an environment of innovation, but also to conflicts.

In this brief introductory chapter, the main characteristics, functions, and qualities of global cities are presented. Special emphasis is put on the cultural significance of urban centers because the focus of this study is on the interplay of globalization, culture, identity formation, and urban space. Hence, the global city's peculiarity as a cultural nodal point of a global network of flows is of particular importance. As Sassen explains, the global city represents the connecting 
link between different ways of life, resulting in new movements and trends when creativity takes shape. Moreover, the concept of global cities as creative centers for translating a city's cultural multiplicity into literature is of interest. In literary works, the changing values and attitudes of society are often challenged and discussed in an innovative way before the 'real' urban society deals with it. Therefore, the definitions of the 'real' city will lay the groundwork for the subsequent discussion of the 'literary' global city in contemporary North American literature.

\subsection{URBAN StUdies}

Global cities are mainly examined with regard to geography, sociology, anthropology, and economics but are also of particular interest in cultural studies. Urban studies summarize the collective interests of the different fields. The two rivaling academic movements of urban theory are the traditional Chicago School of Urban Sociology of the early twentieth century, influenced by scholars such as Georg Simmel or Max Weber, and the more recent Los Angeles School of Urbanism, which emerged in the mid-1980s and was mainly influenced by postmodernism and critics such as Edward Soja and Mike Davis. Both schools argue that their city, Chicago or Los Angeles, is 'paradigmatic' for the general analysis of cities (Brenner 2003: 205). Whereas the Chicago School focuses on the city around its core, Los Angeles and Southern Californian studies include the edges as well. ${ }^{9}$ With the evolvement of the L.A. school as a second school, comparative urban studies were encouraged. Further schools of urban theory based in New York or Miami failed to build momentum. A counter-movement called anti-urbanism subsists. This movement dates back to the industrial revolution and gained significance in the 1980s along with ecocriticism (Wilson 1991: 9), which is the interdisciplinary study of the environment and literature (e.g. Heise 2008). Nowadays, ecological interests and urban planning are not necessarily antagonistic, as, for example, studies on environmental policies in Los Angeles and Toronto show (Keil et al 2003).

Key terms applied in urban theory include the expression metropolis, originally referred to the 'chief city of a country,' which is now used to describe any larger city (Rodger 2010: 85). Edward W. Soja (2000) introduced the term postmetropolis as a compound blend of 'metropolis' and 'postmodernism' to define

9 For more information about the two schools of urbanism, see Dear, Michael J. (ed.) From Chicago to L.A.: Making Sense of Urban Theory (2002). 
'the new urbanism' (2000: xiii) and "the heterogeneous mega city of the postmodern age" (Brandt 2010: 125). The terms world city (e.g. Friedmann 1986) and global city (Sassen 1991), however, are the predominating expressions employed in the analysis of larger cites in a global context. Both terms are recurrently used interchangeably.

The expression 'global city' was coined by Saskia Sassen to describe a new kind of city emerging in a globalizing age (1991). New York, London, and Tokyo function as Sassen's leading examples to explain the parallel changes in the spatially distant and culturally diverse cities. In this study, Sassen's term and concept is used to highlight the parallel developments ('synchroniCity') of the three selected North American global cities of Toronto, New York, Los Angeles.

Friedmann's hierarchy of world cities laid the groundwork for the definition of Sassen's 'global cities' as a new type of city in a globalizing age. In his renowned World City Hypothesis, Friedmann presents a hierarchy of world cities, featuring Toronto as a world city of second tier as well as New York and Los Angeles as world cities of first tier (1986: 72). Friedmann's seven interrelated theses of world cities are concerned with global capital, division of labor, integration with the global economy, global control functions, structural design, and cities as important destination points for migrants. In this study, the emphasis is on the last thesis. Thus, based on Friedmann's definition of world cities as organizational nodes (1986), the common quality of Toronto, New York, and Los Angeles as cultural nodal points in a global network is stressed. Nevertheless, economic issues cannot be disregarded because apart from global effects, the peculiarities of a city are determined by its economic, social, and spatial attributes (Abu-Lughod 1999: 417).

The city as such and larger cities in particular are defined by their ability to concentrate and control flows of individuals, goods, and ideas (Augé 2008: vii [1995]). ${ }^{10}$ With the world-wide rise of cities to about 20 with over 10 million citizens and 400 with at least one million citizens by the end of the millennium (Lehan 1998: 287f.), urban space has become "the predominant form of settlement" (Clark 1996: 186) and "the world's dominant social structure" (Lehan 1998: 287f.). This agglomeration of people and resources in a comparably limited space is intensified in a globalizing age. Similar to the concept of globalization as an amplification of global interconnectedness, an acceleration of financial

10 The term 'city' designates a crucial difference between the English and the American conception (Raleigh 1968: 310). In the U.S., the expression 'city' can refer to a wide range of different urban areas, including a small town or a village as well as a larger city or megacity. 
and cultural flows, and a growing trend towards border porosity, global cities are differentiated by their range and sphere of influence as global control centers of different types.

The contrary but concurrent processes of decentralization and concentration summarize the effects of globalization on global cities (Sassen 1991: 106). On the one hand, space and distances have been increasingly neutralized by technological advancements, such as faster flows of information via the Internet or better means of transportation. This furthers decentralization. On the other hand, financial, migratory, and other cultural flows are concentrated and coordinated in urban centers. Global cities serve as nodes in a global network with each node functioning as a cluster of transnational flows. A global city thus operates as the center of a complex network (Abu-Lughod 1999: 44). This complex urban network of interlinked global cities is characterized by exchange, dependency, simultaneity, and immediacy. Major cities function according to their own system, which is detached from the nation-state (Sassen 1991: 8) and mirrors the demise of political borders as an effect of globalization.

Global cities are studied predominantly in economics and sociology. Analyzing urban space can enhance the understanding of global processes in general and the world economy in particular. According to most critics, a global city must first and foremost be a strong financial center with powerful transnational connections to a complex web of other global cities that are synchronized by specific globalizing forces such as increased flows of capital and information. Yet, these characteristics of the global city are not an entirely new phenomenon because New York showed these signs of an emerging global city as early as the late nineteenth century (Abu-Lughod 1999: 2). These signs included its economic power and the cultural diversity of its inhabitants. Los Angeles and Toronto followed much later. The global cities of today, however, are set apart by both "the scope of internationalization, in terms of both capital and labor" (Soja 2000: 184 ) and its population's range of diversity.

Global capitalism is rooted in global cities. It is "a process of constant negotiation between homogeneity and difference, played out locally and globally, which makes itself especially manifest in the changing physical and cultural geography of cities" (Shiel 2001: 13f.). Hence, capitalism, globalization, culture, and urban space cannot be analyzed separately. Global cities function as global economic nodes, as "loci of industrial production; centers of command and control over inter-urban, interstate and global circuits of capital" (Brenner 1998: 17). Since the 1980s, the command centers for transnational businesses and organizations are concentrated in global cities (Sassen 1991: 5). Thus, a few important places coordinate a majority of global flows of capital, goods, and information. 
Most global cities are home to several Fortune 500 headquarters, thereby fulfilling the criteria for being important financial centers. Global cities function as economic networks in which, for example, the transnational corporations and international institutions are linked between cities. This 'networked economy' (Sassen 2005: 40) does not work 'internationally' as in 'between nations' but between cities, often facilitating an erosion of socio-political influence.

Politics and geopolitics also play a major role. Political and international institutions are commonly concentrated in global cities. The location of a state capital is often a strategic decision, such as investments made in transportation systems. Therefore, global cities function as nodes of political power of a certain state or, as in the case of New York, as the United Nations headquarter. As a consequence, global cities accumulate economic forces and reterritorialize political power and cultural exchange.

\subsection{Cultural Nodal Points}

In addition to their quality as global hubs for financial transactions and transportation of goods, global cities operate as structural centers of a network of bordercrossing flows. Global cities are sites of intense, accelerated processes of cultural exchange, facilitated by their physical networks of transportation, communication, information, and digital networks that, in a global age, "can double as networks of transportation, at least for virtualized media, goods, and services" (Freyermuth 2010: 67). Thus, global cities are determined by their connecting qualities and "spatially, their importance can be measured by their quality and scale of the highway and rail networks linking them with their airports" (Augé 2008: vii). One measurement for inter-city relationships, for example, is air travel between global cities (Smith et al 2002: 118). Consequently, the physical and digital networks of transport and exchange constitute even now an important quality of global cities in economic, political, and cultural terms.

Similar to the earlier presented topic of globalization and its effects, the global city's quality as cultural node is the most significant with regard to analyzing urban literature and identity politics. Consequently, ethnic diversity, immigration, and the integration of different cultures into a society play a major role in the description and analysis of global cities. Therefore, the peculiar quality of global cities as cultural nodal points in a global network of worldencompassing flows is examined in the following.

Urban space serves as a contact zone, where different worlds meet and a constant encounter and intermingling of a multitude of cultures is taking place. A 
global city is a place where the different cultural flows or so-called 'scapes' (Appadurai 1996) come together. Due to the richness of cultural resources and the diversity of urban space under extreme spatial density, global cities feature many worlds. As Marc Augé puts it, every city is "a summary of the world with its ethnic, cultural, religious, social and economic diversity" (2008: xii [1995]). Due to their large population and high degree of global interconnectedness to other urban spaces, global cities constitute the best example for this phenomenon.

A global city's public space is very diverse and is shared by a diversity of people. This diversity encourages creativity but causes conflicts as well. On the one hand, the various different cultural influences encounter each other in a cultural contact zone, often resulting in new and creative forms of interaction, and cosmopolitan trends and styles. On the other hand, the different ideologies inherent in one city collide from time to time, causing social, cultural, or political frictions. Therefore, it is no coincidence that cultural clashes, such as the 1992 L.A. Riots, occur chiefly in global cities. Conflicts and contradictions arise in global cities partly due to the concentration of global capital and the mass of immigrants, underprivileged minorities, and low-income groups within one territory (Sassen 2005: 39).

One of the main characteristics of the metropolis is that it "has always been the preferred destination of migration, and thus a site of highly intensified ethnic, social, and cultural diversity" (Reif 2010: 33). Hence, increased immigration from within and outside the national borders is another characteristic. Immigrants are generally welcome as cheap labor in prospering global cities. In times of recession, however, minority workers and immigrants often become a subject of hatred due to non-immigrants' fear of unemployment and social degradation. Immigrants nevertheless represent a vital part of city life and urban culture because they "are the active formulators of metropolitan aesthetics and life styles, reinventing the languages and appropriating the streets" (Chambers 1994: 23). Immigrants change urban space and urban life. The different ethnicities, religions, and ideologies often create urban subcultures or worlds, transforming the streetscape, spreading beyond the city limits.

Ethnic urban neighborhoods often serve as destinations, access points, and global connecting hubs for immigrants and transmigration. The concentration of particular ethnicities in one area is a result of the increasing number of immigrants (Hou 2004: 2). Global cities as significant parts of this global network are often subject to an occurrence of so-called chain migration (Foner 2000: 19), describing the process of how earlier immigration influences later immigration of the same ethnic group. Global cities then function as ethnic clusters that support 
their families or ethnic group in terms of infrastructure, import and export, or monetary funding. Thus, supportive networks are created in global cities worldwide. Examples of different 'city-worlds' are neighborhoods with a majority of one ethnicity or underdeveloped ghettos (Augé 2008: xiii [1995]). Gated communities, however, also qualify as an ethnic cluster because a cluster does not necessarily depend on low-income inhabitants. Income-levels are likely to be similar within ethnic clusters. The descriptions of ethnic neighborhoods range from minority clusters to ethnic enclaves or silos to a ghettozation process. Whether in infrastructural, geographical, political, or imaginative terms, different urban neighborhoods and districts represent separate worlds and, taken together, the diversity of the world.

\subsection{Toronto, New York, ANd Los ANGeles}

In 1986, John Friedmann categorized New York and Los Angeles as a primary and Toronto as a secondary world city (Friedmann 1986: 72). The significance of each world or global city is measured by how often the three cities are used as an example global city by a selection of scholars. A study of sixteen texts on world city research published between 1971 and 1999 revealed that New York is cited every single time while Los Angeles is mentioned thirteen times and Toronto an astonishing eleven times (Taylor 2004: 40f). Whereas New York and Los Angeles are ranked first and second with regard to metropolitan areas by population by the US Census Bureau in 2000 (Pacione 2009: 97), the Greater Toronto Area is ranked first with regard to census metropolitan areas and agglomerations in Canada (2011). Los Angeles and New York are considered "the two American cities with the strongest claims to global city status" (Gladstone et al 2003: 79). Likewise, Toronto, which is often considered the smaller and safer Canadian copy of New York City (Rosenthal 2011: 7), has the strongest Canadian claim to a global city status (Hall 2010: 63).

The three North American global cities Toronto, New York, and Los Angeles play a major role in the global network of flows, forming a so-called clique in the world city network (Taylor 2004: 117), translating into a high connectedness of flows between the three cities. With regard to their connectivity in the global network, New York is in the lead while Los Angeles and Toronto follow up respectively with a very high and high degree of connectedness (Taylor et al 2002; Taylor 2004: 73). In a contemporary study of global cities in terms of businesses, banks, stock markets, flight passengers, harbors, and international institutions, New York is in the lead, while Los Angeles is ranked six as a city with partial 
global 'command function,' and Toronto is ranked twenty-fourth as a city with a specialized command function (Bronger 2004: 191). Moreover, New York and Los Angeles are described as American 'headquarters' that function as 'corporate centers' for financial control, including international banks and transnational corporations, infrastructural centers for transportation and communication as well as the leading place for cultural production (Pacione 2009: 124). Toronto, Canada's financial hub and 'multicultural city,' functions as the Canadian headquarter equivalent.

Although Toronto, New York, and Los Angeles differ in size and population, the three urban regions are united in their high cultural diversity. In 1996, both, Toronto and Los Angeles feature a higher rate of foreign-born population of almost 50 percent and 31 percent, respectively (Anisef et al 2003: 3) than the former number one American immigrant city New York with 23 percent. New York, however, has a greater range of diversity of its immigrants (Foner 2000: 5). Although the cities are united by their cultural multiplicity, their different histories, politics, geographies, and infrastructure have formed a different ground for how each of the diverse ethnic groups integrate in the respective global city. Due to its geographical position at the Southern West Coast of the United States, for example, the 'Pacific Rim' Los Angeles features a proximity to Asia and Mexico that Toronto and New York do not have.

The phenomena of urban growth and the urbanization of the globe, which refers to the increase of population in big cities, are linked to the globalization of major cities. This dialect or global-local nexus (Pacione 2009: 8) of globalization and urban space, also referred to as glocalization, translates into the localization of the global and becomes particularly visible in global cities. Urbanism, which is the extension of urban lifestyles, turns into a way of life to the whole society. A global urban society (Clark 1996: 187) emerges in which different values are transported, communicated, copied, and adapted across the world. Increasing connectivity, for example, conveys the idea that the world we know has become one. The constant and multidirectional exchange of information results in this global-local dialogue, thereby implicating global 'unicity' (Tomlinson 2001: 10).

Globalization and urbanization have made global cities more similar in economic, but also in cultural terms (Huyssen 2008: 4). Thus, apart from being ranked as global cities of first or second tier with regard to economy, politics, and infrastructure, Toronto, New York, and Los Angeles stand out because of their remarkable ethnic diversity and several waves of immigration, continuously changing the city's population, space, and images, thereby indicating certain parallel developments ('synchroniCity'). To describe and analyze the integration 
of different minorities into a particular urban society as well as particular attitudes towards immigrants, however, the different national and local forms of acceptance and incorporation need to be investigated ('specifiCity'). In the next chapter on 'Cultural Diversity in a Globalizing Age,' the variety of the terms describing 'diversity' will be presented, providing an overview of the exhaustive field of study and the differences and similarities of the numerous different terms used, such as 'hybridity,' 'multiculturalism,' or the 'melting pot.' 



\title{
4 Cultural Diversity in a Globalizing Age
}

\author{
What if identity is conceived not as a boundary \\ to be maintained but as a nexus of relations and \\ transactions actively engaging a subject. The \\ story or stories of interaction must then be more \\ complex, less linear and teleological.
}

(CLIFFORD 1988: 344)

In a 'global age,' sole linear self-conceptions and political constructs such as 'national identity' are not adequate anymore (Antor 2006: 30). Instead, as Clifford's quote hints at, an individual's multiple identities and different affiliations have to be taken into account. The concept of human identity is subject to change and contradictions. The model of 'one cohesive identity' is a sociopolitical construction because "the whole, the full, the complete 'I' (...) is (...) a fabricated reality like any other" (Chambers 1994: 26). By the era of postmodernism and deconstruction, at the latest, this nonconformity of identity was acknowledged. The different possible affiliations of belonging and identity encompass several features, such as "sexual orientation, gender, class, race, ethnicity, nationality, age, dress, politics, food, or taste” (Rosaldo 1989: 208; Ewing 1998: 263).

Enhanced by globalization and its effects, cultural exchange is increasingly understood and practiced in a multidirectional way. As exemplified in the abovementioned quote, cultures are not monocultural only but instead are characterized by mixing processes, resembling a 'human mosaic' (Nederveen Pieterse 2004: 47). As a consequence, constructions such as 'national identity' are progressively questioned. Identity is understood in a more flexible and dynamic way. The 'container' metaphor, for example, conceives the nation and its narratives as separate and enclosed containers (Beck 1997: 50). Nowadays, in addition to national conceptualizations, transnationalism is of increased interest. Due to the interconnecting forces of globalization, as in the complex phenomenon of transmigration, a change of perspective is required (Schulze-Engler 2006: 43). 
The approach of increased cultural mixing and permeations is not entirely new. Cultures have always been influenced by mobility and mixing processes, of so-called multidirectional, transnational 'cultural flows' (Appadurai 1996: 33) and cultural mixing is the presupposition for diversity (Welsch 1997: 78). Culture itself is a construct that aims at describing ways of life, customs and traditions as well as further similarities of individuals or groups. Shared language and heritage usually define the common ground for a specific cultural group. The acceleration of cultural flows, the interconnectedness of cultures, and the porosity of borders, however, is highlighted and furthered in the age of globalization.

Due to its political correctness, the term 'diversity' has become "a sacred concept in American life today" (Michaels 2006: 12). It is a relatively neutral term with regard to individual and group identity formation, designating "the presence of a variety of cultures and cultural perspectives within a society" ( $\mathrm{Pa}-$ rekh 2000: 165). The expression 'diversity' as such designates the opposite of uniformity, thereby involving a variety, assortment, mixture, or range of different elements. Similar to the concept of 'hybridity,' the term 'diversity' refers to the variety of different species or genes in biology. It also refers to multiplicity in algebra. Nowadays, the term diversity is the predominant term used with regard to human rights and the labor market, promoting equal opportunities for different genders, sexual orientations, ethnic groups, age groups, or people with disabilities. Launched in America in 1990s, diversity management in international businesses and globally-operating corporations has become one of the buzzwords in modern entrepreneurship and in the running of particular internationally operating political, economic, and non-profit organizations. It was adopted into German human resources as a topic in the new millennium. The management of diversity, however, is sometimes taken to an extreme like the introduction of "diversity of birth order workshops" (Michaels 2006: 13), in which groups of the oldest and the youngest siblings in a company are formed.

The expression 'diversity' gained significance in the United States in 1978 with the Bakke v. Board of Regents case of the Supreme Court (Michaels 2006: 3). In this case, university applicants were sorted by 'race' to ensure a 'diverse student body.' Thus, diversity became closely connected to the anti-racism movement as well as the goal to turn American society from a 'color-blind' into a positively connoted 'color-conscious' one (Michaels 2006: 5). Further features of anti-discrimination, such as class and social status, age, income, gender, sexual orientation, religious beliefs, and people with disabilities. Interestingly, the civil rights movement of the 1960s did not manage to trigger this change of conception, although 'affirmative action' was initiated by John F. Kennedy as a 
promotion of equal opportunity for minority groups and as a mean of nondiscrimination for the hiring of government employees in 1961.

The achievements of affirmative action formed the base for a change of attitude towards diversity. In the 1980s, the term 'political correctness' gained momentum not only in neutral, unprejudiced language use but also in terms of behavioral norms and values (Hughes 2010: 4) towards diversity. A reframing process has taken place. Instead of the elimination of difference, its appreciation was stressed (Michaels 2006: 5). Thus, the essential American belief of 'liberty and justice to all,' as featured in the pledge of allegiance, was extended to diversity. Political correctness, affirmative action, and the appreciation of diversity promoted equal opportunities and soon spread to other disciplines and topics, even to discussions on animal rights (Hughes 2010: 3).

Nevertheless, there are drawbacks to diversity. Celebrating diversity, for example, potentially ends up as ridicule (Michaels 2006: 14) because it encourages differences and category-thinking. Minority discourse, a related topic, is the study of American ethnic cultures and literatures, aiming at the promotion and revival of writing by Native Americans, African Americans, Latin Americans, or Asian Americans (Culler 2000: 131) as well as feminism, queer studies, or whiteness studies. This new perspective, however, can also enforce container logic, thereby creating ethnic silos with little exchange between the disciplines or departments.

In literary and cultural studies, the term 'diversity' is connected to a multitude of neighboring concepts, such as 'postcolonial hybridity,' 'transnationalism,' and 'the melting pot.' These concepts are employed in cross-cultural discussions on literature, self-definition, and lifestyles. The full range of terms is frequently used interchangeably, although they can have a different meaning. All terms emerged in a similar academic environment that dealt with cultural identity formation. All terms refer to some kind of mixing, blending, stirring, crossover, or métissage of cultures (Nederveen Pieterse 2004), indicating topics of integration, immigration, adaption, cultural dominance, or assimilation and loss. Every concept has its strengths and weaknesses and became known in a different period of time, discipline, or geographical location.

The three main groups of terms related to the term 'diversity' are distinguished in the following sections. First, there are the six interconnected postcolonial terms of 'hybridity,' 'syncretism,' 'creolization,' 'mestizaje,' 'diaspora,' and 'liminality.' Second, the concepts of 'intraculturalism,' 'interculturalism,' 'multiculturalism,' and 'transculturalism' respectively concentrate on the interaction within a culture, the interaction between cultures, the interaction of different cultures within one social setting, or the interaction across cultural bounda- 
ries. The third group of terms is metaphors and images, including the predominantly North American concepts such as 'the melting pot,' 'the salad bowl,' or 'the Canadian mosaic.' However, the ideas of 'identity' and the 'self' as well as psychoanalysis are essential for the understanding of each of the terms used. In order to examine the concept of cultural identity, the particular outlines and conceptualizations of the term are laid out in the following.

\subsection{CONCEPTS OF IDENTITY}

A simple explanation of the term 'identity' seems impossible. In psychology, the term 'identity' relates to topics such as self-image, self-esteem, and individualism. Identity portrays the congruence of being and consciousness while forming the self (Weidtmann 2002: 110). The model of a static position of identity is a direct establishment of society and its history, people, and traditions. Consequently, dominant discourses and social categorizations, such as ethnicity, class, and gender, play a major role in identity politics. Nowadays, identity is understood as an ongoing process of self-conception, self-construction, and the revision of this self (Glomb 1997: 7ff.).

In the context of cultures with diverse and multiple elements, such as the North American one, the identification process can be very difficult, often causing marginalized identities. In addition, a single person's identity can vary as a result of the power of mightier themes, such as conformity, collectivism, or the cultural pressure of constantly trying to adapt. Cultural identity is also determined by how a person is categorized by others in a specific social arrangement or cultural setting because the act of self-affiliation can be largely ascribed to the morals and mentality of a society. Therefore, the process of identity formation represents a continuous negotiation of societal influences, individual selfperception as well as the presentation and revision of the self (Glomb 1997: 27).

With regard to identity formation, early psychoanalysts distinguished between the conscious and the unconscious self (Langbaum 1977: 9). The most renowned name in this field is Sigmund Freud, a major part of whose studies included self-analysis, the interpretation of dreams, and the innovative account of the structure of the mind in the superego, ego, and $i d$. Like Freud, Jacques Lacan is convinced that the conscious and the unconscious are bound together but with transference between the two (Slethaug 1993: 20f). This double state and the negotiation between the two parts are important when taking the split identity of a culturally mixed individual into account. 
The crisis of the individual is frequently intensified in a multicultural context. Robert J. C. Young explains that "identity is self-consciously articulated through setting one term against the other" (1995: 4). Ferdinand de Saussure, the father of twentieth century linguistics, stated in his premise that there are no positive terms but only a difference (Wunderli 1972: 45), which was expanded upon and termed binary opposition by Jacques Derrida (1973). In this model, one body of terminology is set against another. This opposition becomes hierarchical as soon as one element is constantly dominated by the other (Reckwitz 2000: 25). According to Derrida's concept of deconstruction, strongly opposing relations are necessary in order for power imposition to be effective. A positive quality can only be determined as positive in relation to another, opposing entity. Thus, the negative term has to exist, needs to be identified and legitimized as a negative dichotomy in order to justify the existence and reasoning of a positive term.

When former colonies gained their independence, an awareness of otherness or alterity was accompanied by a strong feeling of a split or double identity. The colonized population was soon declared as and they themselves felt like the other. Stereotypes, clichés, and jokes aided the creation of various imaginary 'others.' Examples include the possible frightening uncanny other or the exotic other. 'The other' can further be defined as the alien, unknown, mysterious, feared, secretly admired, fascinating exotic, or the dissimilating 'other.' According to Sigmund Freud (1986), the unknown can easily end up being the uncanny or das Unheimliche. Therein, the one which used to be homely and known became the unknown or suppressed.

In the context of a colonized or a diverse culture, these oppositions are usually concerning ethnicity and race. Taken to the extreme, 'the other' then does not only represent the values, morals and other traits that the self is not but also these qualities that the self does not want to be or stand for, e.g. weakness or femininity. This constructivism is enhanced by the use of stereotypes and clichés, which establish images and a category of thinking in the Western mind. In colonialism, this dichotomy is translated via hard factors, such as laws and regulations, and soft factors, such as language, clothes, or the habit of having tea in the afternoon. Edward Said chooses this aspect as his central theme in his famous work Orientalism (1978). Fixed categories define a person or thing as the same or 'the other, rarely anything in-between. Henceforth, 'difference' is used as a tool to encourage a polarity between the known and the unknown, the colonizer and the colonized, the civilized and the wild or exotic, the good and the evil, the center and the margin, or the self and 'the other.' 
These cognitions in the fields of psychoanalysis, post-structuralism, and linguistics contributed and continue to contribute to the development of different cultural and identity topics in the diverse areas of research. These landmark revelations paved the way for discourses on diversity and identity, a strong concept of 'hybridity,' and a number of further neighboring terms emerging in the postcolonial context, which are introduced and discussed in the following section.

\subsection{Postcolonial Discourse}

Hybridity is one of the emblematic notions of our era. It captures the spirit of our times with its obligatory celebration of cultural difference and fusion, and it resonates with the globalization mantra of unfettered economic exchanges and the supposedly inevitable transformation of cultures.

(KRAIDY 2005: 1)

As exemplified by the above-mentioned quote, the term hybridity has become a key term in the phenomenon of globalization from a cultural studies perspective. This concept of cultural mixing and in-betweenness, however, has come a long way from its original meaning and connotation. Over the course of its development, the term 'hybridity' has gone through several stages, of which postcolonialism is the most significant. Homi K. Bhabha and further post-colonial critics grounded their ideas of 'identity' and cultural influence on earlier concepts originating in the field of psychoanalysis, post-structuralism, and linguistics. Critics, philosophers, and linguists, such as Said, Fanon, Bakhtin, Lacan, Freud, De Saussure, Derrida, Deleuze, Barthes, and Foucault laid the conceptual groundwork for the progression and maturation of the term 'hybridity' with regard to cultural studies and identity formation.

The peak usage of the term 'hybridity' was reached in the context of postcolonial discourse in the late twentieth century. Hybridity is discussed in various professional fields, such as sociology, cultural studies, history, political science, and literary criticism. Seven different fields of hybridity exist (de Toro 2006: 22). Among others, it can be found beyond its biological origin in technology, media science, and philosophy. In each field of study, hybridity features intertextuality, interdisciplinarity, and a mixing of categories. It also includes elements of alterity, recombination, or new approaches to viewing known things from a 
different angle. The first discussions about hybridity, however, began as early as in the eighteenth century. The term was related to "the perceived contamination of White Europeans by the races they colonized" (Kraidy 2002: 319), which is referred to by the term miscegenation. In the late nineteenth century, this particular characteristic of the term's origin in biology was applied to evoke racial connotations and was utilized as an instrument to validate colonial dominance (Grobman 2007: 21).

By the 1990s, the growing power of the concept of 'hybridity as a part of an awareness of post-colonial identity formation was recognized. One of the most eminent post-colonial critics of contemporary time is Homi K. Bhabha, who was the first to notice that both sides of the colonial coin, the colonized and the colonizer, are affected by the colonizing process. This readjusted the stereotypical way of viewing hybridity as simply exotism (Bhabha 1994: 38).

Bhabha derives his definition of hybridity from the Russian philosopher Mikhail Bakhtin (Easthope 1998: 342), who distinguishes single-voiced and double-voiced texts. Whereas single-voiced texts, such as poems, portray only one viewpoint, novels with a narrator that provides two or more perspectives are double-voiced texts. This is a revelation because Bhabha's definition of hybridity "stresses the interdependence and mutual construction" of the colonizer and the colonized (Ashcroft et al 2000: 118). Thus, while Said $(1978,1994)$ is mainly concerned with the colonizer and Fanon (1967) with the colonized (Kraidy 2002: 320), Bhabha takes both into account. He explains that cultural discourse "overcomes the given grounds of opposition and opens up a space of translation: a place of hybridity, figuratively speaking, where the construction of a political object that is new, neither the one nor the other" (Bhabha 1994: 25).

Furthermore, Bhabha's revolutionary model of the Third Space paved the way for the term 'hybridity' to develop a new meaning, namely, a 'hybridity' that encourages mixing and cultural diversity. This conception is predominantly used in an age of globalization. The 'Third Space of enunciation' (Bhabha 1994: 37; emphasis original) represents a more positive space in which culture and identity are constructed while taking the influence of both colonizer and colonized into account. Hence, the so-called 'in-between' space is a non-prejudice space, like a mélange, open to a hybrid cultural identity formation. Thus, hybridity is gaining a process character, namely a process of hybridization on both sides. In a Third Space, cultures are not influenced by a hierarchy or power imposition (Bhabha, 1990: 211). This creates the opportunity of an empowering hybridity (Ashcroft et al 2000: 118) in which the exoticism of cultural diversity is left behind because the hybridity of culture per se is acknowledged (Bhabha 1994: 38). 
In a hybridization process, both, colonizer and colonized, have to rethink their identities. The use of language constitutes a prime example because not only the culture and speech of the colonized are changed but also that of the colonizer (Beise 2002: 221). This influence is related to the act of speech communication. The colonizer and the colonized have to find a common ground in order to understand each other. Thus, the search for similar elements leads to correspondence and eventually to a mixing of language and culture because culture is articulated via language. The colonizer-colonized relationship goes beyond dependence. It is of interdependence and mutual influence, changing both of the cultural identities. Thus, neither side of the discourse is left untouched. This influence, however, is unbalanced due to the colonizer's power. Bhabha explains this situation of dependency with the concepts of 'ambivalence' and 'mimicry.'

Along with hybridity, ambivalence is an important stepping stone in postcolonial vocabulary. The term 'ambivalence' is frequently exchanged with hybridity in Bhabha's work and features a close connection to the concepts of 'inbetweenness' and 'Third Space.' The expression 'ambivalence' is initially taken from psychology, referring to a situation of indeterminacy (Young 1995). Ambivalence, meaning 'duality' or 'indecision,' results in a state of ambiguity (RohSpaulding 2002: 21). Bhabha chose the term 'ambivalence' to illustrate the constant love-and-hate relationship between colonizer and colonized. This relationship of the colonial presence of the colonizer or formerly colonized areas results in an ambivalent situation of both repulsion and attraction towards the colonizer. In his landmark essay The Location of Culture Bhabha argues that "colonial presence is always ambivalent, split between its appearance as original and authoritative and its articulation as repetition and difference" (1994: 107) because the colonized is never simply and exclusively opposing the colonizer. Nederveen Pieterse defines this love-and-hate relationship as a "continuum of hybridities: on one end, an assimilationist hybridity that leans over towards the center, adopts canon and mimics hegemony and, at the other end, a destabilizing hybridity that blurs the canon, reverses the current, subverts the center" (2004: 73). Hence, the colonized is in Bhabha's famous words "less than one and double" (1994: 166) or, put differently, being torn between cultures or being in two places at once. This draws attention to the concept of mimicry.

The term mimicry derives from the verb 'to mimic,' which refers to an act of copying. ${ }^{11}$ Mimicry describes an act of replication or camouflage in which the colonized unconsciously tries to become like the colonizer. This reaction is

11 For more details, please see V.S. Naipaul's The Mimic Men (1967). It provides excellent examples of how colonial mimicry works. 
caused by the love-and-hate relationship. Bhabha's concept of 'mimicry' is based on Lacan's mirror stage (1978). Lacan uses the example of an infant to show that self-consciousness precedes identification of 'the other.' At a certain age, the child manages to identify its own mirror image and then starts to perceive a self and other, recognizing difference. Mimicry can be compared to a modern form of guerilla warfare (Lacan 1978; Bhabha 1994: 85). In this approach, the colonized continuously struggles to meet the colonizer's expectations, constantly trying to fit in. The colonized then unsuccessfully tries to be like the colonizer himself. This draws the attention to the concept of 'otherness,' which explains and supports the hierarchical application of binaries that support the colonial rhetoric.

The term 'otherness' was first used by Georg Wilhelm Friedrich Hegel who is renowned for his master-slave dialectic (Barnett 1998). The colonial process of othering deeply entrenched boundaries. It can be employed on many levels of difference, such as geography, economy, gender, ethnicity, and race. This process is also regarded as a strategy of reversal, a so-called Umkehrung of the self into the alien. Edward Said, for instance, explains in his Orientalism (1978) the discursive invention of the 'exotic other,' which is constructed through language, laws, and further rhetoric devices. He manages to illustrate how imperial countries, such as France and England, used the theme of 'the other' to explain colonizing and being superior, or having the privilege to impose laws and regulations on the colonized peoples.

Hence, imperial culture utilizes alterity with a process of 'othering,' aiming at legitimizing their pretension of power. Thus, in the process, the colonized is marginalized. This is performed by the projection of selective information via stereotypes, clichés, and fears that work due to the establishment of an 'uncanny other.' Then, the putatively universal is connoted as, for instance, white, male, and heterosexual. The trial of equating this stereotype is extremely problematic due to the underlying categorization in homogenized groups and the natural habit of viewing your own group as good and good to begin with (Kley 2002: 61). In most cases, this act of setting one term against the other results in a process of grouping or categorical thinking.

This categorical thinking can be traced back to the intuitive assertion that the self is better than 'the other', which is a result of the trail of conformity or the assumption of one's own normalcy. The phenomenon is called ethnocentrism. As the word suggests, the rhetoric encompasses a centering on the own ethnicity, which comes quite naturally. The term describes the act of automatically viewing one's own culture as good and, consequently, ascribing to it only positive connotations. With regard to the concept of 'alterity,' viewing the other automat- 
ically as the opposite symbolizes the extension of ethnocentrism. Typical dichotomies applied include white versus black, good versus evil, and civilized versus uncivilized. Thus, categorical thinking is established that carries a binary opposition. With the help of colonial power, dominance and hierarchy are articulated, e.g. via language. Ethnocentrism can also boost this difference while creating and intensifying new clichés of another ethnicity. In Orientalism, for example, the East is portrayed as being exotic, female, and weak, in opposition to the West, which automatically gains the opposite attributes of being the usual, male, and strong. Ethnocentrism of the dominant culture is the rhetoric logic of why the assimilation of 'the other,' as in 'mimicry', can never be accomplished completely (Beise 2002: 222). Colonialism needs a binary opposition in order to function and, thus, culturally diverse individuals can never fully become like the colonizer but remain hybrid or marginalized.

The term 'hybridity' existed before under the disguise of other names, such as 'syncretism' or 'creolization' (Fludernik 1998; Brathwaite 1971). Different perceptions of mixing and the various terminologies are heavily dependent on the particular culture, its geographical location, history, and political as well as (post)colonial experience. The six concepts of 'hybridity,' 'syncretism,' 'creolization,' 'mestizaje,' 'diaspora,' and 'borderlands' have the underlying process of an identity crisis in common. The majority of the concepts developed in a combination of the same circumstances: an aboriginal culture that, in one way or another, was suppressed by a more dominant culture. For this reason, many similar or even synonymous terms are used when it comes to explaining a process of identity formation in association with either colonial rule, migration, or being a so-called 'scattered culture.'

The term closest to and most frequently exchanged with hybridity is syncretism. It derives from the field of theology, referring to the merging of analogies and the combination of different practices. It is sometimes exchanged with the term eclecticism. ${ }^{12}$ The term's religious background constitutes the fusion of different cultural elements. Many critics view hybridity and syncretism as aliases (Nederveen Pieterse 2004: 71). Stuart Hall draws a direct connection between hybridity and syncretism by saying that both are a mixture of cultural traditions (1992). Syncretism was established in post-colonial works of literature, such as Bill Ashcroft's The Empire Writes Back, to relate to the frequent association with the idea of 'synergy' (Ashcroft et al 2000: 229). This definition arose because of a possible negative connotation of the term 'hybridity,' which was emi-

12 The term 'eclecticism' originates in architecture and refers to the mixture of different styles. 
nent throughout the nineteenth century. Syncretism circumvents the racial issue and instead concentrates on "cross-cultural plots of music, clothing, behaviour, advertising, multi-ethnic and multi-centric patterns" (Canevacci 1992: 3). In contrast to hybridity, Fludernik interprets syncretism as something that "emphasizes a peaceful coexistence rather than an uneasy and agonistic self-splitting" (1998: 19). Therefore, syncretism is employed to circumvent the problematic features of the term 'hybridity' because 'synergy' describes the more positive process of cultural mixing of the different but equal elements (Ashcroft et al 2000: 229).

Creolization was used interchangeably with the term 'hybridity' before its canonization in postcolonial discourse. Whereas creolization was predominantly referred to colonized Africans, hybridity does not refer to any particular skin color (Fludernik 1998: 12f.). The term 'creolization' itself was coined in the sixteenth century. The idea developed and was shaped by the experiences from living in a new environment that required adaption of its new inhabitants, e.g. black individuals born in Brazil. The term and the concept designate a linguistic blend of French, Spanish, and Portuguese influence, triggered by European colonialism in the Americas, Africa, and parts of Asia. Creolization, like hybridity and transculturality, focuses on a rather "flexible concept" of cultures and their characteristic of being "a social practice" (Doff et al 2011: 3).

Creolization is closely connected to the concept of mestizaje. The term 'creole' was incorporated into the English language as a generic and thus was more often used than the term 'mestizo' (Ashcroft et al 2000: 137). Mestizaje, also commonly referred to as 'mestizo' or 'métisse,' was originally applied with regard to the cultural and racial mixing of Amerindians and Europeans. ${ }^{13}$ The term was coined by José Vasconcelos in 1925 to describe the cultural encounter close to borders. Both terms, 'hybridity' and 'mestizaje,' are considered aliases (Nederveen Pieterse 2004: 53) and have undergone a shift from a negative to a positive connotation. Mestizaje is now widely accepted as a name for the interchange of cultures between diasporas (Ashcroft et al 2000).

Diaspora can be translated as 'the scattered' because it derives from 'to disperse.' The term has been used since the late nineteenth century to refer to many different ethnic, religious, or minority groups that have been separated from their home country and scattered across the world, such as, among many others, Jews. This movement can be forced or voluntary (Ashcroft et al 2000: 68f.). The minorities who are forced to leave their homes do not necessarily leave their traditions behind. In the age of European imperialism, for example, forced migration

13 The term 'mestizo' is of Spanish origin, whereas métisse designates the French origin equivalent. 
and slavery were accounting for the global diffusion of different diasporas. Nowadays, many writers utilize the term 'diaspora' and 'diasporic identity' to highlight their hybridity in a positive way (Ashcroft et al 2000: 69f.).

Chicana or Chicano literature focuses on borderlands, border crossing, biculturalism, and bilingualism. Gloria Anzaldúa's 1987 Borderlands/La Frontera: The New Mestiza remains the most prominent text. Whereas 'the frontier' refers to a dominant center and its weak periphery, the expression 'borderlands' implies a transterritorial cultural contact zone with multidirectional exchange (Kaplan et al 1993: 16). The related term liminality derives from 'limen' or 'limit,' meaning a threshold, an interstice, or something in-between (Ashcroft et al 2000: 130). Hence, liminality is related to the concepts of 'borderlands' and 'border crossing' but concentrates on the space in-between instead.

As the brief definition of the neighboring concepts has shown, 'hybridity' as a concept is more developed than its many competitors presented. Thanks to Homi K. Bhabha, hybridity as well as his approach of a Third Space were a break-through in the field of colonial discourse and identity politics. Its terminology is defined in detail and by now canonized. The key words forming this vocabulary, such as 'mimicry,' 'ambivalence,' and 'displacement,' have been cited various times by the majority of post-colonial critics and, as a matter of fact, symbolize milestones in the cross-cultural discourse, its theories, and beyond. As contemporary critics of globalization and culture, such as Nederveen Pieterse (2004) Kraidy (2005), and de Toro (2006), have shown, hybridization processes play a major role in a globalizing age.

Nevertheless, some critics argue against the concept of 'hybridity.' Due to its theoretical approach, hybridity is sometimes disputed and viewed as a 'political dead end' (Hutnyk 1997; Kraidy 2002; Werbner 1997). Moreover, 'hybridity,' as a term stemming from biology, is still criticized because it has been used in the past to justify racism and colonial rule (Young 1995).

The criticism of the term 'hybridity' justifies this study's presentation of further terms used with regard to cultural mixing, self-definition, and group identification in the subsequent sections. The term 'transculturality,' for example, does not have a long history of negative connotations associated with genetics; rather, a history of acceptance. In contrast to hybridity, it has been widely accepted in Latin America because it has no racial implication to start with. Instead, transculturality, as its name spells, focuses on culture or ethnicity and transaction between the two. Since the different prefixes 'intra,' 'inter,' 'multi,' and 'trans' are recurrently used interchangeably, the different assumptions of their distinct meaning will be elaborated on in the following section. 


\subsection{INTRA, INTER, MULTI, AND TRANS}

Following in the wake of previous concepts in cultural and literary studies such as creolization, hybridity and syncretism, and signaling a family relationship with terms such as transnationality, translocality, and transmigration, 'transcultural' terminology has unobtrusively, but powerfully, edged its way into contemporary theoretical and critical discourse.

(SCHULZE-ENGLER ET AL 2009: IX)

By the end of the twentieth century, the German philosopher Wolfgang Welsch sparked a new, mainly German-based discourse on the modern form of cultures with his landmark essay "Transculturality - The Puzzling Form of Cultures Today" (1999). His concept has by now spread across national discussions. More recently, several disciplines, such as media and communication studies (e.g. Hepp 2006) as well as transcultural educational studies (e.g. Doff et al 2011), have developed a discourse on Welsch's definition of 'transculturality.' Several critics of literary and cultural studies propose 'transculturality' as the appropriate descriptive term for the modern form of cultural mixing that does not exclusively rely on one nation state or culture in a globalizing age (Antor 2010; Huggan 2006; Schulze-Engler et al 2009; Eze 2005; Birkle 2004).

Most critics do not distinguish between the similar yet different concepts of ethnic diversity, such as 'multiculturalism' or 'interculturality.' The different prefixes have considerable impact on the meaning of the terms and their concepts of culture. The prefixes 'intra,' 'inter,' 'multi,' and 'trans' are used in frequent combination with nouns such as culture, ethnicity, difference, nation, locality, or migration. The selected nouns can specify a space or region, a political construct, a movement, or other means of categorizations. Selected terms are used with two different suffixes 'ality' or 'lism' as in multiculturality and multiculturalism, translocality and translocalism, or internationality and internationalism. The different suffixes are recurrently used interchangeably across the disciplines and discourses. Thus, a slightly different meaning is generated, which respectively focuses on a person's attributes or functions as a descriptive term of the phenomenon as a whole. To illustrate the function of the different prefixes, the noun 'culture' is used exemplarily. The delineation of 'transculturality' from 'interculturality' and 'multiculturality' stresses the difference between the different prefixes and the accompanying conceptualizations. Intraculturality focuses 
on the interaction within a specific culture and within its limits. Interculturality describes the interaction of different cultures and multiculturality concentrates on different cultures and their interaction "within one society" (Welsch 1999: 196; emphasis original).

To Welsch, the two terms 'interculturality' and 'multiculturality' are almost as inappropriate as the outdated model of 'single culture' because all three feature an element of separation that can easily trigger racial connotations (1999: 195). According to the theory of 'single cultures,' cultures can be compared to 'billiard balls,' 'islands,' or 'silos,' which translates into an underlying model of separate units. This theory relates to Johann Gottfried Herder's concept, which dates back to the eighteenth century (Welsch 1999; Tomlinson 2001).

Similar to the concept of 'intraculturalism' and 'multiculturalism,' 'interculturalism' assumes cultures as separate entities (Huggan 2006: 58). Intercultural self-definition, though, is still practiced around the world, mostly referring to monocultural narratives, such as the nation (Antor 2006: 36). Interculturality focuses on the relationship between cultures. Therefore, an intercultural conception is not superfluous but needs to persist (Schulze-Engler 2006: 45). One example is the reduction of racism through recognition and respect of cultural difference within a multicultural society. While the term 'interculturality' is chiefly applied on an international level, 'multiculturalism' is predominantly used with regard to most national debates (Antor 2006: 29).

Multiculturalism tends to entail clear-defined and differing cultures within one society and thus, the prefix 'multi' can create borders, boundaries, and categorizations of different cultures. The prefix 'multi' is frequently used interchangeably with the prefix 'poly,' as in 'multiculturalism' and 'polyculturalism.' There is, however, a difference between the two terms. Whereas the former is criticized for focusing on the division of the different cultures, the latter focuses on the interrelated and integrative function of all world cultures.

Multiculturalism, a model for considering a variety of different cultures and their interplay within one society, captures only half of the picture of modern cultures of today (Welsch 1997: 87). The term is flawed because it still conveys separate entities of cultures as in the outdated model of 'single cultures' (Welsch 1999). Welsch acknowledges, however, that different societies have different forms of multiculturalism (Welsch 1999: 196). Welsch refers to a number of cultural influences within one society as 'inner transculturality' that only explains part of the actual polycultural societies of today (Gippert et al 2008: 11; Welsch 1997: 87).

In addition to Welsch's 'inner transculturality,' the external networking of different cultures defined as 'outer transculturality' explains cultural exchange 
across national borders more precisely (Welsch 1999). A global transcultural network of cultures illustrates their constant and dynamic processes of intertwining, interlocking, and exchange. Multiculturalism, which describes "the existence of different cultures in one nation" (Birkle 2004: 6), stresses the coexistence of different cultures rather than their dialogical exchange and the productive transgression of (cultural) boundaries (Antor 2006: 330). This uniqueness and thus difference of a particular culture constitutes the weakness of the concept of 'multiculturalism.' Some critics claim that this conception of culture relies on the concept of single cultures as monolithic entities based on Herder (Welsch 1999; Eze 2005: 21; Benhabib 2002: 4). This understanding of cultures as distinct cultural communities within a society can result in mutual forms of separation or even 'ghettoization' (Welsch 1999).

In contrast to the neighboring terms mentioned above, Welsch's 'transculturality' describes a potentially non-hierarchical networking of cultures across borders. The concept of 'transculturality' manages to capture the multidirectional relationship both between and within cultures because 'the prefix 'trans' clearly expresses the transitional character, which includes the adoption of various cultural elements as well as the change of the groups involved" (Fitz 2001: 38).

Welsch's definition of transculturality goes beyond the early concept of 'single cultures' and the more recent ideas of 'multiculturalism' and 'interculturality' (1999: 194). In the age of globalization, cultures are not monocultural but instead have undergone a shift towards increased mixing and permeations. According to Welsch, transculturality describes a new form of cultures today that "passes through classical cultural boundaries" (1999: 196; emphasis original). The approach of different, separate spheres as in monocultures is no longer valid. Rather, cultures are characterized by mobility and inspired by constant dynamics of change and exchange. Complex hybridization processes take place between different cultures as well as within individual cultures. Thus, Welsch introduces the term 'transculturality' as a new concept of culture that transcends the notion of "inner homogenization and outer separation" (1999: 195).

Wolfgang Welsch makes the distinction between transculturality on the macro-level and on the micro-level. The macro-level of transculturality refers to cultures as societies. Enhanced by globalization and its effects, cultures are both increasingly diverse within themselves and also progressively interconnected with and influenced by other cultures. In addition to the global and almost instantaneous availability of cultural elements, the detachment of culture from a specific location weakens the definitions of cultural 'ownness' or 'foreignness.' Identity formation on the micro-level refers to the cultural identity of the individual. Welsch claims that "we are all cultural hybrids" (1999: 197). In his approach, 
Welsch calls for more acceptance and tolerance. He argues that recognizing "a degree of internal foreignness forms a prerequisite for the acceptance of the external foreign. It is precisely when we no longer deny, but rather perceive, our inner transculturality, that we will become capable of dealing with outer transculturality" (Welsch 1999: 201). Hence, inner plurality must first be recognized before global plurality can be acknowledged.

The transgression from 'inter' to 'trans' can be summarized by a change of perspective and the degree of subject involvement from what different cultures do with an individual to what different individuals do with culture (SchulzeEngler 2006: 46). This change of perspective designates a new form of agency in which an individual has the ability to select different cultural affiliations. Although a new trend can be recognized, political, social, or economical oppression are still present. Nonetheless, both, intercultural and transcultural conceptions, continue to coexist.

Wolfgang Welsch's concept of 'transculturality' provides many opportunities but also features some limitations. Welsch's interpretation of Herder's concept of culture is heavily criticized for misinterpreting Herder as 'culturally racist' (Löchte 2005: 23). Welsch argues that single cultures are defined by "social homogenization, ethnic consolidation and intercultural delimitation" (1999: 194). In line with this approach, cultures barely have contact with each other due to their isolation. Moreover, 'transculturality' is conceived as a model of a cultural pluralism that "leads to openness and a limited form of freedom, although loss of orientation and aimlessness may also be experienced" (Nadig 2004: 10). Indeed, transculturality can lead to processes of cultural (de-)fragmentation as in some cases of migration, diasporas, or political and religious exile. Therefore, the question needs to be raised whether Welsch fails to consider the negative aspects of his idea of culture. Transculturality does include processes of destructing and restructuring, however, "the new construction of geographicallyindependent, transcultural and virtual identities is the central theme" (Nadig 2004:10). Hence, borders and categories are redefined. Moreover, Welsch fails to mention whether transculturality is a final stage of something culturally new or simply a type of interstage of cultural identity. Thus, the main question is whether 'transculturality' truly is a new approach or simply a new version of the renowned concept of 'hybridity' in disguise. Transculturality can function as an additional model to describe cultures and their (co)existence but not every culture is transcultural.

The notion of 'transculturality' is not entirely new. In his works published in the 1990s, Welsch does not mention the term's earlier diffusion in Central and South America. In 2009, the critic explains that he just learned that the attribute 
'transcultural' has been used in cultural studies as early as the 1960s (2009: 3). In fact, Welsch' definition of 'transculturality' is closely linked to Fernando Ortiz's concept of 'transculturation.' In the 1940s, Ortiz coined the term 'transculturation' (1978; Ashcroft et al 2000: 233) in his book Contrapunteo cubano del tabaco y el azúcar (Cuban Counterpoint: Tobacco and Sugar). The Cuban sociologist aimed at replacing the coupled terms of 'deculturation' and 'acculturation,' which referred to the one-directional transfer between cultures in a fashion envisioned by the colonial center (Pratt 1992: 228). Whereas 'acculturation' explains the process of a forced adoption of foreign cultural elements of the colonized by the colonizer, 'deculturation' describes the act of losing or abandoning culture of the 'uncultivated' colonized, a process that is forced by the colonizer. Both entail the underlying assumption of a hierarchical dichotomy in which the colonizer dictates cultural adoption or loss.

With Ortiz's studies, the concept of 'transculturation' sparked a predominantly Latin American discourse in the 1960s, which has slowly been recognized in non-Spanish speaking countries recently. According to Malinowski, who is quoted in Ortiz's Cuban Counterpoint - Tobacco and Sugar, transculturation "provides us with a term that does not contain the implications of a certain culture towards which the other must tend, but an exchange between cultures, both of them active, both contributing their share, and both co-operating to bring about a new reality of civilization" (1995: ix).

The terms 'intraculturalism,' 'interculturality,' 'multiculturalism,' and 'transculturality' continue to exist, each describing cultures and their specific interplay in a distinct way. The existence and coexistence of the different forms is a social reality. The prefixes help to distinguish between different forms of cultural exchange as well as forms of integration within one society. Their difference, however, it not always recognized as many use the prefixes interchangeably. Furthermore, many metaphors of identity and integration, such as the Canadian mosaic, describe cultures and their forms of adaption and integration of immigrants. These literary idioms are introduced in the following section.

\subsection{The Melting Pot, Salad Bowl, and Canadian Mosaic}

Literary idioms such as the melting pot, salad bowl, and mosaic are commonly used with regard to immigration, integration, and cultural pluralism in North America. The three metaphors function as an ideological guideline of how cultural adaption is expected (Wilson 2010: 24). These forms of narratives, myths, 
and stories are thus often used for nation-building purposes. They are applied as a socio-political strategy, targeted at new arrivers to easily refer to the concept of how cultures interact in a certain society. Depending on the type of concept, cultural integration is limited.

This idea of 'cultural fusion' was sparked along the major waves of immigration to the U.S. at the turn of the twentieth century (Wilson 2010: 2). The play The Melting-Pot by Israel Zangwill (1916 [1909]) described a new form of cultural pluralism and thus initiated the term's usage. The melting pot model is similar to the less renowned concept of a 'stew' in which different ingredients mix into one new entity. Taken in a cultural context, different cultural influences blend to form one identity, such as a national one. The metaphor of the melting pot was used to unite the relatively young American nation and its diverse people. Thus, the melting pot has become the famous illustration of how immigrants should assimilate, integrate, and incorporate into American society upon arriving. Some critics describe the concept as an unsuccessful form of assimilation (Glazer et al 1964; Wilson 2010: 15) because intracultural individualism is lost.

The main difference between the metaphor of the 'melting pot' and the 'salad bowl' lies in the different degree of assimilation and cultural uniformity. In contrast to the 'melting pot,' the metaphor of the 'salad bowl' improves the acknowledgement of these intracultural variances because the distinct ingredients do not simply mix but form a picture in its entirety. The prerequisite is, however, metaphorically speaking, an interesting dressing that goes well with all ingredients. The common culture of Americans can be interpreted as such a dressing (Fitzgerald 1997: 68). The idiom suggests that one nation is made of different parts that remain different but connected by a common American identity. This understanding of distinct cultures forming a whole is similar to the $\mathrm{Ca}$ nadian model of the mosaic.

The Canadian model of the 'mosaic' is similar to the U.S. American model of the 'salad bowl.' Both argue against wholesale assimilation. A mosaic features different sizes, colors, and shapes of its pieces, forming a picture only in its multiplicity, a so-called 'patterned whole' (Fitzgerald 1997: 68). The metaphor of the mosaic was established much later in the history of the Canadian nation and represented a shift in Canadian society and the integration of different ethnicities at the beginning of the twentieth century (Ernst et al 2010: 7f.). The sociologist John Arthur Porter introduced the concept of the 'vertical mosaic' to describe Canadian culture and society and its hierarchical ranking of classes and thus ethnicities (1965). He explains that Canada has different cultures, languages, and regions that can be compared to the form of a mosaic. The theme of the 'mosaic' is uniquely Canadian and mostly contrasted with the American 
model of the 'melting pot' in which every immigrant's culture is dissolving to form the new, assimilated American culture. In a mosaic, the distinct cultures within a society remain visible, forming together the whole picture of Canadian culture, society, and identity.

The distinct entities of a multicultural society, however, may form ethnic silos due to their coexistence instead of intermingling processes. Thus, the criticism of the Canadian model of multiculturalism encompasses three main issues. First, the 'vertical' aspect of the Canadian mosaic metaphor, as Porter claims, can hint at the uneven distribution of power through classes (1965: 27). Second, the government's involvement in a society's cultural and ethnic issues is criticized (Ernst et al 2010: 9). And lastly, two of the most deep-rooted Canadianbased groups, the French-speaking in Quebec and the indigenous population (Inuit), have been largely neglected in this model. Since English and French, in this order, are still the official languages and the favored cultures in Canada, the concept of a multicultural mosaic is somewhat undermined (Ernst et al 2010: 8).

In the three selected novels of this study, different forms of cultural identity, community and incorporations of immigrants into the city's and nation's society prevail. Even within a novel, different ideologies exist, coexist, and sometimes clash. With the help of the poetics of narrative, place, and code-switching, the different concepts of cultures and their mixing, coexistence, or coercion will be analyzed. Thus, before the literary analysis, the basic features of comparison will be identified in the following chapter. 



\section{The Poetics of diverCity}

In this study, 'the poetics of narrative,' 'the poetics of place,' and 'the poetics of code-switching' represent the common aesthetics of 'diverCity' and serve as the leading themes of the subsequent analysis of global cities as a literary phenomenon because global literature, urban fiction, and different forms of ethnic writing have several features in common. Migration and transmigration, forms of movement and space, and multilingualism, to name but a few, are shared qualities of each of the three types. In the following, further common features of global, urban, and ethnic literature are presented, beginning with a brief introduction to the general aesthetics of the novel as such.

As Bakhtin argues, the novel and its characteristics better suit modern society and better represent its diversity than other genres (1981). Novels function as creative laboratories that challenge social, cultural, political, geographical, or mental boundaries. Ideas of culture in a work of fiction and actual social discourses have an intrinsic relationship. Literature has a long tradition of influencing society. Taking the effect that literature has on reality into account, fiction can be employed as a strategy to communicate uniformity. The sense of community created by nations serves as a prominent example (Anderson 1983: 40). ${ }^{14}$ In British imperialism, for instance, the distribution of literary works across the Empire aimed at integrating the new population as well as supporting the traditional members (Culler 2000: 35f).

An improved understanding of our culture through literature grants access to a better appreciation of and insight into different and foreign types of literature and diverse cultures. Social discourses on culture are reflected in novels, and

14 The key to nation-building and awareness is universality - of "characters, speakers, plot, and themes" - because "the more universality of literature is stressed, the more it may have a national function" (Culler 2000: 37). In the case of the British Empire, standards like customs, social behavior, or morality were established. 
cultural discourses are triggered by fictional constructions of reality because "great writers are (...) specialists in cultural exchange. The works they create are structures for the accumulation, transformation, representation, and communication of social energies and practices" (Greenblatt 1990: 230). Literature can also question ideologies. Stylistic devices, such as metaphor, irony, alliteration, simile, or parody, are often used as a tool to overtly or covertly criticize certain ideologies or conventions. Harriet Beecher Stowe's Uncle Tom's Cabin (1852), for example, brings injustice to light in an emphatic way and thus "helped create a revulsion against slavery that made possible the American Civil War" (Culler 2000: 39).

In a globalizing age, the novel functions as a tool to reflect on globalization and its effects. A reciprocal process can be identified. Not only does the 'globalization of the novel" describe the "global system of production, reception, and translation of novels" but, additionally, the 'novelization of the global' includes "the production of images of a globalized world as they are constructed in specific novels" (Siskind 2010: 338). Thus, a paradigm shift of literature has taken place in a globalizing age (Schmeling et al 2000). Moreover, in a global age, global cities function as significant and interrelated nodes in a network of worldwide flows of individuals, goods, and ideas that are accelerated by globalization and its effects. Global issues of migration, identity, and belonging are essential themes of current urban life and are commonly reflected on in the contemporary urban novel.

In addition to economics, sociology, and cultural studies, contemporary literary studies are not only influenced by globalization but also have an intrinsic interest in how globalization and its effects change the world and how this process is perceived. Literature in a global age often focuses on processes of borderscrossing and its limitations as well as the well-established ways of thinking and structuring our world (Schmitz-Emans 2000: 286). Global literature is characterized by a text's range of distribution, structure, and literary themes (Schmeling et al 2000: 8). Writing and reading from a global perspective translates into acknowledging multiple perspectives because, nowadays, a sole Western point of view is questioned (Chambers 1994: 24). Moreover, in a globalizing world, literature becomes more intercultural as well as intertextual (Mall 2000: 62) due to the increasingly interconnecting of different national or ethnic literatures.

Global literature often presents and represents the effects of globalization, such as increased connectivity or the acceleration of global flows. William Gibson's Pattern Recognition (2003), for example, portrays the search for new trends of branding and marketing in global cities around the world, such as London, Moscow, New York, and Tokyo. The novel critically reflects upon the 
commercialized world and internet culture, portraying world-wide connectedness, time-space compression in a globalizing age, and the impact of imagined communities.

The phenomenon of globalization is not always celebrated but also criticized. In Karen Tei Yamashita's Through the Arc of the Rain Forest (1990) and Richard Powers' Gain (1998), for example, globalization and its negative ecological and economical 'butterfly effect' are exposed in a 'local-global dialect.' Don DeLillo's New York novel Cosmopolis (2003) elaborates on themes of cosmopolitanism, the global economy, the financial system, stock market, and monetary success, criticizing the power of technology, cyber capital, and American capitalism.

Similar to a number of cultural critics who are concerned about the homogenizing effects of globalization, some literary critics fear that globalization turns literature into a standardized process, channeling into a collective loss of individual and national identity. However, a holistic 'McDonaldization' of literature (Sturm-Trigonakis 2007: 250) cannot be observed. Instead, in literature of a globalizing age, standardization and a process of diversification are taking place at the same time (Steinmetz 2000: 193). Hence, while literature is available and read across the world, new forms of literature become popular around the globe. Viewing globalization merely as a form of Westernization or neo-colonization and thus as a continuation of colonialism is too narrow. This conception can be compared to the rather limited view that the modern novel is a colonial instrument (Siskind 2010: 342). An intercultural perspective on world literature, however, forms a cohesive field with the common feature of difference (Mall 2000: $63)$. It is characterized by the mixing of languages or styles and therefore mirrors the concept of globalization as a process of hybridization.

Not only cultural geographies but also literary studies have had and still have a growing interest in the developing and expanding city. In the eighteenth century, an ever-increasing number of people were living in urban areas around the world (Meckseper et al 1983: 5). As a consequence, the city, its space and its society have also become a subject of interest in literary studies that was further increased by modernization processes. Hence, urban literature is not a new phenomenon because cities were a part of literature from its beginning (Pike 1981: 3). A number of critics even claim that the expression 'city novel' is redundant because the rise of the novel concurred with the rise of the modern city. ${ }^{15}$ Promi-

15 The city novel is an exhaustive field of study. Ian Watt's The Rise of the Novel: Studies in Defoe, Richardson and Fielding (1974 [1959]) is considered a standard piece of work with regard to the English novel and urbanization (Raleigh 1968: 294). For more 
nent examples of the city novel encompass James Joyce's Dublin in Ulysses (1922), Alfred Döblin's Berlin in Berlin Alexanderplatz: Die Geschichte vom Franz Biberkopf (1929), or Paul Auster's New York in City of Glass (1990 [1985]).

Moreover, there is an intrinsic relationship between the 'real' city and the 'imagined' city. In postmodern fiction, the writer and the reader (Edwards 2012: 168) as well as the city's inhabitants and visitors have an influence on the meaning of the city and its space because, as Roland Barthes puts it, "the city is a writing. He who moves about the city, e.g. the user of the city (what we all are), is a kind of reader" (1997: 170). Authors of urban fiction are continuously associated with the cities they write about and vice versa (Augé 1998: 401). This correlates with the notion "of the text and city as a palimpsest" (Edwards 2012: 170). Both concepts are repeatedly adapted to recent developments. Hence, globalization, the city, and literature are interrelated and impact each other.

The main difference between city literature and the modern urban novel is the shift of focus onto urban space instead of the conventional antagonism of country versus city (Wirth-Nesher 1996: 203). Moreover, since John Dos Passos' Manhattan Transfer (1925), at the latest, the textual form of the modern city has been a focus of attention. Among others, the overarching theme of fragmentation, such as the discontinuous narrative and the mixing of languages and dialects, serves as an example for urban fiction (Vanderwerken 1977). Pursuing this line of argument, the distinct characteristics of the contemporary global city novel are presented and examined in this study. Thus, in addition to its focus on urban space, the contemporary global city novel includes the global intersections of flows and the interconnection to further places.

Themes of world-wide interconnectedness, global migration, and multiplicity are recurring in this work's selected novels - Dionne Brand's Toronto, What We All Long For (2005), Change-rae Lee's New York, Native Speaker (1995), and Karen Tei Yamashita's Los Angeles, Tropic of Orange (1997). The city is celebrated as a space of diversity and as "positioned in ever more complex networks of urban relations" (Brantz et al 2010: 9), connecting urbanities around the world and highlighting the significance of urban space as well as tropes of global identity and loss. Whereas "for the modern urban novel there is no world outside the metropolis worth portraying" (Wirth-Nesher 1996: 207), for the global city nov-

information on the early American city novel, see Betsy Klimasmith's At home in the City: Urban Domesticity in American Literature and Culture, 1850 - 1930 (2005). Added to this, not every novel is dominated by an urban setting, since novelists are also a non-urban phenomenon (Raleigh 1968: 295). 
el, as this study argues, the awareness of the global as well as of globalization and its effects come into perspective. Thus, the contemporary city novel is essentially a global one because the effects of globalization are "seen nowhere more clearly than in the contemporary city" (Carter et al 1993: viii). The different discourses of the narrated modern metropolis, such as "loneliness, isolation, fragmentation, alienation" (Wirth-Nesher 1996: 17) remind one of the themes of ethnic literatures. The novel Native Speaker (1995), for example, begins with a protagonist who feels like an alien in American society, has a fragmented identity, and has just been left by his wife.

The metropolis plays a prominent role in literature in a globalizing age because when the traditional 'center-periphery dichotomy' is suspended or reversed, urban space is claimed by different ethnic groups (Sturm-Trigonakis 2007: 2245). Specifics of place and space have mostly been disregarded in city literature. Instead, the modern novel favored aspects like plot, character, and theme (Wirth-Nesher 1996: 3). In contrast to city novels of Realism or modern times, the contemporary city novel creates non-hierarchical and transnational spaces in a global network (Sturm-Trigonakis 2007: 225). In this study's analysis, the focus is shifted to the global city as one distinguished cultural 'contact zone' (Pratt 1992) in a globe-encompassing network of flows. Scenes at the airport, which serves as the prime-example of 'non-places' (Augé 2008), are incorporated to show that global cities function as global hubs for world-wide tourism, business as well as migration and transmigration. Moreover, several languages, translations, and narrative voices illustrate a city's unique diversity.

Similar to the plethora of terms describing cultural diversity ${ }^{16}$, quite a number of different expressions with common characteristics are employed regarding literature on diversity. These include minority, ethnic, postcolonial, migrant, intercultural, multicultural, or transnational literature. The application of the terms varies significantly from one national discourse to another as well as in the context of different academic fields. The prevailing terms in North America are of interest, since the three selected novels are written and set in either Canada or the United States of America. Whereas Canadians make use of the generic term 'ethnic minority writing,' 'minority writing,' or simply 'Canadian writing,' American writers are usually referred to by their specific ethnic group or sub-

16 More information about the concept of 'diversity' and its numerous neighboring terms are provided in Chapter 4 on 'Cultural Diversity in a Globalizing Age.' 
group. ${ }^{17}$ This conception of ethnic literature as distinct, coexisting 'ethnic containers' is recurrently criticized.

The categorization process of writers turns out to be arbitrary when, for example, considering second-generation immigrants or those who cannot easily be assigned to one particular ethnicity. Karen Tei Yamashita, a Japanese American writer who teaches Asian American literature, incorporates Spanish and 'magic realism,' which originated in Latin America. Her typical categorization as an Asian American writer by publishers appears arbitrary because she is a third generation Japanese immigrant born in California and incorporates several languages as well as a multi-ethnic cast of characters in her novel Tropic of Orange (1997). Likewise, the classification 'immigrant literature' faces similar skepticism because it is commonly perceived as a subgroup of 'national literature' (Sturm-Trigonakis 2007: 247) and thus correct labeling fails as soon as national borders are transgressed.

The term 'third-world literatures,' also referred to as 'world literature,' has been established to summarize literatures from former colonies and other nonWestern literatures (Siskind 2010). The contemporary notion of 'world literature' represents both Western and non-Western literatures and is commonly understood as 'literature of the world.' The 'new world literature' (SturmTrigonakis 2007: 241) of a globalizing age is conceived as a hybrid text form with overlapping features of national, migration, and postcolonial literatures as well as literature on globalization. The three key aspects of new world literature are multilingualism, border-crossing, and the focus on the local (Maurer 2010: 330). The disadvantage of this approach is that monolingual texts are excluded, although those texts can be considered global literature (Sturm-Trigonakis 2007: 252). Nevertheless, world literature is often used interchangeably with global literature or literature on globalization.

Postcolonial literature, e.g. agglomerated in The Empire Writes Back (Ashcroft et al 1989), designated a first step towards global literature. It changed the way cultures of the world are perceived and discussed from a new, global perspective (Reichardt 2010: 79). With the post-colonial period and the accompanying growing migration and transfer of goods and values in a globalizing age, cultural flows became increasingly multidirectional from 'Third World' to 'First World' countries (Chambers 1994: 3). Thus, global literature represents a change of perspective, often rewriting Western hegemony, thereby taking multiple iden-

17 Similarly, the prominent American writers Toni Morrison, Sandra Cisneros, Maxine Hong Kingston, and Leslie Marmon Silko are commonly labeled as African American, Chicana, Asian American, and Native American, respectively. 
tities and perspectives into account, which reminds of the qualities of postmodern literature.

In general, literature on diversity has the majority of the following recurring themes in common: 1) immigration or upward mobility, such as the American dream, California dreaming, or manifest destiny, 2) search for an identity or an identity crisis on the macro-level, including different national models of integration or assimilation, such as the Canadian mosaic, 3) self-definition or identity crisis on the micro-level, including independence, individuality, and freedom of speech and language, political pressures, religion, or sexual orientation, 4) generational conflicts due to cultural, language, or societal differences, and 5) themes of motion, including travel, migratory movements, relocation, displacements, global availability of cultural elements, such as traditions, clothes, food, music, dance, and arts. Thus, themes encompass, for example, a young group of second-generation immigrants is united in the struggle of a generational conflict, although the four protagonists are of diverse ethnic backgrounds, or a personal, marital, and professional crisis of an Asian American protagonist.

The common aesthetics of global literature, urban fiction, and ethnic writing identified in this literary analysis are 'the poetics of narrative,' 'the poetics of place,' and 'the poetics of code-switching.' Thus, the three selected contemporary North American novels serve as examples of how an analysis by a 'poetics of diverCity' provides the opportunity to analyze ethnic urban literature in a globalizing age in a structured way. In global literature, for example, a shift towards hybrid texts can be identified, stressing the need for an analysis of narrative. Therefore, the general structure of the novel but also the use of different types of intertextual devices and the application of narrative voices are of particular interest. Concepts of place play a significant role in the three novels because identity and space form an intrinsic relationship in global cities. The use of multiple languages, translations, and other forms of code-switching typically function as markers for both global and ethnic literatures, literally giving the cultural diversity of urban complexities a voice. Different narratological strategies are employed to emphasize the novel's different forms of diversity and integration. What the narrative strategies are as well as how and why they are employed is presented in the following section.

\subsection{The Poetics of NarRative}

Analyzing diversity and globality in a work of fiction goes beyond the close reading of cultural themes and motifs. The hybrid design of texts has often been 
neglected (Sturm-Trigonakis 2007: 106) in both multilingual and global literature. Moreover, the city and its growth and development are regarded as always connected to literary movements, such as the development of the novel (Lehan 1998: 3). Therefore, in this study, apart from plot, character, and theme, special attention is directed to intertextuality and narrative voice with 'the poetics of narrative.'

The term 'narrative' has multiple meaning. In literary studies, narratology is defined as "the academic study of narrative" (Fludernik 2009: 158), which is often used interchangeably with narrativity or narrative technique, structure, and style. A 'poetics of narrative' "attempts to understand the components of narratives and analyses how particular narratives achieve their effects" (Culler 2000: 83). Mode, tense, and voice are the three major categories of narrative theory (Genette 1993; Fludernik 2009: 99). In this study on the literary diversity of the global city in a globalizing age, the novel's genre, intertextuality, and narrative voice are the focal point.

This work also looks at the application and implication of the term 'genre' in literary studies. The term refers to norms in different disciplines in the arts and sciences. In the biological sense, genre refers to categories such as the human species or gender (Derrida 1980: 56). In order to maintain their purity, genres should not be mixed. Derrida calls this 'the law of genre.' Bakhtin, however, stresses the fact that the novel has always made use of different genres because "the novel parodies other genres (precisely in their role as genres); it exposes the conventionality of their forms and their languages; it squeezes out some genres and incorporates others into its own particular structure, re-formulating and reaccentuating them" (1981: 5).

The reformulation process mentioned by Bakhtin is achieved through intertextual devices. The term 'intertextuality' is closely connected to genre and was coined by Julia Kristeva in 1966. It is the most renowned and repeatedly used expression for the reference to one text within another (Genette 1993: 10). This 'borrowing' of elements can encompass quotations, references to or from critics, books, or concepts. Moreover, intertextual devices can refer to forms of literature but also to other national canons, languages, and cultures (Sturm-Trigonakis 2007: 162). Examples of the three selected novels include the mixing of different genre conventions, the blending of fiction and fact, or a network-like composition of diverse characters and their stories.

With regard to new world literature in a global age, a tendency can be identified in which hybrid texts may contain more transtextual elements (SturmTrigonakis 2007: 143). In ethnic writing, a similar process can be identified (Birkle 2004: 231). The term 'transtextuality' is increasingly used synonymously 
with 'intertextuality.' Aside from 'intertextuality', there are four more forms of 'transtextuality,' encompassing 'paratextuality', 'metatextuality', 'architextuality', and 'hypertextuality,' listed in their quality of increasing abstraction, implication, and globality (Genette 1993: 10).

Paratextuality, for example, includes the title of a work or a table of contents. This "visual presentation of the text" (Fludernik 2009: 23) functions as an author's direction for the reader (Genette 1993: 11), including "choice and size of font, marginal notes or illustrations accompanying the text" (Fludernik 2009: 23). ${ }^{18}$ One form of paratextuality is metafictional comments that tend to transgress literary conventions. These explicit or implicit comments by the author directly or indirectly address the reader. Examples of the three selected novels include a different justification, the use of italics to mark translations, telling titles, or quotes and statements featured before the first chapter.

The strategy of incorporating transtextuality is, first and foremost, to open up a literary canon (Sturm-Trigonakis 2007: 155), whether an established national canon or a particular genre. Any recombination is accepted as long as a transformation of a known aspect to a new theory is productive because "transtextuality leads to multiple recodifications and reinventions of cultural signs without asking where a certain element is coming from or if it is 'original' or 'authentic' or not" (de Toro 2006: 23). With the help of transtextual devices or different elements of genre, a 'transtextual space' (Sturm-Trigonakis 2007: 156) is created in which different forms of texts but also different ideologies coexist. Thus, different forms of diversity can mirror particular narratological strategies and vice versa.

Language functions as a central marker of cultural diversity. Buzz words such as 'polyphonic ensemble,' 'polyglotism,' and 'heteroglossia' hint at a writer's ability to describe cultural diversity from a language perspective. Language in general, and the kind of speech, jargon, and translation in particular, play a major role in the three selected novels. Linguistic instruments, such as codeswitching, translation, metaphors, and symbols are consistently used as a tool to mediate between the different cultures.

Bakhtin's term polyglossia, which is frequently interchanged with 'multivocality' and 'heteroglossia,' refers to several coexisting languages within a novel but also to a multiplicity of "verbal-ideological belief system" (1981: 311). Thus, a novel is always a dialogue of several voices, cultural influences, and ideologies. The presupposition of polyglossia is that language is never static but "al-

18 Interestingly, with the technological development and increasing use of electronic versions of a book, e.g. on an Amazon Kindle, these elements fall to the side. 
ways borrowed, shared, and alien as well as mine" (Shevtsova 1992: 753). Narrative voices manage to illustrate cultural diversity graphically because, as Bakhtin puts it, "speech diversity achieves its full creative consciousness only under conditions of active polyglossia" (1981: 68). Bakhtin identifies and values diversity through language. Different languages are uttered in different social, geographical, or political settings, involving different interlocutors of different class, gender, race, or profession. Therefore, speech genres vary widely and encompass formal and informal speech.

The Latin American critic Ángel Rama introduced the term 'transculturadores narrativas,' to refer to writers who function as mediators, negotiating between the different languages and cultures inherent in one Latin American society (Bernal 2002). Authors in such a transcultural society have to negotiate between different worlds, traditions, and languages. In a dialogical novel, this negotiation of another's language than the author's constitutes a tolerant process (Bakhtin 1981: 409). In transcultural Native American fiction, for example, writers aim at a negotiation of written works and oral traditions (Fitz 2001: 194).

One function of exercising multiple languages in a novel is mimesis. ${ }^{19}$ Mimesis is a form of imitation, resemblance, or a mirror effect. In literature, mimesis is referred to as the truthful literary resemblance of reality (Sturm-Trigonakis 2007: 147) with regard to a certain time, place, or person. A character's narrative voice is adapted to highlight the sense of reality or impression of authenticity. Sometimes, linguistic stereotypes of certain native or non-native speakers are employed to intensify the experience of the reader. Examples of the three selected novels include different narrative voices and writing in a polyglot fashion. The narrative voice is altered every chapter to suit the respective character in focus, mirroring and sometimes parodying 'ethno-linguistic' stereotypes. This polyglossia creates closeness to the characters and an impression of 'authenticity,' envisioning different perspectives and coexisting worlds.

Language thus functions as a 'point of view' and as a means to question the dominance of one perspective. Bakhtin's notion of the novel is that of a 'zone of contact' (1981: 27f.), in which different languages, cultures, and ideologies intersect. This is a reminder of the crucial characteristic of the global city as a cultural node in a global network of flows. How concepts of place and space form a leading category of analysis for the diversity of global cities as a literary phenomenon will be presented in the following section.

19 For more information, please see Gunter Gebauer et al's Mimesis: Culture-ArtSociety (1995). 


\subsection{The Poetics of Place}

Place can be as varied and as multiple as the various 'chronotopes' that Bakhtin (1981: 84) attributes to the novel. The 'concrete whole' of the novel (analogous to place) is shaped by a fusion of 'spatial and temporal indicators' so that 'time, as it were, thickens, takes on flesh, becomes artistically visible' while 'spaces become charged and responsive to the movements of time, plot and history'.

(HARVEY 1996: 294)

The term chronotope was coined by the Russian critic Mikhail Bakhtin in the 1930s and was spread across the predominantly English-speaking discourse on genre theory and literary conventions when the first English translation of Bakhtin's works was published in the 1970. The term's literal translation is 'time space,' stressing the "intrinsic connectedness of temporal and spatial relationships that are artistically expressed in literature" (Bakhtin 1981: 84). The chronotope "functions both on the level of small text units and on the level of an 'overarching' world model" (Keunen 2001: 421). Moreover, and as the geographer and social theorist David Harvey demonstrates, Bakhtin's notion of the 'chronotope' inspired not only literary theorists but forged an interdisciplinary discourse aimed at describing the qualities of place. Thus, by the late 1980s, critics across the disciplines called for a new conception of our sense of place in a globalizing age. This new understanding of place is more progressive and suits the discussion of the world-wide effects of global convergence, interconnectedness, and the acceleration of transnational cultural flows.

In a globalizing age, the image of a 'shrinking world' is produced by the illusion of a 'time-space compression' (Harvey 1989), which describes the "movement and communication across space, to the geographical stretching-out of social relations, and to our experience of all this" (Massey 1994: 147). This phenomenon explains the perception of the world's compression to a 'single place' (Robertson 1992: 6). Due to globalization and its effects, concepts of identity, place, and space are more dynamic because the conception of foreignness as a spatially distant phenomenon no longer holds true (Clifford 1998: 14). Likewise, common cultural roots, values, or interests can be interlinked across distances in the form of, for example, 'imagined communities' (Anderson 1983). 
In A Global Sense of Place (1994), the social geographer and cultural critic Doreen Massey argues that places can have multiple associations and identities. In the geographer's understanding, places are not restricted to particular individuals, communities, or boundaries. Places and their associations change over time and thus are naturally and frequently mapped differently. A place can have an individual, social, political, cultural, geographic, and religious or spiritual meaning. Meaning is not exclusive. It is multi-layered and in constant flux. Therefore, a 'single sense of place' (Massey 1994: 153) is rarely the case. Instead, a sense of place is created by a combination of different, individual and collective associations that change over time. Similar to Massey, David Harvey seeks to comprehend "places as internally heterogeneous, dialectical and dynamic configurations" (1996: 294). Whenever an individual encounters a new space (either by choice or forced, as in diasporas), confusion of those new cultural codes can result in an identity crisis (Böhme 2005: XXI).

Due to their diverse connections, places are not only subject to constructed boundaries but are also influenced by world-wide networks of exchange, combining 'a sense of the global' and 'a sense of a local' (Massey 1994). Similar to conceptions of different and coexisting worlds within one world (Nassehi 2003), multiple associations of spaces exist and coexist. Similar to the outdated concept of single cultures, the identity of a place is not singular, enclosed, fixed, and static. This phenomenon translates into "a simultaneous multiplicity of spaces: cross-cutting, intersecting, aligning with one another, or existing in relations of paradox or antagonism" (Massey 1994: 3). This segment or snapshot of one world within the world can be described as a specific "time-space 'slice' of an individual's overall activities" (Giddens 1991: 83).

A specific movement in a certain space is dependent on different variables, such as race, gender, class, or income. Doreen Massey, for example, distinguishes between mostly Western jetsetters and typically non-Western refugees. While both groups are 'on the move,' the power and influence varies widely, favoring the jetsetters (1994: 149). ${ }^{20}$ Thus, different social groups have a different relationship to movement, referring to a rather active or passive role regarding mobility, the mover's power and influence, and the possible positive or negative side effects of these movements.

20 Doreen Massey stresses the fact that no movement can be considered as a separate occurrence. Instead, she highlights the global interdependence and poses the question of "whether our relative mobility and power over mobility and communication entrenches the spatial imprisonment of other groups" (1994: 151). 
In a globalizing age, one of the crucial questions is whether 'time-space compression' (Harvey 1989) equals cultural compression. The most controversial issue with regard to the discussion of globalization as a process of standardization or Westernization is whether the world is becoming a single cultural setting and, thus, whether cultural convergence leads to the unity or uniformity of cultures (Tomlinson 2001: 11). Relating to the example of air travel connecting different worlds but thereby neglecting the complex geographies in between (Birkett 1991: 38), Massey argues that the process of compression is subject to inequality (1994: 148). In this "power geometry of time-space compression" (Massey 1994: 149; emphasis original), some locations are affected more by globalization than others and some cultures and individuals are naturally disregarded, whether intentionally or unintentionally.

Space, place, and time are social constructs (Harvey 1996: 293). These constructs depend on different power relations of a society and naturally change over time. The terms 'place' and 'space' are often used interchangeably. In modernity, a growing difference in meaning between 'space' and 'place' can be identified, which is characterized by a relationship of a growing 'spatial' distance between the two concepts (Giddens 1990: 18; Massey 1994: 5f.). This translates into the hypothesis that local places are increasingly influenced by social, political, or economic phenomena in distant places around the globe, thereby creating larger space between places.

The concepts of 'time' and 'space' are inseparable. Edward Soja's Postmodern Geographies. The Reassertion of Space in Critical Social Theory (1989) insists on the concentration of 'time' and 'space' with regard to critical studies in order to fully grasp the interdependence of the two concepts (Hallet et al 2009: 15). Nevertheless, in a globalizing world, the false conception commonly prevails that "'time' is equated with movement and progress, 'space/place' is equated with stasis and reaction" (Massey 1994: 151).

In a time of globalization, places seem progressively more fragmented in contrast to the earlier conception of places being culturally homogenous. However, places have always been dynamic and their meaning was constantly changing. Political models like nationalism, however, created a fairly stable, coherent, and nostalgic sense of place to counteract change, intermingling, and hybridization processes. In literary studies, this changed conception of 'place' and 'space' manifests itself and is recurrently and increasingly identified in global and transnational literary works, expressed in literature by using spatial vocabulary "such as speed-up, global village, overcoming spatial barriers, the disruption of horizons" (Massey 1994: 146). These markers of globalization, identity, and space in 
the form of expressions, descriptions, or images are the focal point with regard to 'the poetics of place' as a part of this analysis.

Since the 1990s, several 'turns' were identified in the field of cultural studies (Bachmann-Medick 2006) that had considerable impact on critical analysis and related discussion (Günzel 2007: 13). Well before the compilation of cultural turns, 'space,' as a concept in literary studies, was mainly associated with cultural production as well as the three critics Ernst Cassirer ${ }^{21}$, Jurij Lotman ${ }^{22}$, and Mikhail Bakhtin (Hallet et al 2009: 16). With the spatial turn, ${ }^{23}$ space and spatiality are increasingly discussed and reflected in literature. Edward Soja, who coined the term 'spatial turn,' was inspired by Michel Foucault, ${ }^{24}$ Henri Lefebvre ${ }^{25}$ (Hallet et al 2009: 11f.), and by cultural criticism and postcolonial critics such as Said, Spivak, and Bhabha, as well as Appadurai (Soja 2009: 25). Thus, similar to the development of world literature and global literature, post-colonialism again paved the way for a new research interest in studies of place and space.

The topographical turn ${ }^{26}$, in contrast, refers to the different forms of space and their representation (Günzel 2007: 13). The two turns, the spatial and the topographical, are not to be confused (Günzel 2008: 221) but nonetheless are often used interchangeably. The term topology, which originated in the field of mathematics, describes the critical study of the concept of space, its production as well as its presentation and representation across various disciplines. There

21 Cassirer focuses on the aesthetic function of space. For more information, see Cassirer, Ernst. "Mythischer, ästhetischer und theoretischer Raum." Raumtheorie. Grundlagentexte aus Philosophie und Kulturwissenschaften. Eds. Jörg Dünne, Stephan Günzel. Frankfurt: Suhrkamp, 2006 [1931]. 485-500.

22 For more information about the 'spatial turn' in literary studies, see Michael C. Frank. "Die Literaturwissenschaften und der spatial turn: Ansätze bei Jurij Lotman und Michail Bachtin." Raum und Bewegung in der Literatur. Eds. Wolfgang Hallet, Birgit Neumann. Bielefeld: transcript, 2009. 53-80.

23 For more information on the 'spatial turn' in cultural studies and sociology, see Jörg Döring et al's Das Raumparadigma in den Kultur- und Sozialwissenschaften (2007).

24 For more information about Foucault's idea of other spaces or heterotopia, see Foucault, Michel, Jay Miskowiec. "Of Other Spaces.” Diacritics. 6.1. (Spring 1986; based on a lecture in 1967): 22-27.

25 For more information about Lefebvre's concept of space, see Lefebvre, Henri. The Production of Space. Oxford: Blackwell, 1991 [1974].

26 For more information on the 'topographical turn,' see Sigrid Weigel's "Zum 'topographical turn'. Kartographie, Topographie und Raumkonzepte in den Kulturwissenschaften.” KulturPoetik. 2.2. (2002): 151-165. 
are several possible approaches to understanding the relationship between topology and literary and cultural studies. Topology is employed as a literary technique, which focuses on the (re)presentation of space as a reality, and is different from cartography, which is the study of maps. Topology can be used as a method to analyze literature in terms of, for example, the production and dynamics of space as well as positioning (Borsò 2007: 289f.).

Imagined space in a novel represents a particular selection. The aesthetics of a narrated space are the result of the network-like configuration of the selected elements as a whole as well as their combination and reference to objects (Nünning 2009: 42). The three selected novels in this study describe and create a sense of place in global cities because "when authors import aspects of 'real' cities into their fictive reconstructions, they do so by drawing on maps, street names, and existing buildings and landmarks, enabling a character to turn the corner of a verifiable street on the map, to place him in a 'realistic' setting" (Wirth-Nesher 1996: 10).

Urban space designates much more than the setting of a novel because cultural meaning, such as norms and values, are invoked (Hallet et al 2009: 11). The novelist is the one "who both reconstructs in language aspects of 'real' cities and invents cityscapes" (Wirth-Nesher 1996: 10). Different forms of (re)presentation of 'real space' can be identified, such as naming, telling, listing, reproduction, and reframing (Jäger 1998: 23; Nünning 2009: 45). Relevant for a literary analysis is why certain places of interest or further details of the real world have been selected because the city in literature functions not only as a 'physical place' but also as an 'atmosphere' and a 'way of life' (Gelfant 1970: 4).

In this study, the different forms of literary place and space will be analyzed with narratological categories. Description and figurative language are used to create or convey a specific literary setting (Nünning 2009: 45), which will form the basis for this work's analysis of urban space with regard to diversity in the three selected North American global cities. Description functions as a tool in literature to refer, represent, or interpret (Wolf 2007: 16). Providing topographical details or so-called cognitive mapping (Herman 2002) helps to envision 'real' places as well as imagined space in a novel. Urban geography, for example, uses mental maps to examine urban space and its concentration of cultural diversity (Pacione 2009: 21) within one city to understand urban lifestyles and mentality.

In texts, descriptions of place and space often remind the reader of stage directions. Whereas the names of a city's neighborhoods, streets, or other major attractions highlight the sense of the 'real' city, generic expressions such as 'this city' tend to describe the nonspecific global city as such. Alfred Döblin's Berlin 
Alexanderplatz: Die Geschichte vom Franz Biberkopf (1929) probably remains the most significant German city novel, in particular with regard to the specific narration of the city. The city's 'local color' is emphasized by detailed topographies (Sieg 2010: 198). Thus, the particular ensemble of topographical details reveals the role of urban space in the novel, such as economic, political, or cultural space or a representative node in a global network of flows.

Moreover, the types of places mentioned are of significance. A major distinction is made between public and private space. In addition, different types of escapes, including ethnic, gendered, and generational, are of importance when describing forms of integration and suppression in urban space. Another distinction can be made between static and dynamic places. Whereas static places often refer to where we live, grow up, work, or feel safe, dynamic places are subject to movement and change. Migration, border-crossing, or transportation of people on the subway, the highways, or bicycles involves forms of 'time-space compression,' conveying shifting geographies, increased connectivity, or interdependence of places. Therefore, motion verbs are a basic element for 'cognitive mapping' (Herman 2002: 282) because literary characters are typically described by how they move or do not move in a certain space (Hallet et al 2009: 25). Whereas the portrayal of a continuation of anti-immigrant racial politics is interpreted as a rather static cityscape, the distortion of geography presents a city in flux.

The four types of 'narrated cityscape' are "the 'natural,' the built, the human, and the verbal" (Wirth-Nesher 1996: 11f.). The natural environment of the narrated city may include elements such as parks and the weather and highlights the interdependence of nature and culture, such as a winter setting. The 'built' cityscape, for example, refers to infrastructural elements, which function as representatives of existing monuments, landmarks, or artifacts of the 'real' cities, such as the depiction of a highway system.

The second narratological category used for the examination of literary space is figurative language or literary trope. This category includes metaphor, metonymy, and synecdoche (Nünning 2009: 45). However, further literary devices such as irony, oxymoron, hyperbole, litotes, antithesis, allegory, and antanaclasis should be considered as well. Figurative language and the metaphor in particular go beyond the literal, thereby "expressing meaning or conveying insight which nonfigurative language is incapable of expressing or conveying" (Anthony 1970: 225). Different types of narrating the city can be identified, and these are conveyed with the help of figurative language. The types include themes of fragmentation and collage, as in the time-space compression and the redefinition of borders, or symbolism. Moreover, different languages are used as a tool to con- 
vey the cultural diversity of the global city. The following section will define and describe how code-switching is used and what the strategies are for its application.

\subsection{The Poetics of Code-Switching}

So if you really want to hurt me, talk badly about my language. Ethnic identity is twin skin to linguistic identity - I am my language. Until I can take pride in my language, I cannot take pride in myself. Until I can accept as legitimate Chicano Texas, Spanish, Tex-Mex and all the other languages I speak, I cannot accept the legitimacy of myself. Until I am free to write bilingually and to switch codes without always having to translate, while I still have to speak English or Spanish when I would rather speak Spanglish, and as long as I have to accommodate the English speakers rather than having them accommodate me, my tongue will be illegitimate.

(ANZALDÚA 1987: 59)

As illustrated in Anzaldúa's quote, multilingualism is one key aspect of both ethnic literature and individual or group identity formation. The use of diverse languages and translation is not only a linguistic but also a cultural process that is the focus of attention with regard to the diversity of the global city as a global contact zone. The neighboring concepts of 'multilingualism' and 'codeswitching' are and often used interchangeably. Multilingualism is the use of multiple languages and is often referred to as polyglotism, which is the ability of speaking more than one language. Different languages can include dialects, slangs, and vernaculars. Whereas 'multilingualism' generally indicates a characteristic of a speaker or writer, code-switching commonly refers to the act of changing languages within a speech act or a written text. Code-switching serves as the appropriate basis for this analysis because the switching process itself indicates a negotiation of difference. This section will explain the different forms, strategies, and effects of switching languages.

Code-switching became a popular field of study in the 1980s (Erfurt 2005: 30 ). The term originates in linguistics and designates a mixing process of two or 
more languages within one act of communication. The term is related to styleshifting, borrowing, and often used interchangeably with code-mixing. Speakers who make use of code-switching are typically bilingual or multilingual. ${ }^{27} \mathrm{~A}$ code can be a letter, word, phrase, or gesture which entails a piece of information. ${ }^{28}$ When translated, or decoded, the meaning may vary due to different cultural contexts or shared knowledge. When information travels globally, contexts and shared knowledge vary significantly.

As a prerequisite for analyzing code-switching and the use of multiple languages, the distinction between matrix language and embedded language needs to be made. The term 'matrix language' (Myers-Scotton 1989) was coined to describe the dominating language in terms of quantity in a specific context (Eastman 1992: 2). The words or phrases spoken or written in a different language than the matrix language are usually referred to as 'embedded language.' Forms of multilingualism include the different types, such as grammatical interference, analogies, and neologies or metamultilingualism, which are directions for the reader about the language in which a particular event takes place (SturmTrigonakis 2007: 123ff.). A typology of code-switching depends on its length. The length of language switching can vary from one morpheme, which is the smallest linguistic entity, to a word, a phrase, or a whole sentence, as in intersentential or intra-sentential switching (Myers-Scotton 1989).

Multilingual texts as such are not a new phenomenon. However, the quantity, diversity of its form, functionality, and the reception has changed in a global age (Sturm-Trigonakis 2007). In literary studies, multilingualism is employed to describe acts of code-switching in hybrid texts. Global literature or literary texts in a global age increasingly include several languages to portray the diversity of its characters and settings, stressing "the necessity for readers and writers to demonstrate linguistic flexibility in order to contend with the polyphonic qualities of texts that construct hybrid identities" (Wilson 2011: 236). Hence, multiple languages function as an instrument of how global processes of hybridization are translated into literature (Ette 2007: 14). Thus, English, Japanese, and Spanish are incorporated, for example, to highlight the diversity of a novel's characters, their linguistic flexibility and hybrid identity.

27 For more information, please see Wei, Li (ed.). The Bilingualism Reader. London: Routledge, 2000.

28 The most renowned codes include the international Morse code of on-and-off sounds or different forms of sign languages that consist of body language and manual communication, usually varying from one culture to another. 
Transcultural writers, "also variously referred to as multi, hetero-, poly- or translingual writers" (Wilson 2011: 236), are one version of describing transnational, diasporic, or migrant writers who frequently make use of at least one language other than their primary language. Translingual authors express "themselves in multiple verbal systems" and can be considered as "the prodigies of world literature" (Kellman 2003: ix). The linguistic fluency of a particular writer in a specific language is of minor importance when analyzing literary diversity (Sturm-Trigonakis 2007: 108). The network of transcultural Anglophone writers, for example, includes natives as well as non-natives (Doff et al 2011: 4). Authors who choose to write in a different language than their mother tongue are associated with the field of exophony. ${ }^{29}$ As an example serve the incorporation of nonnative languages or featuring characters with a different ethnic background than the author.

The introductory quote to this section by Anzaldúa is asking for linguistic integrity, hinting at the interdependence of language and identity. The Texas-born Chicana Gloria Anzaldúa is renowned for her critical cultural studies on the Mexican-American border, as in her famous collection Borderlands/La Frontera: The New Mestiza. A border conflict commonly entails a language conflict because the border zone remains a symbol for migration, bilateral or transnational politics, and identity conflicts. Anzaldúa is physically and metaphorically in a border position because, as she claims, "I am a border woman. I grew up between two cultures" (Anzaldúa 1987: 6).

Multilingualism, which is paradigmatic for a border region, is maintained because code-switching implicates multiple identities (Myers Scotton 1982: 435). The concept of translational identity (Wilson 2011: 235) captures this notion of transnational speakers or writers who employ elements of polylinguality and code-switching to express their dynamic process of cultural self-conception. Switching languages or dialects within the same speech group is a strategy (Myers Scotton 1982: 432) to enrich the conversation and the dynamics of individual and group identification. Reasons for switching encompass "changes in setting, interlocutor, conversational goals and other social factors" (Isurin et al 2009: ix).

The context of speech events is important, including sociohistorical, ethnographic, ethnic and racial, political, economic, generational, and communal (Eastman 1992: 16f.) as well as regional and national aspects. Translingual liter-

29 For more information on the field of exophony, see Arndt et al's Exophonie: AndersSprachigkeit (in) der Literatur (2007), and for its strategies, see Wright's "Exophony and Literary Translation: What it Means for the Translator when a Writer Adopts a New Language." Target. 22.1. (2010): 22-39. 
ature aims at a transcultural aesthetic and "symbolizes the variety, the contact and the crossing of cultures and languages" (Wilson 2011: 245) in a literary piece as well as being a representative for diverse urban or global space. The polylinguistic design of texts is one criterion for new world literature in a globalizing age (Sturm-Trigonakis 2007: 108). The process of code-switching often results in experiments of language use and translation, such as creative blends or new word creations (Wright 2010). Yoko Tawada, for example, is considered a translingual writer because she writes in German and Japanese with a focus on translation, hybridity, and awareness of 'the other' (Maurer 2010). ${ }^{30}$

Code-switching is a specific urban phenomenon. Some studies identify the correlation of switching codes in mainly urban spaces and multicultural settings (Eastman 1992: 16). In a global city, both presuppositions occur at the same time. The use of multiple languages and translations is employed as a strategy to convey diversity and to illustrate the intermingling of cultures in a specific time and place. Moreover, this feature can describe various forms of cultural contact and encounter, such as coexistence, cooperation, or chaos.

Translation is an important marker for global and ethnic literatures because global cultural flows and migratory movements lead to a growing need for translation between different language and cultures that are increasingly in contact. Therefore, the various forms, lengths, and strategies of translations in a novel need to be analyzed. The term 'translation' is closely connected to the concept of 'code-switching'. In addition to its use in the academic field of linguistics, translation becomes a vital practice in various fields in a globalizing world of increased connectivity and interdependence. In a globalizing age, the notion of translation goes beyond the reproduction of the original. It always involves a cultural process of negotiation. In addition, the transformation of cultures as well as the in-between space or overlapping border space becomes the center of attention (Bachmann-Medick 2006: 253). Thus, translation also functions as a cultural analysis of global flows, such as world-wide migration, and the description of "the complex process of cultural signification produced under the impact of such displacements, migrations, relocations and diasporas and the unprecedented development of transnational electronic communications and media systems" (Wilson 2011: 236).

As a consequence, a so-called translational turn can be observed in social studies and cultural studies, which goes hand in hand with a cultural turn in in-

30 Tawada's writings include a selection of short stories called Überseezungen (2002), which is a pun on the German word for 'translation' and the similar-sounding blend of the two German words 'transatlantic' and 'tongues.' 
ternational translation studies (Bachmann-Medick 2006: 238f.). The basis of the translational turn is grounded on a broader understanding of the term 'translation' that includes the representation, negotiation, and transformation of cultural differences. Translation is not a unidirectional but a 'dialogic process' (Bassnett 1998: vii) because "to translate is always to transform" (Chambers 1994: 4). Literary translation is a movement that highlights the interdependence of comparative literature and translation studies (Bassnett 1998: viii), thereby acknowledging the significance of the cultural turn in translation studies.

Not only translations in a literary work but also translations of a novel need to be taken into consideration because the range of distribution and translations of novels hints at a change of reception of multilingual literature. Reasons may include a larger readership of more multilingual than monolingual speakers. Another function of translation and multilingualism is the practice of not translating embedded language intentionally. Sometimes, no further explanation of an embedded word or phrase is provided. This 'lack of translation' is occasionally employed as a strategy to turn the non-native reader of translingual comments into a position of alterity because translations and thus explanations are not provided. This 'border position' can be compared to the one of the new arriver or immigrant who cannot master the dominant language yet. In this case, the writer abandons the option to function as a mediating authority. Nevertheless, this procedure is an effective means to raise awareness of the linguistic or cultural 'other' by reversing the roles and putting the reader in an outsider's position.

With a structured literary analysis involving a poetics of narrative, place, and code-switching, this work provides the connecting link for examining the triad of globalization and its effects, global cities as cultural nodal points, and cultural diversity as the common aesthetics of global, urban, and ethnic literature ('diverCity'). Before analyzing the three selected North American novels, the context of each of the three 'real' global cities will be introduced briefly. These intersections of the literary with the 'real' are of special interest because the city's image or myths often influence the works written about it since the 'real' city "is itself a text that is partly composed of literary and artistic tropes" (WirthNesher 1996: 10). Therefore, after a short introduction to the economic and infrastructural details of Toronto, New York, and Los Angeles respectively in the following three chapters, overarching tropes of the respective global cities are identified as a prerequisite for the analysis of the respective global ethnic urban novel. This forms the basis for identifying synchronic and specific aspects of global cities as a literary phenomenon. 



\section{Dionne Brand's Toronto, What We All Long For}

\subsection{The Global City of Toronto}

'Diversity, Our Strength' is the motto for which the global city of Toronto has become recognized and celebrated (Lo 2008: 122). This distinguishing slogan has come a long way from the once WASP-dominated 'Toronto, the Good' (Rosenthal 2011: 32). In the past 30 years, Toronto has transformed from an almost "exclusively white enclave" (Troper 2003: 20) to the immigrant city and role model of social integration it is today. Canadians are proud of Toronto and attempt to cross-sell this form of cultural diversity to different cities all over the world because this model of integration can function as a best practice for other countries and help promote prosperity (Kymlicka 1998: 3). The unique official government policy partially explains how Toronto has rapidly changed into the multicultural setting of today (Siemiatycki et al 2001: 1): indeed, "the World in a City" (Rosenthal 2011: 32). To fully grasp Toronto's evolution, the city's immigration story needs to be examined.

Essentially, Toronto's population has changed from a homogenous to a heterogeneous one. Until the early twentieth century, Toronto's population consisted mainly of those of British descent (Siemiatycki et al 2001: 1). Between 1931 and 1996 however, the percentage of immigrants of British descent declined from 81 percent to just 16 percent (Siemiatycki et al 2001: 373) as the city grew in size and immigration policies were relaxed. Since the 1970s, for example, the percentage of immigrants from Asia and the Pacific as well as Africa and the Middle East has grown steadily. This growth is largely due to the 1976 Immigration Act aimed at the reunion of Canadian immigrant families, fostering of the Canadian economy, and supporting refugees and diasporas (Jansen et al 2003: 66f.). By the 1980s, Toronto's image had transformed into a culturally tolerant cosmopolitan city of 'polyethnic character' (Harney 1983: 1) of "a remarkably 
diverse ethnic, racial, linguistic and religious metropolis" (Siemiatycki et al 2001: 1).

Toronto's strength is its diversity (Siemiatycki et al 2001: 454). Each year, Toronto attracts an average of 70,000 immigrants from close to 170 countries, and, as a result, more than one hundred languages are spoken in the city (Anisef et al 2003: 3f.). Between 1995 and 2001, Toronto was mainly shaped by Asian and Caribbean immigrants (Hoernig et al 2010: 155). Currently, the three largest ethnic groups in Toronto are Chinese (an estimated 450,000), Italians (an estimated 400,000), and Afro-Caribbean (an estimated 250,000) with Vietnamese immigrants making up one of the fastest-growing ethnic groups (Troper 2003: 20).

Toronto is described as Canada's preeminent global city. In the Census Metropolitan Area, it features both Canada's highest rate of foreign-born population in 2006 (46.6 percent) and the highest rate of recent immigrants arriving between 1996 and 2006 (15.8 percent) (Langlois 2010: 448f.). Almost 50 percent of Toronto's inhabitants are thus foreign-born, highlighting the city's unique trait as a cultural hub and a so-called 'gateway city' for immigrants and transmigration. In contrast, in 1996, both New York and Los Angeles featured a smaller foreignborn population of 23 percent and 31 percent, respectively (Anisef et al 2003: 3). However, unlike those two North American cities, the Canadian metropolis has been largely disregarded in studies on urban complexity.

Toronto is considered to be Canada's only global city (Hall 2010: 63). In 1986, it was the only Canadian city featured in Friedmann's classification of world cities and was categorized as second tier (1986). Nearly twenty years later, Taylor (2005) similarly considers Toronto an 'incipient' (Hall 2010: 63) leading world city of second class, following global cities such as New York and Los Angeles. In both studies, Toronto is in the same category as the North American cities of Miami and San Francisco. The city is ranked thirty-sixth in population and twentieth in Gross Domestic Product (GDP). Overall, it is ranked fourteenth in the recent Global Cities Index Methodology $2010^{31}$.

Toronto is viewed as the Canadian 'high-connectivity gateway' (Taylor et al 2002; Taylor 2004: 92) in terms of economy, capital, and business locations. It is

31 The data used for the Global Cities Index Methodology is collected, analyzed, and evaluated by Foreign Policy, A.T. Kearney, and The Chicago Council of Global Affairs, taking various issues into account, such as business activity, human capital, information exchange and access to information, cultural experience, and their influence on global discourses. For more information see <http://www.foreignpolicy.com/ articles/2010/08/18/global_cities_index_methodology $>$. 
the country's unchallenged economic center with almost half of Canada's corporate headquarters (40 percent) based in the Greater Toronto Area (Lo 2008: 125). The area surrounding Bay Street has become Toronto's high-rise business district. Due to its significance to the national economy, Toronto, as Canada's financial hub, is often likened to its sister city New York and its significance for the American market.

Immigration has had an impact on Toronto's economy as transnational business networks have been shaped and expanded with the flow of immigrants. In Toronto, both so-called 'working-age immigrants' and immigrant entrepreneurs and their capital have reshaped the city's labor market, simultaneously connecting the different ethnic clusters in Canada and across the globe (Hutton 2010: 117). Thus, international immigrants provide links to the global network, allowing Toronto to play a major part on the world scene. In particular, Toronto's cultural industry has been a key to the global city's economic success. In the video and film industry, for example, geo-proximity, lower costs, and the concentration of talents and resources have meant that many North American television series and blockbusters previously taped in New York or Los Angeles are increasingly filmed in Toronto (Hutton 2010: 117). Nowadays, the film industry's growth rate is even greater than that of Los Angeles (Vinodrai 2010: 105).

The Greater Toronto Area is Canada's largest city (Hutton 2010: 119). In 1998, Toronto's profile as a city changed significantly when it became the megacity of roughly 5.5 million inhabitants it is today. Through a process of amalgamation, several municipalities were fused, the goal being more efficient local government spending and a new, economic level of global competitiveness (A1lahwala et al 2010: 210). Additionally, raising Toronto's attractiveness as a location for international headquarters became a key focus. Thus, the city of Toronto was fused with the districts of Etobicoke, East York, North York, York, and Scarborough. However, the integration of different minority groups has proven to be less efficient than the municipal amalgamation as the cultural integration of the municipalities still remains to be implemented. The expansion of public transportation was one of the measures taken to counteract this development.

Public transportation distinguishes Toronto from many American automobile-focused cities. Toronto opened the first subway line in Canada in 1954 (Perl et al 2010: 204) and features today one of Canada's highest rates of public transportation. Although Yonge Street, Toronto's main street, is one of the longest in the world and serves as an infrastructural support for the settlement of NorthWestern Canada, Toronto's private transportation mobility is relatively low compared to other global cities (Perl et al 2010: 194) and in particular to the car use per capita in Los Angeles. 
Toronto's population has become a vital part of urban planning and environmental policies. Recognizing the interdependence of identity and space, Toronto's authorities aimed at the integration of the diverse city dwellers in the infrastructural development. The Humber River Pedestrian Bridge, for example, was designed and built in the mid-1990s to honor Toronto's aboriginal people by integrating their cultural icons, such as animals and totemic masks, into the structure (Miller et al 2010: 175). The city's government thus aimed at honoring a minority, which has been and still is mainly neglected nationwide.

The large number of immigrants arriving in Toronto in the few past decades has transformed not only the city's image but also its physical appearance as "immigration has become a singular force shaping and reshaping Toronto's streetscape" (Troper 2000: 4). Immigration, racial segregation, poverty, and neighborhood formation are often interlinked phenomena. Immigrants tend to form ethnic clusters, sometimes resulting in ethnic enclaves or so-called ethnoburbs (Liu 1998; Hall 2010: 60), a term originating for Chinese clusters in Los Angeles, which are formed when specific immigrants cluster in a city in dispersed patterns. This settlement and resettlement process is one of the key issues that change a city's social space.

Pre-World War II, Toronto had a few immigrant neighborhoods, such as the Caribbean-influenced Kensington Market. They were disregarded by the majority of the population and did not represent a vital part of urban life (Troper 2000: 5). Following World War II, however, new immigrants mainly settled in urban Canada (Hou 2004: 1). This post-war continuity and diversity of immigration changed the city of Toronto and its spatial pattern: "Anglo Toronto has given way to a rich montage of ethnic villages, an urban complex where variegated ethnic and racial core zones nuzzle up against one another in an overlapping pattern that stretches from the inner city well into the outer suburban ring" (Troper 2003: 58). Until the 1970s, immigrants had originally settled in ethnic neighborhoods in Toronto's inner-city and then resettled later in mixed-ethnic neighborhoods in the suburbs, whereas post-1970 immigrants were likely to immigrate directly to the suburbs (Murdie et al 2003: 139).

Canadians coined the term visible minority to address inequalities within the labor market. Similar to the American policy of 'affirmative action' introduced in the 1960s, Canada's employment equity of minorities is ensured by establishing quotas. Visible minority neighborhoods, which have grown steadily in Toronto since the $1980 \mathrm{~s}$, consist of at least 30 percent of individuals from the same ethnic group (Hou 2004: 8). Although a trend towards more visible minorities in Canadian urban areas can be identified, a ghettoization process is not taking place (Walks et al 2006: 294). 
The phenomenon of the accumulation of same ethnicity members in one area is explained by identifying three different processes in the formation of visible minority neighborhoods: 1) relational concentration - when all members of a community increase but the visible minority increases relatively more, 2) gradual transition - the effect is age-related and explains the natural fluctuation of people in the course of their lives, e.g. teens moving out to find their own home, families with children moving closer to education facilities or older community members tending to need appropriate age-based housing, and 3) partial replacement - non-visible minority members moving out and members of a visible minority moving in at the same time (Hou 2004: 3). This last process explains the formation of a large number of visible minority neighborhoods of Chinese, South Asian, and Black decent in Toronto (Hou 2004: 19). Nevertheless, the degrees of visible minority neighborhood segregation are much lower than in the majority of American cities (Walks et al 2006: 294).

The metaphor of the Canadian mosaic quickly became popular across the nation and helped to strengthen the nation-building process. John Murray Gibbon's Canadian Mosaic: The Making of a Northern Nation (1938) constituted one of the key texts of Canadian identity. Sociologist John Arthur Porter introduced the concept of the vertical mosaic to describe Canadian culture and society in his 1965 book The Vertical Mosaic: An Analysis of Social Class and Power in Canada. Porter explains that Canada has different cultures, languages, and regions that can be compared to the form of a mosaic. The theme of the mosaic is uniquely Canadian and mostly contrasted with the American model of the 'melting pot' in which every immigrant's culture is dissolving to form the new, assimilated American culture. In contrast, in a mosaic, the different pieces remain recognizable and together form the whole picture of Canadian culture, society, and identity. The 'vertical' aspect of the metaphor of the Canadian mosaic can hint at the uneven distribution of power through classes (1965: 27).

Canadian multiculturalism can be described in different contexts: "a social reality, a federal government policy, and a myth-based ideology (Day 6-7, 1625; Kallen 75-94)" (Ernst et al 2010: 7). In 1971, Canada's Prime Minister Trudeau initiated the country's transformation from a former British colony to a new form of national ideology by making multiculturalism an official policy and establishing a Ministry of State for Multiculturalism (Cameron 2004: xvii). In 1988, the Canadian Multiculturalism Act became part of the constitution. Canadian multiculturalism translates into the acceptance of the system of 'a stateimposed integration,' including the adoption of the new, shared language(s) of Canada (Kymlicka 1998: 39). Multiculturalism can be summarized as the current and future position of Canada as an immigrant country and as the acknowledge- 
ment and 'promised 'recognition' of previously suppressed, marginalized, and excluded ethnic identities" (Ernst et al 2010: 8).

The growing proportions of non-European immigrants to Canada have posed difficulties to the social integration of 'visible minorities' (Anisef et al 2003: 4). The increased immigration from Asian countries, such as India and China, was a major shift as they began to arrive in the 1960s (Hoernig et al 2010: 154). In Canada, discrimination in the form of racism is less common than in the United States (Anisef et al 2003: 4). Toronto particularly serves as a role model for acceptance to all Canadians. Although many pride themselves on their country's multiculturalism, disillusionment among some Canadians is growing towards this national model of ethnodiversity (Kymlicka 1998: 4)

Despite Canada declaring ethnic integration a government policy, some critics are convinced that the Canadian approach of multiculturalism is doomed to fail as an integrative measure for immigrants. As evidence, they cite the fact that the policy of multiculturalism has not succeeded in putting an end to the problems ethnic minorities currently face, such as prejudice, hatred, and discrimination. A survey conducted in 1993 revealed that 72 percent of the Canadians polled were in favor of the American immigration model of a 'melting pot' over their own model of a 'mosaic' (Ernst et al 2010: 11; Dupont et al 2001: 310ff.). These results are disconcerting, as the Canadian 'mosaic' was originally championed as an alternative to the American model of wholesale assimilation. The Canadian model of 'multiculturalism' can be problematic as it views cultures as 'finished products' (Eze 2005: 24), resembling fixed entities or isolated single cultures as opposed to more dynamic conceptions of cultures, such as Welsch's concept of 'transculturality' as the new form of cultures today (1999).

Although multiculturalism has proved to be a success for the integration of minorities, some Canadians are concerned that the government's multicultural policies may threat national unity (Kymlicka 1998: 180). Thus, it is feared that the grouping of particular ethnicities in one location results in social ghettoization processes. Further skepticism of the Canadian approach to the integration of minorities arises as a result of government spending for the endorsement of diversity. The Canadian government's policy of multiculturalism is often criticized for selling illusions and supporting clichés where ethnic food, music, and dance are considered (Bissoondath 1994). The controversial 'T.O. live with culture' campaign that was launched in 2005 as a 'cultural promotion package' for local artists in Toronto (Bain 2010: 265f.), for example, was not condoned by the same artists it was trying to promote. They claimed that the high rent and mass construction of high-end condos in the city was resulting in a gentrification process that changed the neighborhoods and their inhabitants substantially. 
Despite the criticism of Canadian multiculturalism, the government's policy has raised awareness of and fostered official support for the different minority groups, their cultures and literatures (Padolsky 1996: 24). Beginning in the 1970s, non-fiction writing on Toronto's cultural diversity slowly became a comprehensive research topic. Examples of the wide range of texts about Canadian multiculturalism and particular minorities in Toronto include the African Canadian community (Head et al 1975), Ukrainians (Gregorovich 1976), the French (Maxwell 1977), the Finnish (Lindstrom-Best 1979), Poles (Morawska et al 1982), Italians (Zucchi 1988), Chinatown (Thompson 1989), the Greek community (Almyroudis 1991), the Caribbean community (Henry 1994), the Jewish community (Torczyner et al 1995), Somali refugees (Opoku-Dapaah 1995), Portuguese Women (Giles 2002), Latin Americans (Veronis 2006), Croats (Winland 2007), and Muslim homosexuals (Khaled 2009).

Toronto's literary scene has been habitually neglected for some time. It only started to be of interest to the international community about ten years ago (Rosenthal 2011: 33). This neglect explains the relatively small internationallyknown literary canon in comparison to the wide range of works from Los Angeles and the huge selection of literature describing city life and nation-building from New York. One reason for this phenomenon may have been the traditional former colony's orientation towards the British Empire and its literature as Toronto's population was mainly of British origin until the 1970s. Since then, however, Toronto's self-conception as 'the world in a city' and its reflection in fiction and arts in general has slowly been developing. As a result of the significant waves of immigration, the city's literary scene has gradually changed and adapted to its new ethnodiverse texture.

The Romanian-born Canadian poet Irving Layton was one of the first to recognize the changing city space in the 1970s. It is no coincidence that he chose the setting of Kensington Market as a prominent place of international foods in his poem called Varied Hues (Elton et al 2009). In the poem's market scene, the different ethnicities of the city, such as Italian, Jewish, and Jamaicans, are coming together to form a literary 'map of the world.' The Sri Lankan-born Canadian author Michael Ondaatje rewrites Toronto as a changing city and a place of class struggle for early twentieth century neglected immigrants in his 1987 novel In the Skin of a Lion (Lowry 2005: 64). The famous Toronto-based writer Margret Atwood was among the first to recognize the city as a setting for her literary work (Rosenthal 2011: 34). Her retrospectively written novel Cat's Eye (1988), for example, illustrated the change of Toronto's society from a mainly Protestant one in the 1950 s to a more tolerant one in the 1970 s, one in which multiculturalism and the women's movement gained significant momentum (Rosenthal 2011: 
34). Pico Iyer describes Toronto as "The Multiculture" in his globe-trotting search for home and belonging in The Global Soul (2001). Toronto is illustrated as a city in which categories of who is Canadian and who is not become blurred, different religions coexist, and boundaries between former enemies, such as Serbian and Croatian, dissolve in an Italian café.

The subject of the intersection of a number of different minorities developed very late in Canadian literature (Kortenaar 2009: 578). Considering the immense increase of international immigration to Canada beginning in the 1970s, the phenomenon of 'true' multicultural writing appears to be at least one generation delayed. The shift towards ethnodiverse writing assumedly took place when second-generation immigrants, ${ }^{32}$ who naturally became native speakers, began writing in English. Beginning in the 1990s, besides the author's culture and the 'host culture,' further ethnicities were included in the multicultural casts of characters (Kortenaar 2009: 578). This period can be described as a time of diversity in a globalizing context.

Dionne Brand's depiction of Toronto serves as the prime example for this new type of global interethnic Canadian literature that includes more than one ethnicity. With the multicultural cast of characters and the remapping of ethnic urban space, Brand's novel What We All Long For (2005) represents the first attempt to translate the contemporary city's diversity and its 'uniqueness' into literature, as Rinaldo Walcott argues in The Globe and Mail (2005). Brand considers the global city of Toronto an 'awakening city' in which the imaginative city in literature is still struggling to keep up with the material city of multicultural reality (Rosenthal 2011: 33). The following sections describe and analyze how the global city of Toronto is imagined as 'the world in a city.'

\subsection{TORONTO IMAgINED: THE WoRLd IN A CITY}

The slogan 'the world in a city' describes the global city of Toronto imagined in Dionne Brand's novel What We All Long For (2005). The novel rewrites the formerly anglicized city of Toronto by focusing on a selection of non-white characters of diverse background. Going beyond the idea of the nation (Brydon 2006: 3), a concept of identity is presented in which the four second-generation immigrant friends form "a culturally hybrid, rhizomatic coalition" (Quigley

32 This study distinguishes between 'first-generation immigrants' and 'secondgeneration immigrants' to emphasize the intensification of the generational conflict within immigrant families. 
2005: 65) across the boundaries of the different worlds within the city. Although prejudice and racism are still prevalent in the 'multicultural city,' the younger generation's search for an urban selfhood explores diversity in Canada on a more positive note than in Brand's earlier writings (Dobson 2009: 189).

In What We All Long For (2005), Canadian multiculturalism is depicted as a double-edged sword. Brand's literary Toronto is a place where people of different ethnicity, class, or gender and sexual orientation encounter each other and intermingle peacefully, while others still struggle for the integration, equality, and social acceptance promoted by the political ideal of Canadian multiculturalism. The cosmopolitan citizenship is proposed as a counter-narrative in which identities are made of multiple global influences that are nevertheless rooted in the global city of Toronto (Johansen 2008: 50). Thus, Brand's novel significantly contributes to the field of English Canadian urban fiction, which is only recently emerging (Rosenthal 2011: 267).

Dionne Brand was born in Guayguayare, Trinidad in 1953 and moved to Canada after high school to attend the University of Toronto in 1970. She received her B.A. in English and Philosophy in 1975 and graduated with an M.A. in the philosophy of education from the Ontario Institute for Studies in Education in 1989. She is a literary critic who is mostly famous for her poetry such as No Language is Neutral (1990), thirsty (1998), and Ossuaries (2010), which won the 2011 Canadian Griffin Poetry Prize. The author also publishes fiction, such as In Another Place, Not Here (1996) and At the Full and Change of the Moon (1999), non-fiction, such as A Map to the Door of No Return: Notes to Belonging (2001), and documentaries, such as Borderless: A Docu-Drama About the Lives of Undocumented Workers (2006). She is a human rights activist and committed to social justice in terms of race and gender. She received the City of Toronto Book Award for What We All Long For in 2006. Brand is currently a Professor of English at the University of Guelph, Ontario near Toronto.

Dionne Brand is considered to be in the major league of authors on multicultural issues in Canada. Her literary work is mainly concerned with identity on a personal and a national level, immigration, diaspora, and cultural politics. She has become known as a voice for the 'black' community in Canada. ${ }^{33}$ Her work often relates to influential texts by Derek Walcott, Toni Morrison, and Kamau Brathwaite. Thanks to the popularity of Brand's work, Toronto has become associated with 'black' writing. This association is in contrast to that of the period

33 To highlight the diversity of the regional and cultural background of the 'black' community and experience in Canada, the term is opted often in favor of the expression 'African Canadian' here and in the following. 
before the 1990s, when the city was conceived as a predominantly white literary scene (Ball 1994) in which the 'black' experience was mostly disregarded (Rosenthal 2011: 216). What We All Long For (2005) represents a shift in Dionne Brand's writing. The novel explores Toronto as a culturally diverse city, exploring city life and integration above and beyond the 'black' community.

What We All Long For (2005) is set in the present-day city of Toronto. After a short introduction to the winter setting, the summer of the 2002 Soccer World Cup is the story's main time frame. A blend of characters with Italian, Vietnamese, Caribbean, and African Canadian background functions as a snapshot of Toronto's cultural diversity. The four twenty-something, second-generation immigrant friends, Tuyen, Carla, Oku, and Jackie were born in the city of Toronto to immigrant parents from within or outside Canada. The novel manages to show the opportunities as well as the drawbacks of an immigrant experience in Toronto.

In the novel, urban space is used as a tool to reflect on identity politics and the Canadian model of 'multiculturalism.' The younger generation chiefly identifies with the global city, its streetscape, and the dynamic cultural intermingling, rejecting concepts of purely ethnic, hyphenated, or national identities. In contrast, their first-generation immigrant parents experience the city as a 'racist space' (Dobson 2009: 186), oscillating between the incomplete integration as Canadian citizens and the preservation of their cultural roots. This contrast results in a generational conflict, showing how integration potentially works better for second-generation immigrants.

Dionne Brand's novel What We All Long For (2005) is analyzed in six sections, addressing issues of code-switching, narrative, streetscape and countergeographies, the gap between immigrant generations, and the significance of the title. The following section explores how the novel translates the steadily growing cultural diversity of Toronto as a global city. Thus, the novel becomes a 'polyphonic ensemble' (Fruner 2007: 7) of different languages, cultures, and voices: The portrayal of more than one ethnicity channels as a "polyphonic murmuring" (WHA 149) in which various languages voice the city's ethnic diversity.

\subsubsection{Polyphonic Murmuring}

When creating Toronto in imaginative terms, the portrayal of merely one or two ethnicities proves to be insufficient because, as the novel explains, "that was the beauty of this city, it's polyphonic murmuring" (WHA 149). This polycultural view of Canadian society includes a selection of the global city's major ethnic 
groups, such as Asian, Italian, and Caribbean blacks. The collection of different characters, languages, and perspectives as well as Tuyen's installation called lubaio mirror the different worlds within the city, turning the novel into "a feast of metropolitan polyglottism, a paradigm for urban heteroglossia" (Fruner 2007: 7).

Subsequent to the introduction to the city and its harsh winter setting, the narrator skips forward to summer-time and zooms in to the main characters. Three of the four second-generation immigrant protagonists, Tuyen, Oku, and Carla are introduced in the course of the opening scene on the Toronto subway, one of the city's major cultural contacts zones for the city's inhabitants (Rosenthal 2011: 221). The train ride functions as a synecdoche for the dynamics of space and the transitory character of city life: An analogy to the tram ride in Alfred Döblin's Berlin Alexanderplatz: Die Geschichte vom Franz Biberkopf (1929), one of the most renowned city novels.

Similar to a documentary-style camera-eye perspective, the young friends' physical appearance is described in a style of a non-participating observer, thus presenting an outsider's view of life in the city. This first depiction appears to be a coincidental portrayal of random citizens as the protagonists are not yet referred to by their names. Only when reading the opening paragraphs a second time, the reader is reminded of the young group of friends. The Toronto-born second-generation immigrants Tuyen, Carla, Oku, and Jackie are of Vietnamese, African Italian, Caribbean, and African Nova Scotian background, respectively. Thus, the global city's three major ethnic groups are featured in the novel while the literary portrayal of the Vietnamese diaspora, one of Toronto's emerging ethnic groups, provides an additional perspective on immigration and loss.

Tuyen, the daughter of Vietnamese refugees is introduced as "beautiful in a strange way" and possessing "the beauty a falcon has: watchful, feathered, clawed, and probing" (WHA 2). The allusion to a falcon hints at her alternative life as a creative avant-garde artist in Queen Street West, which is a dynamic space for Toronto's younger population (Rosenberg et al 2010: 357). Art is Tuyen's means of language, communication, and expression of emotions. The strong, stubborn woman's descriptions are prose-like, illustrating the full variety of her fascinating personality and her androgynous appearance that attracts men and women alike (WHA 22).

Tuyen is in love with her next-door neighbor Carla, who is a bike courier and described as "not phenotypically black" (WHA 106) and who "might be Italian, southern" (WHA 3). Carla's description shows the narrator's rejection of the demarcation of "absolute ethno-national borders" (Dobson 2009: 190). The bike courier suffers from low self-esteem and the suicide of her mother, Angie, 
caused by Carla's father Derek ending his extramarital affair with her. Carla is constantly worried about her younger brother Jamal's inability to adapt to Toronto's multicultural society and its norms.

The only male of the four high school friends is a good-looking Caribbean black called Oku (WHA 2f.). He is a poet who dropped out of university and is desperately in love with Jackie, who herself prefers the much older German, Reiner. Jackie dyes her hair red and calls herself 'Diva.' She runs a 'postbourgeois,' second-hand store called 'Ab und $\mathrm{Zu}$ ' that is located 'just on the border where Toronto's trendy met Toronto's seedy" (WHA 99).

Toronto's polyphonic sound is translated into the different narratives voices. Bakhtin's concept of multivocality describes the coexistence or incorporation of a number of different languages. This literary technique expresses the cultural diversity of characters in the form of different tongues, speech, jargon, dialect, and vernacular. In the novel, the style of narration is adapted to the particular speech patterns of the respective characters, such as “Tuyen's and Jackie's slang sparkling speeches; Quy's disenchanted, often disinfected tone; Fitz's sour-andbitter rebukes; Rasta's idiolect and hipsters' jargon; disco leaflets oozing technofunky vibes; Kwesi's jungle bluntness; Jamal's juvenilish replies, angry and tender at the same time" (Fruner 2007: 7). With the help of the individual narrative voices, several perspectives are created, envisioning the world in the global city of Toronto.

Occasionally, linguistic stereotypes of certain native or non-native speakers are employed to intensify the experience of the reader. This strategy of mimesis, a tool to translate multivocality, is a form of imitation, resemblance, or a mirror effect. In literature, mimesis is referred to the truthful literary resemblance of reality (Sturm-Trigonakis 2007: 147) with regard to a certain time, place, or person. Jackie, for example, "spoke valley girl, baller, hip-hopper, Brit mod, and French from watching RDI" (WHA 45) on TV. She also makes use of powerful expression and graphic language as fillers that stereotypically function as nouns, adjectives, verbs, and transition phrases. This kind of speech stresses Jackie's image as a strong and independent African Canadian woman. Her character's narrative voice is adapted in order to highlight this impression of 'authenticity.'

In a similar fashion, Jamal's character incorporates specific ethnic slang words to sound like an African Canadian, aiming at identification with and becoming a respected member of the ethnic group he desires. The vernacular is illustrated in direct speech with supporting exclamation marks only, as in "Me nah 'fraid nutten, Carla!" (WHA 31). Jamal employs typical elements of African Canadian vernacular, such as double negation and the omitting of word parts. His sister Carla is annoyed whenever he uses this vernacular because she "didn't 
know why he insisted on speaking in this accent. Something he'd picked up with his friends on the street. He did it to assume badness" (WHA 30). As a consequence, and due to his African Canadian appearance, Jamal is repeatedly stopped and searched by the police. Jamal even branded a ' $G$ ' for 'Ghost' on his breast, a gang marker. Emphasizing his African Canadian background in terms of appearance, symbols, and slang is his attempt to integrate into Toronto's multicultural society.

Rasta, the homeless person Oku meets at Kensington market occasionally, is another example of an authentic mimesis of slangs. Rasta is poetically begging for money in front of a Caribbean food store: "The streets them hard, you know, dread. The air is abstraction me tell you. Give a likkle something for the I and I (...) Beg you a likkle something to hold I soul together, man. The spirit massive but the body weak" (WHA 169). The substitution of the letters 'kk' for 'll' as well as the pronouns 'I' for 'me' and 'my' function as stereotypical language markers. The effect is the literary resemblance of the character's Caribbean background, giving the city's ethnic diversity an 'authentic' voice.

The novel translates and negotiates between the different worlds within a society. This dialog of languages is taking place on eye-level because no voice is prejudiced or in a supreme position. Language thus functions as a 'point of view' and as a means to question the dominance of one perspective. This translates into process of mediation between heterogeneous cultures and languages. Antonio Cornejo-Polar proposes a concept of a dialogic culture in which the differences of cultures are recognized. The interaction in this dialogical mode is more democratic, imagining "culture as an open space where diverse languages, ethnicities, cultures, and histories enrich each other by means of that multiple dialogue without losing their idiosyncratic character" (Cornejo-Polar 1998: 24f.). Thus, Toronto's "polyphonic murmuring" (WHA 149) can be described as a network of languages that is not hierarchical but tolerant. This heteroglossia is how the imagined Toronto achieves its effect because it "is so well-balanced and intermodulated, it turns the novel into a sheer polyphonic ensemble, performing the many lingos multiethnic Toronto performs" (Fruner 2007: 7).

Cataloging is applied as a device to visualize this dialogue of languages and cultures. This listing in the form of a meditative catalog illustrates the diversity of Toronto and is reminiscent of the literary technique of word accumulations employed by Walt Whitman. An example is provided in the following lines, which are used as the introduction to chapter SEVEN. In contrast to the major part of the book, the advertisement Jackie reads is presented in no grouped style of justification, disrupting the standard flow of reading the novel: 
Juice/solid Garage featuring Jephte Guillarme - New York - born in Haiti, uprooted to Brooklyn with his family, turning vodun spirituality into something understood. Hit single "The Prayer." Voyage Dreams "Mad Behind the Tet Kale Sound" - Friday 5th - Una mas/Funk d'void - Techno meets funky jazzy house meets Glasgow Funk d'void/Grand Master Flash "immortalized by Blondie, feted by the hip hop cognoscenti, Grand Master Flash turned the humble record deck into an instrument as potent as the piano or guitar"/Afrika Bambaata. B. Boy and Dance classics Saturday 29th (Mancccc Wabanakkk) ... (WHA 45)

This mishmash of languages, music, and styles of different cultural background represents the jargon and complexity of Torontonian fashion, arts, music, and entertainment. The device of cataloging creates an egalitarian basis and results in a democratizing effect of the listed items. Thus, Toronto is described as a dynamic space of cultural interaction and dialogue, "where identity and alterity, where what is one's own or another's, live together and interact in a productive manner" (Cornejo-Polar 1998: 24f.).

Dionne Brand can also be considered a translingual author, frequently illustrating the city of Toronto in different verbal systems. Various accents, dialects, and vernaculars of Canadian English as well as Vietnamese, Portuguese, and Italian are featured in the novel to express the city's particular cultural diversity in linguistic terms. One example of multilingualism and code-switching is Quy's second chapter, which is situated between chapters SIX and SEVEN. It concludes with a Vietnamese saying that is immediately followed by the English translation, reading "Troi co mat. Troi phat. Heaven has eyes. Heaven punishes" (WHA 79; italics original). The first sentence is a common Vietnamese saying, translating into the all-seeing eyes of heaven that are "always on the look out for people's moral violations" (Kingsley 2002: 94). This act of code-switching is emphasized by changing to italics. It foreshadows Quy's tragic death. Moreover, not only translations in a literary work but also translations of a novel can hint at a change of reception of multilingual literature. Apart from English, the Torontobased novel is very popular in Italian, probably due to the city's large Italian community.

The 'lack of translation' is occasionally employed as a strategy to turn the non-native reader of translingual comments into a position of alterity because translations and thus explanations are not provided. This 'border position' is suggestive of an immigrant who cannot master the dominant language yet. In this case, the writer abandons the option of functioning as a mediating authority. The Portuguese note Tuyen finds: "A janela já foi consertada, ele só queria dinheiro" (WHA 148; original in italics) are an example of the practice of intention- 
ally not translating embedded language. This language swap is an effective means of raising awareness of the linguistic or cultural 'other' by reversing the roles and putting the reader in an outsider's position.

The strategy of presenting and representing more than her 'own' language and culture identifies Dionne Brand a 'transcultural writer' (Kulyk Keefer 1995). Transcultural writers function as critical representatives of their own ethnicity or culture but also require readers to acknowledge processes of change and exchange between and within cultures in order to transgress conceptions of cultures that are fixed and intrinsically logical (Schulze-Engler 2006: 48). Instead of showing a coexistence of different but distinct cultures within a society, the novel's second-generation characters of diverse background are interacting, emphasizing the transition from a multicultural to an interethnic or transcultural perspective of writing.

Moreover, What We All Long For (2005) not only portrays the interaction, intermingling, and collaboration but also shows the coexistence, clustering, and isolation of different cultures. A whole section is dedicated to Toronto's aboriginals, raising awareness of the desolate situation of the Inuit and First Nations in Canada. Although government policies and spending aim at facilitating the minority's integration into society, aboriginals are still generally not treated as equals in Canada. In addition to this range of ethnic perspectives, various bordercrossing characters with different gender, sex, and sexuality are incorporated into the novel to complement the multiperspectival portrayal of Toronto's society.

The novel's most significant symbol of translation and multivocality is Tuyen's installation called the lubaio that captures the world within the city as a "gathering of voices and longings" (WHA 149). As artists are "a cultural means of framing space" (Zukin 1995: 23), the work on the installation is Tuyen's contribution as a citizen and her way of honoring the city she was born in. For Tuyen, "the city becomes a space for shape-shifting and for slipping into another body by imagining what people long for" (Rosenthal 2011: 233). The piece of art is consistently referred to in italics in the novel, emphasizing its significance. The lubaio is made of different notes and pictures, illustrating the diversity of characters, languages, and memories of the city (WHA 158). With her creation of the lubaio, Tuyen functions as a translator who transforms the city's "polyphonic murmuring" (WHA 149) into a visible object of art. As artists are considered "the ultimate agents of transculturation" (Birkle 2004: 232), Tuyen deems the use of traditional Vietnamese elements to be artificial. She instead opts to function as a representative of "the city's heterogeneity" (WHA 142) and thus plans to "have the audience post messages on the lubaio. Messages to the city" (WHA 17; italics 
original). Her achievement is making sense of the individual voices by incorporating them into a cohesive but tolerant patchwork-like structure.

Similar to the ethnically diverse graffiti crew who is 'overwriting' the anglicized city with spray paint, ${ }^{34}$ the lubaio captures Toronto's new ethnic diversity and becomes a symbol of the metamorphosis of the formerly British-dominated urban space. The design of the lubaio reflects a different vision of Toronto's society, serving as a counter-symbol to the Canadian model of 'multiculturalism.' In the Canadian vertical mosaic and the American model of the 'melting pot' alike, individual cultures rarely overlap, favoring a coexistence with a formation of ethnic silos rather than an intermingling of processes. Tuyen's creative woodwork, however, illustrates the overlapping pictures and longings in an egalitarian manner, reminding one of a collage or "bricolage" (Bentley 2005), emphasizing the fact that integration is an ongoing process that is never completed nor absolute. This work-in-progress mirrors the dynamics of identity because "Brand's Toronto is a city in everlasting translation, with selves and tongues meeting and morphing" (Fruner 2007: 7). That the lubaio is not finished by the end of the novel shows that the transformation from a multicultural to a transcultural society is not completed yet. ${ }^{35}$

As the patchwork-like lubaio mirrors the city's different cultures and longings, the novel's structure resembles the convergence of different stories, cultures, and worlds in the city. The following Section 6.2.2 'Converging Threads' examines how two seemingly opposite narrative strands and the different worlds converge by the end of the novel when the allegedly lost son Quy is reunited with his family in Toronto.

\subsubsection{Converging Threads}

With the introduction of the fifth main character Quy, a second major thread is established after the first chapter in terms of narrative structure and story line. His chapters feature I-narration, a different narrated time, space, and voice, and an outsider's perspective. Quy's disruptive voice is incorporated to dissolve the order and challenge the other stories (Rosenthal 2011: 252). In the course of the novel, the two major stories are weaved together and eventually converge in the

34 For more information on the intrinsic relationship of identity and space as well as the Graffiti crew's transformation of the anglicized city, see Section 6.2.4 on 'CounterCartographies.'

35 For more information on the different concepts of diversity and the interaction between Toronto's cultures, see Section 6.2.6 'Longing and Belonging.' 
same time and space, thereby showing multiple angles of the immigrant experience and the interconnectedness of the different worlds in Toronto.

The novel's structure resembles the two narrative threads. A different time frame, different locations, and a different number of chapters distinguish the two threads. Of the 32 chapters in total, 25 are consecutively 'numbered' with capital letters. Tuyen, Carla, Oku, and Jackie and their families are the center of attention, representing the major story line. The chronology of the novel is interrupted by seven interposed chapters, named 'Quy,' that constitute the additional thread of narration and a counter-story in many respects. The illegal immigrant Quy, for example, serves as the flip side of the coin, representing the undesired 'other' or "the alter ego of the four friends' lives" (Rosenthal 2011: 255).

The seven short chapters on the character Quy are inserted throughout the novel in random order, disrupting the linearity without comment. The different justification in Quy's chapters is a paratextual device that functions as an author's direction for the reader (Genette 1993: 11). Thus, whereas the consecutively-numbered chapters feature a justification in grouped style, Quy's chapters are not grouped, visualizing the interruption from a non-linear narration and the alteration of perspective.

Moreover, Quy's chapters are told achronologically to the rest of the novel. While the main story is set in Toronto in 2002, Quy's story begins before his arrival in Toronto when he was a young child and lost by his parents during their flight from Vietnam. Thus, whereas the main story of Tuyen and her friends takes place within a short period of time, Quy's story recaptures his whole life without his family in a fast-forward manner. The stories of the past and the present converge in 2002 in Toronto, thereby resembling a 'time-space compression' (Harvey 1989) in a globalizing age.

Whereas every character is portrayed from a third-person's point of view, Quy is depicted in the interim chapters from an I-perspective, thereby highlighting the differences of experience and point-of-view. The pronoun ' $\mathrm{I}$ ' is used repeatedly in his chapters, addressing the reader directly in a story-telling manner. Comments and questions such as "You see what I'm talking about?" (WHA 74) are incorporated, inviting the audience to interact. This strategy of switching to a different poetics of narrative serves as a strategy that simultaneously involves and detaches the reader. Quy, for example, confuses the reader about the correctness of his recounts by asking "now who would make up a story like that?" (WHA 141). Moreover, Quy also describes his innermost feelings to make the disparity of his life style more obvious. Therefore, the reader's relationship with the character Quy oscillates between closeness or distance and compassion or disgust. 
A different narrative voice is used in Quy's chapters, highlighting the diarylike narration of the lost son growing up at the other end of the world. In the course of the novel, the style of narration changes from a child-like to a nonnative speaker English with straightforward language. In his first chapter, Quy's words, "I was a boy at that time. It was night. Because it is at night that these things happen. I was with my parents and my sisters. (...) I was loved" (WHA 2005: 6), sound like an infant's tongue. The sentences consist of verbs and nouns with few extras. Hardly any adjectives or adverbs are used. In the course of the novel, his struggle with linguistic fluency as an English non-native speaker is stressed, something that is achieved by copying and sometimes parodying ethnolinguistic stereotypes. This narrative voice is similar to the Asian character Bobby in Karen Tei Yamashita's Tropic of Orange (1997). Quy explains that he "learned a little English. My first step to humanity" (WHA 137) because, similar to the character Henry Park in Chang-rae Lee's Native Speaker (1995), speaking English signifies to him access to a better world. By the end of the novel, Quy is portrayed as angry and provoking with the graphic expressions of a grown-up, thereby illustrating his frustration and despair at being left behind in a cruel world.

In the novel, the loss of Quy becomes the synonym for every immigrant's suffering, pain, and loss, symbolizing the sacrifice made when leaving a previous life behind. The parents' longing for the lost son and reminiscence per se cause the disruption between the two generations. The first generation of immigrants often suffers from nostalgia, constantly looking back when immediate integration into their new home country fails. Moreover, the immigrant children in the novel are split into two antagonistic groups: the so-called one-and-a-half generation immigrants born in Vietnam who witnessed the tragic incident and the second-generation immigrants, Tuyen and Binh, who were born in Toronto and are haunted by their brother's absence. Furthermore, Quy stands for the ones who did not make it to the 'Promised Land' (Rosenthal 2011: 253). His life with the monk is dominated by cruelty, brutality, crime, opium, smoking, drinking, gambling, fighting, disguising, and theft. This shows how a particular place and its characteristics shape an identity. The character Quy thus demonstrates the full range of consequences of a diaspora's immigration to Canada and is a reminder that loss and mourning are an inevitable part of every immigration experience.

The immense loss and guilty consciousness of leaving Quy behind is expressed in the numerous search letters his mother writes to find him. The letters are written in an Asian immigrant English, illustrated in italics with no grouped justification and several tabs. Each time, they are presented as a new paragraph: 
June 29, 1999

Dear Mr. Chiu, astrologer,

I am sending you \$350 today as agreed. The day is indeed auspicious as you promised. I slept somewhat last night for the first time since arriving in this country and I know that must mean that my son is safe.

Respectfully and sincerely, Vu Duong Cam (WHA 118)

The unconventional strategy of including letters in a novel facilitates the understanding of political refugees and their struggles across ethnic constraints. This effect illustrates the tendency that hybrid texts contain more transtextual elements in both new world literature (Sturm-Trigonakis 2007: 143) and ethnic writing (Birkle 2004: 231). In the letter featured above, Quy's mother, Cam, calls her home 'this country' instead of Canada, signifying the perceived distance to the country she lives in now, caused by the struggle to integrate as a first-generation immigrant. The search letters constitute one link between the novel's two major story lines. This intertextual device also joins the different perspectives, such as the present and the past, Canada and Vietnam, and the 'first' and the 'third' world.

In chapter TWENTY-TWO, the two stories come together when Quy explains how the monk who raised him was responding to his mother's search letters. His sister Tuyen is scared when she is first confronted with her brother after more than two decades of him being lost because he symbolizes "the excluded body, the sacrifice made for saving the lives of his siblings" (Rosenthal 2011: 253). She was "aware of the man as one is aware of a gecko, a spider, a shadow" (WHA 298) and a "ghost" (WHA 300), remaining skeptical and questioning his authenticity. Tuyen is, nevertheless, determined to include Quy as a part of her life and thus stops neglecting and alienating herself from her family, their loss, and their past.

By the end of the novel, it becomes clear that Quy was embedded in the novel's main story from the beginning. He was sitting in the same subway train as his sister Tuyen and her friends in the novel's opening scene. He even recognizes her laughter and is flashbacked to his childhood. However, neither knows nor guesses that the siblings are that close. This illustrates how small the world is and how the different threads come together in Toronto imagined as 'the world in a city.' Finding Quy, however, and curing the loss does not solve every problem. In the end, the reader knows more about Quy's story than his own parents and siblings because it is assumed he is killed before he can recount his stories. It thus remains unsolved whether Quy truly is the lost son or not. Jamal allegedly 
murdering Quy is a violent and radical form of connecting the different story lines.

Quy, who is, strictly speaking, an illegal, newly-arrived, first-generation immigrant, does not have the opportunity to create a sense of belonging and identity in the city. On the contrary, his character provides a radically different, much more skeptical world view, resembling the outsider's angle on the city of Toronto, Canadian multiculturalism, immigration, and identity. He envies the opportunities of the second-generation because "they have their friends and this city" (WHA 137). Quy's difficult relationship to Toronto is revealed when strolling the dark and suspicious parts of the city. He is restricted to the places an illegal immigrant would go to, such as "the alleyways that lead to the back doors of Chinatown in this city" (WHA 283). Nevertheless, Quy values the anonymity of the city and the similar criminal network of global cities by provocatively concluding that "anonymity is a useful thing. In some places they think people like me are preparing to bomb buildings and murder children" (WHA 138).

The converging threads of the different immigrant experiences, the past and the present, the 'third' and the 'first' world come together in the global city's urban complexity. In the following section on 'Mapping the World in a City,' the different coexisting and sometimes collaborating worlds in the city are explored. The strategy of mapping urban space reshapes the formerly anglicized city of Toronto, illustrating the city's new diversity.

\subsubsection{Mapping the World in a City}

The different forms of literary place and space are envisioned with 'cognitive mapping' (Herman 2002). Brand's Toronto is mapped as 'the world in a city' (Rosenthal 2011: 32) because numerous perspectives on the global city are offered, including first and second generation, male and female, different ethnic backgrounds, different sexual orientations, positive and negative immigrant experiences as well as insider's and outsider's views. The diversity of different worlds within Toronto "attempts to speak for every city inhabitant, and for the city as collective experience" (Smith 2009: 245). This sensual introduction to the city and the depiction of the experiences of the different city dwellers remaps the urban space of Toronto (Rosenthal 2011: 219).

The particular ensemble of topographical details reveals the role of urban space in the novel. Brand's imaginary Toronto is introduced as a natural space in which the characteristic skyscrapers play a minor and the experiences of the characters play a major role. Toronto's introduction as a winter setting serves as an example for a natural cityscape. This particular form of narrated cityscape 
(Wirth-Nesher 1996: 11f.) concentrates on the city's natural environment and the weather conditions. The winter setting functions as the prerequisite for a new beginning in which everything man-made, such as infrastructure, legislature, or racial prejudice, is covered by snow. The power of nature over man is stressed because "winters here are inevitable, sometimes unforgiving" (WHA 1). The transition to spring signifies the new beginning when "new lives can be started" (WHA 2). This scene indicates a new kind of writing about Toronto, a new "way of symbolically building the city" (Rosenthal 2011: 22). Brand's imagined space of Toronto thus rewrites the former anglicized Toronto, incorporates a number of ethnicities, and criticizes the partly controversial concept of Canadian multiculturalism.

The skepticism about Canadian cultural politics is stressed by the first chapter's harsh critique on the government's ability to displace aboriginals residing in Toronto: "All of them sit on Ojibway land, but hardly any of them know it or care because that genealogy is willfully untraceable except in the name of the city itself' (WHA 4). Ironically, the city of Toronto, originally named 'Taronto,' is built on stolen land. It is the paradox of the city that stolen aboriginal land is given to people and minorities from around the world. Therefore, the pronoun 'them' featured in the quote above can be read as referring to the first Englishspeaking settlers in Toronto and to the growing numbers of recent immigrants. Thus, the banishment of Toronto's original citizens remains an atrocity that cannot simply be reconciled by featuring typical aboriginal design patterns on the city's Humber River Pedestrian Bridge.

The built narrated cityscape (Wirth-Nesher 1996: 11f.) comprises infrastructural elements, such as monuments, landmarks, or artifacts. The description of places, space, and the movement of characters within a particular space convey a specific literary setting (Nünning 2009: 45). Thus, topographical details, such as "the city hovers above the forty-third parallel" (WHA 1) or street names, create a strong sense of space. Similar to Irving Layton's realistic description of Kensington Market in the 1970s, Dionne Brand's repetitive use of street names and mentioning of landmarks create a sense of the city, thereby reimagining Toronto's urban complexity in literary terms.

The immigrant neighborhoods Vanauley Way and Alexandra Park, for example, are described as an "urban warren of buildings and paths" (WHA 92) with "the scarred brown buildings" (WHA 260), where newly arrived immigrants are "hoping to find a job in Toronto" (WHA 92). This run-down area resembles the sad stories of its immigrant residents, such as Jackie's family, thereby stressing the relationship between identity and space. The Bernard family's dream of the city diminishes after Jackie's father served time in jail and her mother had to sell 
her body (WHA 263). Unlike her parents, Jackie is able to detach herself from this dismal place through the power of her imagination, by actively choosing the city (Rosenthal 2011: 244) as her home. Jackie rewrites the city in her own terms, "allowing herself to see the possibilities of the city" (Johansen 2008: 59f.). She suggests planting flowers to change the dismal appearance because "the sense of space might have triggered lighter emotions, less depressing thoughts, a sense of well-being" (WHA 261), thereby criticizing the city's government and officials (WHA 264) for not preventing the area's ghettoization process.

The novel's setting is mainly reduced to Toronto's inner city because to Jackie and her friends, "it is downtown that promises freedom" (Rosenthal 2011: 244). In both the novel and in the city of Toronto, the younger generation of immigrants resides in downtown, an area in which immigrants predominantly settled until the 1970s (Murdie et al 2003: 139). Whereas immigrants now first settle or resettle in the suburbs, the younger generation enjoys downtown as a cultural contact zone, interacting and being inspired by different ways of life, connecting with the diversity of Torontonians, and forming "affiliations across racial and ethnic boundaries" (Rosenthal 2011: 248).

Queen Street West, an area alive with galleries, vintage shops, trendy cafés, and restaurants, is one key example for gentrification in Toronto, because "since the 1950s this neighbourhood has been transformed from an economically depressed, largely immigrant, community in the light industrial garment district into a trendy 'new Soho'" (Bain 2010: 270). The term 'new Soho' refers to New York's artists and avant-garde sector. Toronto's similar creative space, called West Queen West Art and Design District, is filled with art galleries and ethnic food stores. Tuyen and her friends live in this area. Similarly, Kensington Market developed from a Caribbean neighborhood to a cross-cultural meeting place for artists, hippies, and intellectuals. The area between Marlee, Dufferin, and Eglinton (WHA 190) is Toronto's hub for West Indians and their products, illustrating one of many worlds within one city. Oku regularly goes to a coffee shop in Kensington Market to read African American poetry by Amiri Baraka and Jayne Cortez.

Whereas airports typically signify the predominant cultural contact zone in most global cities, the novel concentrates on public transportation, ethnic neighborhoods, and the streetscape. Whereas citizens of Los Angeles, for instance, keep their sovereignty by mainly driving in their own car, Toronto's system of public transportation encourages cultural contact. In the novel, the subway is presented as a vital cultural contact zone, as "the crossroads of the city" (WHA 3 ), in which people intermingle although they pretend to remain separate by try- 
ing to avoid "letting the city touch them" (WHA 3). However, intersection, exchange, and mixing are inevitable because "anonymity is the big lie of a city" (WHA 3) and "any minute you can crash into someone else's life" (WHA 4).

The city of Toronto is portrayed as a space of cultural multiplicity and urban complexity. The power of this cultural encounter and mixing is stressed because "it's good, it's like walking on light" (WHA 4). The novel thus becomes a zone of contact (Bakhtin 1981: 27f.) in which different languages, cultures, and ideologies intersect. Brand's Toronto is introduced as a place of diversity: "There are Italian neighborhoods and Vietnamese neighborhoods in this city; there are Chinese ones and Ukrainian ones and Pakistani ones and Korean ones and African ones. Name a region on the planet and there's someone from there, here" (WHA 4; emphasis added). This catalogue of different ethnic neighborhoods represents the many worlds coexisting in one city, capturing the diversity of Toronto's citizens from 170 countries, speaking more than 100 languages (Anisef et al 2003: 3f.). Considering the quote's arrangement of neighborhoods as separated into sectors explains how certain worlds within the city maintain their own space. Thus, figuratively speaking, minority neighborhoods particularly stand next to each other like ethnic silos. The term 'silo' is frequently used to illustrate the low interaction between and isolation of ethnic groups. This metaphor describes how Toronto's different city cultures coexist rather than intermingle. If this is true, part of the government policy's vision of a culturally diverse Canada remains unfulfilled with isolated minority neighborhoods coexisting rather than interacting. The coexisting worlds of diverse but distinct pieces resemble the model of the 'Canadian mosaic' or the similar American version of the 'salad bowl.'

In the novel, both the city of Toronto's particular traits and the common characteristics of the cultural diversity of any global city are stressed. Whereas the names of a city's neighborhoods, streets, or other major attractions highlight the sense of the 'real' city, generic expressions such as 'this city,' describe the global city in general. The novel's repetitive use of the phrase 'this city' instead of 'Toronto' emphasizes the impression of a nonspecific global city and thus turns the specific urban experience into a global one. Therefore, readers become aware of their local situation and of the global context (Brydon 2006: 6), combining 'a sense of the global' and 'a sense of a local' (Massey 1994). Earlier Canadian writers such as Morley Callaghan omitted particular street names as a strategy to include the American readership (Rosenthal 2011: 33). This novel's repetition of the phrase 'this city' implies that the story can also take place in any other global city, thereby identifying it to be at eye level with other urban literature. 
The 2002 FIFA Soccer World Cup is reenacted in the novel. During this event, Torontonians of different ethnic background encounter each other on the street. Public space is turned into private space by waving national flags and fans occupying the streets. The huge public event transforms Toronto's streetscape because "every four years, June in the city is crazy. Cars speed about flying emblems of various nationalities" (WHA 203). People of different age, class, and ethnic background gather in the streets to celebrate the global event of fairness. Instead of stressing the difference, creating rivalry, or forcing the competition between countries, a collective is formed based on a global interest in sports and the similar goals of entertainment, winning, and fairness.

For the young generation, streets translate into a liminal space because their homes are cluttered with their family and their cultural traditions. To create a new, cosmopolitan identity, the young Torontonians need to leave the familiarity of home to find their new sense of belonging. Thus, the streets and their intersections and the various hideaways, such as Tuyen and Carla's apartments, are important places for self-management and the formation of the friends' crosscultural group identity.

When Korean, Brazilian, and fans of further nations celebrate together, the streets resemble the meeting point for this post-national, interethnic, or transcultural encounter. Tuyen enjoys the diversity of Toronto on the streets when the crowd cheered and the cars were lined up with waving flags, she "felt elated, infected by the mood on the street" (WHA 204f.). Since the Vietnamese team had not made it, Tuyen decided to be Korean for that day, exemplifying how "lives in the city are doubled, tripled, conjugated" (WHA 5). The twenty-something friends celebrate Korea's unexpected victory, disregarding ethnic demarcations by "watching and waving and singing, 'Oh, Pil-seung Korea! Oh, Pil-seung Korea!"” (WHA 214; emphasis original). ${ }^{36}$ This celebration signifies "a crosscultural moment that empowers anyone who identifies with its minority ethos" (Buma 2009: 16). Thus, members of one minority show "solidarity with others who are equally dependent on the sense of tolerance within the wider society" (Shaw 2006: 29). This collective feeling of 'shared otherness' enables and tolerates diversity across ethnic, language, or social borders.

The Soccer World Cup, however, also demonstrates the breaks of Toronto's society because the sports event makes the citizens feel culturally close and apart

36 The novel offers no translation. This expression is Korean and translates into "Oh, Korea must win! Oh, Korea must win!" For more information on the strategy of codeswitching and the intentional lack of translation, see Section 6.2.1 on 'Polyphonic Murmuring.' 
at the same time. On the one hand, a feeling of unity and belonging is created. On the other hand, the tensions between ethnicities are revealed when "resurgent identities are lifted and dashed" (WHA 203). It becomes clear that the immigrants' integration into Canadian society is an ongoing, exhausting process that will never be completed by some, thereby "suggesting the extent to which old nationalisms remain in effect despite the post-national outlook of Brand's characters" (Buma 2009: 17). The novel illustrates that, in a multicultural society, an immigrant's original identity is not erased as in the assimilationist model of the 'melting pot.'

The soccer fans' national pride thus reveals the truth about Canadian multiculturalism and integration when "small neighborhoods that seemed at least slightly reconciled break into sovereign bodies" (WHA 203). The novel's repeated allusion to Toronto's clustering of visible minority neighborhoods hints at the society's multicultural design in which the 'sovereign' neighborhoods resemble 'ethnic enclaves' or 'ethnic silos.' However, the statement that the World Cup "reimposes borders on the city's 'borderless' space, exposing the idea of borderlessness as a fictional construct" (Buma 2009: 17) represents merely one side of the coin. The crucial difference between the different immigrant generations also needs to be taken into consideration. ${ }^{37}$ Whereas the imposition of borders proves to be true for the parents "who are isolated along clearly defined ethnic lines" (Johansen 2008: 58), most of the second-generation characters have the potential to cross ethnic, national, and spatial borders. The second-generation's development of so-called 'counter-cartographies' represent a key prerequisite for integration into Toronto's society.

\subsubsection{Counter-Cartographies}

The perception, presentation, and the representation of urban space bring to light the relationship between the city and its dwellers. The novel's culturally diverse urbanites identify with different parts of the city. Whereas Toronto means home and a place of possibilities to the four friends Tuyen, Carla, Oku, and Jackie, the city's geography symbolizes a space of prejudice to Jamal or Quy. The different types of place, such as public and private or static and dynamic, are of importance when analyzing forms of integration or suppression in urban space. Graffiti art, Carla's bike ride, or ethnic, gendered, and generational refuges function as means of 'counter-cartography' (Bentley 2005), rewriting the cityscape

37 For more information on the generational conflict of immigrant families caused by the different levels of integration, see Section 6.2.5 on 'Time-Space Discrepancy.' 
and thereby presenting other and sometimes unconventional ideas of urban place and space (Rosenthal 2011: 229).

In the novel, with the help of tags, pictures, and writings, the ethnically diverse group of graffiti sprayers rewrites the city of Toronto creatively, thereby changing the former anglicized city's physical appearance and the significance of urban space. The graffiti crew leaves its traces across the city, literally rewriting the city in their own terms with "Kumaran's grinning pig, Abel's 'narc' initial, then Keeran's desert and Jericho's lightning bolt. (...) They had practically filled all the walls of the city with these four signs" (WHA 31f.). Graffiti thus radically transforms Toronto's public space (Rosenthal 2011:229) with the help of an illegal underground activity by inscribing the cultural diversity of its young residents.

Graffiti thus serves as one example to describe Toronto as a palimpsest-like dynamic space that is constantly modified. The Greek term 'palimpsest' literally translates into a seemingly unending process of being "again rubbed away" (Cuddon 1999: 631). As pictured by the following quote, the city of Toronto is in constant transition because

One moment a corner is a certain corner, gorgeous with your desires, then it disappears under the constant construction of this and that. A bank flounders into a pizza shop, then into an abandoned building with boarding and graffiti, then after weeks of you passing by it, not noticing the infinitesimal changes, it springs to life as an exclusive condo. (WHA 183)

The process described is urban gentrification. This term is commonly used in urban geography to describe the dynamic process of urban development and change that takes place in cities of different sizes around the world. As the quote illustrates, urban places frequently undergo changes in appearance, meaning, and relevance. New urban study approaches concentrate on the powerful influence of gentrification in association with the mushrooming of condominiums. Luxury condominiums are built in the last phase of the four-stage gentrification process (Bain 2010: 269), attracting upper-class citizens. When standards and prices are raised, artists and further residents are displaced to different neighborhoods with cheaper housing. Then, the cyclical process starts over. Culture and arts like graffiti play an important role with regard to the constant change of Toronto's inner-city neighborhoods, being a vital part of the gentrification process and transforming urban space.

By illegally spray-painting a new layer on top of walls and other surfaces, places are provided with new meaning. Graffiti functions as urban territorial 
markers (Ley et al 1974) because the sprayer's tag claims a certain possession of space, crossing borders and thereby marking territory of influence. The sprayers' ability to perform wherever they want is a unique proposition of power. It is their way of claiming a space in the city as their own, leaving text and pictures messages, and often criticizing social conventions or societal constructions. Graffiti thus functions as a form of integration by force. The artists are making themselves belong, and graffiti becomes their means of self-determination and inclusion.

The young Torontonians like Carla and Tuyen acknowledge this provocative and illegal form of urban art, identifying themselves with this kind of resistance. Instead of showing the breaks, rivalry, and violence of Toronto's youth, the graffiti crew illustrates how ethnically heterogeneous group identity formation works (Rosenthal 2011: 230). They translate the desires and longings of the secondgeneration immigrants through their art. The walls close to Tuyen's and Carla's apartments, for example, are miraculously painted in exactly the way Carla had always imagined her city of Toronto: "On one side there was a flowering jungle, lianas wrapped around the $\mathrm{CN}$ Tower, elephants drinking by the lake, pelicans perched on the fire escapes. On the other side there was a seaside, a woman in a bathing suit and hat shading her eyes, looking out to sea" (WHA 301). Carla thus connects with the city in an intimate, spatial experience when she identifies with the scenes sprayed and finally manages to cope with her mother's suicide.

The creative work of the graffiti crew is a type of experimental topography (Ley et al 1974: 505; Rosenthal 2011: 229). It is a strategy to picture the transformation of urban space and its residents. The change from a mainly British Toronto to the nearly 50 percent foreign-born population of today has a tremendous effect on the city's physical appearance and its streetscape (Troper 2000: 4). In the novel, the graffiti crew functions as a facilitator to drive this change and make it visible because "they saw their work - writing tags and signatures - as painting radical images against the dying poetics of the anglicized city. The graffiti crew had filled in the details of the city's outlines" (WHA 134). This phenomenon marks a cultural turn in the city. The shift from anglicized poetics to a culturally heterogeneous creative art community through the conquering of public space serves as a visualization of the second-generation immigrant's voice, adapting Toronto's urban space to its new, culturally diverse community.

Carla's bike ride represents another form of urban imaginary, revealing the character's innermost feelings and what she longs for. Riding the bike translates into Carla's strategy "of making sense of the city and her position in it" (Fellner 2010: 233). Urban space functions as her 'sparring partner' (Rosenthal 2011: 228). Carla's impressions of the city can be compared to Walter Benjamin's 
concept of the plural dialectical image (Fellner 2010: 232). In this approach, the intrinsic relationship between language and image is stressed. Benjamin's dialectical image "is a dimension of reality made recognizable rather than a representation in the mind, whether past or present" (Friedlander 2008: 4). The different images of the city "come together in dialectical Benjaminian fashion, creating a transcultural space that is characterized by fragmentation, dislocation and the various contradictions of urban experience" (Fellner 2010: 232).

The particular depiction of urban space on Carla's route reveals her attitude towards specific places, the neighborhood's citizens, and socio-political norms. The young woman identifies with the places that have been reassigned with meaning by her generation, such as "the triangulating girders now possessed by the graffiti crew" (WHA 32). Carla feels at home in the dynamic, creative, and trendy space of Toronto downtown in which "the city was vivid. Each billboard screeching happiness and excitement. The cars, the crowds intense" (WHA 28). When riding the bike, Carla feels comfortable as a part of the city (Rosenthal 2011: 225), establishing an intimate and empowering relationship with the city because "she loved the feeling of weight and balance it gave her" (WHA 32). Her bike becomes a powerful tool in identifying with and reassigning sense and meaning to urban space. The bike courier even becomes one with the bike, fusing with the handlebars (WHA 29).

Carla's aversion to particular places away from the lively downtown areas is emphasized by making use of motion verbs. She is racing through the rundown suburb Etobicoke, which is described as "the badlands of some alienated city" (WHA 28) with "low seemingly unfinished buildings, the stretches of uncreative streets, the arid after-winter look of everything, the down-in-the-heel, stranded feel of the people" (WHA 28). Furiously riding the bicycle at the speed of light (WHA 26-30) shifts the city's geographies, thus involving a perceived 'timespace compression' (Harvey 1989). With the act of 'racing' by High Park's "old British-style houses" (WHA 29) and the running of red lights, Carla is revolting against the artificial constructions of Toronto's elite. The neat alignment of manicured yards makes her sick because those spaces are still dominated by the city's British past. On her bike, however, Carla feels independent because she determines the route and decides the speed. Riding the bike thus becomes a process of border-crossing because Carla "saw the city as a set of obstacles to be crossed and circled, avoided and let pass" (WHA 32), rewriting the earlier meaning that "the white bourgeois elite of the city has written for itself" (Johansen 2008: 57).

Places of refuge, whether in terms of ethnicity, gender, or generation, serve as private or public counter-cartographies, aiming at comfort, freedom, or es- 
cape. The identification with a certain place can thus function "as a source of belonging, identity and security" (Massey 1994: 170). Tuyen's and Carla's apartments on College Street function as generational escapes where secondgeneration immigrants are independent from their first-generation immigrant parents. Their places serve as creative laboratories where different counterculture realities can be created. Their apartments are home to several subcultures and "became places of refuge, not just for their immediate circle but for all the people they picked up along the way to their twenties. Like the Graffiti Boys across the alleyway, Tuyen's friends from the gay ghetto, a few hip-hop poets" (WHA 23; italics added). The creative chaos of the place is conceived as a form of liberation (Rosenthal 2011: 224), testing unconventional life styles. In the apartments, the young friends have "free reign of the place" (WHA 23), experimenting with alternative forms of arts and drugs such as Ecstasy and magic mushrooms. The refuge therefore represents independence from paternal control, cultural constraints, and social pressures.

The bar Pope Joan on Parliament Street nearby the city's LGBT ${ }^{38}$ community serves as a gendered refuge in the novel and is described as "the last eastern outpost of gay life in downtown Toronto" (WHA 268). Toronto's LGBT community is chiefly situated in Church and Wellesley. Canada's largest gay enclave provides an unprejudiced space for sexual orientation, celebration, and acceptance (Lynch et al 2010: 331f.). In a gay village, sexual orientation, which is usually confined to private space, is transferred to the public. Thus, gay villages represent urban places of liberal identity politics.

The Pope Joan is a feminine space where suppressed personalities have the opportunity to become visible and, in particular, overcome gender, sexual, and sexuality constructions imposed by society because "all that couldn't be lived outside was lived in here" (WHA 268f.). The term 'feminine space' is commonly used in human geography, gender theory, and sociology of space. Earlier conceptions view feminine space as limited to the private sphere. The same concepts define the public sphere as a predominantly male space because in Western societies, the majority of places are traditionally dominated by masculine views (Massey 1994: 170). In the novel, Tuyen enjoys the Pope Joan because the masculine dominance of society is neglected and turned into a predominantly feminine space in which women are the ones in power. In this gendered refuge, the emancipated bisexual character trespasses these constructions of masculine dom-

38 The English-speaking gay community itself started using the term 'LGBT' to include lesbian, gay, bisexual, and transgender. 
inance, thereby disregarding and abandoning social norms and political categorizations.

The establishment of ethnic refuges constitutes "a meaningful strategy towards a more inclusive urban citizenship" (Hoernig et al 2010: 158) because a sense of belonging is created when public space is transformed into an ethnicity's private space. Minority neighborhoods often function as ethnic refuges for newly arriving citizens, operating as major hubs in a global network of immigration and transmigration. Ethnic clusters, however, occasionally develop into isolated ethnic silos in which intercultural intermingling is rarely facilitated.

In the novel, the Paramount is described as a counter public space for Toronto's Black diaspora (Johansen 2008: 53). The club serves as an ethnic space for "black people and a few, very few, hip whites - whites who were connected" (WHA 95). Jackie's parents enjoyed the club, which served far more purposes than dancing. It was an ethnic contact zone where "people went to feel in their own skin, in their own life. Because when a city gets finished with you in the daytime, you don't know if you're coming or going" (WHA 95). In this urban retreat, people was valued for their dancing, clothing, and for being a good lover instead of their visible otherness.

Moreover, in the parallel world of Paramount club life, individuality within ethnic groups was recognized that was otherwise disregarded by Canadian society and "elided by the city" (Johansen 2008: 53). In the novel, this "heterogeneity of blackness" (Johansen 2008: 53) is illustrated by the intercultural fights between men, women, and couples of different nationalities. When the club closed down, both their social acknowledgement within their countercultural space and their intraethnic individuality were lost because they once again were considered a part of a society-determined, visibly homogenous minority. By closing down the club, the ethnic network was destroyed and "all the athletes and the intellectuals, the jazz aficionados, the new-comers from down home, the just-comers from the Caribbean, all of them had to fly solo, go places where nobody knew them" (WHA 179). As a result, the integration of black Canadians into Toronto's urban space became more difficult.

In the novel, a general difference of social integration within first-generation immigrants can be identified. Whereas the black Canadian diaspora is able to create a temporary place of refuge, immigrants of other ethnic background often "occupy spaces that are defined by prescribed visions of ethnicity and gender" (Johansen 2008: 53). Tuyen's Vietnamese parents, for example, feel obliged to adapt the interior design of their house to a mainstream look in order to be accepted as Canadians. Considering that their furniture is covered with plastic, however, signifies their simultaneous obsession with preservation and nostalgia. 
This contradiction is exemplary for the first-generation's oscillation between unsuccessfully striving for a Canadian identity and their reminiscence of their cultural background and identity before immigrating to Toronto. In contrast to their children, first-generation immigrant parents are not able to create a permanent place of refuge in the city. How this difference of political and social integration into Canadian society results in a generational gap is explored in the following section.

\subsubsection{Time-Space Discrepancy}

David Harvey's notion of 'time-space compression' (1986) explains the perceived convergence of time and space in a globalizing age. In What We All Long For (2005), a generational gap is caused by a 'time-space discrepancy' between the different immigrant generations. Whereas first-generation immigrants are commonly focused on a lost past, second-generation immigrants have stronger ties to their birth place. Due to language skills, prejudice, and invisibility, the two generations differ in their level of integration into Canadian society. Once the second generation comes of age, the gap widens in a double sense by them disconnecting from their families to form an adolescent self and finding their own, mixed cultural identity in Toronto.

In the novel, first-generation immigrants often lack social standing, opportunity, and equality. The perspective of the first generation is incorporated to "show the multiple ways in which bureaucratic authorities and stereotypical assumptions about immigrants' skills make them invisible or reduce them to broad categories" (Johansen 2008: 52). This categorization process of an immigrant's profession is exemplified in a cataloguing technique at the beginning of the novel: "In this city there are Bulgarian mechanics, there are Eritrean accountants, Columbian café owners, Latvian book publishers, Welsh roofers, Afghani dancers, Iranian mathematicians, Tamil cooks in Thai restaurants" (WHA 5).

In What We All Long For (2005), the first-generation parents are prejudiced against due to their foreign appearance and possible language barriers. Their previous way of life, social standing, and any achievements are commonly neglected and stereotypes are cast on specific ethnicities, mostly regarding professions. Upon arrival in Canada, for example, Tuyen's Vietnamese parents cannot continue working as a doctor and an engineer (WHA 65). Her mother "Cam became a manicurist in a beauty salon near Chinatown while Tuan unloaded fruit and other produce from trucks to the backs of stores on Spadina" (WHA 65). Thus, upon arriving, they were being defined by the city. To be successful in Toronto, they had "to see themselves the way the city saw them: Vietnamese food" 
(WHA 66f.). When Tuan and Cam realize that their previous professions are erased, they give in to the pressure of ethnic categorizations in Canada by opening a restaurant.

In the novel, the Canadian model of multiculturalism is criticized as arbitrary, showing how this concept of cultural diversity is influenced by stereotypes and clichés. The demonstration of how ethnic categorizations with regard to profession and food influence an immigrant's life serves as a strategy to question these labels. Comical remarks emphasize the ridicules of a British-dominated society that longs for exotica because, ironically, "neither Cam nor Tuan cooked very well, but how would their customers know? Eager Anglos ready to taste the fare of their multicultural city wouldn't know the differences" (WHA 66f.). This critique can be compared to the comment "multiculturalism is bullshit" (TRO 128) by the character Emi in Karen Tei Yamashita's Tropic of Orange (1997). The Japanese American disapproves of an Asian woman wearing chop sticks in her hair to artificially convey the attachment to a certain ethnicity.

In the novel, first-generation immigrants can be described as time-focused instead of space-focused, resulting in a time-space discrepancy between the two immigrant generations. The detachment of the first generation from their former life often proves to be a difficult task. Oku, for example, believes that his Caribbean parents Fitz and Clare "somehow lived in the near past and were unable or unwilling to step into the present" (WHA 190). The same nostalgia makes Tuyen's parents suffer. Her father is sick from drawing buildings like a civil engineer "as if he was still what he was" (WHA 114). Her mother is sick of pacing, her insomnia, and writing letters to find her lost son. The repetition of these tasks underlines their despair. They are torn between the two worlds and identities. Letting go of the 'former' world is not possible, however, because they are constantly haunted by a tragic reminder of the past, impersonated by their lost son Quy. ${ }^{39}$

In contrast to the second generation, the parents can rarely influence the city's space. The first generation is largely "being defined by the city" (WHA 66) instead of being able to create counter-cartographies. Thus, for the first generation, Toronto remains the anglicized city, "a site of marginalization where the places open to them are predicated upon invisibility and separation" (Johansen 2008: 50). The term marginalization describes the process of how some ethnicities are on the edge of society in terms of equal rights and representation. The effect of 'uprootedness' results in a sense of displacement. In this condition, mi-

39 For more information on the significance of Quy as a symbol for immigration and loss, see Section 6.2.2 on 'Converging Threads.' 
grants oscillate between two worlds: not being integrated into society and the nostalgia of a lost past (Chambers 1994: 27).

Trauma and the effect of deterritorialization cause many immigrants to move to ethnic neighborhoods. The Bernards, Jackie's black parents from Halifax, Nova Scotia, for example, choose to remain within their own cultural sphere, thereby supporting the creation of ethnic silos and enclaves. Nevertheless, cultural clusters also offer a supportive network, aiding newly arriving immigrants when settling down.

The first generation is convinced that social standing offers the opportunity to eradicate ethnic differences and prejudices, facilitating political integration. In the novel, many newly-rich immigrants therefore "flee to rangy lookalike desolate suburbs like Richmond Hill where the houses give them a sense of space and distance from that troubled image of themselves" (WHA 55). They aim at setting themselves apart from poorer immigrant families with the realization of the American dream in a "from rags to riches" manner. Their objective is acceptance by their neighbors as fellow Canadians. The suburb Richmond Hill serves as their artificial refuge from being an immigrant outsider that "will somehow eradicate that person once and for all" (WHA 55). Cam and Tuan's Canadian-style decorated house is an important object of social prestige. It functions as mimicry or camouflage, emphasizing the family's strong urge to fit in. Tuyen nevertheless recognizes that her parents' house is in fact artificial, antiseptic, rootless, contrived, and desolate (WHA 55).

Like many immigrants, Tuyen's parents simultaneously want to blend in and shake off the stigma of "that troubled image of themselves" (WHA 55). As part of a visible minority, they suffer from not being recognized in terms of acknowledgement and integration. They come to hate "that self that keeps drawing attention, the one that can't fit in because of colour or language, or both" (WHA 55). As a result, the immigrant self turns into a socially-determined unwanted 'other' that is described as "helpless, weak, unsuitable, and always in some kind of trouble" (WHA 55). This escapism from their 'immigrant other' will, however, never be accomplished completely because, as the novel explains, "they end up living with all the other immigrants running away from themselves" (WHA 54f.). The first-generation immigrant thus remains in an 'in-between' situation, or, as Bhabha puts it, "less than one and double" (1994: 166). Thus, the immigrant's dream of integrating by being successful in monetary terms remains an illusion, as only the second generation can seize the opportunity to become an accepted Torontonian in the novel. Consequently, a strong intergenerational conflict arises.

The second-generation immigrant children are portrayed as steadily disconnecting from their parents, their parents' stories, nostalgia, and their culture be- 
cause the children identify themselves with the city and its space. This results in a clash of time and space between the two immigrant generations. The parents raise their children in an environment in which the second-generation is torn between the 'old' and the 'new' culture. As a consequence, their children are torn between two ways of life, "as if they inhabited two countries - their parents' and their own" (WHA 20). Jackie's parents, for example, "pictured Nova Scotia, Halifax, as a paradise on earth and Toronto as a wretched hellhole" (WHA 93). To the younger generation, however, Toronto functions as a cultural contact zone that facilitates a bonding process within the same immigrant generation across ethnic boundaries.

For Tuyen, Carla, Oku, and Jackie, the formation of "a culturally hybrid, rhizomatic coalition" (Quigley 2005: 65) functions as a strategy to counteract sole ethnic or national identity constructions. In this family-like bonding process, societal constructions such as cultural background, class, gender, and sexual orientation play a minor role. On the contrary, "their common oddness, held all of them together" (WHA 19). Rejecting their ethnic background, and thus their families, results in the formation of a community based on empathy (Rosenthal 2011: 258). Thus, the four friends agreed "on distancing themselves as far as possible from the unreasonableness, the ignorance, the secrets, and the madness of their parents" (WHA 19).

Culture, language, and concepts of individuality and community constitute the major disparities in the generational conflict. Troubled by their families' stories and refused to hear about their parents' past times, the four friends are bonding when growing up (Fellner 2010: 233). Their coming-of-age process is exemplified by a long, poetic journey when "each left home in the morning (...), untangling themselves from the seaweed of other shores wrapped around their parents" (WHA 20). The cultural glue in the form of the 'seaweed of other shores' resembles the attachment to their parents' cultural background. The procedure of 'untangling' signifies the difficulty to be independent.

The immigrant children born in Toronto are constantly "translating the city's culture to their parents" (WHA 120), mediating between different languages, cultures, generations as well as time and place. This translation of the city and Canadian life is offered to the parents and for the reader (Smith 2009: 243). The younger immigrant generation thus functions as a "translator of the city" (Smith 2009: 243), acting as their parents' "interpreters, their annotators and paraphrasts, across the confusion of their new life" (WHA 67). Tuyen and Binh were asked "to disentangle puzzlement; any idiom or gesture or word they were counted on to translate" (WHA 67) to their parents and their older sisters born in 
Vietnam. Thus, the parent-child relationship is reversed, resulting in lack of respect (WHA 125), revealing that language and translation are powerful tools.

Whereas the children have little interest in their parents' mother tongue, a language they "did not live in" (WHA 131), the first generation's lack of English skills intensifies the generational conflict. Carla, for example, cannot identify with her father's Jamaican language, food, and values, considering the foreign customs and traditions as "embarrassing oddities that she would try to distance herself from in public" (WHA 131). Similarly, Tuyen rejects her Vietnamese identity, revolting against ethnic constraints by speaking English to her parents' Vietnamese customers, drinking milk, and calling herself 'Tracy' (WHA 20). This rejection is a counter-strategy to the society's othering process of ethnicities.

Tuyen's two sisters Lam and Ai belong to the one-and-a-half generation immigrants who grew up in the former home country. In the novel, Lam and Ai are compared to "shadows" (WHA 59) with no individual identity, no selfconsciousness, and no self-determination. Similar to their parents, the one-and-ahalf generation is torn between the one and the other, their home country and their original culture as well as between the different languages, places, and customs. Tuyen's two sisters are a constant reminder of the "past, their other life; the life that was cut in half one night on a boat to Hong Kong. Lam and Ai had become shadows; two little girls forgotten in the wrecked love of their parents" (WHA 59). The two sisters blame themselves as much as their parents do for losing Quy. This difference in experience separates the two sisters form the other siblings as well as the second-generation from the one-and-a-half generation.

In What We All Long For (2005), the second-generation immigrant perspective offers a more positive and culturally diverse view of Toronto's society because, to them, "finding community is a specifically urban project" (Dobson 2006: 88). The following section on concepts of longing and belonging illustrates how the different characters in the novel identify with the city and thus can create or cannot create a sense of belonging.

\subsubsection{Longing and Belonging}

The novel's title What We All Long For functions as a paratextual device for the reader, signifying the importance of longing and belonging in the global city of Toronto. The title's inclusive 'we' refers to the longing of every Toronto citizen and of the globe (Dobson 2009: 182). This inclusive, multiperspectival portrayal of life in the global city explores the various forms of integration of and within the different immigrant generations. Whereas the four second-generation immi- 
grant friends form a culturally diverse urban identity, to some immigrants 'belonging' to Canadian society remains an unfinished task. Due to their 'hypervisible' otherness in terms of language and appearance, prejudice and racism are much more apparent towards first-generation immigrants and black Canadians of both generations. Moreover, female immigrants appear to integrate more easily. Finally, as Quy's death violently demonstrates, illegal immigrants are least likely to integrate into Canadian society.

Dionne Brand's non-fictional memoir A Map to the Door of No Return: Notes to Belonging (2001) can be considered a pre-text to her novel What We All Long For (2005), as the resemblance of the novel's title and the memoir's subtitle indicate. In the memoir, Brand questions the concept of 'national identity' as "a dance of artificiality" that "obscures its own multiplicity by insisting on itself as unchanging" (2001: 72). Her 'notes on belonging' question static sociopolitical constructions in a rapidly changing, globalizing world. In Brand's 2005 novel What We All Long For, the second-generation immigrant characters similarly reject socio-cultural categorizations and opt for an 'anti-national' (Dobson 2006: 88), cosmopolitan identity (Johansen 2008: 55).

In What We All Long For (2005), the generational conflict becomes particularly apparent in terms of identification or no identification with a nation-state. Both generations are not part of a nation-state identity structure. Whereas the parents "try to belong to a nation-state that refuses to recognize them because of their ancestry" (Dobson 2006: 88), their children long for an identity that goes beyond the idea of the nation (Brydon 2006: 3) because "the daily reality of being non-white within Canada gives them strong anti-national political consciousness" (Dobson 2006: 88). Instead of focusing on a national identity that fails to recognize them, the second-generation immigrant friends focus on urban life and the counter-geographies they create in Toronto.

The younger generation experiences "a universalizing cosmopolitanism" (Dobson 2009: 186) in which identification with the city and its locales is crucial. In this "urban, post-national community" (Buma 2009: 23), the four friends identify with the urban space of the global city. To the four friends, the influence of the nation is not as prominent any more in a globalizing world. Instead, the awareness of living in a global city is stressed by being conscious of their urban surroundings and the whole world (Dobson 2006: 89) because their urban life style "is connected to global modes of living before it is connected to discourses of the nation" (Dobson 2009: 191).

The younger generation is "part of Sassen's battle to decolonize the city. They fight their colonization by both the white hegemony in the city that others, them and their parents' desire for them to remain tied to a homeland to which 
they have no physical connection" (Johansen 2008: 60). Although the secondgeneration friends are often "shut out from full participation in the official world, they create their own spaces within the interstices of the city" (Brydon 2006: 7), forming their identity as Torontonians. Moreover, in a global city, struggles of identity take place on the streets and in the neighborhoods (Sassen 1996: 197). Areas such as Bloor West signify a constant intermingling with other people, cultures, and ideologies. The four second-generation friends "believed in it, this living. Its raw openness. They saw the street outside, its chaos, as their only hope. They felt the city's violence and its ardour in one emotion" (WHA 212f.). As a result, a 'counter Toronto' (Smith 2009) is imagined by crossing the borders of socially-constructed categorizations.

In Toronto's urban space, the second-generation immigrants manage to erase borders and make distinctions irrelevant by ignoring the British-dominated space and by creating their own escapes and refuges. Tuyen, Carla, Oku, and Jackie were constantly "trying to step across the borders of who they were. But they were not merely trying. They were, in fact, borderless" (WHA 212f.). Their borderlessness refers to several aspects of freedom. In comparison to many other characters in the novel, their life in the city is a relatively independent one. They form coalitions across ethnic and gender boundaries and "actively move into the city's public places" (Johansen 2008: 49). To them, Toronto becomes a space of agency, a place with which all four can identify because "as disturbing as all they were living was, they felt alive. More alive, they thought, than most people around them" (WHA 212f.).

This identification with urban space and Toronto's streetscape results in "new, territorialized cosmopolitan identities" (Johansen 2008: 50) that have a strong relationship with the city. This close connection is emphasized by explaining the children's relationship with their birth place as if "a new blood had entered their veins; as if their umbilical cords were also attached to this mothering city" (WHA 67). This gendered personification (Paxson 1998: 154) of the city of Toronto makes the inanimate object appear human by using female traits. The unborn child's attachment to the umbilical cord in the mother's womb is possibly the strongest metaphor to express an intimate connection of two entities. The maternal relationship with the city is described as being so close that it even affects their identity and thus, to the four second-generation friends, the space of the global city provides the opportunity to search for their new, own, and mixed cultural identity. They form a cosmopolitan citizenship and identities with multiple positionalities that are nevertheless rooted in Toronto (Johansen 2008: 50). 
Tuyen and her friends experience the city as a chaotic and creative place in which they generate "a viable sense of self" (Dobson 2009: 180). To the four friends, the city becomes "a space for building culture from below" (Dobson 2009: 180), symbolizing a grass roots revolution that reshapes the formerly anglicized city. They disregard the hyphen (Smith 2009: 243), viewing themselves as Torontonians and part of the diverse life of the global city. The secondgeneration's global vision of a 'diverCity,' however, is often interrupted by the multicultural design of Toronto's ethnic integration.

In What We All Long For (2005), several drawbacks to the Canadian concept of 'multiculturalism' are presented. The novel clarifies that prejudices, stereotypes, and racism still prevail in Toronto because, "at multiple points, we see characters being physically imprisoned or socio-economically restricted" (Dobson 2006: 90). Thus, to some Torontonians, integration into Canadian society remains an urban legend. In addition to first-generation immigrants, visible minorities and illegal immigrants constitute further exceptions to the rule of integration. The various outsiders' perspectives on longing and belonging are presented to provide an integrated view of multiculturalism and the integration of minorities.

With regard to the Canadian concept of 'multiculturalism,' the metaphor of the mosaic was originally introduced to counteract notions of wholesale assimilation. However, due to the coexistence of the diverse but distinct cultures within the mosaic, categorizations and clichés are naturally supported. Due to the growing number of immigrants from Asian countries, who began arriving in the 1960s (Hoernig et al 2010: 154), the social integration of visible minorities became a considerable challenge (Anisef et al 2003: 4). In What We All Long For (2005), Canada is partly portrayed as a "racist country" (Dobson 2006: 93) in which some immigrants fail to integrate as a result of ethnic stereotypes. As a consequence, their sense of belonging is lost. The homeless person Rasta, for example, claims that the white man makes the African Canadians mad and destroys him. He warns Oku: "follow the white man ways and you doomed" (WHA 173).

The novel illustrates "the experience of blacks in Canada as oscillating between invisibility and hyper-visibility" (Rosenthal 2011: 235). Jamal functions as a prime example of racial stereotypes and pressures. Oku and Jamal are both constantly faced by clichés and racial stigmatization due to their status as a visible minority. They are both stopped by the police because of their 'African look' (WHA 35). The strategy of incorporating these stories in the novel can be read as a critique of the superficiality of the Canadian government, its agencies, and officials. When Carla's brother feels disconnected (WHA 236) from his family but also from society as a whole, he is getting involved with the negative space of 
the city (WHA 32). Jamal's decision to opt for the black part of his cultural heritage is doomed to result in negative prospects. Nevertheless, he chooses to belong to a black gang, although Carla warns him that because he is black, he "can't be in the wrong place at the wrong time" (WHA 35).

A difference in social struggles between African Canadian men and women can be identified. Female characters of the younger immigrant generation manage to adapt to urban space and life in Toronto better than their male counterparts (Rosenthal 2011: 249). Oku explains to Jackie that being in jail is a "rite of passage in this culture, girl. Rite of passage for a young black man" (WHA 46). Oku's female traits of wiring poetry and cooking make him an exception to the rule (Rosenthal 2011: 249). Whereas Jamal is trapped within societal constructions of ethnic classifications and the accompanying stereotypes, Oku questions the society's structures and conventions when dropping out of school and protesting against establishments. The police, however, are different. Although Oku had also been stopped by the police stigmatically due to his African Canadian appearance, he soon learned that revolting is useless. Instead, "he simply lifted his arms in a crucifix, gave up his will and surrendered to the stigmata" (WHA 165). This explains why Oku "cultivated the persona of the cool poet - so that he wouldn't have to get involved in the ordinary and brutal shit waiting for men like him in the city. They were in prison, although the bars were invisible" (WHA 166). The reference to invisible bars' stand for the societal and ethnic constraints that keep young African Canadians literally 'imprisoned' in their stereotypical predetermined destiny. The ones who did not surrender and insist on their rights had to fight even harder and "ended up in the system fighting to get out. They ended up hating everyone around them. Homicidal" (WHA 165). This statement criticizes Toronto's multicultural society. Moreover, it foreshadows Jamal becoming a murderer by the end of novel. This quote also criticizes the entanglements in the invisible and underlying pressures of racism, revealing that Canadian multiculturalism remains a myth for many minorities.

Some critics claim that if there is a unifying sense of being Canadian in the novel at all, it is only expressed in the conformity that is demanded by officials, such as those at school or the police (Buma 2009). These institutions, however, are portrayed as prejudiced or even racist rather than contributing to a feeling of unity. In the novel, the literary device of situational irony is applied to show the artificiality of ethnic category-thinking when the police introduce "salt-andpepper cops" (WHA 98) "to smooth the way. One of 'their own' to make them feel comfortable and make them talk" (WHA 98). The wider acceptance of cops across ethnic boundaries failed, however, when the "pepper cop" from the West Indians was considered "a race traitor" (WHA 98). This example illustrates that 
the officials' concept of 'multiculturalism' is limited to employing simplistic categories, such as black and white only, thereby disregarding variances within the heterogeneous Canadian minorities.

Furthermore, the novel makes clear that prejudices are not a one-directional process but all-encompassing. Ethnic stereotypes and racism are reversed to transcend the conventional expectations of cultural prejudices. Oku's jealously of Jackie's German boyfriend Reiner, for example, illustrates that racism is also directed towards whiteness and the artificial sense of belonging through the imitation of slang. Reiner, the only white character of significance in the novel, represents the anglicized Toronto. Oku envies him for being "white" and thus "safe" and in control of the city. Reiner "could not possibly see the city as a prison" because he is taking possession of the city's space and Jackie (WHA 176). In his rage, Oku is tempted to judge his opponent in racist terms, calling Reiner a Nazi. He is disgusted by Reiner's efforts to sound like a "brother" when he is uttering "Hey, man, what's happening?" (WHA 177). Oku does not accept Reiner's attempts at befriending him by speaking in a kind of second language, imitating Oku's own tongue. Interestingly, although Oku is part of an interethnic group of friends, he does not value the white immigrant's efforts to belong to another ethnic group.

The projection of British-dominated Toronto's racism towards visible minorities on other ethnic groups is also exemplified by Carla's case. Although Carla and Jamal have the same parents, she is rejected by the African community, and by her father's and stepmother's family in particular, due to her light complexion. Although whites usually were not aware of her African background, "most black people recognized her anyway. There were more attuned to the gradations of race than whites" (WHA 106). Carla's mother Angie faced similar criticism for crossing a racial border. Her Italian family refused to accept her liaison with a Caribbean black, considering her a dead person (WHA 106). Both examples of this category-thinking process constitute the main arguments against 'multiculturalism' because it is a model of diverse but distinct cultures within one society that rarely interact.

The novel's most powerful strategy for showing how racism sometimes forces minorities to think in racist terms themselves is illustrated by Jamal killing Quy. Ironically, whereas their sisters, Tuyen and Carla, love each other, Carla's brother kills Tuyen's brother. Moreover, Jamal's allegedly killing Quy in the end shows the dangers of not integrating. Jamal is stigmatized due to his hypervisible otherness and his choice to become a gang member by catering to specific stereotypes. The sad ending deconstructs Toronto's myth of being the prime example of Canadian multiculturalism because Jamal, a Canadian of Caribbean Italian 
background who is unable to adapt to society due to his hypervisible otherness and the regularly experienced racism, kills an illegal Asian immigrant. This violent encounter of Jamal and Quy can be read as symbolizing a cultural clash on city level, since Italians, Asians, and the Caribbean constitute Toronto's three major ethnic groups. Thus, the ending questions "the peaceful coexistence of cultures in a society demarcated by differences" (Rosenthal 2011: 255). With this narrative twist, the model of 'Canadian multiculturalism' is criticized for supporting parallel worlds within one society that rarely interact and sometimes severely clash.

With respect to the significance of the title, the main question is whether the characters find what they long for in the end. The reconciliation of the two immigrant generations remains a difficult task due to the first generation urge to preserve their cultural roots, symbolized by the search for Quy. The prospect of reuniting two generations by reuniting Tuyen's brother with her family fails when Quy is killed before the reunion takes place. After Quy's tragic death in Toronto, it becomes apparent that the second generation's past cannot be combined with their Toronto present. The state of ambivalence will subsist.

Quy's death also shows that "the biggest illusion Brand's text destroys in the end is that racism might end with the unanglicized city" (Rosenthal 2011: 256). Since multiculturalism is associated with the coexistence of different but distinct cultures within one society, this model of integration can create stereotypes, categorization processes, and borders. In order to transform the anglicized city into a more tolerant form, a 'dialogical exchange' (Antor 2006: 330) across cultural boundaries is necessary.

The lubaio, a polycultural art installation that captures multiple forms of code-switching, serves as the novel's model of cultural exchange in a dialogical fashion. Tuyen, the main agent for the longings of Torontonians in the novel, accepts her role as a translator between the present and the past, her own life and that of her parents, the different traditions, cultures, and generations. Moreover, she acknowledges her role as an artist who translates the culturally diverse, individual voices of the city into the lubaio, by asking "wasn't that what her art was all about in the end? She had a vision of the cloth on the wall in her apartment, the scores of scribbled longings (...). She would take photographs of the people of the city too, and sprinkle them throughout" (WHA 308).

Tuyen's mediation of ethnic diversity in a random manner resembles a new form of socio-cultural integration. Rinaldo Walcott reviews Brand's novel as an approach to a new form of "everyday multiculturalism" that "requires us to think about the lives people make across differences and, importantly, connections that produce new modes of relationality and being" (2007: 19f). Therefore, as 
Tuyen's patchwork-like, work-in-progress installation on longings illustrates, the Canadian model of 'multiculturalism' requires revision to adapt to global cities such as Toronto that are increasingly characterized by multidirectional migration and the acceleration of cultural flows.

\subsection{INTERIM CONCLUSION}

Dionne Brand's What We All Long For (2005) can be analyzed in terms of poetics of code-switching, narrative, and space to identify the ethnic diversity of the imagined global city of Toronto in a globalizing age. The city unites the sometimes antagonistic young people of different mixed ethnicities. The different lives are interwoven, forming a network of different cultures in the city. This phenomenon of intermingling and group identity formation, however, is limited to a selection of second-generation immigrants born in the city who claim the city's space for themselves and thus voice their agency. Thus, the secondgeneration characters function as 'translator-protagonists' (Smith 2009: 244) who interpret the city to their parents and the reader.

Regarding multivocality, the novel functions as a medium, translating the new ethnic diversity of Toronto's formerly anglicized society to the reader: "It's like this with this city - you can stand on a simple corner and get taken away in all directions (...) then the other languages making their way to your ears (...) this all sums up to a kind of new vocabulary" (WHA 154). This new vocabulary makes Toronto's new ethnic texture audible, giving the different cultures a voice. The city's "polyphonic murmuring" (WHA 149) is expressed in different forms of code-switching such as narrative voice, jargon, and translation. The use of polyglossia creates closeness to the characters and an 'authentic' impression of Toronto's cultural complexity.

With the introduction of Quy, an additional narrative thread and perspective is presented on immigration and loss, showing that the illegal immigrants' perspective is a considerable part of the immigrant experience. The novel's different perspectives, localities, and times are incorporated to position the "contemporary cast of characters within longer histories of migration and struggle" (Brydon 2006: 2). The first generation's immigration struggles, their current situation, but also their children's situation in Toronto and the experiences of a newly arriving illegal immigrant are portrayed to illustrate the great array of experiences and perspectives involved in the immigrant experience.

In association with the poetics of space, different types of narrating the city can be identified, which are conveyed with mental maps or cataloging. With the 
different characters and events, the city's space is illustrated from various perspectives, thereby revealing the multiple meaning and associations inscribed in a certain place, such as public and private, static and dynamic, male and female, or different ethnic escapes. Although the second generation is also displaced (Dobson 2009: 189) in Toronto, the four friends seize the opportunity to shape their own space in the city.

In the novel, the two immigrant generation perspectives are incorporated to show the effect of 'time-space discrepancy.' Whereas the first-generation parents unsuccessfully long for a Canadian identity and the preservation of their cultural roots and thus the old times, the second generation opts for a global, cosmopolitan self-definition that rejects hyphenated, national, or ethnic concepts of identification.

The novel manages to combine two contradictory discourses. On the one hand, the drawbacks of multiculturalism as a policy are presented when, for example, the failed integration of the Caribbean Italian Canadian Jamal is portrayed. The discrimination of blacks in Canada and other 'visible minorities' are still effective in many areas, such as politics, the labor market, and the public space of the city (Rosenthal 2011: 215). Moreover, as the novel shows, firstgeneration, male, and illegal immigrants cannot integrate as easily. On the other hand, Toronto offers a space of diversity and tolerance to second-generation immigrants who identify with the city. The group of second-generation immigrant friends and Tuyen's art installation the lubaio serve as such a new form of 'interethnic networking' in the city. The bonding across ethnic, gender, or class demarcations is a "rhizomatic form of political resistance" (Dobson 2006: 89). In this new form of urban and global citizenship, predetermined socio-political constructions, such as ethnic boundaries or the concept of 'Canadianness,' are rejected. 



\section{Chang-rae Lee's New York, Native Speaker}

\subsection{The Global City of New York}

In the 1970s, the slogan 'the Big Apple' once again boosted the popularity of the global city of New York (Rosenthal 2011: 7), attracting world-wide flows of tourists and increasing to more than six million international visitors in 2000 (Gladstone et al 2003: 81). New York lends itself to several exceptional images, such as the 'quintessential immigrant city' (Foner 2000: 5), "the capital of the capital' (Bell et al 2011: 269), 'a multicultural mercantile city' (Abu-Lughod 1999: 23), or 'the city of ambition' (Bell et al 2011: 249). The American metropolis is continuously evolving into something new because change is the city's only steady characteristic (Lach 2000: 8); the city always recovers despite the severity of its moral, social, or economic crises (Bell et al 2011: 250). Due to this 'pragmatic pluralism' of not having a single logic, New York is considered 'the unfinished city' (Bender 2002: xii).

New York is a political, financial, and economic nodal point, a center "of global corporate power" (Clark 1996: 148). The metropolis of about eight million (Halle 2003: 24) is the 'prototypical' global city (Beauregard 2003) and one of Sassen's three leading examples when coining the term 'global city' (1991: 4). New York is in the top tier of global cities (Brenner et al 2006: 3) with regard to numerous rankings. In a comprehensive study of world city research, New York is one of the four cities cited 16 out of 16 times (Taylor 2004: 40f.).

Often conceived as the unofficial capital of the American nation by foreigners, New York "casts its 'world city shadow' over all other US cities" (Taylor 2004: 160; Beaverstock et al 2000). The metropolis has long influenced the entire country and its values and continues to be of major significance for America.

40 For more information about immigration and cultural diversity in the United States, see Marzio, Peter C. (ed.). A Nation of Nations. New York: Harper and Row, 1976. 
Illustrating the intrinsic relationship of the country's image and the global city's perception, New York represents "the nation's sometimes glorious, sometimes horrifying other and at the same time is part of its self-imagination" (Rosenthal 2011: 28). The following elaborates how the most un-American metropolis continues to shape its country's image but has also developed into "a center of difference" (Bender 2002: 182).

As early as in the seventeenth and eighteenth century, the city of New York and its culture were based on two pillars: interest and diversity (Bender 2002: 193), with trade and financial transactions across cultural, political, and religious boundaries being considered as the key to monetary success. From a global perspective, New York has come to be recognized as a "city of difference par excellence" (Sennett 1990: 128; Miles 2007: 58). New York has always been "a multicultural mercantile city" (Abu-Lughod 1999: 23). Its quality as the North American gateway for immigrants from around the world supported its early development as a financial node and global city. New York thus became the major starting point for American consumerism, commercialization, and global Westernization.

New York is often contrasted with Los Angeles, the second largest American city, because both are so-called 'core primary cities' in the world city hierarchy (Friedmann 1986). As America's "leading immigrant destinations" (Waldinger 1996: 1078), both cities operate as important nodes in the global network of migration and transmigration. New York, however, fulfilled the criteria of a global city as early as the 1870s (Abu-Lughod 1999: 40), already being the classical heaven for immigrants to America.

The past and present immigrant experience differs greatly in New York and Los Angeles (Waldinger 1996: 1079). Although immigration to Los Angeles accelerated in the twentieth century, New York still represents "the most visible site of the struggle over American identity" (Corley 2004: 67). Due to the city's history, economy, and politics, an immigrant's integration accelerated in New York (Waldinger 1996: 1083). In return, the steady flow of immigrants, their capital and their labor have helped the city of New York to become the financial center it is today (Bell et al 2011: 259). Thus, in addition to economics and infrastructure, ethnic diversity constitutes the global city's key characteristic. Nevertheless, in both cities, immigrants are still discriminated against in terms of income distribution (Friedmann 1986: 76).

The city of New York was originally referred to as 'New Amsterdam' when a Dutch company settled at the harbor in 1624 (Abu-Lughod 1999: 23). The harbor's proximity to Europe has influenced the city's growth in size and its infrastructural importance for national and transatlantic commerce. New York's port 
and the construction of canal systems accelerated national and international trade. By the nineteenth century, New York had become a central nodal point for information and transport, representing a regional and global command center (Taylor 2004: 90f.) with a major impact on America and influence well beyond the national. As early as in 1643, eighteen languages were spoken in New York (then referred to as 'New Amsterdam') (Abu-Lughod 1999). This diverse background of the city's residents served as the basis for a new form of politics and society in New York, "one that embraced difference, diversity, and conflict - as well as the dollar" (Bender 2002: 192).

New York fulfilled the economic criteria of a global city much earlier than its North American counterparts Los Angeles and Toronto. As early as 1820, the so-called "city of ambition" (Bell et al 2011: 249) was a national center for finance, stock exchanges, insurance, and real estate. This growth in the economic sector, often referred to as 'FIRE,' is symptomatic for major cities in a globalizing age (Abu-Lughod 1999: 37). New York's specialization on finance was accelerated by its central position in the triangular-trade slave market (Bell et al 2011: 267) and further enforced by the country's domination in politics and economics following World War II (Rodriguez et al 2006: 39). Although the city was severely shaken by the Great Depression in 1929 and the Wall Street crash in 2008, from which it is still recuperating, New York's economic supremacy has lasted for more than two centuries (Bell et al 2011: 269).

New York is a leading transnational financial center of global impact (Clark 1996: 159). It is not only the American financial hub but remains to be the world financial center for global transactions and exchange. The "hyper global city" has strong ties to and influence on the regional, national, and international economy (Olds et al 2004). In terms of bank network connectivity, for example, New York is ranked second behind London (Taylor 2004: 99). In "the business city that never sleeps" (Short 1999: 49; Parker 2004: 126), Wall Street and the New York Stock Exchange have become icons for world-wide financial transactions and globe-encompassing capitalism. In 1971, the World Trade Center was opened and became one of the most popular buildings in New York, invigorating the financial district (Bell et al 2011: 265) and the city's image as the financial capital of the world.

New York functions as a 'global command center' of mega influence (Taylor et al 2002; Taylor 2004: 90) and, along with London, the American metropolis is the global city with the highest global network connectivity (Taylor 2004: 73; Taylor et al 2002), linked to various world cities of different tier. Together with London and Amsterdam, New York is described as a 'hegemonic city' (Lee and Pelizzon 1991; Taylor 2004: 14), demonstrating the global city's importance for 
America and for the global network of world cites. This effect is of particular importance for financial control centers that usually outlast their country's hegemony (Taylor 2004: 14).

New York is also referred to as a 'specialist service city' with regard to banking, finance, and law (Taylor 2004: 83). The city is the strength of America's manufacturing where "a sizeable component of global production and consumption is controlled" (Clark 1996: 141). Whereas Los Angeles was ranked eighth and Toronto fifteenth with regard to control and command in 1984, New York is considered the center for it with almost 60 of the 500 largest transnational companies' headquarters (Clark 1996: 148; Smith et al 1987). Thus, it is more globally than regionally oriented (Taylor 2004: 154).

Better infrastructure has led to the steady growth of the city's population, and, as in most North American cities, immigrant groups generally favor the city center as their destination (Abu-Lughod 1999: 302). In 1800, although Manhattan had only 57,500 residents, it was still one of the largest cities in the U.S. at that time (Bronger 2004: 74). Between 1820 and 1870, New York's ethnic population grew due to migration to urban areas (Abu-Lughod 1999: 40). The opening of the Brooklyn Bridge in 1883provided the first non-ferry based connection from Manhattan to Staten Island (Bronger 2004: 114) and facilitated the larger area's growth in infrastructure and population. Today, New York city's subway system is one of the world's most dense with more than 400 stops and more than 200 miles of tracks (Bronger 2004: 114), connecting the core city with the central areas since 1904 .

Then and now, the city's competences, services, and labor options are focused on the five boroughs (Halle 2003: 1) with the greater metropolitan area featuring a population of almost 20 million. In 1898, the so-called 'Greater City of New York' was formed with the amalgamation of the five boroughs Brooklyn, Manhattan, Queens, Staten Island, and the Bronx, doubling the population, expanding its size significantly, and creating an integrated municipal government (Bell et al 2011: 253). Manhattan is still regarded as New York's core city, and since the agglomeration, the boroughs Queens, Brooklyn, Staten Island, and the Bronx have been considered the city's core area (Bronger 2004: 67). The global city's main attractions, such as the Empire State Building, the Chrysler Building, Times Square, Fifth Avenue, and Central Park, are all situated in Manhattan.

The city's infrastructural and economic development is often associated with the Manhattan street grid, which was introduced in 1811 to facilitate organic growth. Land was leveled and streets and avenues were planned and built in a rectangular manner (Bell et al 2011: 265). This structure was visionary at its 
time (Bender 2002: xv) and aimed at making money in real estate when subdivided land lots were leased to poor immigrants (Monahan 2002: 164). The grid structure helped New York, in stark contrast to Los Angeles, to be "one of the most pedestrian-friendly" American cities (Bell et al 2011: 266), shaping how New York City dwellers experience an 'intersecting' life on the streets.

American immigration policies changed over time to accommodate immigrants and the economy, beginning with traditional boat people arriving at Ellis Island to modern air-fare passengers landing at JFK (Foner 2000) or LAX. Immigrants arriving before and after 1965 are "overwhelmingly city-bound" with about 40 percent living either in the greater areas of New York or Los Angeles in 1980 (Waldinger 1996: 1078). Ellis Island, a government facility built near Liberty Island, remained the single destination for new arrivers from 1892 to 1954 (Koman 1999: 31), operating as "an immigrant-processing center" (Foner 2000: 1) in which 12 million immigrants were 'managed.' Consequently, more than 100 million Americans had their ancestors passing through Ellis Island (Koman 1999: 31), and today, roughly 50 percent of all immigrants continue to "pass through New York's portals" (Abu-Lughod 1999: 19). Since 1990, Ellis Island, now a national immigration museum (Koman 1999: 31), has attracted millions of visitors annually (Foner 2000: 2). Ellis Island remains the most prominent symbol of the 'American passage' (Cannato 2010) and American immigration experience. $^{41}$

Two major waves of immigrants mainly affected the immigrant heaven New York. The first wave spans from 1880 to 1920 , while the second peak concentrates on the period starting in the mid-1960s (Foner 2000: 6). Most immigrants arriving in the mid-nineteenth century, before the first peak, were of German and Irish descent (Foner 2000: 10). The first peak was mainly influenced by Russian Jews and Italians, who still make up a significant part of New York's population. Most immigrants following this peak in the first wave were of Eastern European, Mediterranean, and Chinese descent (Bell et al 2011: 258). The first wave was stopped by the Johnson-Reed Immigration Act of 1924, which limited immigration numbers from Eastern and Southern Europe.

Following the Hart-Cellar Act of 1965, which put an end to the former country-of-origin quotas (Foner 2000: 23f.), new immigrant groups started to pass through and settle in New York, including Asians, Caribbean, and Latin Americans (Sabagh et al 2003: 101f.). A regulatory shift from ethnic quotas towards an immigrant's skills took place, favoring western and northern Europeans (Foner

41 For more information on Ellis Island as the gate to America, see Thomas M. Pitkin's Keepers of the Gate: A History of Ellis Island (1975). 
2000: 23f.). In contrast to Los Angeles, New York received many immigrants from outside Europe before 1965 (Waldinger 1996: 1079). The 1986 Immigration and Control Act (IRCA) or Simpson-Mazzoli Act reformed immigration laws by granting amnesty to illegal immigrants who had resided in America since $1982 .{ }^{42}$ With the Immigration Act of 1990, immigration policies became more liberal, inviting immigrants "from underrepresented countries" (Foner 2000: 13f). Thus, by the new millennium, new arrivers were primarily immigrants from Asia, Latin America, and the West Indies (Foner 2000: 1). Thirtytwo percent were Hispanics and non-Hispanic whites, while African Americans accounted for 16 percent and Asians for 12 percent (Sabagh et al 2003: 104).

According to the 1990 census, the three largest immigrant groups living in New York were born in the Dominican Republic, China, and Jamaica, featuring the largest Chinese American community (Foner 2000: 11ff.). Between 1980 and 1990, the five major immigrant groups to New York consisted of over 145,000 Dominicans, about 75,000 Chinese and Jamaicans, about 67,000 Colombians, and around 58,500 Koreans (Abu-Lughod 1999: 302). In the twenty years before 1992, the majority of Caribbean immigrants to America settled in New York and the surrounding areas, including "half of the Haitians, Trinidadians, and Jamaicans and close to three-fourths of the Dominicans and Guyanese" (Foner 2000: 12).

Describing the so-called 'newest New Yorkers' of the 1990s, who, in comparison to immigrants from previous eras are even more different in cultural, educational, or economic terms, the term 'diversity' emerges as a metropolitan, national, and international catchphrase (Foner 2000: 35). About 30 percent of New Yorkers speak a language other than English at home (Sabagh et al 2003: 103) and in 1990, 28.4 percent of New York City's residents were foreign-born, with percentages of 25.8 in Manhattan, 22.8 in The Bronx, 29.2 in Brooklyn, 36.2 in Queens, and 11.8 in Staten Island (Abu-Lughod 1999: 303). In 1996, however, with almost 50 percent and 31 percent, respectively (Anisef et al 2003: 3), both Toronto and Los Angeles featured a higher rate of foreign-born population than the "quintessential immigrant city" (Foner 2000: 5). Nevertheless, New York continued to be America's "most culturally various city" (O'Connell 1995: xv), considered "a city of difference par excellence" (Sennett 1990: 128; Miles 2007:

42 Approximately three million undocumented immigrants were affected by this immigration policy. For more information, see Susan Gonzalez Baker's The 'Amnesty' Aftermath: Current Policy Issues Stemming from the Legalization Programs of the 1986 Immigration Reform and Control Act (1997). 
58), outnumbering most American cities in terms of the range of immigrant diversity (Foner 2000: 5).

Similar to Toronto's rapid development from an 'anglicized city' to a city of immense diversity, proportions of whites and non-whites changed quickly in New York, from 94 percent whites in 1940 to 52 percent in 1990, with 59 percent in Manhattan, 47 percent in Brooklyn, 36 percent in The Bronx, 58 percent in Queens, and 85 percent in Staten Island (Abu-Lughod 1999: 297). Thus, by the 1990s, "the new New Yorkers from abroad" made up 28 percent (Waldinger 1996: 1079) of the population, which was still lower than in Los Angeles. This rapid development is partly explained by the effect of 'chain migration' (Foner 2000: 19) in which earlier immigration influences later immigration of the same ethnic group. Cultural nodal points and ethnic clusters are formed, supporting family members or members of the same ethnicity in terms of housing, job opportunities, import and export, or monetary funding.

New York is considered not only as the financial capital but also as the world cultural capital (Bell et al 2011: 260). In 1998, mayor Rudolph Giuliani depicted New York in his second inaugural address as "the capital of the world" in terms of finance and business as well as culture and arts (2002; Bell et al 2011: 249f.). The dominance in arts and culture can be derived from the global city's outstanding diversity and its enduring status as the significant North American immigrant destination. Along with Los Angeles, New York is a center "for the production and dissemination of information, news, entertainment and other cultural artifacts" (Friedmann 1986: 73). Although Los Angeles remains the American or even global center for media and entertainment, New York is still considered the node for the proliferation of American culture and the headquarter of its publishing industry (Abu-Lughod 1999: 290).

In terms of culture, New York is of national and global significance, symbolizing "the hybridity of American identity through its cultural centrality within the American national consciousness" (Corley 2004: 68). In 1886, the New York Statue of Liberty, the city's tallest structure of the time, became the nation's symbol for liberty, peace, and justice for all (Bell et al 2011: 258). New York's Ellis Island has long served as the symbol of the nation's cultural history and plurality, now attracting numerous national and international tourists. The city's historical pragmatism of marketing plurality furthered this impression and thus, New York's large African American population, for example, contributed immensely to the cultural development of music and dance.

New York's art and literary scene continues to shape public opinion, continuously incorporating the city's contradictory images into its literary representation. Walt Whitman, Randolph Bourne, and William Livingston are three of the 
most important writers and historical public figures defining New York's culture, politics, and society (Bender 2002). Apart from post 9/11-literature, three major recurring themes can be identified as shaping New York literature: The city's quality as the financial center of the world, existentialism and avant-garde as well as themes of the American dream.

The city's success as the 'world's capital of capital' results in "a rich literature on the urban ills of life" (Bell et al 2011: 250), including the paradox between capitalism and ethics or morale. Examples include Herman Melville's Manhattan-based short story "Bartleby, the Scrivener: A Story of Wall Street" (1853), John Dos Passos' Manhattan Transfer (1925), and Don DeLillo's novels White Noise (1985) or Cosmopolis (2003).

While Edith Wharton's The Age of Innocence (1920) portrays New York's upper class and themes of morality at the end of the nineteenth century, the city's contemporary literature is dominated by writers such as Paul Auster and his wife Siri Hustvedt. Themes of existentialism, self-searching, identity crisis as well as of physical or psychological sickness are the recurring subjects of this avantgarde-like fiction writing. Whereas Auster's Moon Palace (1989), for example, focuses on "the uncanny aspects of the city, the mystery of its interconnectedness," illustrating how the city's history shapes that of the whole country (Lehan 1998: 281), his City of Glass (1985), part of The New York Trilogy, functions a as "anti-detective fiction," as the novel questions authorship when the author is thought to be a detective (Sorapure 1995: 72f.).

The third recurring theme has always inspired New York's literature because its "literary image has embodied the American Dream like no other city" (Rosenthal 2011: 27). Well before Los Angeles and Hollywood became the 'American dream factory,' New York and Ellis Island were its predecessors. To immigrants, New York became a 'land of promise' and the ideal "place to realize one's potential" (Bell et al 2011: 261). New York's ethnic fiction mirrors this aspect but also reflects on the city as a place of prejudice and resistance. Toni Morrison's historical novel Jazz (1992), for example depicts Harlem in the 1920s and Ralph Ellison's Invisible Man (1952) portrays the African American experience in New York "as the promised land of freedom" (Wirth-Nesher 1996: 17f.). One of New York's greatest writers is the nineteenth century poet Walt Whitman, whose work continues to play a major part in New York's process of "metropolitan self-definition" (Bender 2002: xii). With poetry such as Leaves of Grass (1855), Walt Whitman succeeded in translating New York's cosmopolitanism, diversity, and difference into literature.

With the World Trade Center twin towers collapsing after the 9/11 terrorist attacks, New York's image as the economic capital of the world was severely 
shaken. Following the atrocity of the terrorist attacks, New York became the symbol of a unified American mourning. Although the terror attacks, paralyzing American society as well as American writers and readership, took place more than a decade ago, New York's contemporary literature is, even now, influenced by the tragic events that traumatized the ambitious world city and the entire American nation. Post-9/11 literature includes international bestsellers such as Jonathan Safran Foer's Extremely Loud \& Incredibly Close (2005) and Don DeLillo's Falling Man (2007). Both novels portray the dramatic events in the city and cope with the images of New York that went out to the world, processing the atrocity and loss while narrating the immense sense of community.

Following the attacks, a paradigm shift took place in which different themes in New York and American fiction writing became more important to the publishing industry. As a result, New York's ethnic literature was not the center of attention anymore, although the city strengthened its feeling of community, reducing 'racial tensions' (Homberger 2008: xvi; Bell et al 2011: 276). Even Mayor Giuliani has changed: "Mayor Giuliani, formerly viewed as a combative, moralistic, and deeply partisan figure, transformed himself into a resolute and compassionate leader who was spontaneously applauded when he walked down the street" (Bell et al 2011: 276).

Chang-rae Lee's Native Speaker (1995) was written and published six years before 9/11 when Mayor Giuliani was still another character. In the 1990s, minority politics played a major role in New York. The city gained about two million immigrant residents within 15 years (Abu-Lughod 1999: 303) and high numbers of illegal immigrants moved to and through the city. According to estimates by the INS, 90 percent of the state's illegal immigrants had no visas in 1996 (Foner 2000: 17). Giuliani was determined to fight illegal immigration, which had a serious impact on minority politics as the city "has become more polarized by ethnicity, race, and class" (Abu-Lughod 1999: 296). At that time, America was dominated by strong interracial conflicts, such as the 1992 Los Angeles Riots. Moreover, the 1991 Crown Heights riots between Jews and African Americans in Brooklyn heavily influenced New York's political development, such as the 1993 mayoral elections (Halle et al 2003a: 344) when Giuliani beat the former and first African American Mayor Dinkins.

Lee's Native Speaker (1995) takes place in this difficult era of extreme interethnic conflicts and fierce unrests in America of the 1990s. With and beyond the Korean American experience, the novel's linguistically-crafted depiction of the global city of New York shows the possibilities and limitations of an integrated minority ethos. Using the combined case of the ethnic spy Henry Park and John Kwang's running for mayor, the novel tests how a Korean immigrant's integra- 
tion into society can be stretched to embody the entire "polyglot city of New York" (Chu 2000: 2).

This literary strategy of a 'panethnic movement' (Ty et al 2009) represents a growing trend towards an 'interethnic imagination' in Asian American fiction (Rody 2009). With the creation of an exclusive minority ethos that is the combination of an African American vernacular and the extension of Korean family values, Lee's novel functions as a literary consolidation of the different, often rioting ethnicities by showing that a sense of community across ethnic lines can be possible in political, cultural, and, most importantly, linguistic terms. The following sections describe and analyze how the global city of New York is imagined as 'a city of wor(l)ds.'

\subsection{NeW York IMAGined: A CitY OF Wor(L)DS}

Whereas Brand's literary Toronto is conceived as different coexisting and overlapping worlds within the city with a focus on concepts of place and space, the literary city of New York and its cultural diversity is repeatedly described as a "polyloquial cosmopolis" (Moraru 2009: 86). Although poetics of place and narrative play an important role in Native Speaker (1995), the poetics of codeswitching is the novel's dominating strategy in visualizing, exploring, and translating urban immigrant life and in the integration of the different ethnic groups into society. The immigrant experience in New York in general and Henry's struggle in the city in particular are repeatedly depicted in linguistic terms. Thus, in Chang-rae Lee's Native Speaker (1995), New York becomes 'a city of words' (NAS 319) or, better, 'a city of wor(1)ds,' pinpointing the literary imagination of the global city's urban space and ethnic complexity.

Chang-rae Lee was born in Seoul in 1965, moved to the U.S. three years later (Kellman 2003: 89) to grow up and reside in New York. Lee received a Bachelor of Arts in English from Yale University and graduated with a Master of Fine Arts from the University of Oregon. After working one year as a Wall Street analyst, he decided to specialize in Creative Writing. Lee wrote the manuscript of his debut novel Native Speaker as part of his master's degree (Lee 2004: 215). Lee was only 29 at the time of the novel's publication, recognized as one of The New Yorker's ' 20 best American writers under the age of 40.' The novel won a number of prizes, including the '1995 Discover Award' (Kich 2000). Lee is currently a professor at Princeton University.

Lee writes poetry and publishes autobiographical and non-fictional texts. His relationship to his mother at the moment of her death is depicted in The Faintest 
Echo of Our Language (1993), describing how one's identity is interwoven with language and the act of speaking. This experience helped the author in becoming a skillful writer (Lee 2004: 216). The memoir-like novel A Gesture Life (1999) features narrator-protagonist Doc (Franklin) Hata, an elderly Korean American and Second World War veteran who grew up in Japan, as well as so-called Korean 'comfort women,' who have been forced to sell their bodies to the Japanese enemy. Writing beyond the author's ethnic constraints, the novel Aloft (2004) focuses on an Italian American in suburban New York. His multiperspectival, historical-fiction style novel The Surrendered (2010) on different Korean War experiences was a finalist in 'The 2011 Pulitzer Prize.'

Native Speaker (1995) was marketed as immigrant fiction (Huang 2010: 1). The publishing strategy was of utmost importance for the publisher Riverhead because the spread of the specific 'ideology of multiculturalism' "required the commodification of minority subjects as aesthetic exemplars" (Corley 2004: 70), addressing both the self-perception and an outsider's perception (RotheramBorus 1990) of the often biased 'ethnic label.' The author's multicultural ethnicity was strategically used and commodified for the respective literary market (Chang 2010: 142) because how an author and the reader belong to a certain ethnic group facilitates a book's marketing as ethnic literature (Chu 2000). This limited notion of culture as separate entities and pigeonholing as ethnic silos, is problematic. Lee thus discards being classified as a sole Asian American author (Chang 2010: 66), being concerned about the fact "that a novelist who chooses to focus on his ethnicity or region is too readily categorized as 'ethnic' or 'regional"' (Kich 2000: 175f.). The novel nevertheless attracted a broad, 'universal' readership, was recognized widely across America, and was translated into numerous languages, particularly successful in Italian and French (Kellman 2003: 94).

When writing Native Speaker, Lee was inspired by his own life growing up as a Korean American and by different literary techniques, such as Whitman's voice, offering 'a novelistic glossolalia' that "speaks to us in tongues" (Moraru 2009: 68). Using the method of an 'ethnographic autobiography' (Song 2005: 169f.; Chang 2010: 66), Lee was trying to analyze an immigrant's assimilation in a structured way (Lee 2004: 217) because Lee himself knew the simultaneous and contradictory feel of exile and citizenship (Garner 1999). At the same time, Lee underlined the importance of language because the "sense of the world, the reader's sense, comes from the language" (Quan 2004).

In the novel, the immigrant experience or outsider position is cleverly expressed through language, exploring linguistic fluency and nativity, authenticity and voice, accents and vernacular, or silence and body language. This language 
consciousness translates into the novel's specific 'rhythm and sound' (Kellman 2003: 92). The author's writing skills and 'the lyrical prose' astonished many readers (Rhee 2011: 157) because, as Lee explains himself, the global city novel about New York is first and foremost "a story of language and how language forms" (Quan 2004).

Lee's Native Speaker (1995) focuses on the thirty-something Korean American Henry Park, who faces a personal, marital, and professional crisis in New York of the 1990s. Although the main protagonist is American by birth and sounds like a native speaker, he is struggling to be recognized as a wellintegrated American citizen. In a parallel story line, the Korean American, skillful speaker, and mayoral candidate John Kwang's rise and fall in New York's society is described. The two story lines are connected by Henry's controversial profession as an ethnic spy in Dennis Hoagland's Glimmer \& Company that supports the harsh measures on 'unwelcomed' immigrants. Henry is asked to befriend and betray Kwang, who is secretly observed by the Immigration and Naturalization Service (INS). ${ }^{43}$

With the depiction of Henry and Kwang, the novel manages to show the opportunities and drawbacks of an immigrant experience in New York as well as a possible interethnic imagination through language and in politics. Henry is married to the speech therapist Lelia Boswell, who is introduced as his opposite, "a fiery New England Caucasian woman" (Yoo 2005: 57). When their young son Mitt tragically suffocates and dies and Lelia discovers that Henry works as a spy, the couple splits up. Departing on a self-searching trip to the Mediterranean, Lelia leaves a fragmented note of her husband's character traits behind. Reading Lelia's description "false speaker of language" (NAS 5; emphasis original) triggers Henry's personal and professional identity crisis because he has been desperately trying to integrate into American society by sounding like a native speaker.

The novel is analyzed here in five sections, addressing issues of polyglotism, the interdependence of language and identity, the significance of the title, the narrative and the genre, the metaphor of the immigrant as a spy, the concepts of visibility, invisibility, and hypervisibility, streetscape and voice, and the interethnic upheaval and collaboration in the paradigmatic immigrant city. The next

43 As a consequence of the 9/11 terrorist attacks, the now-called 'Legacy INS' was split up into three components in 2003: The 'United States Citizenship and Immigration Services,' the 'United States Immigration and Customs Enforcement,' and the 'United States Customs and Border Protection.' The three sections now belong to the then newly created 'Department of Homeland Security.' 
section explores how the steady flow of immigrants to New York influences the growing cultural diversity of the global city. In the novel, the phrase "the strangest chorale" (NAS 319) articulates New York's urban space and the closely intertwined ethnic diversity.

\subsubsection{The Strangest Chorale}

This is a city of words.

We live here. In the street the shouting is in a language we hardly know. The strangest chorale. We pass by the throngs of mongers, carefully nodding and heeding the signs. Everyone sounds angry and theatrical. Completely out of time. They want to buy something, or hawk what you have, or else shove off. The constant cry is that you belong here, or you make yourself belong, or you must go.

(NAS 319)

Different types of narrating the city are conveyed with the help of figurative language. Chang-rae Lee's New York is presented as a 'verbal cityscape' (Wirth Nesher 1996) because the multi-ethnic metropolis, its urban space, political sentiment, and social commentary are imagined and voiced in linguistic terms. Similar to chronotopic and olfactory perceptions of the city's topography in Dos Passos' Manhattan Transfer (1925), New York's literary urban space and cultural diversity are mapped as "a city of words" (NAS 319). The North American haven for immigrants is easily associated with a 'city of words' because it has been characterized by ethnic and linguistic diversity since its founding (Corley 2004: 67). As the quote shows, verbal skill is employed to generate the city's geography and as a social commentary technique in which auditive vocabulary, such as 'shouting,' 'language,' 'chorale,' 'sounds,' and 'cry,' predominates.

In the three-stage transformation of personal pronouns depicted in the quote, the atmosphere, the political circumstances and the urban setting of the novel are illustrated. At the same time, an immigrant's experience and the three major groups involved in the process are introduced: Immigrants in general ('we'), American society ('they') as well as the individual immigrant ('you'). The paragraph begins with an inclusive 'we' as in 'we live here,' referring to all immigrants as non-native speakers. The pronoun 'we' stresses the common features of an immigrant's fate in America, disregarding ethnic boundaries. The diversity of 
immigrants is expressed by their foreign-sounding multivoicedness as 'the strangest chorale.' When 'carefully nodding and heeding the signs,' immigrants are described as reacting with silence and obedience, reinforcing the stereotype of Asian Americans as the silent and obedient 'model minority' (Wong 1998). Then, a transition from an inclusive 'we' to an exclusive 'they' is made, the latter representing American society as such. The disruption between the two contrasting groups is expressed in terms of emotion ('anger') and temporality ('out of time'), hinting at the challenge of integrating immigrants into society.

In the above-mentioned quote, New York's multiethnic society is compared to a market, thereby referring to famous American myths, such as pursuing the 'American dream' by rising 'from rags to riches' (Jillson 2004), which still attracts immigrants from around the world. New York is thereby narrated as a 'commodified city,' in which 'the urbanite is constructed by the consumer's drive to acquire goods resulting in self-display as a commodity" (Wirth-Nesher 1996). Finally, the exclusive 'you' as in 'you make yourself belong' emphasizes every individual immigrant's duty to integrate.

The novel recurrently imagines New York in linguistic terms as a space of diversity and multivocality, highlighting the importance of language. When listening to boys practicing English, Henry muses about the city's resemblance: "Then language. Ancient Rome was the first true Babel. New York City must be the second. (...) to enter this resplendent place, the new ones must learn the primary Latin. Quell the old tongue, loosen the lips. Listen, the hawk and cry of the American city" (NAS 220). In this quote, the importance of learning and mastering the English language is stressed because the ability to adapt one's tongue symbolizes the key to integration and success. Moreover, the comparison with ancient Rome and Babel stresses the national and global impact of the city of New York. This reference, however, also associates American hegemony with the history of Roman imperialism and dominance.

The imagined ethnic diversity of the global city New York is explained and portrayed with prose-like descriptions without drawing on voicing vernacular in a written form. Instead, poetic transcriptions of language use, accents, and slang are employed in a vivid yet diplomatic fashion to convey the auditive experience of the city. Henry, for example, recalls his father in terms of his unique speech as "the crash and bang and stop of his language, always hurtling by" (NAS 313). This technique echoes Whitman's voice, ${ }^{44}$ articulating the imagined global city's 'polyglossic' cosmopolitanism (Moraru 2009: 84).

44 For more information on Whitman's voice and the poetics of narrative in the novel, see section 7.2.4 on 'The Immigrant City.' 
Moreover, 'telling' instead of 'showing' is the novel's preferred literary technique. Instead of mocking linguistic divergence, the different immigrant tongues and their sometimes imperfect American English grammar or pronunciation are described poetically with John Kwang as the most important example. ${ }^{45}$ Only a vague description of Kwang's linguistic qualities is presented (NAS 139). The lacking illustration of a spoken or written Asian American dialect forces the reader to imagine this novelty, filling in the conceptual gap of an American minority vernacular that reminds one of the African American but has not existed before. Thus, while Dionne Brand's What We All Long For (2005) and Karen Tei Yamashita's Tropic of Orange (1997) show different, sometimes clichéd narrative voices to portray the global city's linguistic and cultural diversity, this feature is of minor importance in Chang-rae Lee's Native Speaker (1995).

In the novel, ethnic conflicts are articulated with extraordinary sensual experience regarding a particular language or dialect. When Henry recounts how his father spoke to a female customer in his grocery, the conversation is transcribed as a provocative fight with "the strong music of his English, then her black English; her colorful, almost elevated, mocking of him, and his grim explosions. They fight like lovers, scarred, knowing. The song circular and vicious" (NAS 173). This example shows how language not only forms a dialogue but also manages to visualize the interethnic tensions at the time. It is the novel's achievement that the ethnic conflict is portrayed in linguistics terms when "the clash between the two cultures begins to affect even the language spoken" (Eoyang 2003: 26). Thus, this "most awful and sad opera" (NAS 173) becomes representative of the all-pervasive conflict of Korean and African Americans per se and the interethnic uproar of the 1990s as depicted in the novel.

So-called 'metamultilinguism' (Sturm-Trigonakis 2007: 133f.), directions for the reader in which language a particular event takes place, are provided repeatedly in the novel, and Kwang's vernacular is the most prominent example. In an argument towards the end of the novel, for example, Henry and Kwang, both Korean Americans, switch from spoken English to Korean. This change is printed in English, but illustrated in italics in the novel ( $N A S$ 280). This paratextual device is a strategy to highlight the poetics of code-switching. And, by translating the Korean language into English, Lee also includes the non-Korean readership.

Another form of paratextuality is the use of metafictional comments that tend to transgress literary conventions. These explicit or implicit comments directly

45 For more information on Kwang's vernacular, see section 7.2.5 on 'Interethnic Imagination.' 
or indirectly address the reader, such as the use of italics to mark translations in "I put out my hand, 'Yuh-gi ahn-juh'. Come here and sit"" (NAS 249; italics original). In addition to the translation, explanations and contextualization are sometimes provided. No Korean letter symbols, written from top to bottom, are included in the novel. Instead, Korean is presented in phonetics written from left to right, again assuming and serving a non-Korean audience. Moreover, words or simple phrases, possibly familiar to non-Korean natives, such as greetings, are articulated with 'mimetic cliché' (Eoyang 2003: 24), a linguistic tool for translating cultural diversity into language.

In light of the perfect and prose-like language and the ease of translation and code-switching, the significance of the novel's title, 'Native Speaker,' raises questions. The next section discusses how and when a speaker is determined a native speaker or a 'false speaker of language' (NAS 5), thereby examining the interdependence of language and integration into society.

\subsubsection{False Speaker of Language}

The novel's 'polysemic title' (Corley 2004: 78) serves as a paratextual device, functioning as the author's direction for the reader (Genette 1993: 11). This "visual presentation of the text" (Fludernik 2009: 23) accentuates how language, nativity, and voice play a major role in the ethnic global city novel. Lee himself explains that "everyone in the book has a certain relationship to language" (Quan 2004). Thus, the novel's title Native Speaker is representative of the significance of language and belonging, linguistic fluency and social integration because language is not only a means of communication (Chambers 1994: 22) but foremost a method of creating, defining, and reassuring cultural belonging.

Linguistic fluency is often the first and foremost indicator when measuring an immigrant's degree of cultural adaptation. In the novel, the focal point is the 'binary opposition' (Derrida 1973) of being a 'native speaker' versus a 'false speaker of language' and its impact on an immigrant's experience because the idea of being a 'native speaker' automatically brings up the possibility of 'false identity' (Chen 2005b: 171). For immigrants in America, speaking their native tongue constitutes the greatest difficulty when assimilating (Kich 2000: 176). Thus, the combination of the novel's title and the reference to a "false speaker of language" (NAS 5; emphasis original) stresses the influential interdependence of language determining one's identity and vice versa.

The novel begins with a Korean American protagonist who is left by his wife. The recurring themes of ethnic literatures are combined with the discourse of "loneliness, isolation, fragmentation, alienation" of the narrated modern me- 
tropolis (Wirth-Nesher 1996: 17). Lelia triggers Henry's identity crisis when leaving a list before departing for a self-searching trip, calling her husband a "false speaker of language" (NAS 5; emphasis original). This "indictment-love poem' (Moraru 2009: 71) serves as a literary device, correlating with Whitmanesque-like 'cataloguing' and a juxtaposition of terms:

You are surreptitious

B + student of life

first thing hummer of Wagner and Strauss

illegal alien

emotional alien

genre bug

Yellow Peril: neo-American

great in bed

overrated

poppa's boy

sentimentalist

anti-romantic analyst (you fill in)

stranger

follower

traitor

spy

(NAS 5)

The incorporation of this intertextual device and employment of Whitman's narrative style introduces and reworks the great American poet's vision, recontextualizing similar challenges more than a hundred years later. Walt Whitman expresses his ideas through his poetry, conveying the equality of all human beings while highlighting diversity at the same time. Whitman reinforces themes of universal empathy and democracy through a nonhierarchical assembly of items. The ethnic global city novel modifies Whitman's vision to an America that is 'postethnic' and 'postnative' (Moraru 2009: 72). By transferring the poet's renowned technique of 'cataloguing' to a contemporary ethnic global city novel, the author turns himself into a 'global' Whitman, emphasizing urban diversity and equality in a globalizing age.

The catalogue of labels presented above is crucial for the novel's plot and resolution, the introduction of the main protagonist, and his character development. It also describes and dominates his relationship with his wife and triggers 
Henry's quest for identity. Through his spying, for example, Henry becomes a 'traitor,' estranged from his Korean-American community. After his son Mitt died, Henry conceals his sorrow, becoming an 'emotional alien' to his wife. As taught by his Korean father, Henry prefers silence and absolute control over his facial muscles instead of voicing his innermost feelings. This cultural exceptionalism of being "tight-lipped and expressionless" (Yoo 2005: 57) fuels his integrity as a spy but makes him a 'stranger' to his wife. Henry constantly tries to conceal his cultural markers, although Lelia is obviously attracted by them.

The incompatibility of the ethnically-diverse couple is violently expressed in their son's tragic death. Henry always hoped for his son to have "a singular sense of his world, a life univocal" (NAS 249; emphasis added), explaining that "this is assimilist sentiment, part of my own ugly and half-blind romance with the land" (NAS 249). Although Mitt is American by birth and thought to be a native speaker, his 'univocality' is significantly silenced, suffocated beneath his upper-class white friends who formed a 'dog pile' above him. This circumstance symbolizes the social-political challenges and difficulties for intercultural children. Some critics even agree with Cowart's claim that Mitt's death means "that hybridity carries its own doom like a virus" (Cowart 2006: 125).

Lelia plays a major role in Henry's identity formation process because the couple is introduced in a 'self-and-other' manner. This notion of 'othering' encourages hierarchical dichotomies by being reminiscent of postcolonial discourse and concepts such as 'the other,' 'hybridity,' or' ambivalence' (Bhabha 1994). Underlying binaries, such as black versus white, are often inherent in discourses on cultural diversity. Although still commonly neglected, white is also an 'ethnic' (skin) color (Hill 1997), and Lelia's American identity is repeatedly expressed with this color-coded awareness. Henry describes his wife as 'very white,' 'opalescent,' 'unbelievably pale,' almost transparent, or as white as you can be (NAS 8). Even her name 'Lelia' translates into 'white lily,' indicating the character's Anglican background.

This technique of contrasting the couple highlights Henry's immigrant role and thus outsider status in society. Henry is attracted by Lelia's whiteness, an appearance he cannot acquire. Whereas his "American wife" (NAS 7), "the lengthy Anglican goddess" (NAS 14), represents the 'old' immigrant and therefore 'traditional' American, Henry is introduced as 'exotic' and 'neo-American' (NAS 5). To enforce this effect, Henry's descriptions of his wife at the beginning of the novel resemble that of a 'white Supremacist,' a colonizer, or conqueror, being obsessed with maps (NAS 3) and "overrunning the land" (NAS 3). Lelia is even presented as provocative, almost sounding like a racist, when telling Henry 
about her work in "whole secret neighborhoods brown and yellow" (NAS 10). This drastic framing of Lelia by Henry is eased in the course of the novel.

The couple's 'binary opposition' is further stressed with regard to speaking abilities. Henry is attracted by Lelia's perfect execution of language, a quality he desperately longs for. She is introduced as a speech therapist who assists "children [to] manipulate their tongues and their lips and their exhaling breath, guiding them through the difficult language" (NAS 2), thereby highlighting the difficulty of English as a foreign language. The speech therapist not only teaches 'nonnative speakers' ( $N A S$ 2) language skills but also how to adapt to the 'proper' American way of life. Thus, Lelia is depicted as "the most careful performer of American identity" (Corley 2004: 77).

The construction of native speakers occurs because one social group is in the position of power (Singh 1998: 25), and in the novel, Lelia represents this power. Henry is immediately identified as a "native speaker in training" (Kim 2005: 218) by his wife, the 'standard-bearer' (NAS 11) of American English. She claims that he is trying too hard, listening to himself speak, and his body language is giving away that the language is not produced naturally. Nativity, however, is a grammatical as well as a social construction (Singh 1998: 22). Similarly, the concept of a 'native speaker' is a grammatical (Paikeday 1985) or political construct, representing linguistic purity or standards. This standardization, however, involves a process of othering. By pronouncing a standard, speakers are split in 'insiders' versus 'outsiders,' resulting in a naturally prejudiced 'wethey distinction' (Singh 1998: 16). ${ }^{46}$

Henry's struggle to be an accepted native speaker can be compared to the colonized's persistent urge to become like the colonizer to escape the othering process. In postcolonial theory, 'mimicry' (Naipaul 1967) refers to a masquerade or camouflage, in which the colonized unconsciously tries to become like the colonizer. When describing Henry's attempt to copy the sound of his wife's voice (NAS 12), for example, the expression 'to mimic,' is used. Henry, an exceptionally sufficient speaker but socially-designated false speaker of language, strives to assimilate by adapting his pronunciation. He tries to speak 'clean' English with no accent because he learned from his Korean father that speaking proper English is the key to success. Henry even practices in front of the mirror to bring his pronunciation to perfection, paralleling Lacan's mirror stage (1978), often referred to in postcolonial theory, in which the child manages to perceive a 'self' and 'other' when it identifies its own mirror image.

46 Linguists would opt for the more diplomatic term 'ideal speaker-hearer' (Singh 1998: $15)$. 
To Henry, being recognized as a native speaker represents full integration as an American citizen with equal rights. In his case, however, nativity remains merely a 'masquerade' (Kim 2005: 218) because Henry's degree of political integration is not only judged by his proficiency in American English but also by his looks. Although Henry achieves linguistic sameness, the Korean American cannot change his 'physiognomic appearance' (Moraru 2009: 79). When he realizes that it is impossible to attain the desired identity completely and that he will always remain "almost the same, but not quite" (Bhabha 1994: 86), a severe identity crisis is initiated.

Henry's struggle with language and identity becomes emblematic for the American immigrant experience per se. Linguistic fluency is used as a tool for reflecting on identity politics and the American model of integration beyond mere ethnic-specific constraints. The character's Korean background thus functions as an exemplary experience of an immigrant's struggle to integrate while being labeled as a 'false speaker of language.' In the following section on 'Amiable Man,' the novel's negotiation of genre and identity is explored. Therein, the conventions of a spy, for example, are simultaneously enforced and rewritten from a narrative and cultural perspective.

\subsubsection{Amiable Man}

The 'poetics of narrative' seeks to comprehend narrative components by examining "how particular narratives achieve their effects" (Culler 2000: 83). In Lee's Native Speaker, the immigrant novel, detective story, and spy thriller are reworked in a 'cross-genre' fashion (Huang 2010: 2) to demonstrate how globality and diversity manifest themselves in the novel's structure and form. By rewriting Ralph Ellison's notion of African American 'invisibility' to Asian American 'amiability,' an immigrant's struggle for integration is examined by analyzing how narratological categories mirror particular forms of diversity and integration of the literary global city in a globalizing age.

The novel's non-linear narration that varies in narrative time and tense is as fragmented as the protagonist's postmodern identity. The novel's 23 unnumbered chapters are told in a non-linear fashion, interrupted by brief stories, flashbacks, foreshadowing, memories, and prose-like sequences. The narrated time period ranges from Henry's childhood to when he quits his job as an 'ethnic spy' and is finally reunited with his wife. Similar to the achronological account, a change in the narrative tense is conducted. In the course of the novel, the narrator protagonist shifts to present tense when "he notices the timelessness of his spying" (Ludwig 2007: 233). This variation in narrative tense highlights the pro- 
tagonist's moment of revelation and change in perception. Similarly, the narrative perspective changes from an unreliable 'narrating I,' providing "a distorted picture of (fictional) reality" (Fludernik 2009: 27) and thereby mirroring the loss of credibility, to a reflected, third-person narration focusing on the intertwined experiences of Henry and Kwang.

New York's globality, complexity, and diversity are expressed in the novel's manifold narrative structures, shuttling "back and forth between multiple plots" (Song 2005: 170). While the storyline changes "from unity to dissolution in the Kwang subplot" (Corley 2004: 72), the main plot moves from dissolution to unity when Henry is left by his wife to when he is a speech monster in Lelia's English class. The mirrored fate, or opposite, yet symmetrical and interdependent rise and fall of Henry and Kwang, depicts the spectrum of Korean American experiences (Lee 2002: 292), acting as exemplary immigrant experiences in New York.

Narrative conventions are reworked to accommodate the image and imagination of New York's cultural diversity. The creative mixture of genres, in particular the spy thriller and the immigrant novel, is one of the core achievements because "the text refuses the clarity of division and categorical distinction" (Chen 2005b: 181). This 'cross-genre' writing (Huang 2010: 2) creates a 'transtextual space' (Sturm-Trigonakis 2007: 156) in which different forms of texts but also different ideologies coexist. Thus, an interethnic imagination is created and the rewriting of both, the immigrant novel as well as the spy thriller genre, aims at raising awareness of social-political, literary, and cultural framing processes.

With its allusion to politics and the inclusion of the spy story theme (Lee 2004: 215), the novel differs from previous Asian immigrant literature. The characteristic immigrant novel is written like a Bildungsroman, focusing on a 'coming-of-age' process, the physical or psychological development in stages accompanied by a moment of clarification. In contrast, this 'anti-Bildungsroman' (Corley 2004: 62) presents a protagonist who is not an adolescent. This 'political bildungsroman' (Song 2005: 185) is one of the first Asian American novels to focus not on the domestic but on the political, the most important realm beyond the domestic. Thus, the novel also becomes a 'meta-novel' that explains, narrates, and rewrites "the process of Asian American authorship" (Chang 2010: 142). Moreover, the typical completion of the story with a happy interracial marriage is not featured (Corley 2004: 76) as the novel begins with the interracial couple breaking up. The Bildungsroman-like awareness-raising process, however, is featured in the end when both Henry and Lelia eventually acknowledge and 
accept different voices, languages, accents, dialects, and thus, cultural interstices. $^{47}$

The genre of the 'detective story' is interwoven into the novel's narrative poetics to increase reader involvement by identifying with the investigator and confusing the roles of the writer and the detective. New York detective fiction, such as Paul Auster's City of Glass (1990 [1985]), illustrates the "continuity between the activities of writing and investigating" (Sorapure 1995: 72). The same phenomenon is rewritten in the novel when Henry, like a detective, investigates and writes reports about ethnic fellows. As a quote of City of Glass (1985) explains, "the detective is one who looks, who listens, who moves through this morass of objects and events in search of the thought, the idea that will pull all these things together and make sense of them. In effect, the writer and the detective are interchangeable" (Auster 1990: 9 [1985]). Whereas a character called 'Paul Auster' becomes the detective by accident, Lelia's nickname is pronounced like the author's last name ('Lee'). Moreover, a metafictional comment about Henry writing a crime novel about John Kwang in New York, the "city of novelists" (NAS 83), correlates with Ralph Ellison's reference to the writing process of Invisible Man (1952).

Irony and parody are effective tools for questioning genre distinctions because the unconventional 'spy novel' features an 'anti-hero' and reworks the clichés of the 'classic' spy thriller genre, showing both parallels and variations of conventional spy stories (Xiaojing 2005: 23). The 'archetypical' spy is associated with a smart white male political agent who fights in secret missions for his country's continued wellbeing. Being familiar with every means of deception, from linguistic fluency, state-of-the-art technology to killing, a country trusts and relies on secret agents. Whereas Ian Fleming's British MI6 agent James Bond is portrayed as a smart woman magnet who speaks several languages, masters his gun, and saves the world from evil, Henry and his fellow 'ethnic spies' are not well-trained and "knew nothing of weaponry, torture, psychological warfare, extortion, electronics" (NAS 15). The 'antiheroic protagonist' Henry (Chen 2005a: 253) is spooked by guns (NAS 15) and does not even master the English language properly in the eyes of the American standard-bearer.

Incorporating this act of spying in different forms enables the novel to assess and question genre distinctions (Chen 2005b: 153). Henry's description of the job at Glimmer \& Company functions as a telling example: "We pledge allegiance to no government. We weren't ourselves political creatures. We weren't

47 For more information on the significance of the novel's ending, see section 6.2 .5 on the 'Interethnic Imagination.' 
patriots. Even less, heroes" (NAS 15). This parody of the common conception of secret agents (Chen 2005b: 158) aims at highlighting the difficult socio-political position and integration of Asian Americans. The author himself explains his strategy as the following: "I purposely tried to work outside the genre conventions in exploring an immigrant / outsider consciousness" (Lee 2004: 217). This simile of comparing an immigrant to a spy works on a metaphoric as well as on narrative level. By showing the similarities and differences of a conventional spy and the public conception of Asian Americans, American immigration policy and cultural politics are examined. The novel thus rewrites not only the spy thriller genre, but also the convention of the Asian American immigrant and immigrants per se.

The resonance of Lee's narrative strategy to portray Asian Americans as spies is biased because some critics are disappointed in Henry's role and how readers are forced into imagining Korean Americans as 'traitors' (Yoo 2005: 59). The Chinese American writer Maxine Hong Kingston faced similar criticism when comparing Chinese Americans to ghosts in her novel The Woman Warrior: Memoirs of a Girlhood Among Ghosts (1976), resulting in strong criticism and boycotts.

Compatible to ethnic spies employed by Hoagland's Glimmer \& Company who are asked to spy on 'their own kind,' ethnic writers usually write about their ethnicity. This publication strategy aims at the optimal reader's consumption on the ethnically labeled book market, forcing writers "to turn into 'business people,' cashing in on their ethnicities" (Rhee 2011: 160). Thus, when writing a story about an 'ethnic spy,' the author can also easily turn into an 'ethnic spy.' Most critics, however, claim that Lee's spy novel is a success (Chang 2010: 147) because "by simply casting the Asian American as a spy, Lee has put a door in the wall between the genres of immigrant fiction and spy fiction" (Huang 2010: 2). In this self-reflexive form of writing, the writer makes categorization processes transparent. This narrative strategy may serve as a role model for further minorities and their literary discussions of an individual's identity in interaction with American society.

As most ethnic communities in America, Asian Americans are subject to specific, homogenizing group categorizations. Individuals from different Asian destinations gain their shared experience when immigrating to America (Lim et al 2006: 4). Due to this labeling process, recognition of the variety of Asian cultures is ignored and intra-Asian individuality is neglected. The collective definition 'Asian Americans,' however, was helpful in the 1960s and 1970s to form a political coalition (Ty et al 2004: 1) similar to that of African Americans fighting segregation. In literary studies and on the literary market, these labeling process- 
es (Chae 2008: 32) have been applied to counteract the American panic resulting from various issues such as labor force competition or another military attack like Pearl Harbor (Wu 1982: 1).

In the novel, the expression 'Yellow Peril' is addressed and reworked ironically to reveal the term's artificiality. The politically-incorrect phrase refers to the color logic accompanying the white-and-black divide. The term dates back to the nineteenth and twentieth century, linked to 'the Asian threat,' a strong fear of East Asians or so-called 'Orientals' at that time. Whereas the expression 'Yellow peril' was first associated only with Chinese immigrants and boosted by the Chinese Exclusion Act of 1882, it soon became associated with further Asian cultures, such as the Japanese after the attack on Pearl Harbor. This strong antiChinese sentiment lead to the formation of segregated Chinatowns, such as in San Francisco (Wu 1982: 2f.). Henry finds relief on "the streets of the city" (NAS 12f.) and eventually identifies with the list of character traits that his wife left behind, including the 'Yellow Peril'. In a run-down bar in East New York, he provocatively asks some grunge guests to call him 'The Yerrow Pelir' (NAS 13; italics original), thereby mocking how an Asian would stereotypically pronounce the term by deliberately switching the consonants ' 1 ' and 'r.' To emphasize the artificiality of the label, the guests of the bar toast Henry with a drink named the same, a significantly colorful mixture of white wine and yellowlooking Galliano.

Following the Watts Riots in the mid-1960s, being the 'model minority' emerged as a binary in particular in comparison to African Americans, which is also addressed and questioned in the novel. The term's first appearance in print referred to Asian Americans as 'America's greatest success story' and the 'superminority' (Wu 2002: 41; Rhee 2011: 159). From that point on, Asian Americans were stigmatized as the 'model minority,' often feeling obliged to internalize and fulfill this vision (Huang 2006: 246). The press encouraged this image by publishing articles on the ethnic group's "achievement, financial success, and low crime rate of this 'trophy population' relative to the statistics of blacks and other purportedly failing communities" (Wu 2002: 41; Rhee 2011: 159). This cliché is addressed in the novel when Kwang explains to Henry: "This is the challenge for us Asians in America. How do you say no to what seems like a compliment? From the very start we don't wish to be rude or inconsiderate. So we stay silent in our guises" (NAS 180).

Moreover, the novel manages to show similarities between different ethnic pigeonholing processes. Most importantly, Asian American 'amiability' is compared to Ralph Ellison's famous notion of African American 'invisibility,' thereby showing parallels of suffering and facilitating understanding. Ellison's Invisi- 
ble Man (1952) ${ }^{48}$ is considered "a masterpiece of African American literature" (Kim 2003: 231). It is partly staged in New York in the 1950s and deals with an African American who "is visible as a feature of the landscape but invisible as a subject" (Wirth-Nesher 1996: 105). Ellison's work is considered "the American story of invisibility, observance, and 'critical voyeurism"" (Moraru 2009: 79; emphasis original). This concept of 'racial invisibility' portrayed in African American fiction (Chen 2005a: 259) serves as a paradigm of the ethnic global city novel's literary and cultural criticism.

The global city novel is a 'reimagination' (Kim 2003: 231) of Ralph Ellison's analysis and criticism of invisibility, yet portraying "another kind of invisible man: the Asian immigrant in America" (Hong 1995: 236, Chen 2005a: 259):

And yet you may know me. I am an amiable man, I can be most personable, if not charming, and whatever I possess in this life is more or less the result of a talent I have for making you feel good about yourself when you are with me. In this sense I am not a seducer. I am hardly seen. I won't speak untruths to you (...) Then I fuel the fire of your most secret vanity. (NAS 6; emphasis added)

An 'interethnic coalition' is formed by comparing Asian American suffering to Ellison's renowned example, highlighting the parallels of societal pressures when integrating. Although the two literary pieces are almost five decades apart, both, Henry's "I am an amiable man" (NAS 6) and Ellison's "I am an invisible man," refer to ethnic clichés inherent in American society, illustrating an immigrant's struggle in New York. Being 'amiable' is one of the Asian American narratives that are enacted repeatedly in literary and cultural studies (Chen 2005b: $\mathrm{xvi}$ ), translating into the myth of being always kind, friendly, and commonly regarded as America's silent 'model minority.' Ellison focuses on the similar pigeonholing of African Americans as 'invisible' when others refuse to see or acknowledge them. The novel's recurring theme of the transethnic problem of being a 'visible minority' and 'invisible' at the same time creates a common immigrant history that is of significance for Asian Americans, African Ameri-

48 Ralph Ellison begins his novel Invisible Man with the following, similar-sounding lines: "I am an invisible man. No, I am not a spook like those who haunted Edgar Allan Poe; nor am I one of your Hollywood-movie ectoplasms. I am a man of substance, of flesh and bone, fiber and liquids - and I might even be said to possess a mind. I am invisible, understand, simply because people refuse to see me" (Ellison 1952: Prologue). 
cans, and other 'visible' minorities. This interethnic comparison signifies a literary reconciliation of Korean Americans and African Americans at a time that is fueled by severe conflicts between the two major minority groups.

The novel repeatedly examines how labeling processes impact an immigrant's role in society. In Ellison's work, invisibility, presupposing an act of not being seen, is two-fold: an individual's personal feeling of invisibility and the effect of being invisible to others. Likewise, multiple perspectives of invisibility are introduced in the global city novel, where "the invisibility of the spy coincides with the in/visibility of race" (Chen 2005a: 255). This strategy is used to illustrate the similarities of the spy's border-position and the marginalized position of the immigrant. Similar to Ellison's character, Henry "suffers from the refusal of others to see him" (Chen 2005a: 249).

This invisibility, however, is partly 'self-imposed' (Moraru 2009: 87) because Henry has "always known that moment of disappearance" and believed that he could go unseen and anywhere he wished (NAS 188). When growing up, Henry recognized his invisibility in his father's grocery store: “They didn't look at me. I was a comely shadow who didn't threaten them" (NAS 49; italics added). This "history of self-effacement" (Chen 2005b: 162) and being "the obedient, soft-spoken son" (NAS 188) facilitate Henry's profession as a spy. Thus, invisibility can be useful because Henry's ability to be 'hardly seen' (NAS 6) as part of "the invisible Asian Other in American society" (Chen 2005a: 255) enables him to become invisible.

Henry's continuous state of ambivalence, fragmentation, and multiple identities results in "the dissolution of self-coherence" (Chen 2005a: 250) when his constant acts of impersonation destroy his authenticity, resulting in a loss of license. Henry states that "I had always thought that I could be anyone, perhaps several anyones at once" (NAS 118). When Henry investigates Dr. Emile Luzan as a mock patient, the psychiatrist examines his split personality. Luzan's name and profession strongly resonate with the renowned psychoanalytic Jacques Lacan, who explained the concept of 'otherness' by arguing that self-consciousness precedes identification of 'the other.' The 'analysand' (Culler 2000: 128) plays a major role in psychoanalysis and, similarly, Luzan is of major significance for Henry's character development. When Luzan asks Henry "Who, my young friend, have you been all your life?" (NAS 191), the psychiatrist diagnoses Henry becoming "inconsistently schizophrenic" (NAS 22) because, due to his profession as a spy, Henry cannot distinguish between different roles anymore.

In the end, Henry questions whether invisibility is what he longed for (NAS 188). The process of making oneself invisible can be compared to post-colonial 'mimicry' because, as a spy at Glimmer \& Company, he believed he had found 
his "truest place in culture" (NAS 18). Mimicry, a function of hybridity, is used as a strategy including masking, deformation, and inversion (Bhabha 1994: 120), supported by stereotypes, jokes, and clichés. Henry had been trained for this 'masquerade' when his father asked him to speak English to his customers. Thus, whereas Ellison's visibility translates into performing "the white man's version of the black self" (Wirth-Nesher 1996: 204), Lee's invisibility translates into performing the white man's version of the Asian self. When Henry eventually realizes that his pretended integration is only effective through betrayal and it is impossible to assimilate through spying, he acknowledges his 'inbetweenness' or being "less than one and double" (Bhabha 1994: 166). The novel then functions as a 'therapeutic narrative' (Kim 2003: 235) when Henry manages to cope with his son's death, his wife leaving him, and his performance of role play.

Henry's profession symbolizes the attempt to assimilate by betraying his own ethnicity (Chen 2005a: 249f.). His act of spying on "co-ethnic targets" (Chang 2010: 142) thus "metaphorically adds a new level to our understanding of what immigrants do for their adopted country" (Dwyer 1999: 74). How the imagined global city of New York functions as the immigrant city representative of American society as a whole is examined in the next section.

\subsubsection{The Immigrant City}

Still I love it here. I love these streets lined with big American sedans and livery cars and vans. I love the early morning storefronts opening up one by one, shopkeepers talking as they crank their awnings down. I love how the Spanish disco thumps out from windows, and how the people propped halfway out still jiggle and dance in the sill and frame. I follow the strolling Saturday families of brightly wrapped Hindus and then the black-clad Hasidim, and step into all the old churches that were once German and then Korean and are now Vietnamese. And I love the brief Queens sunlight at the end of the day, the warm lamp always reaching through the westward tops of that magnificent city.

(NAS 321) 
Describing a scene in Flushing, Queens, this quote functions as a "rhapsodic tribute to the multicultural city of New York" (Rody 2009:81), inspired by the famous New Yorker Walt Whitman, a true "celebrator of the City" (Raleigh 1968: 313). In the novel, the urban space of New York is poetically imagined "as a quintessentially immigrant city" (Waldinger 1996: 349). The city's spatial and cultural heterogeneity is repeatedly portrayed in linguistic terms, described as the interdependence of ethnic diversity and urban complexity with 'cognitive mapping' (Herman 2002: 282). Renowned incidents of American ethnic turmoil are interwoven into the imagined global city of New York, highlighting the city's significance as a site of identity struggle. And, as the long-lasting, exclusive destination for American immigrants, the global city and its diversity are depicted as emblematic for American society as a whole.

Lee's Native Speaker (1995) is of major significance for urban, ethnic, and literary studies because it is "one of the first Korean American fictions" to employ and engage in 'the urban multiculture' (Rody 2009: 70). Ethnic diversity is communicated through the global city's 'chronotope' (Bakhtin 1981: 84) and "the heterogeneous urban crowd" (Rody 2009: 81) is conveyed through careful visual and acoustic sensuality. The quote at the beginning of this section, for example, translates into color and sound how the appearance of the city and its public space changes with the arrival of new immigrants. The quote's German church that turned into a Korean one and is now Vietnamese, for example, illustrates how the meaning of places is altered by new cultural influences. Similar to Brand's What We All Long For (2005), the phenomenon of gentrification is depicted by showing how different immigrant groups change the global city's appearance.

The novel borrows several elements of Whitman's celebrated literary technique, thereby creating a similar sense of ethnic pluralism and democracy. Considered a 'poetic genius,' Whitman has exerted an immense impact on the development of American poetry (Pickering 1977: 48). Whitman's particular fascination with the city of New York is expressed in the section Mannahatta in his Leaves of Grass (1855), among others, carefully cataloguing the defining elements of the city, such as islands, streets, high-rise buildings, houses, and arriving immigrants (Moraru 2009: 85). In the novel, similar to Whitman's description of day and night (Whelan 1992: 25), for example, the city's complexity is observed as a diversity of street activities from 'early morning' to 'the end of the day' (NAS 321).

The intertextual and intervocal references to Whitman's themes of universalism emphasize that cultural diversity constitutes a vital part of New York's urban character and identity. As an "archdemocrat and humanitarian reformer" 
(Pickering 1977: 46), Whitman recognized America's 'plural body politic' (Moraru 2009: 85). Encompassing the multiple perspectives of the young and old, female and male, or anonymous and popular (Whelan 1992: 25), his renowned 'I-narration' became "the representative figure of humanity" (Corley 2004: 73). The repetitive employment of Whitman's multi-perspectival 'I' in the section's main quote resembles a similar intimate connection with the city. While Whitman's 'I' alternates "between I-as-witness and I-as-Other" (Whelan 1992: 25), both, the emotional expression 'I love' and the spatial dynamic 'I follow' correspond to this technique. With this narrative strategy, "Whitman's heritage of representative Americanness" is modified and expanded to take the immigrant experience into account (Corley 2004: 74). With the novel's poetic description of the different colors, clothes, and customs in the above-mentioned quote, the coexistence of a variety of religions and cultures is introduced in a democratic, egalitarian manner.

The imagined New York is depicted as an important cultural node in the global network, shifting the focus to the global city as a distinguished cultural 'contact zone' (Pratt 1992) in a globe-encompassing network of flows. The anaphora 'I love' as well as the quote concluding with "that magnificent city" (NAS 321) serve as a Whitmanian declaration of love for New York, thereby turning the novel's author into a similar "man of the city" (Corley 2004: 73). In the novel, Queens instead of Whitman's Manhattan becomes the prominent example of the city's cultural diversity because in 1990, 36.2 percent of Queens's residents are foreign-born in contrast to Manhattan's 25.8 percent (Abu-Lughod 1999: 303). The steady flow of immigrants since Whitman's poem changed the city and turned Queens into an important meeting ground for immigrants in general and Korean Americans in particular.

In the novel, 'cognitive mapping' (Herman 2002: 282) is used to describe a character's movement in space, thereby implying a character's relationship to space and the people living and shaping a particular place. Henry and Lelia, for example, are constantly on the move when experiencing the city: "It seems to us right now that if we stop moving, we die. We take the subway to parts of the city we've never been to and walk the neighborhoods for hours" (NAS 262). Similar to the portrayal of the subway as a cultural contact zone in What We All Long For (2005), the subway is a door to different worlds in Native Speaker (1995). Taking the subway and processing conveys improvement and development. This forced movement ("if we stop moving, we die" (NAS 262)) involves a compulsory 'time-space compression' (Harvey 1989) in which motion verbs are a basic element for the mapping of dynamic spaces. This technique translates a charac- 
ter's dynamic movement in urban space into globalization and its effects, such as shifting geographies and accelerated cross-cultural flows.

How the novel's characters move in the city space also reveals their relationship to the diverse immigrant groups. Instead of conquering the city, Henry and Lelia cherish its diversity as a miniature 'World.' The couple experiences the city by wandering through the streets, treasuring "what the people have brought with them or are bringing in now, to sell to the natives: Honduran back scratchers, Polish mothballs, Flip Flops from every nation in the Pacific Rim" (NAS 262). The significance of New York as the paradigmatic American immigrant city is emphasized by the depiction of miniature Statues of Liberty. As emblematic symbols of the American dream, "each of these national and international icons maintains a dual life as representative instances of material and political connections between New York and a global urban community" (Corley 2004: 68). Thus, similar to Toronto's Kensington Market in Brand's What We All Long For (2005), grassroots culture on the streets turns the particular urban space into a global marketplace. Moreover, Henry's father greeting visitors from Korea who are "hopeful of good commerce here in America" (NAS 56) at the airport, the 'non-place' (Augé 2008) per se, shows that the literary New York functions as a global hub for world-wide business, migration and transmigration.

Ethnic clusters are incorporated in the global city novel to illustrate how ethnic groups, such as Korean Americans and Hispanics, share the same public space or how others, as in the case of Korean and African Americans, are avoiding joint public encounters. When Henry and his family played soccer in Westchester, significantly, "somehow, there were rarely white people in the park, never groups of their families" (NAS 46). The fact that "once, they even played some black men" (NAS 46) illustrates how rare interactions between the two ethnic groups are. This comment foretells the severe ethnic conflict between Korean and African Americans that is depicted later in the novel.

The idea of 'upward mobility,' a significant element of the American dream, attracting immigrants of different ethnic background, is employed in the novel to analyze the socio-spatial possibilities of Korean and African Americans. Immigrants, often considered 'ethnic entrepreneurs,' are claimed to be 'entrepreneurs because they are ethnic" (Chang 2010: 23; emphasis original). Korean-run, small, family businesses function as a prominent example because they offer the possibility to simultaneously protect the Korean culture while fulfilling the American dream (Park 2005: 294). Korean grocery stores are thus a means of economic independence and symbols of improving social status and political integration. Ethnic upward mobility, however, constitutes a form of segregation because Korean American ethnicity functions as a 'commodity' for 'class privi- 
lege' (Chang 2010: 136), resulting in a projection of hatred by less privileged ethnicities. Therefore, Henry's father owning different vegetable stores in the Bronx exemplifies how Koreans, as the 'model minority,' are expected to be shopkeepers in poor African American neighborhoods.

This pressure of assimilating is displayed ironically when Henry muses about his family's socio-political integration as Korean grocers: "We believed in anything American, in impressing Americans, in making money, polishing apples in the dead of night, perfectly pressed pants, perfect credit, being perfect, shooting black people, watching our stores and offices burn down to the ground" (NAS 48). The quote's introductory 'inclusive we' illustrates how Koreans are expected to integrate as the designated model minority. As a result, Asian Americans internalizing racism towards African Americans becomes an integral part of the assimilation process. This internalization explains why poor African American customers feel discriminated and displaced by Koreans.

The restaging of the literary clash of Korean and African Americans in New York is no coincidence because both ethnic groups are intertwined with the city's history. In 2000, African and Korean Americans each made up 12 percent of New York's foreign-born (Sabagh et al 2003: 107f.). The Korean War boosted Korean immigration to New York, and in the 1990 census, Korean-born residents of New York are ranked the seventh largest immigrant group arriving after 1964 (Foner 2000: 11). America's second-largest Korean community is thus now based in New York (Park 2005: 282).

The mutual brutality of African and Korean Americans was the expression of an ethnic class triangular, resulting from the 'sandwich position' of Korean Americans who are 'intermediaries' with regard to ethnic class, being "disadvantaged under whites, but advantaged over blacks" and "scapegoats of black-white tensions" (Chang 2010: 162). Thus, hatred and stereotypes are projected onto the two ethnic groups by each other. Cultural stigmatization and the "fracturing of class spheres" was one of the causes of the Los Angeles 1992 riots (Chang 2010: 140). The reason for this fracturing is the 'culturalization' of Koreans as small business owners who run their shops in predominantly African American neighborhoods. This very effect is claimed by many historians to have caused the L.A. Riots.

The Los Angeles riots are recaptured in the novel to explain the clash between Korean and African Americans. During the five-day, so-called Rodney King riot in Los Angeles in April 1992, 700 businesses were damaged, 9,500 individuals were arrested, 2,383 injured, and 45 killed (Halle et al 2003a: 342). The boycott of Korean grocery stores resulted in violence, arson, and several deaths. Known characters appear in the novel with similar names and stories 
(NAS 180f.). The novel's depiction of Saranda Harlans echoes Latasha Harlins of the L.A. Riots, a fifteen-year-old African American girl shot and killed by a Korean-store-owner Edward Song Lee. This event caused the riots in the novel and is considered one of the incidents that caused the L.A. riots. The method of describing the atmosphere in brief sentences, as in "they had multiple boycotts to cover. Vandalism. Street-filling crowds of chanting blacks. Heavily armed Koreans. Fires in the night" (NAS 179), further highlights the drama of the events.

The competitive clash of the two minorities is further encouraged by Mayor De Roos, Mayor Giuliani's literary character. De Roos' best ally is the African American police commissioner Roy Chillingsworth who, as his name gives away, "had a reputation for being tough on drug dealers and gangs and illegal immigration" (NAS 168). He naturally allies with his community, thereby fueling anti-Korean sentiment. Thus, De Roos and the police campaign against Kwang, who represents Asian Americans and Latinos. Consequently, Korean grocers are boycotted by "a mostly black crowd, watched over by a handful of police, looted and arsoned" (NAS 167).

In a literary 'time-space compression' (Harvey 1989), the novel fictionalizes the 1992 L.A. Riots and several further historical incidents involving different ethnicities in American urban areas from the 1960s to the mid-1990s. In literature, heterogeneous spaces are put together to change the meaning of existing spaces (Hallet et al 2009: 14). Historical and current events at the time of the novel's creation are interwoven to highlight the city's significance as a site of identity struggle and to mirror the atmosphere of New York City in the 1990s, better known as 'Giuliani time.' This period became "the legacy of immigrant and racial minority scapegoating" (Corley 2004: 75) because Giuliani strictly campaigned against illegal immigration. The immigrant tragedy of the 'Golden Venture' is retold in the novel (NAS 229). Hundreds of illegal Chinese immigrants were shipwrecked and several died close to the New York City coast while trying to fulfill their 'American dream,' showing how they risked their lives for prosperity. The survivors, however, were imprisoned and sent back to China.

Similar to Dos Passos' Manhattan Transfer (1925), an instrument of social commentary at its time (Gelfant 1970), the global city novel implicitly and explicitly criticizes the political rhetoric of New York in the 1990s, when the city's minorities, and African and Korean Americans in particular, did not share a common sense of civic identity. In 1994, one year before the novel's publication, Giuliani became Mayor of New York. Hoagland, Henry's boss at Glimmer \& Company, keeps the mayor's picture in his office, thereby highlighting the significance of 'Giuliani time' (Corley 2004: 67). 
Dennis Hoagland's multiethnic spy agency Glimmer \& Company functions as a simile of U.S. cultural politics. The company was founded in the 1970s, a time of "immense racial unrest and cultural nationalism" (Rhee 2011: 160) when the new immigrant wave reached its peak. Hoagland, called "the cultural dispatcher" (NAS 18), compares his agency with the CIA. He teaches his ethnic spies to 'assimilate' by adapting to their surroundings in an act of camouflage: "Just stay in the background. Be unapparent and flat. Speak enough so they can hear your voice and come to trust it, but no more" (NAS 40). This explanation echoes stereotypical notions of the 'model minority' or the 'good immigrant,' who is asked to integrate by matching particular ideals of ethnic group categorizations.

The work as a spy at Glimmer \& Company is an allegory to "what immigrants do for their adopted country" (Dwyer 1999: 74). Henry and his coworkers Jack Kalantzakos and Pete Ichibata call each other "business people" who are "determined by some calculus of power and money. Political force" (NAS 15). Thus, a role is cast for Henry and his colleagues who betray their own to be successful. Henry's assignment within his cultural group equals the creation and enforcement of ethnic clusters in American politics. When Henry quits his job later in the novel, he thereby revolts against his assigned role in society and rejects an immigrant's wholesale assimilation.

It is the novel's literary strategy to reconcile Asian and African Americans in a time of particular interethnic difficulty. Kwang argues that the aggression between the two ethnic groups is a natural consequence, "a race war everyone can live with. Blacks and Koreans somehow seem meant for trouble in America. It was long coming" (NAS 168). The novel explains how the projection of selfhatred caused by internalized racism leads to this scenario. How Kwang tries to achieve political representation of all immigrants in New York and Henry is "working (unwittingly) against it" (Lee 2004: 348) are elaborated in the following section on the 'Interethnic Imagination.' 


\subsubsection{Interethnic Imagination}

They were of all kinds, these streaming and working and dealing, these various platoons of Koreans, Indians, Vietnamese, Haitians, Columbians, Nigerians, these brown and yellow whatevers, whoevers, countless unheard nobodies (...).

John Kwang's people.

(NAS 77)

An 'interethnic imagination' (Rody 2009) is the visionary understanding and cooperation beyond interethnic constraints that manages to show, as in the case of Lee's Native Speaker, how “an Asian American novel can represent and serve all the people, without losing its sense of history and identity" (Rody 2009: 85). With the novel's creation of a 'political vernacular' and a 'literary vernacular' (Kim 2003: 253), a coalition of different ethnic groups in New York seems possible on a linguistic and political level. Analogous to Brand's What We All Long For (2005), Lee's Native Speaker (1995) presents a form of 'panethnic movement' (Ty et al 2009) by concentrating "on how Asian Americans are positioned not only in relation to a white majority but also to other immigrant groups and African Americans" (Kim 2003: 233). Whereas Toronto is imagined as a multiperspectival portrayal of ethnically diverse friends and their different, yet often similar, experiences in the city, New York is imagined from an Asian American perspective that simultaneously portrays the city's diverse cultures and the immigrants' sometimes antagonizing, yet often common experiences.

The vision of 'multiethnic coalition-building' (Song 2005: 185) is personified by John Kwang, who is depicted as "a great ethnic American civic ideal" (Rody 2009: 66). The charismatic politician is unifying ethnic groups not only through language, but also as a father figure, extending the Korean family value and financial support. His initials bear a resemblance to the former American president John F. Kennedy (Ludwig 2007: 227), and he has an equally charismatic appearance, looking "impressive on television. Handsome, irreproachable. Silver around the edges. A little unbeatable" (NAS 21). The scene when Kwang is shot is reminiscent of JFK's assassination (Ludwig 2007: 228). Similarly, Kwang is the "underdog champion" of the political race (NAS 130), having a "truly American vision" (Dwyer 1999: 76) because he is not only seizing the opportunity for himself but for the whole immigrant community. This employment of a "narrative of a political ascendancy" is uncommon in Asian American litera- 
ture or immigrant novels, which usually focus on the domestic sphere (Huang 2006: 243). The novel thus becomes a modern form of urban ethnic literature, incorporating politics of the growing ethnically diverse American population (Kim 2003: 233).

The politician relies on his 'multilingual capacities' (Huang 2006: 252) and on his ability to unite people of different background by articulating their similar past and shared present. As illustrated in the section's quote, Kwang succeeds in giving 'unheard nobodies' a common minority vernacular. Therefore, the different immigrant groups identify themselves as "John Kwang's people" ( $N A S$ 77). The community leader can adapt his speech to include all voices of New York City, "unafraid to speak the language like a Puritan, and like a Chinaman, and like every boat person in between" (NAS 283). Kwang greets "his citizens in Spanish, Hindi, Mandarin, Thai, Portuguese" (NAS 251). He is aware of the cultural differences of 'his citizens' and respects them by speaking their language. By raising his voice for immigrants of different ethnic background, "Kwang gives voice to a much-neglected segment of New York's populace" in which "the invisible is made visible as well as the fragmented made coherent" (Huang 2006: 250f.). As "the living voice of the city" (NAS 304), Kwang represents "groups whose voicelessness is as much the result of verbal diffidence from within as an imposed silence from without" (Huang 2006: 251). Kwang thus linguistically and spatially becomes a vital part of the city because "he is the language now" and "the buildings and streets are written with him" (NAS 157).

With the extension of the Korean family value, Kwang manages to address an audience that goes beyond ethnic boundaries. The respected leader is "willing to speak and act outside the tight sphere of family" (NAS 129), thereby creating an integrated community model, including the whole district of Queens. As the above-mentioned quote illustrates, Kwang's people are catalogued in a Whitmanian democratic fashion. Kwang thereby promotes 'ethnic fellowship' (Kim 2003: 238) for everyone ('all of us') because it is his dream to unite "all kinds of people" (NAS 164), regardless of social standing. Despite not having many white (NAS 133) or African American followers, the politician was not only supported by Koreans and Chinese but also "did exceedingly well with the newer immigrants, the Southeast Asians and Indians, the Central Americans, and blacks from the Caribbean and West Indies. Some Eastern Europeans" (NAS 132f.). Therefore, his staff greets the voters in many different languages, repeatedly convincing them that "Kwang is like you. You will be an American" (NAS 133; emphasis original).

Kwang's key to success is the combination of "superior oratorical talent" (Huang 2006: 249) and extraordinary spatial mobility. He "wanders the streets, 
listens to the city's idiolectal hustle and bustle, and in turn becomes part of this 'marginal English' (NAS 270)" (Moraru 2009: 86). He creates intimacy with his down-to-earth open-door policy of the neighborhood council (NAS 164). To reach his goal, Kwang conducts "street-level urban politics" (NAS 164), walking from door to door, thereby extending his spatial impact, knowing and drawing on the shifting ethnic composition of the city because in Flushing, the ethnicallydiverse district of Queens, "the landscape is changing. Soon there will be more brown and yellow than black and white" (NAS 183).

The imagined urban space mirrors identity politics, in particular when portraying Kwang, who is often pictured as walking the streets. His staff "went straight out to the streets" (NAS 80). Thus, Henry, called "young Harry of the City" by Hoagland (NAS 35, emphasis original), is "scouting the neighborhoods" (NAS 91) for interview hot spots or photo options, such as the Manhattan skyline (NAS 81). This assignment functions as another allegory to Henry's profession as a spy because his mapping of the city to make space accessible for Kwang translates into inspecting, investigating, or surveying, going beyond a mere description of the city. When speaking to and for different minorities of the city, Kwang transcends specific designated space. He transgresses ethnic borders by speaking to Hispanics in Washington Heights and meeting African American church leaders in Brooklyn (NAS 78). Thus, in contrast to Henry's father, Kwang does not accept his socially (pre)determined ethnic space but is ambitious and not afraid to expand his business or political campaign beyond the reach of Korean American influence in New York (NAS 170).

Kwang's most ambitious mission is the reconciliation of Korean and African Americans in a period of strong anti-immigrant sentiment because "his sympathy for either side was a bias for one" (NAS 179). With his "rhetoric of unity in diversity" (Huang 2006: 254), Kwang stresses the similarities and interdependence of the two ethnic groups. When speaking to African Americans, he explains that the common "sadness and the pain and injustice, will always be stronger than our differences" (NAS 142). This form of 'group maintenance' (Song 2005: 178) is incorporated into his speeches, functioning as "a mediatory stance" (Huang 2006: 252). Kwang also shows parallels in African and Korean American suffering and their shared history as slaves (NAS 142). He also reminds Koreans that the social and political standing of the two groups is interconnected: "Know that the blacks who spend money in your store and help put food on your table and send your children to college" (NAS 142). He thus stresses the common difficulties of immigrants, creating empathy and a group identity.

Although no African American main protagonists are featured, the novel nevertheless frequently incorporates important elements of the culture. Besides 
the reference to Ellison's notion of African American invisibility, ${ }^{49}$ the New York politician is presented as an Asian version of the natural leader and great orator Martin Luther King. Historically, Asian Americans do not have popular charismatic leaders. Kwang is "manufactured to fill this void" (Kim 2003: 238), thus becoming "a figure previously unseen in the Asian American literary imagination" (Huang 2006: 245) as well as a figure previously rarely seen in the American political sphere. Moreover, although “African-Americans didn't seem to trust him" (NAS 133), Kwang identifies with the 1960s black power movement. In his political speeches, he makes clear that African Americans have been more prejudiced in America than any other ethnic group.

In his political campaign, Kwang constantly tries to negotiate between African and Korean Americans, diplomatically trying to not upset either group in the ethnic class triangular. When Kwang is asked to speak at events of the National Association for the Advancement of Colored People (NAACP), he realizes that it is a thin line between supporting immigrants and supporting African Americans: "If I mention the first thing about special enterprise zones or more openness towards immigrants I'm suddenly off limits. Or worse, I'm whitey's boy" (NAS 181) because, as Henry comments, "it's still a black-and-white world" (NAS 181), thereby criticizing "the dead-end of black-and-white configurations" (Ludwig 2007: 231). He also explains that the projection of racist prejudice and self-hate cause the violence and inter-ethnic racism (Cowart 2006: 119). This self-hatred is partly enforced by American society and its inherent racism because the feeling of inferiority is a result "of what we loathe and fear in ourselves" (NAS 141).

Kwang claiming more economic, linguistic, political, and public space than Asian Americans commonly do and his high level of social inclusion as a mayoral candidate who "speaks the language of cultural consent fluently" (Huang 2006: 254) pose a threat to Mayor De Roos and those who fear the powerful impact of an interethnic collaboration. Kwang is portrayed in the press as "someone who could bring a fresh face to confront the city's ills, a politician who could better understand the needs of the rapidly changing populace" (NAS 179). De Roos, on the contrary, is a person who does not care about certain parts of the city and thus about certain ethnic groups ( $N A S 140)$.

Kwang's public standing and influence decrease immediately when the INS reveals that the ggeh is supporting illegal immigrants of different nationalities. The INS, which has been secretly employing Henry and further Glimmer \&

49 For more information on the novel's intertextual reference to Ellison's Invisible Man, see section 7.2.3 on 'Amiable Man.' 
Company ethnic agents to investigate Kwang, reveals that the multi-ethnic financial support system ggeh is connected to the smuggling of illegal immigrants to New York. The "Korean money club" (NAS 260) supports incoming immigrants with money and a business network. To be part of this successful but unofficial financial network, newcomers donate money "for the right of knowing a someone in the city for you who are yet nobody" (NAS 258). Kwang expands this originally Korean support "to a supra-ethnic level" (Ludwig 2007: 229), representing an interethnic collaboration on a financial basis. Soon, the media compares the ggeh to the Mafia (Rhee 2011: 164). At the same time, a car accident exposes Kwang's controversial relationship with an illegal immigrant minor.

Due to his mistakes, Kwang is socially excluded, resulting in his loss of trust as a politician and community leader. He is stigmatized as 'Smuggler Kwang,' who supports illegal immigrants 'sneaking into the country' to steal jobs, by an angry mob marching on the streets of "angry white people and brown people and black people, and now even some yellow" (NAS 307f.). This scene illustrates the strong internalized racism of mainly white and African Americans towards immigrants, new arrivers, and illegal immigrants in particular, who are blamed for the unemployment rate among Americans.

The minority ethos of an interethnic imagination was possible in Lee's novel for a limited period of time. With Kwang's fall, the ideal vision of the interethnic imagination in the American metropolis failed. It is revealed that Kwang is "just another ethnic pol" (NAS 303) whose linguistic fluency and speaking skills cannot erase his foreignness (Corley 2004: 71). Kwang fails because he aims at representing (illegal) immigrants, the 'unrepresentable' (Lee 2004: 342) in American society. The tabloid supports Mayor De Roos, casting Kwang as a 'personae non grata' (Huang 2010: 141). As a response to Kwang's fall, De Roos, probably the client of Glimmer \& Company and thus a vital part of the conspiracy against Kwang, significantly argues that "everyone in this town has to follow the rules" (NAS 281).

Angry, drinking youth, mainly comprised of white males protesting against Kwang and carrying sings with "AMERICA FOR AMERICANS" (NAS 308; emphasis original), emphasize that Kwang will always remain a Korean immigrant in the public eye, thereby favoring "the old notion of a white, Eurocentric America" (Huang 2006: 261). As a crowd often represents a city (Lehan 1998: 8), the violent mob who asks Kwang to leave is a metonym for New York's socio-cultural politics at the time. That a small group of immigrants is nevertheless waiting for Kwang signifies a glimpse of hope. His economic and political success shows that 'American classlessness' is possible, breaking through "culturalized glass ceilings" (Chang 2010: 171). 
When Kwang fails, his linguistic, economic, and political influence instantly decreases while his literal 'space of influence' is reduced to his immediate surroundings. Kwang loses his aura, charisma, and voice when "perhaps for the first time in his public life he mumbles, his voice cracks, and even an accent sneaks through" (NAS 274). While his voice, once "strong and clear" (NAS 304), becomes weaker, his Korean accent returns and becomes stronger (NAS 277), revealing his immigrant background. He loses his confidence and his movement in space differs drastically. The man, who is now described as looking "old and weary" (NAS 273), appears to be "standing still" (NAS 273). He now looks and "responds like a man stopped on the streets" (NAS 273). Thus, from a dynamic man representative of a whole neighborhood, Kwang's spatial influence is reduced to an ordinary 'man on the streets,' translating into a standstill in social politics.

Due to John Kwang's failure and the resulting continuation of antiimmigrant racial politics in Giuliani time, the imagined global city of New York is portrayed as a rather static cityscape. Kwang's vision of an interethnic representation fails because "there is no room for such a figure in the story of American politics" (Huang 2010: 142). Kwang's rise and fall as an ethnic politician thus serves as a strategy to show that neither the city of New York nor American society are willing to accept his representation (Rhee 2011: 165).

By the end of the novel, however, a change of perspective has taken place, not in the wider public sphere but in a smaller setting. Henry has changed after befriending Kwang, questioning his designated role as an Asian American in society. Some critics nevertheless claim that Henry seems to be highly dependent on America's white middle-class ideal and has not changed in the end, but only whitened himself (Engles 1997), thereby illustrating that his "desire for solidity, belonging, and a 'true' identity remains (...) unfulfilled" (Chen 2005b: 183). Kwang's friendship essentially contributes to Henry's recovery process because as his relationship to Kwang impacts his effectiveness as a spy, Henry begins to question his position in society, calling it "my ugly immigrant's truth" (NAS 319f). He realizes that he has been instrumentalized, having exploited his own ethnicity (NAS 319f). Due to his past, however, Henry cannot stop playing roles. Thus, after the couple's reconciliation, Lelia makes use of his talent in a positive way by employing him as a 'Speech Monster' (NAS 323) in her ESL class, thereby serving "as a bridge between both worlds" (Yoo 2005: 58). Henry calling himself a 'Speech Monster' ironically refers to socially-determined 'imperfection.'

Moreover, in the course of the novel, the narrator-protagonist deconstructs the stereotypical view of Henry's wife, rewriting her colonizer role. Although 
she belongs to the middle-class, Lelia is open-minded and tolerant. Lelia is the one who accepts not only otherness, but also in-betweenness as well as cultural individuality, such as intra-Asian individuality. By the end of the novel, Lelia accepts linguistic variances when pronouncing the kid's foreign names in her English class carefully: "She calls out each one as best as she can, taking care of every last pitch and accent (...) calling all the difficult names of who we are" (NAS 324, emphasis added). The 'inclusive we' signifies Henry's acknowledgement of "the heterogeneous 'family' to which he knows he also belongs, that of the global, multiethnic city" (Rody 2009: 80f.). He is siding with immigrants now instead of spying on them, thereby accepting difference.

The novel's ending therefore manages to offer on a linguistic level what Kwang fails to realize on the political level: An interethnic imagination with various languages and identities. Lelia's acknowledgement of "a dozen lovely and native languages" (NAS 324) changes the constituencies of nativity, language, and identity. Now, Lelia, the designated standard bearer, allows further Englishes to (co)exist and underlines their political integration by calling the children 'citizens.' The novel thus stresses the fact "that the U.S. nation is dependent on acknowledging the heterogeneity of U.S. citizens both in political and literary terms" (Lim et al 2006: 18). Henry and his wife recognize the fact that "versions and voices have transformed New York into a polyloquial cosmopolis - the Babel of globalization" (Moraru 2009: 86). These multiple versions of 'colloquial' speech describe New York becoming a place of many different native languages in which each person's language - with or without accents - is acknowledged as a native language. This resembles a plea for individuality and authenticity, arguing against 'monocultural' conceptions and wholesale assimilation.

\subsection{INTERIM CONCLUSION}

In Chang-rae Lee's Native Speaker (1995), the global city of New York, its urban complexity and its ethnic diversity are chiefly imagined in linguistic terms. Thus, in addition to the poetics of narrative and place, the poetics of codeswitching represents the novel's crucial strategy. Therefore, New York becomes 'a city of words' (NAS 319) and is presented as a 'verbal cityscape' (Wirth Nesher 1996).

In the novel, ethnic diversity is portrayed with prose-like descriptions without drawing on voicing vernacular in a written form because 'showing' instead of 'telling' is the preferred technique when depicting the linguistic distinctiveness of the diverse immigrant groups. The polysemic title illustrates how lan- 
guage and conventions have the power to both marginalize and integrate, pinpointing the interrelated discussion of linguistic fluency, nativity, and social integration because the idea of being a 'native speaker' automatically brings up the possibility of a 'false speaker of language' and thus 'false identity' (Chen 2005b: 171).

To demonstrate how globality and diversity manifest themselves in the novel's structure and form, the immigrant novel, detective story, and spy thriller are reworked in a 'cross-genre' fashion (Huang 2010: 2). By rewriting Ralph Ellison's notion of African American 'invisibility' to Asian American 'amiability,' an immigrant's struggle for integration is examined, analyzing how narratological categories mirror particular forms of diversity and social integration processes in a globalizing age. Moreover, several elements of Walt Whitman's literary technique are reworked, thereby creating a similar sense of ethnic pluralism and democracy. With the application of this narrative strategy, a collaboration of the different minorities is formed on a literary level. Incorporating the act of spying as well as irony and parody enables the novel to rewrite genre distinctions and question ethnic framing. The protagonist's spying thus powerfully serves as a metaphor for an immigrant's political integration.

The global city of New York functions as the immigrant city representative of American society as a whole. Events of the 1992 L.A. riots and several further historical incidents involving different ethnicities in American urban areas from the 1960s to the mid-1990s are included to illustrate Korean and African American suffering as well as challenges of interethnic understanding as such. The global city novel thus criticizes the political rhetoric of 'Giuliani Time' and anti(illegal) immigrant sentiment. It is the novel's literary strategy to reconcile Asian and African Americans in this time of particular interethnic difficulty.

John Kwang, the Korean American mayoral candidate with immense linguistic skills, poses a threat to established politicians and the INS. He has the ability to unite the various voices of New York, trying to consolidate the interests of many ethnic groups while focusing on their similar history and the common opportunities and challenges of immigrants in America. His linguistic, political, and social sphere literally encompasses much more space than that of other Asian Americans in the city. He eventually fails due to own mistakes and investigations by Henry and other spies at Glimmer \& Co. Although Kwang's ambitions were doomed to fail, Henry has changed by the end of the novel, now questioning his designated role as an Asian American in society. By working as a 'Speech Monster' (NAS 323) in Lelia's ESL class, Henry finally accepts his 'linguistic imperfectness,' thereby moving towards the recognition of multiple linguistic and thus cultural affiliations. 
Both, Henry's role play and Kwang's rise and fall illustrate the possibilities and limitations of a New York immigrant in the 1990s, exploring the sociopolitical forms of an ethnicity's integration into American society. Literature thus becomes a creative laboratory for experimenting with different forms of minority representation and integration in a global city. Although the Asian American politician and polyethnic leader fails, his interethnic imagination of the global city of New York "is truer to the city than the protests of the (presumably) white Americans who want to claim it and America exclusively as their own" (Corley 2004: 68). The novel's engagement with 'the urban multiculture' (Rody 2009: 70) thus goes beyond mere Korean American studies: it is of significance for urban, ethnic, and literary studies as such. An Asian American politician representing a minority ethnos in the global city of New York in the 1990s nevertheless remains "a utopian dimension, a vision of hope" (Ludwig 2007: 239). 


\section{Karen Tei Yamashita's Los Angeles, Tropic of Orange}

\subsection{The Global City of Los Angeles}

The official slogan by the Los Angeles Times that "Los Angeles Brings It All Together" (Soja 1989: 191) captures the paradigmatic and mythological impact of the well-studied 'postmetropolis' (Soja 2000). Once founded on Mexican territory, Los Angeles turned into “one of the most 'Anglo' of all American metropolises" in the 1920s (Abu-Lughod 1999: 134) before it developed into a world city with "extraordinary demographic and cultural heterogeneity" (Soja 2000: 227) and the highest American rate of foreign-born population (33 percent) (Anisef et al 2003: 3). At the turn of the millennium, the global city was, and still is, due to its great ethnic diversity, both, the unofficial Mexican American capital (Ortiz 1996: 247) and the Third World capital (Rieff 1991).

Los Angeles serves as a prototype (Beauregard 2003: 7) of the modern global city (Sawhney 2002: 5). In terms of geography, infrastructure, and size, Los Angeles is considered a "fragmented metropolis par excellence" (Fogelson 1967: 2). The "great big freeway" (Beveridge et al 2003: 49) is the global city's nickname and governing structure, stressing the importance of the automobile. Arising from a desert, the city constantly boosted itself to become the entertainment center of the world (Sudjic 1992: 80). However, the global city's politics, economy, and cultural diversity also supported the development of ethnic clusters and gated communities, lead to it becoming the American homeless capital in the 1980s (Halle 2003: 12), and sparked one of the most violent American interethnic ruptures: the 1992 Los Angeles riots.

Los Angeles began to grow in the mid-nineteenth century when Toronto and New York have long been cities of regional or national importance. In 1835, Los Angeles officially became a city with around 1,000 residents, then still belonging to Mexico. With the Mexican-American War following the California gold rush, 
the city is controlled by Americans (Abu-Lughod 1999: 54f.). Once Los Angeles was connected to the railway network, the city began its development, soon becoming the most important American industrial city (Scott et al 1998: viii). Thus, from 1,000 residents in the mid-nineteenth century, Los Angeles's population exploded to more than 100,000 by the end of the nineteenth century (AbuLughod 1999: 139).

Similar to Toronto and New York, Los Angeles nowadays represents a "heterogeneous mosaic" comprised of various ethnicities of different residence tradition (Soja 2000: 283), quickly developing "from WASP hegemony toward the poly-ethnic diversity" it is characterized by today (Davis 1990: 7) ${ }^{50}$ Dominated by the Spanish language since its founding, Los Angeles became "overwhelmingly 'white' and native-born" by the beginning of the twentieth century (AbuLughod 1999: 134) when a majority of white middle-class Americans migrated from the Eastern states between 1870 and 1900, shaping suburban Los Angeles and its characteristic 'polycentric sprawl' (Soja 2000: 123). Besides the connection with the railroad, the oil-boom, the growing importance of the harbor, and marketing fostered the city's progress (Abu-Lughod 1999: 134ff.), soon establishing the motion picture, petroleum, and tourism industry (Soja 2000: 128).

Between 1900 and 1930, the population of Los Angeles and its counties grew ten-fold to more than 2.5 million (Abu-Lughod 1999: 142f.). Masses of Eastern and Southern Europeans migrated to the metropolis mainly in the 1920s (Davis 1990: 30). Moreover, following the stock-market crash in 1929, the so-called 'Dust Bowl migration' led to migration from the Southern states, including poor white and African Americans who settled in separate urban areas (Soja 2000: 131). Los Angeles was less affected by the Great Depression than New York (Abu-Lughod 1999: 163), offering better economic and social prospects for migrants and immigrants. To accommodate the rising number of residents, a reliable water supply was established, thereby facilitating the city's further growth and continuous development. In 1913, the California Aqueduct provided sufficient water for the region, its population, and industries (Soja 2000: 128), and the size of Los Angeles stretched ten-fold until 1930 through the annexation of new communities (Abu-Lughod 1999: 154f.).

By the 1960s, due to "racist public administration, housing codes, zoning practices, and police work," Los Angeles had turned into one of the American cities that was most segregated in ethnic, political, and geographic terms (Soja

50 The informal term 'WASP' is the abbreviation of 'White Anglo-Saxon Protestant.' It first appeared in the 1950s as a criticism of the elitist group of wealthy White Americans with an English Protestant background. 
2000: 139). Watts, for example, transformed from a mainly white to a largely African American neighborhood in the 1940s, and, after the war, more 'established' Jewish or Mexican immigrants performed the jobs formerly done by African Americans (Abu-Lughod 1999: 248f.). This segregation caused serious ethnic tensions, thereby sparking, among others, the 1965 Watts riots. During the six-day riots, Jewish stores in Los Angeles were destroyed, about 1,000 buildings damaged, 3,952 individuals arrested, 1,032 injured, and 34 killed (Halle et al 2003a: 342).

The period following the Immigration Act of 1965 can be regarded as a 'deWASPing' of Los Angeles and thus represents a reversal of the period between 1870 and 1900. In 1960, non-Hispanic whites still made up more than 80 percent of the city's population (Soja 2000: 136). After the Immigration Act, which stopped the so-called 'country-of-origin quotas' (Foner 2000: 23f.), massive immigrant waves changed Los Angeles (Soja 2000: 283). While before 1965 the city received fewer non-European immigrants than New York (Waldinger 1996: 1079), after the Act, Los Angeles became the leading immigrant destination and thus, it was home to about one fifth of all American immigrants by the end of the twentieth century (Soja 2000: 283)

Following the 1965 Hart-Celler Immigration Act, the foreign-born population of Los Angeles tripled until 1990 to a proportion of 33 percent (Sabagh et al 2003: 102), of which more than 50 percent were Mexican, El Salvadorian, or Guatemalan (Foner 2000: 10f.). Beginning in 1970, within only two decades, a major shift from an Anglo majority of 70 percent to a non-Anglo majority of 60 percent took place in the County of Los Angeles, transforming the white enclave in a Spanish-speaking region into "America's leading Third World metropolis" (Soja 2000: 141). Between 1980 and 1990 alone, two million immigrants arrived in Los Angeles, of which 40 percent were Mexican (Abu-Lughod 1999: 302). This was half a million more than the number of immigrants that arrived in New York within the same period.

In 1990, the Los Angeles population was 39 percent Latino or Hispanic, 14 percent African American and ten percent Asian. While the percentage of Asians remained the same, the proportion of Hispanic or Latino increased to 47 percent and African Americans decreased to eleven percent in 2000 (Halle et al 2003b: 158). Thus, whereas African Americans were a historically more significant foreign-born group in New York, Los Angeles had only about ten percent. This tenyear trend highlights the growing impact of the Spanish-speaking population in the global city, reconnecting the city to its Mexican roots. In 1990, 40 percent of Los Angelenos spoke a language other than English at home, which was ten per- 
cent more than in New York and, in Los Angeles, Spanish was spoken twice as often as in New York (Sabagh et al 2003: 103f.).

Los Angeles, a city with great Spanish influence from its founding and one that 'WASPed' and 'de-WASPed' itself in the course of its history, has again increasingly become a Mexican-influenced city (Waldinger 1996: 1079). In 1990, the 'unofficial Mexican America capital' (Ortiz 1996: 247) featured more than a third of the declared Mexican American population (4.7 out of 13.4 million) (Sabagh et al 2003: 105). In 2000, the proportion of Hispanics was more than 45 percent in Los Angeles, of which more than 80 percent was of Mexican origin (Beveridge et al 2003: 61f.), turning the city into "the world's largest Catholic archdiocese" (Soja 2000: 141). Besides the geographical proximity and better work opportunities, the effect of chain-migration furthers the growing number of Hispanics when ethnic networks facilitate investment and immigration (Keil 1998: 143).

Due to its Pacific Coast location and the relative proximity to Mexico and Asia in comparison to other North American cities, Latin Americans and Asians constitute the two most influential immigrant groups in Los Angeles (Halle 2003: 14). Asians in Los Angeles are of diverse background, of which Japanese constitute less than ten and Chinese 22 percent (Sabagh et al 2003: 107). Although immigrants to New York are the most ethnically diverse in America (Foner 2000: 10), compared to Los Angeles, the New York's Hispanic proportion of only 28 percent was much smaller and featured a different ethnic diversity with a majority of Caribbean and Central and South American origin and Mexicans representing the second to last group in size, with less than ten percent (Beveridge et al 2003: 61f.).

The massive increase of immigrants until 1990, to about four million foreign-born in Los Angeles within twenty years, was the most remarkable in the world, making the West Coast city the immigrant region in America (Sabagh et al 2003: 102f.). The new leading immigrant capital became a magnet of national and international migration (Foner 2000: 10f.). As the so-called 'Ellis Island of the Pacific century' (Sawhney 2002: 5), Los Angeles is now considered the most important contemporary destination for immigration to the United States. Thus, by the end of the twentieth century, the global city of Los Angeles is shaped by a "poly-ethnic and poly-lingual society - with Anglos a declining minority" (Davis 1990: 87f.).

Los Angeles, with almost 18 million citizens in the Greater Los Angeles Area, is "indisputably a global city" (Sawhney 2002: 5) and featured in the top ten of several global city hierarchies. Together with New York, Los Angeles is in the top tier of global cities, while Toronto follows up in second tier (Brenner et 
al 2006: 3). Whereas New York is cited every time and Toronto eleven times in a comprehensive study of "cities cited in world city research," Los Angeles is cited 13 out of 16 times (Taylor 2004: 40f.). Both, New York and Los Angeles are considered to be 'core primary cities' in the world city hierarchy (Friedmann 1986), significant nodes in the global city network, and America's 'leading immigrant destinations' (Waldinger 1996: 1078). In terms of 'global network connectivity,' Los Angeles is ranked ninth and New York second in the top ten world cities (Taylor 2004: 69).

Whereas New York, the classical haven for immigrants to America, fulfilled the criteria of a global city as early as the 1870s (Abu-Lughod 1999: 40), Los Angeles became a 'prototopos' (Soja 1989: 191) in the late twentieth century, functioning as a "prism of different spatialities" (Davis 1990: 84). Los Angeles is therefore referred to as the 'proto-postmodern city' (Dear et al 2002: 70, Löbbermann 2008: 263), operating as a model urban region. The development of the global city is intrinsically linked to globalization and its effects. The increase in world-wide migration from Asia and Latin America, for example, changed the city significantly and urbanization as such (Soja et al 1998: 3).

One of the distinguishing features of Los Angeles in comparison to New York and Toronto is the urban sprawl of the so-called "monstro-City" (Soja 2006: 181). Although New York and Los Angeles are the two most populous cities in America, the population of about four million Los Angeles residents in 2000 is roughly only half of New York's (Halle 2003: 1). The "hundred mile city" Los Angeles (Abu-Lughod 1999: 358; Sudjic 1992: 80), however, is extremely spread out geographically, with businesses and activities extending over a vast, decentralized hinterland (Halle 2003: 1). This structure of 'the postmetropolis' (Soja 2000) is, for the L.A. School of Urbanism exemplary for how cities developed in the twentieth century and are developing in the twenty-first century.

Although Los Angeles is not one of three examples used to coin the term 'global city' by Saskia Sassen (1991: 4), it is nevertheless considered the 'prototype' (Beauregard 2003: 7) of a modern global city. The Los Angeles School of Urbanism $^{51}$ emerged as a result of this uniqueness because the global city "seems to break every rule of urban readability and regularity" (Soja 2006: 181), being unlike previous prototypes such as Chicago and other leading world cities. Inspired by the 'Frankfurt School' (Davis 1990: 84) and developed in the mid1980s at the University of Southern California in Los Angles (UCLA) and be-

51 For more information on urban studies and the different schools of urbanism, see Chapter 3 on 'Global Cities as Cultural Nodal Points.' 
yond, the L.A. School functions as a counter-initiative to the dominant Chicago School of Urban Studies. Main scholars of the L.A. School include Edward W. Soja, Mike Davis, Allen J. Scott, Michael Dear, and Steven Flusty. Although Los Angeles is often criticized as "a city without a past" (Dear 1998: 76), the 'L.A. School' views it "as the paradigm of the future" (Davis 1990: 86).

Los Angeles is exemplary for city building, forming a whole of spread-out towns and villages (Soja et al 1998: 1). Similar to Toronto, which had amalgamated into Canada's largest city by 1998 (Hutton 2010: 119) after fusing several municipalities (Allahwala et al 2010: 210), Los Angeles grew steadily in population and size. By the start of this millennium, the five-county region of Los Angeles encompassed over 170 municipalities (Soja 2000: 141). With 12,561 square kilometers in 2000, Los Angeles was the second most wide-spread city in the world, although it is only ranked twelfth in terms of population size (Bronger 2004: 174). Therefore, the metropolization rate is lower than New York's and very low in comparison to cities such as Soul, Buenos Aires, or Tokyo (Bronger 2004: 174).

From the city's beginning, Los Angeles was characterized by fragmentation and odd infrastructure without a core city (Abu-Lughod 1999: 134). Since Allison Lurie's mid-1960s novel, Los Angeles has been known as "The Nowhere City" (Lurie 1965; Clarke 1988: 126). The "entangled and labyrinthine space" of the 465 square mile city has no single origin and no center (Lehan 1998: 257). Thus, in contrast to the former development of cities around a core, the city is spacious and leveled, reminding one of a doughnut structure. The formerly important downtown has decreased in significance, with many Los Angelenos never having been there (Soja 2006: 180).

Mobility is a key concept of American culture and much more than a necessity for the "great big freeway" (Beveridge et al 2003: 49), Los Angeles. Due to its fragmentation and decentralization, freeways are the global city's governing structure. Mass transportation within the spread-out city was doomed early to failure. Although many attempts were made in the early twentieth century, public transportation by horse-car, cable car, or street trolley was not successful (Abu-Lughod 1999: 143). Due to trains degenerating after the Great Depression, 80 percent of passenger miles in Los Angeles were conducted by car (Fogelson 1967: 274). By the end of the 1930s and as part of the city's industrialization process, the renowned Los Angeles freeway system had been planned, further encouraging the stretched-out infrastructure of today (Abu-Lughod 1999: 253).

The type of living and interaction of the global city's minorities is closely connected to the infrastructural history of Los Angeles. Private transportation mobility in Los Angeles is of more significance than in New York or Toronto 
(Perl et al 2010: 194). In contrast to the 'walking city' New York (Beveridge et al 2003: 49) and the major public transportation system in Toronto, Los Angeles is dominated by its freeway system. Ethnic clusters, poor Mexican neighborhood enclaves, so-called 'barrios,' the many diverse unskilled workers (Soja 2000: 227), the rising number of homeless (Halle 2003: 12) as well as the mostly Anglo so-called 'gated communities' of the privileged, which enforce social boundaries in 'the fortress city' (Davis 1990), are symptomatic of the city's structure and sociality. The freeway construction thus led to tremendous infrastructural displacement in the form of ethnic geographical clusters, enforcing "social divisions in ways that were mostly symbolic before" (Monahan 2002: 164).

The population of Los Angeles moving to the city until the 1930s, however, was united by its perception of a new dispersed and heterogeneous suburbanism, sustainably changing the urban landscape into a "fragmented metropolis" (Fogelson 1967: 273). Chinese clusters in Los Angeles, for example, coined the term 'ethnoburbs' (Liu 1998; Hall 2010: 60), relating to specific established immigrants clusters in dispersed patterns. Moreover, in Los Angeles and its greater region, a so-called 'Tortilla-Mercedes Divide" ${ }^{52}$ has long existed, describing "the social and economic separation between the more affluent White and poorer Mexican populations" (Allen 2002: 701). This gap and many others enforce the city's development. By the end of the 1980s, Los Angeles had become increasingly polarized by ethnicity and class (Abu-Lughod 1999: 367) in demographic as well as geographic terms. Thus, "the epicenter of globalization" (Sawhney 2002: 5) both captures and highlights the coexistence of the 'First world' and the 'Third world' within one city. Los Angeles therefore visualizes the effect of globe-encompassing migration across borders better than most other global cities.

By the mid-1990s, the former 'black-white boundary' slowly began to vanish in Los Angeles due to massive Latino migration (Soja 2000: 142). Racial boundaries, however, were not erased, as the 1992 L.A. Riots violently illustrated. The six-day movement mainly took place in Los Angeles and was sparked by the unsatisfactory jury's verdict on the police officers who beat up the African American Rodney King. The riots resulted in interethnic uproar, assault, arson, and murder. More than 50 people were killed. A regional economic depression followed when the population started to mistrust the local police force (Kaufmann 2003: 323). This violent explosion is explained as grounded in the very compli-

52 The term 'Tortilla-Mercedes Divide' refers to T.C. Boyle's recent novel The Tortilla Curtain (1995), which illustrates the differences between poor (illegal) Mexican immigrants and wealthy Whites in Los Angeles 
cations of space and sociality arising from "the exceedingly volatile cityspace produced by new urbanization processes, with its unprecedented cultural heterogeneity, widening social and economic disparities, and multiplying points of tension and confrontation" (Soja 2000: 299).

The city's economic and infrastructural development, however, was intrinsically linked to the commercialization of the unique city culture and the successful myth-making processes. The global city's culturally diverse labor force inspired the region's entrepreneurship and cultural urban life (Soja 2000: 184). Moreover, tourism is a major asset of the global city, supporting its economy. More than five million foreign tourists visited Los Angeles in 2000 (Gladstone et al 2003: 81), which is a bigger share of national visitors and about a million less international visitors than New York.

The city's image and self-conception have changed immensely over time. The global city emerged from the desert and being driven by American capitalism, has grown to one of the most significant urban complexes in the world. Important stakeholders in this process included 'the Boosters,' 'the Noirs,' and 'the Exiles' (Davis 1990: 22ff.), each searching for the "land of opportunities for all" (Sawhney 2002: 5; italics original). At the beginning of Southern California's 'Booster Era' between 1885 and 1925, Los Angeles was considered "the most violent town in the West" (Davis 1990: 26). The numerous ensuing, sometimes contradicting legends that arose (Taylor 1983: 33), attracted working-class and middle-class migrants alike. By the 1960s, thanks to the 'Noir' scene and a great number of exile writers from Europe, Los Angeles and the Hollywood 'dream factory' had become specialists in the production of images and myths (Soja 2000: 136).

Hollywood and its huge entertainment industry is the symbol for globalization as Americanization. Los Angeles, known as the world's 'entertainment center' (Sudjic 1992: 80) and the culture industry's world capital (Davis 1990: 17), is one of the most mediated American cities (Sorkin 1982: 8; Davis 1990: 20). It is a place where American culture is made, thereby functioning as a marketing machinery of American values. The myth-making in Los Angeles and the proliferation of the ideal of the American dream is commercialized, instrumentalized as a commodity, and then promoted to Americans "like automobiles, cigarettes and mouth wash" (Mayo 1933: 319; Davis 1990: 17).

Global viewers of television and cinema have the images of Hollywood in mind (Clarke 1988: 125), which is the alter-ego of Los Angeles (Davis 1990: 18), and successfully links "the dreamer to the dream" (Lehan 1998: 257). The Hollywood Sign is the advertisement as such, promising and signifying the American dream. In addition to Hollywood, the urban image of Los Angeles is 
also significantly influenced by Disneyland (Clarke 1988: 125). The global city invented 'urban Imagineering' (Soja 2000: 136), absorbing the identity of other cities and consciousness in general (Lehan 1998: 257). Some critics even claim that it is not globalization that affects Hollywood but that the film industry has an effect on globalization (Shiel 2001: 11).

Well before Los Angeles and Hollywood became the 'American dream factory,' New York was the 'land of promise' (Bell et al 2011: 261). New York, however, still provides the financial network for the proliferation of American culture from Hollywood (Abu-Lughod 1999: 290). Due to geo-proximity and lower costs, however, Toronto's film industry's growth rate is greater than that of Los Angeles (Vinodrai 2010: 105). Los Angeles nonetheless remains the world's 'entertainment center' (Sudjic 1992) with its capital, however, still mostly controlled in the financial center New York.

Los Angeles is one of the rare cities in which words are not the central form of expression and representation. Instead, due to its brief history mainly influenced by the film industry, movies are the city's prevailing form of articulation (Ulin 2002: xiv). In the twentieth century, the city's mythologizers were international filmmakers, American novelists working for the film industry, and European academic exiles who "radically reworked the metaphorical figure of the city" (Davis 1990: 20). Thus, Los Angeles literature did take long to flourish. The writers moving west, such as F. Scott Fitzgerald and William Faulkner, or writers looking for political asylum in the twentieth century, such as Bertolt Brecht and Thomas Mann (Ulin 2002: xiv), turned Los Angeles into "the world capital of an immense Culture Industry" (Davis 1990: 17). The growing film industry encouraged national and international work-seeking writers to move to Los Angeles, thereby slowly supporting the development of a literary scene (Ulin 2002: xv).

As Los Angeles is a city of opposites, its literature is also characterized by 'cacophony' (Ulin 2002: xvi). Nevertheless, three recurring themes can be identified with regard to Los Angeles literature: 1) themes of fantasy, dream, and progress, 2) the automobile, and 3) film noir, which constitutes the city's most renowned genre, featuring topics of urban chaos, misery, violence, and apocalypse.

The theme of the American dream and fantasy was linked early to Los Angeles as the most Western frontier of the continental United States. This domination of space, nature, and technology translates into the theme of progress. F. Scott Fitzgerald's The Last Tycoon (1941), for example, is a novel associated with "the frontier movement, Manifest Destiny, California Dreaming" (Lehan 1998: 257). 
The theme of the automobile is closely connected to the theme of progress, individuality, and independence. There is a long tradition of fiction describing Los Angeles as a city ruled by the automobile, such as Thomas Pynchon's postmodern fiction The Crying of Lot 49 (1966), Ed Ruscha's Twentysix Gasoline Stations (1962) and Thirtyfour Parking Lots (1967), Joan Didion's Play It as It Lays (1971), and Hugo Williams' No Particular Place to Go (1981). Driving a car, road signs, and moving through the city on the freeway becomes the major perspective on the city $^{53}$ because automobiles "constitute the essential icons of Los Angeles" (Ulin 2002: xv).

In literary and cinematic terms, the third theme 'noir' is the most associated with Los Angeles, turning the city into a place that "American intellectuals love to hate" (Davis 1990: 21). Hollywood is strongly influenced by the city's noir culture, acting as a counterculture to the glamour and happy Hollywood ending (Ulin 2002: xvii) and as an antithesis to themes of progress and moving West. In the 1940s, Los Angeles turns into the Film Noir city, portraying the downside of the 'American dream factory,' such as violence, murder, death, intrigues, and the unconscious, reminiscent of Edgar Allen Poe's works (Clarke 1988: 142). The city is portrayed as a 'junkyard of dreams,' representing a simultaneous utopia and dystopia (Davis 1990: 18).

As part of the noir movement, Raymond Chandler's The Big Sleep (1978 [1939]) and Nathaniel West's The Day of the Locust (1983 [1939]) form a new and existential literature of Los Angeles (Ulin 2002: xv). West's The Day of the Locust (1983 [1939]), which is considered the "best-known Hollywood novel" (Rhodes 2008: 10), pictures the city as urban hell with "a brutal violence waiting to erupt" (Lehan 1998: 259). Chandler's novel is set in the period of the Great Depression, portraying Los Angeles as "a strange neon world of light and colour" (Clarke 1988: 141) that is full of corruption.

Thus, similar to Los Angeles, a city with 'no unifying center,' its literature is in the same way decentered with no single logic. Karen Tei Yamashita's Tropic of Orange manages to capture this multi-layered identity of the city, its form, literature, and inhabitants by transcribing it into the novel's structure, narrative, geography, and the characters' cultural diversity and the polyphonic sound. Yamashita's novel is inspired by the city's literary past and post-riot images and challenges. The novel is motivated by the most influential genre 'noir,' featuring an apocalypse-like disaster-movie setting that is ironically caused by an orange,

53 For more information about the history of movement, traffic, and the automobile in Los Angeles and its literature, see Graham Clarke's 'The Great Wrong Place': Los Angeles as Urban Milieu (1988). 
the symbol of California dreaming, American progress, and western capitalism across borders. A reporter reminiscent of a noir detective investigates the illegal drug traffic and organ trade. And, finally, with the imagined Los Angeles freeways functioning as a metaphor of the city's veins, all three identified themes of Los Angeles literature are incorporated in the global city novel, thereby imaging Los Angeles as 'The World City.'

\subsection{Los Angeles Imagined: The World City}

Whereas Brand's literary Toronto is expressed as a city with many different, overlapping worlds and Lee's New York as a city, in which language is the governing structure, Yamashita's Los Angeles captures both and the complexity, diversity, and multiplicity of the globe, virtually representing 'the World City.' Similar to the global city, the imagined Los Angeles in Yamashita's Tropic of Orange (1997) is a fragmented urban world in terms of ethnicity, class, and the freeway (Rody 2009: 130). The different worlds are illustrated by a variety of characters with individually tailored narrative voices, interacting as an interethnic network and collaborating in the end when borders are moving and merging in a 'time-space compression' (Harvey 1989). Therefore, the imagined global city of Los Angeles can be regarded as 'the World City,' in which different worlds, such as the 'First World' and the 'Third World,' come together, collide, or cooperate.

Karen Tei Yamashita was born in Oakland, California in 1951. She spent most of her childhood in Los Angeles and returned to the 'city of angels' after a year in Japan and nine years in Brazil to once again become a native in 1984. Yamashita is a so-called sansei Japanese American, a third generation immigrant. ${ }^{54}$ She is married to a Brazilian, whose family is shaped by Portuguese, Spanish, and Italian influence. She considered herself an immigrant when returning from Brazil to California. She is the Professor for Literature and Creative Writing at the University of California in Santa Cruz.

Yamashita's previous works Through the Arc of the Rain Forest (1990) and Brazil-Maru (1992) are mainly set in Brazil and incorporate local-global dialects of the interdependence of the economy and ecology. Circle K Cycles (2001) is a patchwork of fiction and non-fiction on a second-generation Brazilian Japanese

54 A sansei Japanese American is born from Nisei or second generation Japanese Americans, who are the children of first generation Japanese American, also called issei, born in Japan 
family's struggle to assimilate. Her most recent novel I Hotel (2010) was a finalist in the National Book Award in fiction. It manages to capture in a kaleidoscope-like fashion diverse Asian American experiences in a San Francisco hotel in 1968 and the following nine years.

Yamashita is considered 'a global novelist' (Ling 2012: xvi), encompassing and incorporating different 'national' styles, spaces, histories, and characters, creating a global interethnic literature. Transnational travel and research of the Japanese community in Brazil and her bonding with different L.A. communities are mirrored in her writing. L.A. could also function as the abbreviation of Latin America due to the city's huge Latin American community. This influence reappears in Yamashita's writing, including, for example, Mexican American myths and characters. Moreover, she is inspired by international writers and critics, such as Italo Calvino, Toni Morrison, or John Irving (Glixman 2007). With the inclusion of a wide variety of different cultural influences and the rewriting of various literary conventions, Yamashita has played a major role in the redefinition of Asian American literary studies.

Karen Tei Yamashita's Tropic of Orange (1997) takes place in two countries, includes at least three languages and characters of several different ethnicities. Yamashita goes beyond Japanese American literature, focusing on her characters' cultural diversity and mobility in a globalizing world. She manages to portray characters that transgress borders as well as the concept of 'uni-ethnical' identities. In the light of the 1990s 'paradigm shift' from a national to a transnational focus in Asian American literature, Yamashita further broadened the view to a "transnational space of the Americas" (Rody 2009: 128).

Yamashita's style of writing surprised both publishers and readership as she did not comply with previous Asian American genre conventions. Similar to Chang-rae Lee's experience, one of the two other authors focused in this work, ethnic labeling was an issue for Yamashita. The Japanese American author faced difficulty finding a publisher because the novel's poetics of narrative, space, and code-switching are not associated with Asian American literary traditions. Similar to Dionne Brand and Chang-rae Lee, Karen Tei Yamashita can be considered to an extent as a regional writer who is very accustomed to the urban space themed in the novel. In Tropic of Orange, the poetics of place focus on the city of L.A. as well as on the U.S.-Mexican border region. Yamashita blends historical persons and places with detailed fiction and elements of magical realism to illustrate the impact of globalization and its effects. Yamashita presents many provocative and ironic statements in her book and enthralls the reader with a well-structured story and the interplay of the various characters, emphasized by the hybrid layout of the novel. 
The novel is significantly set in the global city of Los Angeles shortly following the 1992 riots and a time of severe incidents of border conflicts and illegal immigration. The novel displays the local and global challenges of cultural diversity, migration, and socio-political integration, featuring regional, national, and international topics of globalization. Moreover, the changing image of the global city is illustrated, incorporating themes of Hollywood, the rising numbers of homeless as well as Spanish-speaking characters and themes in a city that is restructuring from a former black-and-white divide and has become, once again, a home for many Mexicans.

The poetics of narrative, place, and code-switching equally contribute to the ethnic global city novel, displaying the multiperspectival and network-like structure, character relationships, and the interdependency of the 'First world' and 'Third world, converging in the simultaneous urban and border contact zone of the global(izing) city. As a result of the collaboration of the different characters, the seven individual worlds are revealed as one in the end, converging in 'The World City.' Yamashita thus creates a 'third space' in and beyond the urban complexity of the cultural nodal point of Los Angeles, one in which interethnic identities are constantly negotiated beyond cultural lines.

The novel is analyzed in five sections, addressing issues of narrative structure, genre and globalization, polyglotism and interethnic collaboration, globalization and the global, the elasticity of time and space as well as the significance of the title and of borders as connecting or dividing lines. The next section explores how the different themes, ethnicities, and cultural elements of the global city of Los Angeles are interwoven into the novel. This translation of the global city's urban space, including its history and closely intertwined ethnic diversity is illustrated in the novel's introductory overview, called 'HyperContexts.'

\subsubsection{HyperContexts}

As Karen Tei Yamashita's 'HyperContexts' indicates (see Illustration 1), the novel is constructed in a very sophisticated manner. This introductory structure to the book is used as a means of chapter and character overview that manages to capture the multi-layered textuality of the global city, its form, literature, and inhabitants. The author used a Lotus spreadsheet to structure the novel, its time and spatiality, characters as well as the plot and resolution (Glixman 2007). It shows the novel's frame, chapter layout, and different narrative threads at a glance, while simultaneously incorporating different themes of the city of Los Angeles and its history, such as film noir, mass media production, the freeway, and border traffic. 
Illustration 1: HyperContexts

\begin{tabular}{|c|c|c|c|}
\hline & $\begin{array}{l}\text { Monday } \\
\text { Summer Solstice }\end{array}$ & $\begin{array}{l}\text { Tuesday } \\
\text { Diamond Lane }\end{array}$ & $\begin{array}{l}\text { Wednesday } \\
\text { Cultural Diversity }\end{array}$ \\
\hline $\begin{array}{l}\text { Rafaela } \\
\text { Cortes }\end{array}$ & $\begin{array}{l}\text { Midday -Not Too Far } \\
\text { from Mazatlán } \\
\text { chapter } 1\end{array}$ & $\begin{array}{l}\text { Morning } \\
\text { - En México } \\
\text { chapter } 10\end{array}$ & $\begin{array}{l}\text { Daylight } \\
\text {-The Cornfield } \\
\text { chapter } 18\end{array}$ \\
\hline $\begin{array}{l}\text { Bobby } \\
\text { Ngu }\end{array}$ & $\begin{array}{l}\text { Benefits } \\
\text {-Koreatown } \\
\text { chapter } 2\end{array}$ & $\begin{array}{l}\text { Car Payment Due } \\
\text {-Tijuana via Singa- } \\
\text { pore } \\
\text { chapter } 12\end{array}$ & $\begin{array}{l}\text { Second Mortgage } \\
\text {-Chinatown } \\
\text { chapter } 15\end{array}$ \\
\hline Emi & $\begin{array}{l}\text { Weather Report } \\
\text {-Westside } \\
\text { chapter } 3\end{array}$ & $\begin{array}{l}\text { NewsNow } \\
\text {-Hollywood South } \\
\text { chapter } 9\end{array}$ & $\begin{array}{l}\text { Disaster Movie } \\
\text { Week } \\
\text {-Hiro's Sushi } \\
\text { chapter } 20\end{array}$ \\
\hline Buzzworm & $\begin{array}{l}\text { Station ID } \\
\text {-Jefferson \& Nor- } \\
\text { mandie } \\
\text { chapter } 4\end{array}$ & $\begin{array}{l}\text { Oldies } \\
\text {-This Old Hood } \\
\text { chapter } 13\end{array}$ & $\begin{array}{l}\text { LA X } \\
\text {-Margarita's Corner } \\
\text { chapter } 16\end{array}$ \\
\hline $\begin{array}{l}\text { Manzanar Mu- } \\
\text { rakami }\end{array}$ & $\begin{array}{l}\text { Traffic Window } \\
\text {-Harbor Freeway } \\
\text { chapter } 5\end{array}$ & $\begin{array}{l}\text { Rideshare } \\
\text {-Downtown Inter- } \\
\text { change } \\
\text { chapter } 8\end{array}$ & $\begin{array}{l}\text { The Hour of the } \\
\text { Trucks -The Free- } \\
\text { way Canyon } \\
\text { chapter } 19\end{array}$ \\
\hline $\begin{array}{l}\text { Gabriel } \\
\text { Balboa }\end{array}$ & $\begin{array}{l}\text { Coffee Break } \\
\text {-Downtown } \\
\text { chapter } 6\end{array}$ & $\begin{array}{l}\text { Budgets } \\
\text {-Skirting Downtown } \\
\text { chapter } 14\end{array}$ & $\begin{array}{l}\text { The Interview } \\
\text {-Manzanar } \\
\text { chapter } 17\end{array}$ \\
\hline Arcangel & $\begin{array}{l}\text { To Wake } \\
\text {-Marketplace } \\
\text { chapter } 7\end{array}$ & $\begin{array}{l}\text { To Wash } \\
\text {-On the Tropic } \\
\text { chapter } 11\end{array}$ & $\begin{array}{l}\text { To Eat } \\
\text {-La Cantina de Mise- } \\
\text { ria y Hambre } \\
\text { chapter } 21\end{array}$ \\
\hline
\end{tabular}




\begin{tabular}{|c|c|c|c|}
\hline $\begin{array}{l}\text { Thursday } \\
\text { The Eternal Buzz }\end{array}$ & $\begin{array}{l}\text { Friday } \\
\text { Artificial Intelli- } \\
\text { gence }\end{array}$ & $\begin{array}{l}\text { Saturday } \\
\text { Queen of Angels }\end{array}$ & $\begin{array}{l}\text { Sunday } \\
\text { Pacific Rim }\end{array}$ \\
\hline $\begin{array}{l}\text { Dusk } \\
\text {-To the Border } \\
\text { chapter } 24\end{array}$ & $\begin{array}{l}\text { Dawn } \\
\text {-The Other Side } \\
\text { chapter } 30\end{array}$ & $\begin{array}{l}\text { Nightfall } \\
\text {-Aztlán } \\
\text { chapter } 38\end{array}$ & $\begin{array}{l}\text { Midnight } \\
\text {-The Line } \\
\text { chapter } 45\end{array}$ \\
\hline $\begin{array}{l}\text { Life Insurance } \\
\text {-L.A./T.J. } \\
\text { chapter } 26\end{array}$ & $\begin{array}{l}\text { Visa Card } \\
\text {-Final Destination } \\
\text { chapter } 34\end{array}$ & $\begin{array}{l}\text { Social Security } \\
\text {-I-5 } \\
\text { chapter } 40\end{array}$ & $\begin{array}{l}\text { American Express } \\
\text {-Mi Casa/Su Casa } \\
\text { chapter } 49\end{array}$ \\
\hline $\begin{array}{l}\text { Live on Air } \\
\text {-El A } \\
\text { chapter } 27\end{array}$ & $\begin{array}{l}\text { Promos } \\
\text {-World Wide Web } \\
\text { chapter } 29\end{array}$ & $\begin{array}{l}\text { Prime Time } \\
\text {-Last Stop } \\
\text { chapter } 41\end{array}$ & $\begin{array}{l}\text { Commercial Break } \\
\text {-The Big Sleep } \\
\text { chapter } 44\end{array}$ \\
\hline $\begin{array}{l}\text { You Give Us } 22 \\
\text { Minutes -The } \\
\text { World } \\
\text { chapter } 22\end{array}$ & $\begin{array}{l}\text { AM/FM } \\
\text {-FreeZone } \\
\text { chapter } 31\end{array}$ & $\begin{array}{l}\text { The Car Show } \\
\text {-Front Line } \\
\text { chapter } 37\end{array}$ & $\begin{array}{l}\text { Hour } 25 \\
\text {-Into the Boxes } \\
\text { chapter } 48\end{array}$ \\
\hline $\begin{array}{l}\text { Lane Change } \\
\text {-Avoiding the Har- } \\
\text { bor } \\
\text { chapter } 28\end{array}$ & $\begin{array}{l}\text { Jam } \\
\text {-Greater L.A. } \\
\text { chapter } 35\end{array}$ & $\begin{array}{l}\text { Drive-By } \\
\text {-Virtually Every- } \\
\text { where } \\
\text { chapter } 42\end{array}$ & $\begin{array}{l}\text { SigAlert } \\
\text {-The Rim } \\
\text { chapter } 46\end{array}$ \\
\hline $\begin{array}{l}\text { Time \& a Half } \\
\text {-Limousine Way } \\
\text { chapter } 25\end{array}$ & $\begin{array}{l}\text { Overtime } \\
\text {-El Zócalo } \\
\text { chapter } 32\end{array}$ & $\begin{array}{l}\text { Working Weekend } \\
\text {-Dirt Shoulder } \\
\text { chapter } 39\end{array}$ & $\begin{array}{l}\text { Deadline } \\
\text {-Over the Net } \\
\text { chapter } 43\end{array}$ \\
\hline $\begin{array}{l}\text { To Labor } \\
\text {-East and West For- } \\
\text { ever } \\
\text { chapter } 23\end{array}$ & $\begin{array}{l}\text { To Dream } \\
\text {-America } \\
\text { chapter } 33\end{array}$ & $\begin{array}{l}\text { To Perform } \\
\text {-Angel's Flight } \\
\text { chapter } 36\end{array}$ & $\begin{array}{l}\text { To Die } \\
\text {-Pacific Rim Audi- } \\
\text { torium } \\
\text { chapter } 47\end{array}$ \\
\hline
\end{tabular}

Yamashita 1997 
The 'HyperContexts' is one of the novel's methods of incorporating the textuality of the interconnectedness of time, space, and literary conventions. The chapter subheads thereby function as a telling element of the plot, giving away information about the characters and their situation in advance. Chapter 44 'Commercial Break - The Big Sleep,' for example, alludes to Raymond Chandler's famous 1930s noir work and to Emi's death. ${ }^{55}$ Similarly, Roman Polanski's Chinatown (1974) is included as a chapter subhead (Chapter 15) in the overview to show awareness of the movie's implications because this film noir genre classic is the one "against which Asian American writers of crime fiction must write" (Huang 2010: 8). This unique technique of referencing in the 'HyperContexts' produces an 'encyclopedic novel' that is no longer identified as simply "narrative" (Heise 2006: 212f.).

The HyperContexts functions as the novel's skeleton or frame. It is divided into seven parts, both horizontally and vertically, representing either one day of the week or one character. The days are themed from "Summer Solstice" on Monday to "Pacific Rim" on Sunday. The fact that the story is told in one week gives rise to assumptions of biblical associations of how the whole world was created in the course of one week. In the novel, the world is threatened by the apocalypse of a global orange scare, which is resolved within the week. This apocalyptic setting is a satire of the popular Hollywood disaster movie.

In addition to the themed days of the week, the 49 individual subchapter headlines always refer to a location, highlighting the significance of time and space as a vital part of the narrative. The seven main characters' actions take place between Los Angeles and Mazatlán, Mexico. The novel's structure represents the city's infrastructure because, similarly, there is no original and no center (Lehan 1998: 257) but a wide variety of locations and a complex network of seven characters. Thus, like the geography of the global city of Los Angeles, the narrative in not centralized but seems to be shaped by fragmentation. This approach resembles a postmodern representation of urban structure, global narrative, and ethnic diversity (Raussert 2011: 103).

Although the seven stories that suggest separation and isolation make the narrative appear divided and thus "fragmented" (Lee 2011: 319), in the end, a synergy of narrative is created by the converging of the individual stories. The narrative is evenly focused on the protagonists, who each have one chapter a day to tell their story or world view, thus creating equality in terms of the poetics of narrative and political representation. Thus, vertically, the balanced approach of

55 For more information on the significance of Emi's death, please see Section 8.2.5 on 'These Lines.' 
the novel is illustrated in 'HyperContexts' because there is no singular main protagonist from the start but seven characters that evenly contribute to the story line. In the end, as in a mosaic, all pieces of the different and increasingly overlapping worlds come together to form a whole picture. As a result of the characters' interethnic collaboration, seven worlds are established, converging into one in the end. Therefore, the selected characters can serve as a snapshot of the multiplicity of the citizens of Los Angeles, illustrating the diversity of the inhabitants of the global city, the border region, and the world. Thus, a global view composed of seven different but interacting perspectives is created, representing 'The World City" and simultaneously promoting the notion of 'cultural diversity.'

The different individually designed chapter headlines match a description of the respective character. Hence, when reading Emi's headlines (also featured in Illustration 1; read from left to right): 'Weather Report,' 'News Now,' 'Disaster Movie Week,' 'Live on Air,' 'Promos,' 'Prime Time,' and 'Commercial Break,' the audience gains a first impression of her character, interests, beliefs, and flaws. It is revealed from the start that Emi is interested in technology and works in the media industry of L.A. The analysis by chapter headlines works analogously for the remaining six characters. Rafaela Cortes is a Chicana from Mexico, married to Bobby Ngu, and taking care of Gabriel Balboa's house in Mazatlán. Her chapters from 'Midday' on Monday to 'Midnight' on Sunday represent a time-space-compression, reversing the course of a day within a week while travelling from Mexico to Los Angeles. Her husband Bobby is introduced as a hard-working Chinese immigrant, focused on money and social security. Whereas African American Vietnam Veteran Buzzworm is all about music and the radio, Japanese American Manzanar Murakami is crazy about the freeway traffic. Arcangel, the old traveler from Mexico, is primitively described by what he does, such as 'To Wake,' 'To Eat,' or 'To Die.'

Whereas each of the seven characters is narrated with an individual idiolect ${ }^{56}$ to emphasize diversity, Arcangel's chapters feature historical facts intertwined with ironic remarks. Called the "messenger" (TRO 199), Arcangel is inspired by a short story character of the Colombian writer Gabriel García Márquez (Heise 2006: 212). While the novel's characters function as a representative of their class or ethnic group, Arcangel significantly represents Latin America as a whole, including its future and its past (Benito et al 2009: 84). As "the voice of the colonized Latin America" (Sadowski-Smith 2008: 66), he speaks up con-

56 For more information on the seven individually tailored narrative voices, see Section 8.2.2 on 'The Polyglot.' 
jointly for "the indigenous, the displaced, the exterminated, the poor, and the workers" (Lee 2011: 322). Thus, particular narratological strategies can mirror different forms of diversity and vice versa.

Similar to Mexican performance artist Guillermo Gómez-Peña, who is cited in the novel's prologue ${ }^{57}$ globalization is criticized as Westernization and thus Americanization by Arcangel, who recounts the story of colonization. According to him, the doom of the earth is approaching in 2012, which he relates to Columbus' discovery of America. With this discovery, globalization as a phenomenon began (Reichardt 2010: 31), being the first stimulus of world-wide commerce and migration (Ette 2004: 29). With the incorporation of poetry written in italics, the novel recounts "indigenous Aztec mythologies" (Sadowski-Smith 2008: 66). As Arcangel ironically retells, the reason for Columbus' conquest of America happened solely

because of a lousy bunch of spices

to hide the putrefaction of meat! (TRO: 49; original in italics)

The story of Christopher Columbus' conquest of America is combined with elements of magic realism to illustrate the diverse influence on writing and to parody literary conventions. With a trans-categorical blending of fiction and fact, historical bits of information (e.g. TRO: 49-51) are interwoven with autobiographical elements as well as mystical and supernatural elements, thereby creating a Hollywood-like disaster blockbuster with an independent movie's appeal. Magic realism, a typical Chicano style not common among Japanese Americans, is also used in the beginning of the book when Rafaela sweeps different animals from the floor, such as crabs and snakes (TRO: 3), although the house is not situated at the edge of the sea. The novel thus manages to enthrall the reader with knowledge about the Mexican past and literary conventions.

Whereas six of the seven characters are narrated in a limited or omniscient third-person style (Rody 2009: 132), the Chicano newspaper reporter Gabriel Balboa is presented in a detective-like first-person narration (Benito et al 2009: 81). Emi compares Gabriel to Raymond Chandler's 1930s noir detective Philip Marlowe (TRO 22) when he is investigating the downside of Hollywood (TRO: 39). The ending of the story disrupts the cliché of the legendary L.A. detective

57 For more information on the novel's inspiration by the work of Guillermo GómezPeña and his concept of a 'borderless future,' please see Section 8.2.5 on 'These Lines.' 
story approach ${ }^{58}$ because the collaboration of the seven characters is the key to success. Moreover, even though most of the story takes place in Hollywood, the novel ironically does not feature a typical happy Hollywood ending when Emi dies. Nevertheless, the story is staged in a very entertaining apocalypse Hollywood blockbuster style.

Global literature often presents the effects of globalization, such as increased connectivity or the acceleration of global flows. In the novel, the theme of globalization is also translated into the rewriting of binaries and the mixing of genres, such as the immigrant novel, disaster movie, noir, telenovela, magical realism, satire, and detective fiction. Therefore, multiplicity plays an important role in the novel on different levels. Similar to the network-like composition of the seven diverse characters and their stories, different and coexisting forms of genre are mixed. Moreover, myths and metaphors from different cultural spheres are combined. Thus, Latin American magical realism is used, for example, translating between the United States and Mexico as well as the Asian American heritage. This mixing of genres supersedes the former standards of ethnic American fiction, and Asian American fiction in particular, paving the road for new narrative leeway in a globalizing age (Rody 2009: 136).

With the combination of different elements of genre, a "transtextual space" (Sturm-Trigonakis 2007: 156) is created. This aligns with the tendency of transtextual elements accumulate in hybrid texts in ethnic writing (Birkle 2004: 231) and new world literature (Sturm-Trigonakis 2007: 143) in a globalizing age. Moreover, binaries are omnipresent in the story. Oppositional elements old versus new, good versus bad, fiction versus fact, developed versus developing country, or cosmopolitan versus rural areas - are addressed and challenged. In the course of the story, it all comes down to a "showdown between [...] North and South, bad oranges and good, virtual and magical" (Rauch 1998: 29), resulting in a clash of dichotomies. In terms of globalization, negative as well as positive effects are displayed, yet, the direction is clear because the convergence emerges from the South as a promotion of globalization as hybridization and not merely as an Americanization force.

Another important element of ethnic, urban, and global literature is codeswitching. Multilingualism and code-switching are of major importance in border regions (Anzaldúa 1987) and urban areas (Eastman 1992: 16). Due to its geopolitical position and historical development, the global city of Los Angeles

58 The 'L.A. detective story' is a crime drama or film noir usually staged in Hollywood, such as Detective Story (1951) featuring Kirk Douglas. 
features both. In the next section on 'The Polyglot', the impact and importance of code-switching in the novel is examined.

\subsubsection{The Polyglot}

In Yamashita's Tropic of Orange, the poetics of code-switching functions as a tool to convey the diversity of Los Angeles and its inhabitants on numerous levels and from multiple perspectives. The egalitarian structure of the novel as illustrated by the HyperContexts, ${ }^{59}$ the multi-ethnic cast, and the individually tailored narrative voice of each of the characters transcend former Asian American genre classifications, pointing towards a representation of the global. The story is told in a 'polyglot' fashion (Murashige 2006), aiming at a realistic articulation of the characters' culturally diverse identities. By giving every character an individual narrative voice, seven perspectives are featured to envision seven different worlds coexisting and later collaborating in Los Angeles. Thus, a 'narrative polyphony' (Raussert 2011: 100) is created, echoing the chorus of ethnic diversity and multiplicity in the global city of Los Angeles.

In the novel, specific language is used as an indicator for ethnic diversity when, as Yamashita states in an interview, the "rhythmic sound sensibility" is translated into the seven protagonists' different narrative voices (Glixman 2007). While speaking through the main characters, the style of writing is altered from, for example, simple and basic (Bobby Ngu), to street-talk (Buzzworm), to poetic (Arcangel), and to a kind of detective style (Gabriel Balboa). This "chorus of voices" (Adams 2007: 264) emphasizes the 'pan-cultural' approach in the novel (Gier et al 1998). Moreover, English, Japanese, and Spanish are incorporated to highlight the diversity of the novel's characters because global processes of hybridization are translated into literature with the use of multiple languages (Ette 2007: 14).

Yamashita, a multilingual speaker of English, Portuguese, and some Japanese, mimics the production of a language when tailoring the narrative voices. Thereby, individual linguistic markers are absorbed, such as ethnically distinct speech patterns and syntax (Glixman 2007). This type of narration achieves the same effect as when an actor plays seven different roles for a blind audience. The description and conveyance of diverse looks and multicultural appearance alone is not sufficient. Instead, syntax and speech pattern are copied and performed according to pre-assigned roles. Thus, in contrast to Lee's Native Speak-

59 For more information on the significance of the HyperContexts, please see Section 8.2.1. 
$e r$, this effect is accomplished predominantly with the literary technique of 'showing' instead of 'telling.'

Although the story is mostly told in a third-person narration, the narrative voice is altered every chapter in a mimetic fashion to suit the respective character in focus. According to Yamashita, the characters of the novel "all started as 'types,' even as caricatures, in the same way the media represents us" (Glixman 2007). Although Yamashita aimed at criticizing the ethnic framing by the media, the author herself is criticized for the technique of parodying 'ethno-linguistic' stereotypes. This form of mimetic imitation, resemblance, or mirror effect, however, is considered as a truthful literary resemblance of reality (Sturm-Trigonakis 2007: 147) because the polyglossia creates closeness to the characters. Thus, the novel's politics of identity and ethnic representation leave the readership torn "between multicultural mockery and cosmopolitan embrace of diversity" (Raussert 2011: 105).

No white American protagonists are incorporated in a former predominantly white American L.A. Instead, the novel focuses on the city's often underrepresented minorities, emphasizing those ethnic groups with which the author is most acquainted, such as Asian and Mexican Americans. Yamashita wanted to turn the media's "background material" (Glixman 2007) into main stories and characters by representing those who have been neglected in the city's historical and literary past (Adams 2007: 264), including Africans, Asians, and Latin Americans as well as the homeless (Glixman 2007). With its intertwined story of different ethnicities collaborating across class lines and political borders, the novel challenges the literary tradition of the city and "the white middle-class dominant perspective of 'American' society" (Chae 2008: 91).

The novel manages to translate the complex cultural identity of Bobby for the reader's imagination. The Chinese speaks Spanish like a Mexican, demonstrating his linguistic flexibility and hybrid identity. In chapter 2, entitled 'Koreatown', Bobby is introduced as an "Asian dude. Kinda skinny. Short, yeah. But so what? Dark glasses. Cigarette in his mouth." (TRO: 14). He speaks in brief sentences, typified by an absence of articles, with short words, no extras or fancy elements, and many colloquial, more informal than formal elements, such as 'kinda' and 'gonna.' He is displayed as someone who is constantly working with and against established stereotypes.

The following quote illustrates how the novel utilizes common misconceptions and stereotypes to display cultural diversity but also to translate the cultural diversity of the characters to the reader's imagination: 
If you know your Asian, you look at Bobby. You say, that's Vietnamese. That's what you say. Color's pallid. Kinda blue just beneath the skin. Little underweight. Korean's got rounder face. Chinese's taller. Japanese's dressed better. If you know your Asians. Turns out you'll be wrong. And you gonna be confused. Dude speaks Spanish. Comprende? So you figure it's one of those Japanese from Peru. Or maybe Korean from Brazil. Or Chinamex. Turns out Bobby's from Singapore. You say, okay, Indonesian. Malaysian. Wrong again. You say, look at his name. That's gotta be Vietnam. Ngu. Bobby Ngu. They all got Ngu names. Hey, it's not his real name. Real name's Li Kwan Yu. But don't tell nobody. Go figure. Bobby's Chinese. (TRO: 15)

After the confusion and attempts at explanation, the narrator sums up Bobby's cultural identity as being "Chinese from Singapore with a Vietnam name speaking like a Mexican living in Koreatown" (TRO: 15). Hence, language functions as an excellent indicator for cultural diversity. Bobby is fluent in Spanish, sounding like a Chicano (TRO: 8). Thus, he can be considered a hybrid of Asian American and Chicano who has created a 'third space' for himself in the United States.

Whereas all characters of the novel are "transculturated" (Löbbermann 2008: 277), Bobby is the most culturally diverse of all characters. Bobby is not an 'ordinary' Asian American (TRO 15) but is depicted as having "a multi-defined identity" (Chae 2008: 91). He makes use of his diversity, sometimes even opportunistically. Hence, on the micro-level, Bobby's identity has become a mixture of various cultural inspirations. He is not torn but seizes the opportunities offered to him due to his ethnic appearance, for example when he invents his alias to pass as a political refugee. Like a chameleon adapting to his background, he successfully exploits the Americans' blindness to varieties within the Asian American community. He claims to belong to another Asian heritage, taking full advantage of American support and the sympathy of one Asian group while simultaneously circumventing politically-induced racism against another Asian minority, caused by the Vietnam War. The narrator thus interweaves hidden ironic remarks about the common misconception that all Asians appear alike.

The description of the character Bobby goes beyond the concept of cultural 'hybridity' and 'in-betweenness' because the "Asian Latino" (Sadowski-Smith 2008: 62) is a border-crossing character who cannot be described as either-or, protesting against clear categorization. Instead, the character's ethnic intermixture is stressed. Even Bobby's last name "Ngu" functions as a pun (Rody 2009: viii). This pronunciation as 'new' is an allusion to his new form of identity as an interethnic person. Thus, the focus is shifted from one ethnicity to a hybrid state and from there to a global cultural mélange of various influences. It proves that 
an individual's identity can be more easily expressed in a mixture of different cultural manifestations than in categories.

Bobby and his marriage are the embodiment of the similarities and parallels between Asians and Mexicans in America. His wife Rafaela is a Chicana of African slave heritage. She is very educated but nevertheless works as Gabriel's housekeeper. She represents the modern Mexican woman and discovers the illegal organ transplant conspiracy. Rafaela and Bobby, the "pan-Asian" who speaks Spanish fluently, and their son Sol are part of the visible minority, suffering from social invisibility. As the HyperContexts reveals, Bobby's chapters are full of work metaphors and consumerism (e.g. TRO 79). Together, the workaholics stand for "cheap, immigrant labor" (Lee 2011: 321) of the so-called "dreamaddicted Los Angeles middle class" (Davis 1990: 20).

With the seven different narrative voices and modes, the novel achieves coming as close as possible to representing the global (Raussert 2011: 108). The author manages to portray the wide variety of the diverse characters and their different languages in a written form, creating an equality of cultural differences by devoting the same amount of chapters to each of the characters. Language thus functions as a 'point of view' and as a means to question the dominance of one perspective. Bakhtin's notion of the novel as a 'zone of contact' (1981: $27 \mathrm{f}$.), in which different languages, cultures, and ideologies intersect, is a reminder of the crucial characteristic of the global city as a cultural node in a global network of flows.

Section 7.2.3 on 'The Global' examines how globalization affects economic, political, and social networks in the literary global city of Los Angeles. With the network-like structure of the plot, an 'interethnic collaboration' is formed that operates "beyond rigid racial/ethnic boundaries" (Chae 2008: 93). The author focuses on cultural diversity accelerated by globalization, its opportunities and challenges. The novel thus comes as close as possible to representing the global not only with the different narrative voices and modes (Raussert 2011: 108) but also by using the network metaphor for the different globalization processes and for the forms of representations of the global, portrayed by the different characters and their relationships.

\subsubsection{The Global}

The network-like interaction of the culturally-diverse cast is closely connected to the network-like structure of the novel. Seven seemingly independent characters and stories converge into one team, providing one solution to complex bordercrossing problems in the end, each filling in pieces of the whole picture. Thus, 
parallels are established to concepts such as the 'rhizome of culture', globalization as 'hybridization' and 'heterogeneity', a transcultural mosaic, or global mélange. The borderless networking in a globalizing age is mirrored by the interconnectedness of the different characters, their relationships, but also by a globelike, border-crossing orange.

Whereas the novel features different themes of globalization, its structure resembles globalization as such because the various narrative threads are interconnected and interwoven, converging in the end. The three forces and innovations of globalization are depicted. ${ }^{60}$ The increased mobility of people, criminals, oranges, and information enhances the impression of a growing connectivity of the world. Thus, a global consciousness is created. Moreover, technological advancements, the economy, and politics contribute to the erosion of borders as well as to a redefinition of time and space when, in the end, everything happens simultaneously.

Whereas the city of L.A. serves as a "metonym for the global" (Wallace 2001: 153) and the protagonists of the book exemplify the diversity of the world, the airport serves as an example of globalization processes in urban space. ${ }^{61}$ The scene describing the international airport LAX functions as a metaphor for the potpourri of cultures living, arriving, and passing through the city: "KAL from Seoul ARRIVED. VARIG from Rio ARRIVED. QANTAS from Sydney DELAYED. JAL from Tokyo LANDING. MEXICANA from Mexico City LANDED" (TRO 86). The author's detailed description of the arriving flights and airlines in capital letters creates a strong illusion of immediacy, global connectivity, and cultural multiplicity.

The novel also addresses the various effects of globalization, employing irony to criticize economically-driven globalization as Westernization or NeoColonization. Thus, the reader learns that Mexican toilet bowls are cheaper if purchased in the U.S. and then shipped to Mexico than those purchased in Mexico from the start. The novel also raises the critique that globalization possibly harms the globe and humankind, providing a list of negative side effects, including accelerated drug traffic (TRO: 146f). The major threat in the book, however, is lethal narcotics hidden in healthy Mexican oranges. The fruit's globe-like shape (TRO: 12), which functions as a symbol for the world, therefore also be-

60 For more information, please see Section 2.2 on the 'Global Consensus' of globalization and its effects.

61 This exemplification of the diversity of the world constitutes a similarity to Herman Melville's Moby Dick (1851) in which the diversity of different people (yet only men at that time) on the ship represents the whole world. 
comes representative of the downside that globalization can bring to the world, literally bearing dangerous elements.

The book points out how much impact local events can have on the rest of the world. The so-called butterfly effect resembles the forces and innovations of globalization that, for example, accelerate transportation of information and the connectivity of the world, linking "the myriad small everyday actions of millions with the fates of distant, unknown others" (Tomlinson 2001: 25). In the novel, this is explained by the spread of news when the threat of spiked oranges is altered and elevated in the news in an imaginary cycle of every twenty-two minutes. Buzzworm follows the development of the story from "spiked orange alert" to "spiked orange scare" to "illegal orange scare" to "illegal alien orange scare," and finally to "Death oranges" (TRO: 138-141; emphasis original). This effect illustrates how local events can trigger global attention, creating an impression of immediacy, acceleration of information flows, and interconnectedness. Within hours, a healthy orange is turned into something lethal while blaming illegal immigrants at the same time because both, the poisoned orange and illegal immigrants from Mexico or Latin America, are considered "illegal trespassers" (Chae 2008: 99).

The different perspectives on globalization are embodied by different characters in the novel, such as the border-crossing immigrants Arcangel, Rafaela, and Bobby or the complimentary couple of Emi and Gabriel. The character Emi, for example, views globalization as Westernization and predominantly as a process of Americanization in which different cultural fragments are identified and standardized to fit many other cultures. According to her, economic globalization is "about selling things: Reebok, Pepsi, Chevrolet, AllState, Pampers, Pollo, Loco, Levis, Fritos, [...]" (TRO: 126). This resembles the standardization or homogenization approach of globalization.

Emi is a representative of the new network society in the "world media city" (Taylor 2004: 57), whose' "networked computing" (Ling 2012: 137) functions as an alternative to ethnic categorizations. According to Manuel Castells, a 'network society' is made of social networks based on communication technologies (2004: 3), and in the novel, the young Asian American represents the digital age, in which news is spread around the world in an instant. She works as an editor at the local TV station, helps to reveal the organ smuggle, and thereby later discovers that Manzanar Murakami is her grandfather. Instead of being nostalgic about 
her heritage, Emi prefers to circumvent ethnic pigeonholing by being identified by her profession or use of technology. ${ }^{62}$

Emi and Gabriel together represent two sides of globalization, respectively accepting and distrusting technological advancements or change. Whereas Emi is considered "hypercontemporary" (Adams 2007: 260), constantly and 'fearlessly' making use of new technologies, such as the Internet, email, or emoticons, Gabriel is associated with investigation in a black-and-white colored 1930s detective noir style. Gabriel chooses burgers over exotic food that he cannot translate on the menu, thus revealing his conservatism and resistance to change. Emi compliments their relationship and his investigative abilities by showing the reporter the future of "a paperless existence" (TRO: 23), in which the global flow of things, e.g. the news, is vastly accelerated.

Through the border-crossing character Rafaela and Arcangel, who carries the orange northwards, accelerated immigration and the prejudice that Mexican and other immigrants are facing are depicted (TRO: 211), highlighting the differences between the North and the South in the globalization process. In chapter 33, titled 'To Dream - America,' the history of the Mexican-American border is explained in detail (TRO: 161f.) and the United States is criticized heavily for its border politics (TRO: 199-201; 161). Mexico and the South is significantly represented as two-fold, torn between the future and hundreds years of tradition, by Rafaela, the brave, smart, modern Mexican woman and Arcangel, the old, traditional, and respected Mexico, who speaks in metaphors and poetry, is seemingly different, and mysterious. The novel also emphasizes the topic of immigration and racism when describing the fact that (Mexican) immigrants struggle to be welcomed in the United States: "We're not wanted here. Nobody respects our work. Say we cost money. Live on welfare. It's a lie. We pay taxes" (TRO: 80).

Globalization as a phenomenon of a focus on world-wide capitalism and a process of Westernization is predominantly criticized through the roles and perspectives of Arcangel, who fights against a mythically anthropomorphized NAFTA (North American Free Trade Agreement). Arcangel's chapters are significantly told in a third-person narration because he represents 500 years of Latin American history (Ling 2012: 121). His voice is described as "a jumble of unknown dialects, guttural and whining, Latin mixed with every aboriginal, colonial, slave, or immigrant tongue" (TRO: 47). He thus manages to speak for the old, the traditional, the colonized, the conservative, and for things that are severely threatened, affected, altered, or even destroyed by globalization.

62 For more information on Emi's relationship to her heritage and her vision of being 'anti-multicultural,' please see Section 8.2.5 on 'These Lines.' 
Arcangel polarizes the reader because he is bizarre but respected for representing the entirety of Latin American history. Inspired by elements of magical realism and Mexican myths, he has mysterious holes in his body that can pull a truck (TRO: 211), which creates a feeling of something uncanny, unknown, exotic, or of supernaturalism, disgust, and fear. He is mysteriously described as "an actor and prankster, mimic and comic, freak, a one man circus act" (TRO: 47). When Arcangel dreams of the orange, however, he immediately understands its significance and the connection to the tropic.

Arcangel is constantly crossing borders. On his trip North, the "multi-ethnic Latin American wanderer through time and space" (Raussert 2011: 101) stops at a Mexican bar called "Misery \& Hunger" that serves only American convenience products, such as hamburgers with ketchup and beer (TRO: 130f.). This shows how Mexico has been influenced by the American economy, capitalism, and consumerism and how the American economic domination moves across borders (Chae 2008: 100). Arcangel does not like this influence because he values Mexican habits and resists change. Thus, he confronts SUPERNAFTA, who aims at a free flow of people, commodities, and money between Canada, the U.S., and Mexico.

In his role of the historical person of El Gran Mojado, Arcangel confronts SUPERNAFTA in a Mexican-style lucha libre wrestling match (TRO: 232) to fight false promises, corruption, and exploitation by the United States. El Gran Mojado, or "The Big Wetback," is an 'economic refugee' (Anzaldua 1987: 33; Chae 2008: 99). He functions as a counterforce to American capitalist domination and expansion, fighting against consumerist homogenization, artificial freedom with a combination of liberty and consumerism, and dependence on American capital (Chae 2008: 100f.).

The clash of the North versus the South, which significantly takes place "at the very borders" (TRO: 256) of the Pacific Rim Auditorium, represents excessive consumption versus poverty and crime. Supporters of NAFTA claim that employment opportunities in Mexico will increase when more products are sold to North America, simultaneously counteracting Mexican-American immigration (Adler et al 1992: 796). In the novel, NAFTA is criticized as money-focused instead of working for the well-being of the people (TRO: 133), in particular with regard to the Mexican population or immigration. SUPERNAFTA, however, claims that the South belongs to the North (TRO: 132). The human organs' trade illustrates this interdependent relationship, in which one country is exploited and the other benefits. This example is representative of the convergence and interconnectivity of the North and the South and the whole world. 
El Gran Mojado does not survive when fighting against SUPERNAFTA because traditions need to change. Arcangel's awareness that he has to die to make room for something new represents the change induced by globalization. This economic border metaphor of the United States and Mexico symbolizes the global marketplace and the divide between more and less developed countries. Hence, the novel is being critical about American culture and white American hegemony as well as about globalization as a mere Americanization process. However, the last chapter's title, 'American Express - Mi Casa/Su Casa,' shows that globalization a phenomenon of Westernization affects everyone alike because "mi" ('my') globalization is "su" ('your') globalization.

The novel's description of the literary global city of Los Angeles in a globalizing age is as fluid as its narrative mode because it does without classical images of urban space (Raussert 2011: 108). Instead, the whole geography is moved. How the novel redefines urban literature by presenting a dynamic concept of space is examined in the next section, 'ElastiCity.'

\subsubsection{ElastiCity}

Amazing thing was everybody in L.A. was walking. They just had no choice. There wasn't a transportation artery that a vehicle could pass through. It was a big-time thrombosis. Massive stroke. Heart attack. You name it. The whole system was coagulating then and there. [...] Streets'd become unrecognizable from an automotive standpoint. Only way to navigate it was to feel the streets with your own two feet.

(TRO: 218F.)

The poetics of place play a major role in Karen Tei Yamashita's Tropic of Orange because they reveal the interconnectedness of time, space, and cultural diversity in a globalizing age. As illustrated in the above-mentioned quote, everything converges in L.A. in a huge traffic jam and, therefore, the city becomes the center of the world. Yamashita claims that the "idea of a changing geography would be a way to demonstrate very physically the change in Los Angeles" in recent years (Yamashita 1999). She used geography to move borders and the conception of cultural diversity. She decided to alter L.A.'s landscape as soon as an orange is moved north, thereby highlighting the impact of accelerated border traffic, immigration, and globalization. 
The section's title 'elastiCity' describes how time and space become "elastic" (TRO: 123f.) in the imagined global city of Los Angeles and the border region of the U.S. and Mexico. With the 'coming-together' (Lee 2011: 323) of the North and the South, time and space collide when Arcangel carries the orange and thus the Southern Hemisphere with the Tropic of Orange northwards. ${ }^{63}$ This dramatic change is sensed by the different protagonists. Once the orange at Gabriel's house had disappeared, Rafaela soon notices "this elasticity of the land and of time. This sensation of timelessness, of yawning distances, of haunting fear, of danger" (TRO: 149; emphasis added), foreshadowing the threat of the illegal border-crossing organ trade. Similarly, Manzanar had "an uncanny sense of the elasticity of the moment, of time and space" (TRO: 123; emphasis added). He could feel the time-space distortion and a possible apocalypse dooming from the chaotic convergence because he was able to "see the undulating pattern and the changing geography corrupting the sun's shadows, confusing time, so that all events should happen and end at the same time" (TRO: 206).

This time and space shift constitutes a force of globalization. ${ }^{64}$ The distortion called 'annihilation of space by time' by Marx (1973) and 'time-space compression' by Harvey (1989) is explained in the novel through a graphic description: "Streets stretched and shrunk this way and that. Someone put this city in the washer/dryer. Shrunk $50 \%$ in places. Then ironed it out $200 \%$ in others" (TRO: 230). As Gabriel observes, the geography of the city of L.A. is changed into a "distorted version of downtown. At least that's what the street names indicate" (TRO: 227). The phenomenon is also earlier noticed by the smart reporter Emi: "I mean the length of the day. [...] It's got something to do with time. Place." (TRO: 61). Hence, time and place are defined anew and globalization magically affects geography. Everything is moved north, converging in the city of L.A., which is representative of the convergence of the whole world in "The World City,' thereby exposing the interconnectedness of the local and the global.

Buzzworm, who has a naturally strong sense of time, collects watches, and keeps one for every occasion, can also sense the distraction of time. After fighting for his country in Vietnam, the African American is marked as an outcast in society (TRO: 217) due to the anti-war sentiment in the 1970s. The novel is critical of American politics and society, contravening common ethnic stereotypes when the veteran is described as being down-to-earth, helping whenever he

63 For more information on the significance of the novel's title, please see Section 8.2.5 on 'These Lines.'

64 For more information on the perceived convergence as one force of globalization, please see Chapter 2.2 on 'Global Consensus.' 
can, and never giving up. He calls himself 'Angel of Mercy' and functions as the Robin Hood of the district in a time of fierce interethnic riots in Los Angeles. The veteran fights for his home area and against corruption. His connection to oranges is the admiration of palm trees for their sense of time, such as the natural sensing of seasons. He collaborates with Gabriel Balboa, being 'his man on the scene' in L.A., observing how the relationship between time and space changes. He manages to connect the drugs to the oranges, revealing the lethal smuggle.

Buzzworm is listening to the radio constantly, which is a metaphor for his understanding of different cultures because he enjoys any kind of music style and can deal with any kind of person. He acknowledges, respects, and understands diversity. He has interethnic appeal and shows respect when he listens to "rap, jazz, R\&B, talk shows, classical, NPR, religious channels, Mexican, even the Korean channel. Didn't know a thing they were saying, but he liked the sounds. Fact is, he listened to the sounds so much, he could imitate them" (TRO: 29). Thus, he has a good ear for cultural differences. He understands in the sense of listening to and comprehending cultural diversity on the radio and on the streets.

In the novel, the city of Los Angeles and its freeway system is anthropomorphized, being described as "a great root system, an organic living entity" (TRO: 37). The novel compares the freeway to the city's veins like Thomas Pynchon's The Crying of Lot 49, which defines it as "a vein nourishing the mainliner L.A., keeping it happy, coherent, protected from pain, or whatever passes" (1966: 15; Adams 2007: 248). Therefore, and as illustrated in the introductory quote to this section, the notorious L.A. traffic jam is described using the metaphor of a human body with an artery and diseases connected to the blood system, such as a thrombosis, stroke, or heart attack, thereby emphasizing the anthropomorphism of "the great heartbeat of a great city" (TRO: 35). Hence, when the freeway is jammed like a blood clot blocks a vein, the city and its society are revealed as 'sick' from a standstill.

It is no coincidence that the city is described in a "language of organicity" (Lee 2011: 326) because the homeless person Manzanar who conducts the freeway traffic used to work as a surgeon. Once a respected member of society, this constitutes a paradoxical reversal of his status; the man who formerly saved people's lives and now disgusts them makes sense of traffic instead of bodies. All of a sudden, he understands the system, the pattern, the flow of things by conducting traffic. With this symphony of traffic, Manzanar acknowledges and understands the interconnectedness of urban life in the global city. Being aware of the global connectivity of the world, the Asian American represents "the symbolic 
nodal point in which all of humanity, in a spiral of ever-increasing scope, is joined" (Lee 2011: 324; italics original).

Manzanar's unique perception of the world in musical chords is another approach to understanding globalization. He makes sense of traffic in his own special way, seeing patterns that transform chaos into order. To him, the freeway "was nothing more than a great writhing concrete dinosaur and nothing less than the greatest orchestra on Earth" (TRO: 37). The homeless seems to be the most marginalized character of all. In 1984, however, Los Angeles was considered the "homeless capital" by the U.S. department of Housing and Urban Development (Halle 2003: 12) and thus, as the novel states, "no one was more at home in L.A. than this man" (TRO: 36). The novel thus gives the character a voice because he can conduct symphonies made from traffic noise and sees things that others cannot see (TRO: 57). The old man significantly derives his alias from the Manzanar concentration camp in California, where he was born when his parents were interned during World War II (TRO: 110). Following Pearl Harbor, massive numbers of L.A. residents of Japanese descent were deported to internment camps and kept there until 1945. Nowadays, Japanese Americans are considered part of the 'model minority,' having major financial influence in Los Angeles (AbuLughod 1999: 251). Thus, the author does not avoid talking about the atrocities Japanese Americans had faced.

Similar to the mayoral candidate John Kwang in Lee's Native Speaker (1995) who transgresses his designated space as an Asian American in New York, Manzanar is introduced as a powerful border-crossing character. As a conductor of the cars on the freeway, he knows and 'regulates' the major infrastructure of the city. Moreover, Manzanar also similarly identifies a kind of common vernacular of the global city that is "an equivalent reproduction of a perfect Babel or jam session of sounds, discourses, and realities" (Manzanas Calvo et al 2011: 61). Thus, compatible to Kwang's creation of an ethnic minority vernacular, the novel creates another form of vernacular typical of a global city that is determined in auditive, industrial, and mechanical terms.

The freeway, its structure, and the automobile are of major significance for the imagined global city of L.A. The freeway as such is synonymous with endless mobility and the extension of the westward movement by American settlers, driven by the concept of 'Manifest Destiny,' enforcing freedom as an urAmerican value (Manzanas Calvo et al 2011: 54). The last chapter that focuses on Manzanar is named 'Sig Alert,' refers to the infamous L.A. traffic conditions and traffic jams, which are a key element of Los Angeles freeway culture and commuting routine since the 1950s (Gottlieb 2007: 174). By the 1920s, Los Angeles had the country's highest automobile registration (Soja 2000: 128), and in 
a city with no unifying center, the freeway turned into the connecting link and thus became the "new center of the city" (Gottlieb 2007: 175).

The novel's freeway block by the homeless is a very unusual interaction taking place in the global city of Los Angeles. In contrast to Toronto and New York, individuals do not usually meet on the streets, but the novel reverses this peculiarity. As the socio-cultural critical L.A. episode movie 'Crash' (2004) shows, a traffic jam, freeway block, or crash is needed for cultural encounters to happen. As illustrated in the introductory quote to this section, the massive crossing of vehicles is substituted by immobility and a standstill of cars. This immobility of traffic, however, also represents mobility. A pedestrian life develops. Moreover, the homeless are crossing borders of their determined and marginalized space in the city. They mobilize their stigma of belonging to a ghetto and change fixed definitions of using cars for driving purposes only. Thus, with this move, "the nomads, the representatives of the non-city, have trespassed the visible and invisible lines that circumscribed them" (Manzanas Calvo et al 2011: 58). With this redefinition of space, the distinction between race and class are redefined, thereby questioning existing categorizations. Thus, the invisible are made visible when the homeless carjack and control the freeways.

The reader is in a hybrid situation, torn between sympathy for the homeless, who live in abandoned cars, and the car-owners, who want their property back. This dichotomy functions as a metaphor for the strong division of the globe between consumerism and mere survival, such as in 'First World' and 'Third World' countries. Whereas cars are a product of everyday convenience to one half of the globe, the other half struggles for mere survival and basic needs, such as accommodation and nutrition, which is represented by the homeless growing vegetables in the car engines. As a result, a small grass-roots revolution is taking place. The conflict between the car owners and the homeless in the celebrity city of L.A. represents these two contradicting worlds depicted in the following quote.

As the homeless flocked onto the freeway, there were also the usual questions of shelter and jobs, drug rehabilitation, and the closing of the mental health facilities. And as car owners watched on TV sets or from the edges of the freeway canyon, there were the usual questions of police protection, insurance coverage, and acts of God. (TRO: 122)

The homeless can be compared to colonization. They grow their own colony, settling down, naming streets, and planting crops. This functions as a strong critique of colonization and domination in form of irony. For Americans in general and Los Angelenos in particular, cars are their "own home away from home" 
(Lee 2011: 326), resembling key values, such as mobility, freedom, and independence. Moreover, the freeway traffic is symptomatic for the restlessness and mobility of the imagined global city (Raussert 2011: 105). Thus, carjacking is "the ultimate American violence" (Zukin 1995: 43). The homeless, however, are portrayed as an anti-globalization movement because they bring the symbol of mobility and economic globalization to a halt by changing diapers and growing vegetables in high-end cars, such as Porsches or Corvettes. Hence, with the elasticity of time and, in particular, space, the novel also manages to interweave L.A.'s image as a city of differences and paradoxes.

When the homeless are stopped by helicopters and the police, the revolution of space and class is violently stopped, enacting scenes of the 1992 L.A. riots. Thus, the freeways of Los Angeles, which have "long occupied the contemporary imagination as the ills of chaotic urban living" (Lee 2011: 326), are again associated with something negative in the novel. Helicopters flying over the freeway, surveillance systems, video cameras, and the aimed control of public space can be identified as implicit references to Mike Davis' City of Quartz. Davis argues that "security" becomes a positional good" for the rich, as in the many so-called 'gates communities,' and the concept of fear and threat is marketed as an industry (1990: 224f.), enforcing existing social boundaries in spatial terms.

This heterogeneous quality of Los Angeles contributed to the 1992 Los Angeles riots, of which Soja raised a question eight years later: given the "volatile cityspace produced by new urbanization processes, $[\ldots]$ what has prevented the postmetropolis from exploding more frequently and more violently that it has over the past decade?" (2000: 299). With the novel's depiction of the scenes of uprising like in 1992 and the collaboration of the seven different characters, the emphasis is put "on the necessity of forming a political alliance beyond ethnic differences" (Chae 2008: 104) and class in order to stabilize politics and to prevent an apocalypse.

Magical realism functions as an important instrument in the novel to show that the North and the South are dependent and interconnected in an age of globalization with flows of money, goods, people, and ideas but also to challenge traditional concepts of culture, time, and space, in which borders collapse and boundaries are reconfigured, thereby envisioning new utopias (Benito et al 2009: 87). With this technique of visualizing globalization and its effects by moving or changing geographies, parallels to Edward Soja's dynamic notion of 'space' $(1989 ; 2000)$ can be identified. His term 'postmetropolis,' for example, which is inspired by the global city of Los Angeles, shows how globalization "brings all the world's peripheries into the center, drawing in what was once considered 
'elsewhere' to its own symbolic zone" (Soja 2000: 250). In the novel, this process takes place, symbolizing the collision and convergence of the 'First World' and 'Third World' in 'The World City' of L.A. The novel, however, not only features a new, dynamic definition of space in a postmodern L.A. but also an accompanying redefinition of borders and thus ethnic categorizations. How the 'Tropic of Orange' as one of 'these lines' is moved and therefore reconfigured is elaborated in the last section.

\subsubsection{These Lines}

Tied fast to these lines. (...) What are these goddamn lines anyway? What do they connect? What do they divide? What's he holding on to? (TRO: 268; EMPHASIS ADDED)

The 'lines' Bobby is holdings in the quote play a crucial role in the novel. Lines, a synonym for borders in the physical and metaphorical sense, implicate bilateral or transnational politics, border traffic and immigration, or identity conflicts. In this section, the significance of the novel's title is examined because the 'Tropic of Orange' constitutes one of 'these lines.' The Tropic of Orange's development is explored; a development into a 'third space' in which accelerated border traffic and a shifting of borders take place on different levels.

The idea of the plot and the title of the novel originated from the time when Yamashita and her husband lived in the Brazilian megacity São Paulo, a city through which the Tropic of Capricorn runs. When Yamashita moved to L.A., the story about an orange growing at a geographical border moved north with her to Mazatlán, Mexico, which is on the Tropic of Cancer (Glixman 2007). In the novel, the tropic line was renamed the 'Tropic of Orange,' thereby highlighting the significance of the orange. The tropic is introduced when the housekeeper Rafaela sees and describes the fine line on the property of Gabriel Balboa's vacation getaway that seems to be connected to an orange on the tree: "a line - finer than the thread of a spider web - pulled with delicate tautness. It was most visible in the dewy mornings as the sun rose in the east; at other times, it was barely visible. But she always sensed its presence" (TRO: 12). The imaginary boundary continues on both sides of the orange, forming a visible line, thereby creating a border metaphor.

The reporter planting a tree that carries one orange directly at the tropic line signifies the creation of Gabriel's own colony. The reader is reminded of Columbus, who brought the first orange tree to America when he conquered the 
continent in 1492 (Rauch 1998: 28). Gabriel's purchase of the land close to the Tropic of Orange is ironically described in terms of colonization, too. The following quote explains his imperial domination of an exotic place: "Gabriel felt a spontaneous, sudden passion for the acquisition of the land, the sensation of a timeless vacation, the erotic tastes of chili pepper and salty breezes, and for Mexico" (TRO: 5). Thus, as some critics claim, the orange in the novel also functions as an object of revenge (Ling 2012: 125) for the colonization started by Columbus and forwarded by the hegemony of America and globalization as Westernization. The house situated at the Tropic of Cancer also symbolizes Gabriel's quest for paradise in nostalgic Mexico. He dreams the American dream and that of upward mobility (Hauser 2006: 12). Nevertheless, he clings to the past in search for his Mexican roots. Thus, Gabriel's 'inner division' of having two identities, Mexican and American, is also visualized by the line on his property.

The orange creates a 'third space,' being the symbolic connecting link of the tropic line and of different definitions of space and time as well as a through its symbolic role as mediator between the North and the South, different cultures, and histories, This space is established by the movement of borders and the transformation of geography when the orange is dragged north. The orange establishes a life of its own (TRO: 13f) and thus becomes the novel's symbolic center (Raussert 2011: 100). Then, the known geography is transformed into something new that is negotiated by the time and space shift caused by the globalization force. Homi Bhabha elaborates upon this perspective in the following quote.

The importance of hybridity is not to be able to trace two original moments from which the third emerges, rather hybridity to me is the third space which enables other positions to emerge. This third space displaces the histories that constitute it, and sets up new structures of authority, new political initiatives, which are inadequately understood through received wisdom. (Bhabha 1990: 211)

Figuratively speaking, when the threads that originated in the orange forming the tropic line are cut, borders are erased geographically and metaphorically. Indecision and in-betweenness are circumvented. The cultural contact zone is moved to the global city of L.A., and a hybrid discourse can be initiated that encompasses the whole multitude of ethnicities. The seven protagonists investigate together in order to find the criminals who smuggle drugs hidden in oranges and illegally trade human organs in plastic coolers. The message is transported that success lies in diversity and that the problems of the world can be solved with the power 
of networking and the collaboration of the various different people in the world. Hence, a collage of the very different and yet distinct personalities is created in which everyone is working together to save the world. Thus, the emphasis is on unity, while maintaining the cultural diversity of the individual. This can be compared to the concept of 'hybridization' and to that of a 'rhizome of culture' (Deleuze et al: 1987).

The novel is also inspired by Anzaldúa's border metaphor because it manages to portray culturally diverse characters situated in the border region of the American Southwest. The novel deals with the process of identity formation across those borders. The author celebrates cultural diversity while illustrating that things are changing and need to be changing in a globalizing age. The novel depicts characters that cross racial boundaries as well as national borders and cultural spaces (Ty et al 2009: 136). Moreover, a border conflict usually entails growing up between cultures (Anzaldúa 1987: 6), mostly accompanied by a generational, language, and integration conflict.

Gloria Anzaldúa illustrates that the border areas provide a 'third space' in which hybridization is practiced.

To live in the Borderlands means to

Put chile in the borscht

eat wholewheat tortillas

speak Tex-Mex with a Brooklyn accent

be stopped by la migra at the border checkpoints. (Anzaldúa 1987: 194)

Borderlands are crucial when it comes to cultural identity formation because "border zones are the meeting places of different organizational modes [...] hybrid meeting places of state sovereignty and transnational enterprise" (Nederveen Pieterse 2004: 67). When Arcangel carries the orange north, the border discourse is also moved. Thus, borders are shifted physically and metaphorically. As a result, Asian Americans as well as other minorities are included in the border position and transcultural discourse because "the border narrative [goes] beyond that of Mexican/North-American polarities to consider its effects on Latin American, Asian and Southeast-Asian migrants, and neighborhood locals and transients in Los Angeles" (Gier et al 1998).

The novel manages to illustrate the overlapping of histories, experiences, and social or political integration of Asian Americans and Mexican Americans as well as further immigrants in the concurrent urban and border contact zone of Los Angeles. Rafaela and Bobby, or Gabriel and Emi, for example, are both interethnic couples of the lower or upper middle-class who show the difficulties 
and similarities of life in Los Angeles (Sadowski-Smith 2008: 63). Similar to Lee's Native Speaker, which shows parallels between African American and Asian American suffering and marginalization, Yamashita's Tropic of Orange manages to evoke a shared understanding of the cultures of the physical border region and those many more cultures impacted by borders in a wider, metaphorical sense, thus creating "interethnic alliances" (Ling 2012: 137).

Guillermo Gómez-Peña, a Latin American writer and performance artist renowned for his notion of a 'borderless future,' in which separating lines and categorizations do not exist (1995: 175), inspired the author and Arcangel's character (Gier and Tejeda 1998). Similar to Lee's Native Speaker, Yamashita's novel presents an intertextual reference in its prologue. The meta-logical epigraph to Gómez-Peña's The New World Border (1995; TRO: 198) is meant to address the reader and to provide a context for the novel's plot but is not further explained within the novel. Thus, compatible to Gómez-Peña's work, the readership is forced "to examine the junctions of society, culture and language, and to question the static notion of identity" (Cole 2011: 89).

Through the character Emi, the novel tries to do without ethnic borders by arguing against established concepts like 'multiculturalism.' Emi controversially claims that she hates "being multicultural" (TRO: 128) because she disregards people that make assumptions about others with regard to their skin color. Although Emi considers herself as "so distant from the Asian female stereotype - it was questionable if she even had an identity" (TRO: 19), she is connected to her heritage but she is not, in contrast to her co-worker and lover Gabriel, as romantic about it (Glixman 2007). Instead, her controversial arguments, such as "maybe I'm not Japanese American. Maybe I got switched in the hospital" (TRO: 21), underline her insistence on a rethinking of cultural pigeonholing. She "liked trying to be antimulticultural" (TRO: 21) because she does not want to be categorized as a 'J.A.' (Japanese American), thereby circumventing categorizations in general and cultural stigmatization in particular.

Gabriel Balboa, for instance, does not connect Emi to her ethnic community at first because she does not really fit into the tight-knit Asian American society. Instead, Emi is a very individualistic, young, self-confident, and successful Asian American woman. Moreover, the young woman "identifies herself through technology to avoid an ethnical identification" (Hauser 2006: 7). Contrasting the Asian American stereotype of being silenced, for example, Emi uses explicit language in public. She has a big mouth, raises her voice, and thus does not remain silent, as female Asian Americans are commonly stereotyped, as seen in her mother commands, "no J.A. speaks like that" (TRO: 21). 
The author gives Asian American women a voice, working against prevailing clichés. Emi's character circumvents and breaks all rules when it comes to stereotypes. The young woman is self-conscious as well as self-confident. Yamashita explains in an interview about Emi that she wanted "to give her a strong voice, and make her powerful, even bitchy, and proud of it" (Gier and Tejada 1998). This trait of being unafraid to voice her concerns regarding American identity politics is pictured when Emi sees a woman wearing chop sticks in her hair to artificially convey the attachment to a certain ethnicity. Emi confronts a white woman at the Sushi restaurant whether she would believe that wearing two forks would be 'unsanitary' (TRO: 129). With this provocative and ironic example, multiculturalism is revealed as a social construct that needs to be questioned. To illustrate that 'cultural diversity,' which is the term that she prefers over 'multiculturalism,' should not be color-coded, Emi defines it as including "a white guy wearing a Nirvana T-shirt and dreads" (TRO: 128).

Similar to Lee's John Kwang, whose tragic fall stops his political ambitions and significantly decreases his influence as an interethnic leader with a powerful minority vernacular, Emi is killed in the end to show that an innovative character like her, who is defined more by her job and her networking technology than by her ethnicity, is doomed to fail in Los Angeles, still. Emi was brutally killed in a drive-by shooting. The respective chapter, entitled 'Commercial Break - The Big Sleep,' foreshadows Emi's death and alludes to Raymond Chandler's famous 1930s noir work, which portrays Los Angeles as a corrupt city at the time of the Great Depression (Clarke 1988: 141). Her last words, "what color is blood in ... black and ... white?" (TRO: 252), relate to the movie and ironically show that Los Angeles, in some sense, is still stuck in the 1930s.

As illustrated in the introductory quote to this section, Bobby helps to erase borders in the end when he lets go of the two strings that originated in the orange. At first, he was holding on, being in an in-between position and trying to choose sides. Then, Bobby asks the following questions that are meant to address the reader and thus are written in a third person narration: "What are these goddamn lines anyway? What do they connect? What do they divide? What's he holding on to?" (TRO: 268). The most culturally diverse characters of all, who, put in Gómez-Peña's words, is "jumping borders at ease / jumping borders with pleasure" (1995: 175), chooses to let go of the lines and thereby paves the way for a kind of a 'borderless future' of 'the world city' of Los Angeles and thus ethnic diversity beyond monocultural or bicultural constraints. 


\subsection{INTERIM CONCLUSION}

In Karen Tei Yamashita's Tropic of Orange (1997), the poetics of narrative, place, and code-switching are equally important. Set in Los Angeles in the 1990s, the novel displays the changing image of the global(izing) city as well as the local and global challenges of cultural diversity, migration, and sociopolitical integration. With the seven ethnically diverse characters, their individual narrative voices, and interconnected threats, the novel comes as close as possible to grasping the global. Therefore the imagined global city of Los Angeles can be regarded as 'the World City,' in which different worlds, such as the 'First World' and the 'Third World,' come together, cooperate, or collide.

The HyperContexts functions as an overview of the book, alluding to the global city's multi-layered textuality, spatiality and form, its history and literature as well as to cultural conflicts. The characters each have one chapter a day to tell their story, thus creating equality in narrative and socio-political terms. Similar to the city's infrastructure, the novel's structure has no single origin and no center (Lehan 1998: 257). This approach of fragmentation and convergence resembles a postmodern representation of urban structure, global narrative, and ethnic diversity (Raussert 2011: 103). Moreover, the mixing of genres supersedes the former standards of ethnic American fiction generally, and Asian American in particular, paving the road for a new narrative leeway in a globalizing age (Rody 2009: 136).

The poetics of code-switching functions as a tool to echo the diversity of the global city. The novel is told in a 'polyglot' fashion (Murashige 2006) with multiple languages, such as English, Spanish, and Japanese, and seven individually tailored narrative voices with distinct speech patterns and syntax. The novel focuses on the city's often underrepresented minorities in a formerly predominant white American L.A., thereby challenging the literary traditions of the city. Thus, a linguistic, ethnic, and literary 'zone of contact' (Bakhtin 1981: 27f.) is created in the global city of Los Angeles, one in which different languages, cultures, and ideologies intersect.

The novel's portrayal of increased mobility of people, criminals, oranges, information, and other traffic enhances the impression of a growing connectivity of the world, creating a global consciousness. The characters represent globalization from different angles, illustrating the different impact and numerous repercussions of globalization, including the opportunities and the pitfalls of the phenomenon. Arcangel, for example, fights against an anthropomorphized NAFTA, illustrating the South's economic dependence on the North. 
Instead of letting all characters migrate and move, the novel creates the image that the whole geography is moved. Everything converges in the imagined global city of Los Angeles and the neighboring border zone, becoming 'elastic' in geographic and socio-political terms. However, the characters also have the power to change geography when taking their culture with them (Gier and Tejada 1998), ultimately altering the city of L.A., its appearance, and the cultural identity of a place.

Lines, a synonym for borders in the physical and metaphorical sense, play a crucial role in the novel. In the end, the collaboration of the seven diverse characters advocates globalization as a process of hybridization and global mélange when a shifting of borders takes place. Instead of focusing solely on the Asian American minority, the novel manages to evoke an 'interethnic alliance' of the cultures of the border region and those impacted by borders in a wider, metaphorical sense. The novel's notion of 'cultural diversity' thus challenges the insistence on 'these lines' not only in physical-geographic or literary-generic, but also in ethnic-categorical and socio-political terms. 


\section{Conclusion}

Based on the analysis of the three selected North American novels - Dionne Brand's Toronto, What We All Long For (2005), Chang-rae Lee's New York, Native Speaker (1995), and Karen Tei Yamashita's Los Angeles, Tropic of Orange (1997) - this work examined global cities as a literary phenomenon ('diverCity'). As shown, the poetics of narrative, place, and code-switching function as the common aesthetics of global, urban, and ethnic literature. Thus, this structured analysis of a poetics of 'diverCity' provided the connecting link for examining the triad of globalization and its effects, global cities as cultural nodal points, and cultural diversity in a globalizing age as a literary phenomenon.

In this work, the analysis by a poetics of diverCity provides the opportunity to illustrate how the common aesthetics are of significance to each of the three selected novels. The poetics of narrative, place, and code-switching are important in Tropic of Orange (1997) when portraying the cultural multiplicity, urban-geographic complexity, and socio-political ruptures of the global city. Although, both the poetics of place and narrative are essential in Native Speaker (1995), the poetics of code-switching is the novel's dominating strategy in visualizing, exploring, and translating urban immigrant life and the integration of different ethnic groups into urban society. Similarly, with the poetics of narrative and code-switching, What We All Long For (2005) illustrates the different coexisting and overlapping worlds within the city while focusing its exemplifications on concepts of urban place and space. The three poetics thus play an important, albeit different, role in each literary analysis.

In this study, the poetics of narrative mainly concentrates on the novel's genre, intertextuality, and narrative voice. In Native Speaker (1995), for example, different genre conventions, such as the immigrant novel, the spy thriller, and the detective story, are combined to maneuver outside literary and cultural categories. In Tropic of Orange (1997), the story of Christopher Columbus' conquest 
of America is interspersed with elements of magic realism to parody literary conventions and, similar to the network-like composition of the seven culturally diverse characters and their stories, different and coexisting forms of genre are mixed to show multiplicity on different levels. Examples of paratextual devices include the chapter overview called 'HyperContexts' in Tropic of Orange (1997), the use of italics to mark translations in Native Speaker (1995), and the different justification in Quy's chapters in What We All Long For (2005). In the chapters titled 'Quy', a different narrative voice is used to highlight the parallel, diary-like narration of the lost son's story of life, stressing his struggle with linguistic fluency. Moreover, Tropic of Orange (1997) is written in a polyglot fashion, altering the narrative voice every chapter to suit the respective character in focus. Thus, at least seven different voices are found in the novel, mostly achieved by mirroring and sometimes parodying 'ethno-linguistic' stereotypes. This polyglossia creates closeness to the characters, featuring and thus envisioning seven perspectives and different worlds that coexist and later collaborate in the global city of Los Angeles.

The poetics of place focuses on the different forms of literary place and space. Description, figurative language, cognitive mapping, or mental maps create a specific literary setting, forming the basis for examining urban space and its concentration of cultural diversity. Different types of narrating the city can be identified, types conveyed with the help of figurative language or ones including themes of fragmentation and collage, as in the time-space compression and the redefinition of borders in Tropic of Orange (1997), or ones including symbolism, as when the city of New York functions as the immigrant heaven and thus represents the American dream as a whole in Native Speaker (1995). The presented environment of the narrated city is also of importance. Whereas the introduction to the global city in a winter setting in Dionne Brand's Toronto is an example of the natural environment, highlighting the interdependence of nature and culture, the description of the Los Angeles highway system and its comparison to 'veins' is a reference to the 'built' cityscape of 'real' cities. Moreover, a major distinction is made between public and private space, as the different types of escapes, such as ethnic, gendered, and generational, describe forms of integration and suppression in urban space in What We All Long For (2005). Whereas Lee's New York and Brand's Toronto are portrayed as rather static cityscapes due to John Kwang's failure and the continuation of anti-immigrant racial politics in Giuliani's time and the failure of integrating first-generation immigrants in a modern Canada, Yamashita's Los Angeles is presented as a city in flux. The dynamics of Los Angeles include the distortion of geography when the physical 
border of the Tropic of Capricorn is dragged towards the city or the homeless start living in upper middle-class cars.

The poetics of code-switching emphasizes the importance of the various forms and strategies of language use and translations. Functioning as important markers for global and ethnic literatures, the use of different languages or translations always involves a cultural process of negotiation. In Tropic of Orange (1997), apart from English and Japanese, Spanish is incorporated to highlight the diversity of the novel's characters. The character Bobby, for example, speaks Spanish like a Mexican, although he is Chinese, demonstrating his linguistic flexibility and hybrid identity. Similarly, African-Caribbean Canadian Dionne Brand decided to embed Vietnamese to emphasize a character's cultural particularity. Moreover, language constitutes the governing structure in Lee's New York because, as the novel's title indicates, the immigrant experience is repeatedly depicted in linguistic terms. The novel violently portrays how linguistic fluency does not automatically equal the recognition as a well-integrated American citizen, showing that language and conventions have the power to marginalize.

The combined poetics of 'diverCity' - narrative, code-switching, and place formed the basis for the comparative literary and cultural analysis: In Dionne Brand's Toronto, the different worlds of the city and their coexistence and overlap become visible in 'the world in a city;' in Chang-rae Lee's New York, urban immigrant life and the integration of the different ethnic groups into society are visualized, explored, and translated in 'a city of wor(l)ds;' and in Karen Tei Yamashita's Los Angeles, different worlds come together, collide, and cooperate in 'the world city.'

With a literary analysis involving a poetics of 'diverCity,' it was the goal of this work to identify synchronic and specific aspects of global cities as a literary phenomenon. One of the challenges when comparing global cities as a literary phenomenon is that urban centers and their individual composition of cultural diversity are influenced not only by global synchronization processes but also by national, regional, and local particularities, such as the geography or the city's political or economic present and past. By considering the three key terms of this work - globalization and its effects, global cities as cultural nodal points, and cultural diversity in a globalizing age - combined with a structured analysis by a poetics of 'diverCity,' the specific characteristics ('specifiCity') and the synchronic impact ('synchroniCity') of global, urban, and ethnic literature were successfully identified.

The concept of 'specifiCity' describes the specific particularities of global cities as a literary phenomenon, partly shaped by a global city's present and past in economic, geo-political, and socio-cultural terms. Although Toronto, New 
York, and Los Angeles are three of the largest, most culturally diverse and globally connected metropolis in North America, some of their characteristics differ immensely. Whereas Toronto functions as the Canadian role model of 'multiculturalism' but still struggles to integrate particular immigrant groups, New York long functioned as the American immigrant city. Los Angeles, however, slowly became the new representative of American cultural politics following the change of immigration politics in the 1960s. Thus, the three different cities show how different national or regional discourses impact global cities and their politics on cultural diversity in a globalizing age.

Each analyzed global city is characterized by its unique composition of diversity, which developed due to migration politics, geographical proximity, and economic possibilities. Whereas Mexican Americans are a major ethnic group in Los Angeles, for example, New York does not feature one dominant group. Asians, however, play a major role in each of the global cities; a role that started increasing with laxer immigration policies in the 1960s and that has been influenced by the proximity to the Pacific Rim or by military involvements, such as the Korean War. Furthermore, the type and the degree of integration differs in the cities, as is revealed in the novels by the type of interaction, such as through the same ethnicity or other immigrants, the formation of interethnic groups, the description of where immigrants live and how they move and interact in urban space, or how different cultures do or cannot interact on eye-level. Therefore while the scale of immigration is extremely high in each city and has multiplied manifold since the mid-1960s, the origin of recent immigrants and their insertion into the existing political, ethnic, and class structures varies immensely.

The concept of 'synchroniCity' describes parallel phenomena in a global context, such as globalization and its effects, similar qualities of global cities as important cultural nodes in a world-encompassing network of flows as a form of homogenization, or the multiplicity of cultural diversity in global cities as a form of hybridization in a globalizing age. Common developments include increased connectivity, improved technologies, and perceived convergence. These forces lead to a growing global interdependence, multi-directional migrations, and the slow erosion of geo-political borders. Thus, global economic, cultural, and media exchange is triggered, creating a state of synchronicity. In the three novels, these effects are described as a time-space compression, Westernization, or multi-directional migration. Globalization and its effects also manifest themselves in the similar structural, economic, and cultural qualities of global cities. Powered and accelerated by the various globalization forces that are effective particularly in urban space due to the intensity of cultural flows, a synchronization process is expressed in a common urban multiplicity of cultures and their exchange. Global 
city inhabitants thus usually share a similar experience of urban cultural complexity. Therefore, constructions such as 'national identity' or 'nativity' are progressively questioned because cultural identity and exchange are increasingly understood and practiced in a flexible, dynamic, and multidirectional way.

Toronto, New York, and Los Angeles feature an overwhelming diversity of immigrants of different background. The three global cities function as sites of intense cultural contact: peaceful and creative as well as violent and eruptive. This tension is translated into literature, together forming an interethnic literature in Canada and the U.S. that captures the positive and negative effects of increasing encounters between an array of ethnicities in a globalizing age. Although each novel features different ideas of socio-cultural integration and selfdefinition, methods of an interethnic imagination represent a recurring theme. More than one ethnicity is featured in the novels with the goal to rewrite the formerly anglicized cities of Los Angeles or Toronto, to show inequalities, such as in the case of African and Asian Americans in New York or Toronto, or to illustrate collaboration or consolidation in a time of severe interethnic struggles in New York's 'Giuliani Time' or following the L.A. riots. The particular strategies and techniques, however, vary from portraying interethnic friendship combined with an intergenerational conflict to evoking a feeling of a shared history of suffering and a shared minority vernacular and political representation to illustrating a network-like collaboration against a threatening apocalypse.

This work's analysis of three contemporary North American novels has shown how a poetics of 'diverCity' provides the opportunity to examine ethnic urban literature in a globalizing age in a structured way. With the consideration of the common aesthetics of global literature, urban fiction, and ethnic writing 'the poetics of narrative,' 'the poetics of place,' and 'the poetics of codeswitching' - the focus of the analysis was on the impact of globalization and its effects, global cities as cultural nodal points, and cultural diversity in a globalizing age. Thus, globalization served as the temporal frame, global cities as the spatial frame, and cultural diversity as the topical frame.

By presenting different versions of an interethnic imagination identified in this work, the three novels contribute to a new poetics of ethnic global city literature ('diverCity'), which focuses not only on one but on multiple cultures that simultaneously compete and collaborate with each other. Thus, a global perspective of simultaneity and diversity is created, united by a common yet specific literary urban space. With the interdisciplinary paradigm shift, which began in the 1990s and intensified in the first decade of the new millennium, literary and cultural studies as well as their analysis have changed substantially. The perceived increased connectivity and convergence, the erosion of borders as well as the ac- 
celerated migration of the world-encompassing globalization process have been researched across the academic disciplines. Resultingly, North American literary and cultural studies were increasingly denationalizing and interethnic writing emerged, in particular in Canadian multicultural and Asian American literature. At the same time, established schools of urbanism were examining global cities and their qualities as structural, financial, and cultural nodal points in a worldwide network of flows of people, money, and goods. Considering the sum of these recent developments across the different fields, this analysis shows how contemporary North American global city literature in a globalizing age reflects the multiplicity of cultural diversity across ethnic boundaries.

The structured analysis involving a poetics of diverCity elaborates on how the novels illustrate and translate the multiplicity, complexity, and heterogeneity of global cities as cultural contact zones. Although each city and each novel features this phenomenon of an interethnic imagination only in a limited space and period of time, Toronto, New York, and Los Angeles enable such coexistence and tolerant interethnic interaction of their inhabitants. Therefore not only a global turn but also an interethnic turn in cultural and literary studies of the global city can be identified. This paradigmatic shift has the potential to be acknowledged and applied across disciplines. It shows how literary analysis contributes to a global, multi-perspectival understanding of literature, culture, and society. It can provide an interdisciplinary approach to understanding ethnic complexity beyond artificial categorizations, ethnic silos, and monocultural constraints.

Through the comparative analysis of the three novels, this work has identified the trend of globalization and its repercussions as moving in the direction of cultural hybridization and multiplicity. Globalization and its effects will continue to affect more and more people, literally encompassing the entire globe. This trend will be a significant force in the future, enriching the modes of interethnic representation and cross-cultural discourse in a world in which the physical borders and conceptual distinctions that have previously shaped one's identity are increasingly beginning to blur. Furthermore, due to the all-encompassing effects of such an unprecedented phenomenon, the global appeal of ethnic literatures coupled with global cities as a literary phenomenon and the related revelations will inspire and further the development of a juggernaut of future literary and cultural studies. 


\section{Works Cited}

Abu-Lughod, Janet L. New York, Chicago, Los Angeles: America's Global Cities. Minneapolis: University of Minnesota Press, 1999.

Adams, Rachel. "The Ends of America, the Ends of Postmodernism." TwentiethCentury Literature. 53.3. (Fall 2007): 248-272.

Adler, Brian, Beth Jarrett. "Capital v. Labor: Who Wins and Who Loses under the Immigration Act of 1990?" The University of Miami Inter-American Law Review. 23.3. (Spring/Summer 1992): 789-822.

Albrow, Martin. The Global Age: State and Society beyond Modernity. Cambridge: Polity Press, 1997.

Allahwala, Ahmed, Julie-Anne Boudreau, Roger Keil. "Neo-Liberal Governance: Entrepreneurial Municipal Regimes in Canada." Canadian Cities in Transition: New Directions in the Twenty-First Century. Eds. Trudi Bunting, Pierre Filion, Ryan Walker. Toronto: Oxford University Press, 2010. 210224.

Allen, J.P. "The Tortilla-Mercedes Divide in Los Angeles.” Political Geography. 21. (2002): 701-709.

Almyroudis, Eleftheria. Acculturation of Greek Immigrants in Toronto, Canada. Ottawa: National Library of Canada, 1991.

Anderson, Benedict. Imagined Communities: Reflections of the Origin and Spread of Nationalism. London: Verso, 1983.

Anisef, Paul, Michael Lanphier (eds.). The World in a City. Toronto: University of Toronto Press, 2003.

Anthony, M. Paul. "Figurative Language." Philosophy and Rhetoric. 3.4. (1970): 225-248.

Antor, Heinz. "From Postcolonialism and Interculturalism to the Ethics of Transculturalism in the Age of Globalization." From Interculturalism to Transculturalism: Mediating Encounters in Cosmopolitan Contexts. Eds. 
Heinz Antor, Matthias Merkl, Klaus Stierstorfer, Laurenz Volkmann. Heidelberg: Winter, 2010. 1-13.

Antor, Heinz. Inter- und Transkulturelle Studien: Theoretische Grundlagen und Interdisziplinäre Praxis. Heidelberg: Winter, 2006.

Anzaldúa, Gloria. Borderlands/La Frontera: The New Mestiza. San Francisco: aunt lute, 1987.

Appadurai, Arjun. "Disjuncture and Difference in the Global Cultural Economy." Global Culture. Ed. Mike Featherstone. London: Sage, 1990.

Appadurai, Arjun. Modernity at Large: Cultural Dimensions of Globalization. Minneapolis: University of Minnesota Press, 1996.

Arndt, Susan, Dirk Naguschewski, Robert Stockhammer (eds.). Exophonie: Anders-Sprachigkeit (in) der Literatur. Berlin: Kadmos, 2007.

Ashcroft, Bill, Gareth Griffith, Helen Tiffin (eds.). Post-Colonial Studies: The Key Concepts. London, New York: Routledge, 2000.

Ashcroft, Bill, Gareth Griffith, Helen Tiffin (eds.). The Empire Writes Back: Theory and Practice in Post-Colonial Literatures. London: Routledge, 1989. Augé, Marc. "Die Stadt: Vom Imaginären zur Fiktion." Der Sinn der Sinne. Ed. Uta Brandes. Kunst- und Ausstellungshalle der Bundesrepublik Deutschland GmbH. Bonn, Göttingen: Steidl, 1998.

Augé, Marc. Non-places: An Introduction to Supermodernity. London: Verso, 2008 [1995].

Auster, Paul. "City of Glass." The New York Trilogy. London: Penguin, 1990 [1985]. 1-158.

Auster, Paul. Moon Palace. New York: Viking Press, 1989.

Bachmann-Medick, Doris. Cultural Turns. Neuorientierungen in den Kulturwissenschaften. Hamburg: Rowohlt Taschenbuch Verlag, 2006.

Badura, Jens (ed.). Mondialisierungen: 'Globalisierung' im Lichte transdisziplinärer Reflexionen. Bielefeld: transcript, 2006.

Bain, Alison. "Re-Imagining, Re-Elevating, and Re-Placing the Urban: The Cultural Transformation of the Inner City in the Twenty-First Century". Canadian Cities in Transition: New Directions in the Twenty-First Century. Eds. Bunting, Trudi, Brenner, Pierre Filion, Ryan Walker. Don Mills: Oxford University Press, 2010. 262-275.

Bakhtin, Mikhail. The Dialogical Imagination: Four Essays. Ed. Michael Holquist. Austin: University of Texas, 1981.

Ball, John Clement. "White City, Black Ancestry: The Immigrant's Toronto in the Stories of Austin Clarke and Dionne Brand." Open Letter. 8.8. (Winter 1994): 9-19. 
Barabási, Albert-László. Linked: How Everything Is Connected to Everything Else and What It Means for Business, Science, and Everyday Life. New York: Penguin, 2002.

Barber, Benjamin. R. Jihad vs. McWorld. New York: Random House, 1995.

Barbero, Jesus-Martin. "Latin America: Cultures in the Communication Media." Journal of Communication. 43.2. (1993): 18-30.

Barker, Chris. The SAGE Dictionary of Cultural Studies. London: Sage Publications, 2004.

Barnett, Stuart. Hegel after Derrida. London: Routledge, 1998.

Barthes, Roland. "Semiology and the Urban." Rethinking Architecture: A Reader in Cultural Theory. Eds. Neil Leach. London: Routledge, 1997.

Bassnett, Susan. "Preface." Constructing Cultures: Essays on Literary Translation. Multilingual Matters. Eds. Susan Bassnett, André Lefèvre. Clevedon: Cromwell Press, 1998.

Beauregard, Robert A. "City of Superlatives." City \& Community. 2.3 (2003): 183-199.

Beaverstock, Jonathan V., Richard G. Smith, Peter J. Taylor. "World City Network: A New Meta-Geography?" Annals of the Association of American Geographers. 90. (2000): 95-120.

Beck, Ulrich. Was ist Globalisierung? Irrtümer des Globalismus - Antworten auf Globalisierung. Frankfurt: Suhrkamp, 1997.

Beecher Stowe, Harriet. Uncle Tom's Cabin; or, Life Among the Lowly. Boston: John P. Jewitt, 1852.

Beise, Arnd. "The Narrative... I cannot tell: Beryl Gilroy überschreibt die Geschichte von Inkle und Yarico." Räume der Hybridität: Postkoloniale Konzepte in Theorie und Literatur. Ed. Christof Hamann et al. Hildesheim: Georg Olms Verlag, 2002. 213-236.

Bell, Daniel A., de-Shalit, Avner. The Spirit of Cities: Why the Identity of a City Matters in a Global Age. Princeton: Princeton University Press, 2011.

Bender, Thomas. The Unfinished City. New York: The New Press, 2002.

Benhabib, Seyla. The Claims of Culture: Equality and Diversity in the Global Era. Princeton: Princeton University Press, 2002.

Benito, Jesús, Ana Ma Manzanas, Begoña Simal. Uncertain Mirrors: Magical Realisms in US Ethnic Literatures. Amsterdam: Rodopi, 2009.

Bentley, D.M.R. 'Chapter 14: 'Me and the City That's Never Happened Before': Dionne Brand in Toronto." Canadian Architexts: Essays on Literature and Architecture in Canada, 1759-2005. Canadian Poetry Press, 2005. http://www.uwo.ca/english/canadianpoetry/architexts/essays/brand.htm. 
Bernal, Maria Clara. "Transculturation: Representing/Reinventing Latin America." Transit. Art from Latin America in the University Gallery. Londres: University of Essex, 2002.

Beveridge, Andrew A., Susan Weber. "Race and Class in the Developing New York and Los Angeles Metropolises." New York \& Los Angeles: Politics, Society, and Culture. A Comparative View. Ed. David Halle. Chicago: The University of Chicago Press, 2003. 49-78.

Bhabha, Homi K. "The Third Space." Identity, Community Culture, Difference.

Ed. Jonathan Rutherford. London: Lawrence \& Wishart, 1990. 207-221.

Bhabha, Homi K. The Location of Culture. London: Routledge, 1994.

Birkett, Dea. New Statesman and Society. (March 15, 1991): 38.

Birkle, Carmen. Migration - Miscegenation - Transculturation: Writing Multicultural America into the Twentieth Century. American Studies - A Monograph Series. 114. Heidelberg: Winter, 2004.

Bissoondath, Neil. Selling Illusions: The Cult of Multiculturalism in Canada. Toronto: Penguin, 1994.

Böhme, Hartmut (ed.). "Einleitung: Raum - Bewegung - Topographie. " Topographien der Literatur: Deutsche Literatur im transnationalen Kontext. Stuttgart: J.B. Metzler, 2005. IX-XXIII.

Borderless: A Docu-Drama About the Lives of Undocumented Workers. Dir. Min Sook Lee. Narr. Dionne Brand. KAIROS Canadian Ecumenical Justice Initiatives, 2006.

Borsò, Vittoria. "Topologie als literaturwissenschaftliche Methode: die Schrift des Raums und der Raum der Schrift." Topologie. Zur Raumbeschreibung in der Kultur- und Medienwissenschaft. Ed. Stephan Günzel. Bielefeld: transcript, 2007. 279-295.

Boyle, T. C. The Tortilla Curtain. New York: Viking Press, 1995.

Brand, Dionne. A Map to the Door of No Return: Notes to Belonging. Toronto: Random House Canada, 2001.

Brand, Dionne. At the Full and Change of the Moon. Toronto: Knopf Canada, 1999.

Brand, Dionne. In Another Place, Not Here. Toronto: Knopf Canada, 1996.

Brand, Dionne. No Language is Neutral. Toronto: Coach House Press, 1990.

Brand, Dionne. Ossuaries Toronto: McClelland \& Stewart, 2010.

Brand, Dionne. thirsty. Toronto: McClelland \& Stewart, 1998.

Brand, Dionne. What We All Long For. New York: Thomas Dunne Books, 2005.

Brandt, Stefan L., Winfried Fluck, Frank Mehring (eds.). Transcultural Spaces:

Challenges of Urbanity, Ecology, and the Environment in the New Millenni- 
um. REAL - Yearbook of Research in English and American Literature, 26. Narr: Tübingen, 2010.

Brantz, Dorothee, Sasha Disko, Georg Wagner-Kyora (eds.) Thick Space: Approaches to Metropolitanism. Bielefeld: transcript, 2010.

Brathwaite, Edward Kamau. "Creolization in Jamaica." The Development of Creole Society in Jamaica, 1770-1820. Ed. Ashcroft et al. Oxford: Clarendon Press, 1971. 202-205.

Brenner, Neil, Roger Keil (eds.). The Global Cities Reader. Oxon: Routledge, 2006.

Brenner, Neil. "Global Cities, Glocal States: Global City Formation and State Territorial Restructuring in Contemporary Europe." The Global Cities Reader. Eds. Neil Brenner, Roger Keil. London: Routledge, 2006. 259-266.

Brenner, Neil. "Stereotypes, Archetypes, and Prototypes: Three Uses of Superlatives in Contemporary Urban Studies“. City \& Community. 2.3. (September 2003): 205-216.

Bronger, Dirk. Metropolen, Megastädte, Global Cities: Die Metropolisierung der Erde. Darmstadt: Wissenschaftliche Buchgesellschaft, 2004.

Brydon, Diana. "A Place on the Map of the World: Locating Hope in Shani Mootoo's He Drown She in the Sea and Dionne Brand's What We All Long For." MaComere. 8. (2006): 94-111.

Buma, Michael. "Soccer and the City. The Unwieldy National in Dionne Brand's What We All Long For." Canadian Literature. 202. (Autumn 2009). 12-27.

Cameron, Elspeth (ed.). Multiculturalism and Immigration in Canada: An Introductory Reader. Toronto: Canadian Scholars' Press, 2004.

Canclini, García Nestor. Hybrid Cultures. Minneapolis: University of Minnesota Press, 1995.

Canevacci, Massimo. "Image Accumulation and Cultural Syncretism." Theory Culture and Society. 9.3. (1992): 95-110.

Cannato, Vincent J. American Passage: The History of Ellis Island. New York: Harper Perennial, 2010.

Carter, Erica, James Donald, Judith Squires (eds.). Space \& Place: Theories of Identity and Location. London: Lawrence \& Wishart, 1993.

Cassirer, Ernst. "Mythischer, ästhetischer und theoretischer Raum." Raumtheorie. Grundlagentexte aus Philosophie und Kulturwissenschaften. Eds. Jörg Dünne, Stephan Günzel. Frankfurt: Suhrkamp, 2006 [1931]. 485-500.

Castells, Manuel (ed.). The Network Society: A Cross-cultural Perspective. Cheltenham: Elgar, 2004.

Castells, Manuel. End of Millenium. Oxford: Blackwell, 1998. 
Castells, Manuel. The Power of Identity. Oxford: Blackwell, 1997.

Castells. Manuel. The Rise of the Network Society. Oxford: Blackwell, 1996.

Chae, Youngsuk. Politicizing Asian American Literature: Towards a Critical Multiculturalism. New York: Routledge, 2008.

Chambers, Iain. Migrancy, Culture, Identity. London: Routledge, 1994.

Chandler, Raymond. The Big Sleep. London: Penguin, 1978 [1939].

Chang, Yoonmee. Writing the Ghetto: Class, Authorship, and the Asian American Ethnic Enclave. New Brunswick: Rutgers University Press, 2010.

Chen, Tina Yih-Ting. "Recasting the Spy, Rewriting the Story: The Politics of Genre in Native Speaker by Chang-rae Lee." Form and Transformation in Asian American Literature. Eds. Zhou Xiaojing, Samina Najmi. Seattle: University of Washington Press, 2005a. 249-267.

Chen, Tina Yih-Ting. Double Agency: Acts of Impersonation in Asian American Literature and Culture. Stanford: Stanford University Press, $2005 \mathbf{b}$.

Chu, Patricia P. Assimilating Asians: Gendered Strategies of Authorship in Asian America. Durham: Duke University Press, 2000.

Clark, David. Urban World / Global City. London: Routledge, 1996.

Clarke, Graham. "“The Great Wrong Place': Los Angeles as Urban Milieu." The American City: Literary and Cultural Perspectives. Ed. Graham Clarke. London: Vision Press, 1988. 124-145.

Clifford, James. The Predicament of Culture: Twentieth-Century Ethnography, Literature, and Art. Cambridge: Harvard University Press, 1988.

Cole, Dana. "Linguistic Journey to the Border". Apples - Journal of Applied Language Studies. 5.1. (2011): 77-92.

Corley, Liam. “'Just Another Ethnic Pol': Literary Citizenship in Chang-rae Lee's Native Speaker." Studies in the Literary Imagination. 37.1. (Spring 2004): 61-81.

Cornejo Polar, Antonio. "Migrant Conditions and Multicultural Intertextuality: The Case of José María Arguedas." José María Arguedas. Reconsiderations of Latin American Cultural Studies. Eds. Ciro A. Sandoval, Sandra M. Boschetto-Sandoval. Athens: Ohio University Center for International Studies, 1998. 187-198.

Cowart, David. Trailing Clouds: Immigrant Fiction in Contemporary America. Ithaca: Cornell Univ. Press, 2006.

Cuddon, John Anthony. The Penguin Dictionary of Literary Terms and Literary Theory. London: Penguin, 1999.

Culler, Jonathan. Literary Theory: A Very Short Introduction. Oxford: Oxford University Press, 2000. 
Davis, Mike. City of Quartz: Excavating the Future in Los Angeles. London, New York: Verso, 1990.

De Toro, Alfonso. "Globalization - New Hybridities - Transidentities: Recognition - Difference." New Hybridities: Societies and Cultures in Transition. Ed. Frank Heidemann et al. Hildesheim: Georg Olms Verlag, 2006. 19-37.

Dear, Michael J., Steven Flusty (eds.). From Chicago to L.A.: Making Sense of Urban Theory. Ed. Michael J. Dear. Thousand Oaks: SAGE, 2002.

Dear, Michael. "In the City, Time Becomes Visible: Intentionality and Urbanism in Los Angeles, 1781-1991." The City: Los Angeles and Urban Theory at the End of the Twentieth Century. Ed. Allen John Scott. Berkeley: University of California Press, 1998, 76-105.

Deleuze, Gilles, Felix Guattari. A Thousand Plateaus: Capitalism and Schizophrenia. Minneapolis: University of Minnesota Press, 1987.

DeLillo, Don. Cosmopolis. New York: Scribner, 2003.

DeLillo, Don. Falling Man. A Novel. New York, London et al: Scribner, 2007.

DeLillo, Don. White Noise. New York: Viking, 1985.

Derrida, Jacques. "The Law of Genre.” Critical Inquiry. 7.1. (Autumn 1980): 5581.

Derrida, Jacques. Speech and Phenomena and Other Essays on Husserl's Theory of Signs. Trans. David B. Allison. Evanston: Northwestern University Press, 1973.

Didion, Joan. Play It As It Lays. New York: Farrar, Straus and Giroux, 2005 [1970].

Döblin, Alfred. Berlin Alexanderplatz: Die Geschichte vom Franz Biberkopf. Berlin: S. Fischer Verlag, 1929.

Dobson, Kit. "'Struggle Work': Global and Urban Citizenship in Dionne Brand's What We All Long For." Studies in Canadian Literature. 31.2. (2006): 88-104.

Dobson, Kit. Transnational Canadas: Anglo-Canadian Literature and Globalization. Waterloo: Wilfrid Laurier University Press, 2009.

Doff, Sabine, Frank Schulze-Engler (eds.). Beyond “Other Cultures”: Transcultural Perspectives on Teaching the New Literatures in English. Trier: Wissenschaftlicher Verlag Trier, 2011.

Döring, Jörg, Tristan Thielmann (eds.). Das Raumparadigma in den Kultur-und Sozialwissenschaften. Bielefeld: transcript, 2007.

Dos Passos, John. Manhattan Transfer. Boston: Houghton Mifflin, 1925.

Dupont, Louis, Nathalie Lemarchand. "Official Multiculturalism in Canada: Between Virtue and Politics." Comparative Perspectives on Ethnicity, Race, 
and Nation. Eds. Grant H. Cornwell, Eve Walsh Stoddard. Lanham: Rowman \& Littlefield, 2001. 309-335.

Dwyer, June. "Speaking and Listening: The Immigrant as Spy Who Comes in from the Cold." The Immigrant Experience in North American Literature: Carving Out a Niche. Eds. Katherine B. Payant, Toby Rose. Westport: Greenwood Press, 1999. 73-82.

Easthope, Antony. "Bhabha, Hybridity and Identity." Textual Practice. 12.2. (1998): 341-348.

Eastman, Carol M. (eds.). Codeswitching. Clevedon: Multilingual Matters, 1992.

Edwards, Sarah. "Anonymous Encounters: The Structuring of Space in Postmodern Narratives of the City." Writing the Modern City: Literature, Architecture, Modernity. Eds. Sarah Edwards, Jonathan Charley. London, New York: Routledge, 2012. 165-177.

Ellison, Ralph. Invisible Man. New York: The Modern Library, 1952.

Elton, Sarah, Kevin Robbins (eds.). City of Words: Toronto through Her Writers' Eyes. Toronto: Cormorant Books, 2009.

Engles, Tim. "'Visions of Me in the Whitest Raw Light': Assimilation and Doxic Whiteness in Chang-Rae Lee's Native Speaker." Hitting Critical Mass: A Journal of Asian American Cultural Studies. 4.2. (1997): 27-48.

Eoyang, Eugene Chen. "English as a Postcolonial Tool: Anti-hegemonic Subversions in a Hegemonic Language." English Today 76. 19.4. (October 2003): 23-29.

Erfurt, Jürgen. (ed.). Transkulturalität und Hybridität: L'espace francophone als Grenzerfahrung des Sprechens und Schreibens. Frankfurt: Peter Lang, 2005.

Ernst, Jutta, Brigitte Glaser (eds.). The Canadian Mosaic in the Age of Transnationalism. Heidelberg: Winter, 2010.

Ette, Ottmar. "Einleitung: von „Literaturen ohne festen Wohnsitz.” Global Playing in der Literatur: Ein Versuch über die Neue Weltliteratur. Ed. Elke Sturm-Trigonakis. Würzburg: Königshausen und Neumann, 2007. 13-23.

Ette, Ottmar. ÜberLebenswissen: Die Aufgabe der Philologie. Berlin: Kadmos, 2004.

Ewing, Katherine Pratt. "Crossing Borders and Transgressing Boundaries: Metaphors for Negotiating Multiple Identities." Ethos. 26.2. (1998): 262-267.

Eze, Chielozona. The Dilemma of Ethnic Identity: Alain Locke's Vision of Transcultural Societies. Lewiston: Edwin Mellen Press, 2005.

Fanon, Franz. The Wretched of the Earth. Harmondsworth: Penguin, 1967.

Featherstone, Mike, Scott Lash (eds.). Spaces of Culture: City, Nation, World. London: Sage: 1999.

Featherstone, Mike. Undoing Culture. London: Sage, 1995. 
Fellner, Astrid M. "Translating Toronto on a Bicycle: Dionne Brand's What We All Long For and the Challenges of Urbanity." Transcultural Space: Challenges of Urbanity, Ecology, and the Environment. Narr: Tübingen, 2010. 231-244.

Fitz, Karsten. Negotiating History and Culture: Transculturation in Contemporary Native American Fiction. Frankfurt: Peter Lang, 2001.

Fitzgerald, F. Scott. The Last Tycoon. New York: Scribner, 1941.

Fitzgerald, Thomas K. "Understanding Diversity in the Workplace: Cultural Metaphors or Metaphors of Identity?" Business Horizons. (July-August 1997): 66-70.

Fludernik, Monika. An Introduction to Narratology. London: Routledge, 2009.

Fludernik, Monika. Hybridity and Postcolonialism. Tübingen: Stauffenburg Verlag, 1998.

Foer, Jonathan Safran. Extremely Loud \& Incredibly Close. Boston, New York: Houghton Mifflin, 2005.

Fogelson, Robert. The Fragmented Metropolis: Los Angeles, 1850-1930. Cambridge: Harvard University Press, 1967.

Foner, Nancy. From Ellis Island to JFK: New York's Two Great Waves of Immigration. New Haven, London: Yale University Press, 2000.

Foucault, Michel, Jay Miskowiec. "Of Other Spaces.” Diacritics. 6.1. (Spring 1986; based on a lecture in 1967): 22-27.

Frank, Michael C. "Die Literaturwissenschaften und der spatial turn: Ansätze bei Jurij Lotman und Michail Bachtin." Raum und Bewegung in der Literatur: Die Literaturwisschenschaften und der Spatial Turn. Eds. Wolfgang Hallet, Birgit Neumann. Bielefeld: transcript, 2009. 53-80.

Freud, Sigmund. "Das Unheimliche." Gesammelte Werke. 12. Frankfurt: Fischer, 1986. 229-268.

Freyermuth, Gundolf S. "Edges \& Nodes / Cities \& Nets: The History and Theories of Networks and What They Tell Us about Urbanity in the Digital Age." Transcultural Spaces: Challenges of Urbanity, Ecology, and the Environment in the New Millennium. Ed. Stefan L. Brandt, Winfried Fluck, Frank Mehring. REAL - Yearbook of Research in English and American Literature. 26. Tübingen: Narr, 2010. 55-73.

Friedlander, Eli. “The Measure of the Contingent: Walter Benjamin's Dialectical Image". boundary 2. 35.3. (Fall 2008): 1-26.

Friedman, Jonathan. "The Hybridization of Roots and the Abhorrence of the Bush.” Spaces of Culture: City, Nation, World. Ed. Mike Featherstone et al. London: Sage, 1999. 230-256.

Friedman, Jonathan. Cultural Identity and Global Process. London: Sage, 1994. 
Friedman, Thomas L. The World is Flat: A Brief History of the Twenty-First Century. New York: Farrar, Strauss and Giroux, 2005.

Friedmann, John. "The World City Hypothesis." Development and Change. 17.1. (1986): 69-83.

Fruner, Sara. "Dig Her Text Deep to Draw My Text Out! Translating-Exploring Dionne Brand's Land." Journal of Black Canadian Studies (New Dawn). 2.1. (2007): 3-14.

García Canclini, Néstor. Hybrid Cultures: Strategies for Entering and Leaving Modernity. Minneapolis: University of Minnesota, 2005.

Garner, Dwight. New York Times Book Review. September 5, 1999.

Gebauer, Gunter, Christoph Wulf. Mimesis: Culture, Art, Society. Berkeley: University of California Press, 1995.

Gelfant, Blanche H. The American City Novel. Norman: University of Oklahoma Press, 1970.

Genette, Gérard. Palimpseste: Die Literatur auf zweiter Stufe. Frankfurt: Suhrkamp, 1993.

Gibbon, John Murray. Canadian Mosaic: The Making of a Northern Nation. Toronto: McClelland \& Stewart, 1938.

Gibson, William. Pattern Recognition. New York: Berkley Books, 2003.

Giddens, Anthony. Modernity and Self-Identity: Self and Society in the Late Modern Age. Cambridge: Polity Press, 1991.

Giddens, Anthony. The Consequences of Modernity. Cambridge: Polity Press, 1990.

Gier, Jean Vengua, Carla Alicia Tejeda. An Interview with Karen Tei Yamashita. University of California, Berkeley, 1998, 11.03.2008. <http://social.chass .ncsu.edu/jouvert/v2i2/yamashi.htm>.

Giles, Wenona. Portuguese Women in Toronto: Gender, Immigration and Nationalism. Toronto: University of Toronto Press, 2002.

Gippert, Wolfgang, Petra Götte, Elke Kleinau (eds.). Transkulturalität: Genderund bildungshistorische Perspektiven. Bielefeld: transcript, 2008.

Giuliani, Rudolph. "The Second Inaugural Address: The Agenda for Permanent Change." Empire City: New York Through the Centuries. Eds. Kenneth T. Jackson, David S. Dunbar. New York: Columbia University Press, 2002. 908-917.

Gladstone, David L., Susan S. Fainstein. "The New York and Los Angeles Economies." New York \& Los Angeles: Politics, Society, and Culture: A Comparative View. Ed. David Halle. Chicago: The University of Chicago Press, 2003. 79-98. 
Glazer, Nathan, Daniel P. Moynihan. Beyond the Melting Pot: The Negroes, Puerto Ricans, Jews, Italians, and Irish of New York City. Cambridge: M.I.T. Press, 1964.

Glixman, Elizabeth P. “An Interview with Karen Tei Yamashita.” ECLECTICA Reviews \& Interviews (Oct/Nov 2007). 14 Mar. $2010<\mathrm{http}: / / w w w . e c l e c t i c a$ .org/v11n4/glixman_yamashita.html>.

Glomb, Stefan. Erinnerung und Identität im britischen Gegenwartsdrama. Tübingen: Narr, 1997.

Gómez-Peña, Guillermo. The New World Border: Prophesies, Poems and Loqueras for the End of the Century. San Francisco: City Lights, 1996.

Gonzalez Baker, Susan. "The 'Amnesty' Aftermath: Current Policy Issues Stemming from the Legalization Programs of the 1986 Immigration Reform and Control Act." International Migration Review. 31.1. (Spring 1997): 527.

Good, Kristin R. Municipalities and Multiculturalism: The Politics of Immigration in Toronto and Vancouver. Toronto: University of Toronto Press, 2009.

Goodman, Felicitas D. Speaking in Tongues: A Cross-cultural Study of Glossolalia. Oxford: University of Chicago Press, 1972.

Gottlieb, Robert. Reinventing Los Angeles: Nature and Community in the Global City. Cambridge: MIT, 2007.

Greenblatt, Stephen. "Culture.” Critical Terms for Literary Study. Eds. Frank Lentricchia, Thomas McLaughlin. Chicago: University of Chicago Press, 1990. 225-232.

Gregorovich, Andrew. Ukrainian Toronto: A Directory of Ukrainian Cultural Groups, Organizations and Institutions in Toronto. Toronto: Ukrainian Canadian Committee, Toronto Branch, 1976.

Griffin, Keith. "Culture and Economic Growth: The State and Globalization." Global Futures. Ed. Jan Nederveen Pieterse, 2000. 189-202.

Grobman, Laurie. Multicultural Hybridity: Transforming American Literary Scholarship and Pedagogy. Urbana, IL: National Council of Teachers of English (NCTE), 2007.

Günzel, Stephan. "Raum - Topographie - Topologie." Topologie: Zur Raumbeschreibung in den Kultur- und Medienwissenschaften. Ed. Stephan Günzel. Bielefeld: transcript, 2007. 13-29.

Günzel, Stephan. "Spatial Turn - Topographical Turn - Topological Turn: Über die Unterschiede zwischen Raumparadigmen." Spatial Turn: Das Raumparadigma in den Kultur- und Sozialwissenschaften. Ed. Jörg Döring. Bielefeld: transcript, 2008. 219-237. 
Haggis, Paul. Crash: The Movie. Lionsgate: Yari Film Group, DEJ Productions, 2004.

Hall, Peter V. "The Global Imperative." Canadian Cities in Transition: New Directions in the Twenty-First Century. Eds. Trudi Bunting, Pierre Filion, Ryan Walker. Toronto: Oxford University Press, 2010. 56-69.

Hall, Stuart. "NNew Ethnicities' in 'Race'." Culture and Difference. Ed. James Donald et al. London: Sage, 1992. 252-259.

Halle, David (ed.). New York \& Los Angeles: Politics, Society, and Culture. A Comparative View. Chicago: The University of Chicago Press, 2003.

Halle, David, Kevin Rafter. "Riots in New York and Los Angeles: 1935-2002." New York \& Los Angeles: Politics, Society, and Culture. A Comparative View. Ed. David Halle. Chicago: The University of Chicago Press, 2003a. 341-366.

Halle, David, Robert Gedeon, Andrew A. Beveridge. "Residential Separation and Segregation, Racial and Latino Identity, and the Racial Composition of Each City." New York \& Los Angeles: Politics, Society, and Culture. A Comparative View. Ed. David Halle. Chicago: The University of Chicago Press, 2003b. 150-186.

Hallet, Wolfgang, Birgit Neumann (eds.). "Raum und Bewegung in der Literatur: Zur Einführung." Raum und Bewegung in der Literatur. Die Literaturwissenschaften und der Spatial Turn. Bielefeld: transcript, 2009. 11-32.

Hannerz, Ulf. "Cosmopolitans and Locals in World Culture." Global Culture. Ed. Mike Featherstone. London: Sage, 1990. 237-251.

Harney, Robert F. "The Italian Community in Toronto." Two Nations, Many Cultures: Ethnic Groups in Canada. Ed. Jean Leonard Elliott. Scarborough: Prentice Hall, 1983.

Harvey, David. Justice, Nature and the Geography of Difference. Cambridge: Blackwell, 1996.

Harvey, David. The Condition of Postmodernity. Oxford: Basil Blackwell, 1989.

Hauser, Johannes. "Structuring the Apokalypse: Chaos and Order in Karen Tei Yamashita's Tropic of Orange." PhiN. 37. (2006): 1-32.

Head, Wilson A., Jeri Lee. The Black Presence in the Canadian Mosaic: A Study of Perception and the Practice of Discrimination against Blacks in Metropolitan Toronto. Toronto: Ontario Human Rights Commission, 1975.

Heise, Ursula K. "1970, Planet Earth: The Imagination of the Global." The Edinburgh Companion to Twentieth-Century Literatures in English. Eds. Brian McHale, Randall Stevenson. Edinburgh: Edinburgh University Press, 2006. 201-216. 
Heise, Ursula K. Sense of Place and Sense of Planet: The Environmental Imagination of the Global. Oxford: Oxford University Press, 2008.

Henry, Frances. The Caribbean Diaspora in Toronto: Learning to Live with Racism. Toronto: University of Toronto Press, 1994.

Hepp, Andreas. Transkulturelle Kommunikation. Konstanz: UVK Verlagsgesellschaft, 2006.

Herman, David. Story Logic: Problems and Possibilities of Narrative. Lincoln: University of Nebraska Press, 2002.

Hill, Mike (ed.). Whiteness: A Critical Reader. New York: New York University Press, 1997.

Hirst, Paul Q., Grahame Thompson. Globalization in Question. Cambridge: Polity Press, 1996.

Hoernig, Heidi, ZhiXi (Cecilia) Zhuang. "New Diversity: Social Change as Immigration." Canadian Cities in Transition: New Directions in the TwentyFirst Century. Eds. Trudi Bunting, Pierre Filion, Ryan Walker. Toronto: Oxford University Press, 2010. 150-169.

Homberger, Eric. New York City: A Cultural History. Northampton: Interlink Books, 2008.

Hong, Catherine. "In Brief: Native Speaker by Chang-rae Lee." Vogue. April 1995: 236.

Hou, Feng. "Recent Immigration and the Formation of Visible Minority Neighborhoods in Canada's Large Cities”. Research Paper Series. 221. Ottawa: Statistics Canada, Analytical Studies, 2004.

Howes, David. (ed.) Cross-Cultural Consumption: Global Markets, Local Realities. London: Routledge, 1996.

Huang, Betsy. "Citizen Kwang: Chang-rae Lee's Native Speaker and the Politics of Consent." Journal of Asian American Studies. 9.3. (2006): 243-269.

Huang, Betsy. Contesting Genres in Contemporary Asian American Fiction. New York: Palgrave Macmillan, 2010.

Huggan, Graham. "Derailing the 'Trans'? Postcolonial Studies and the Negative Effects of Speed." Inter- und Transkulturelle Studien: Theoretische Grundlagen und interdisziplinäre Praxis. Ed. Heinz Antor. Heidelberg: Winter, 2006. 55-61.

Hughes, Geoffrey. Political Correctness: A History of Semantics and Culture. Malden: Wiley-Blackwell, 2010.

Huntington, Samuel P. The Clash of Civilizations and the Remaking of World Order. New York: Simon \& Schuster, 1996.

Huntington, Samuel P. The Third Wave: Democratization in the Late Twentieth Century.Norman: Oklahoma University Press, 1991. 
Hutnyk, John. "Adorno at Womad: South Asia Crossovers and the Limits of Hybridity-Talk." Debating Cultural Hybridity: Multi-Cultural Identities and the Politics of Anti-Racism. Ed. Pnina Werbner et al. London: Zed Books, 1997. 106-138.

Hutton, Tom. "Economic Change in Canadian Cities: Locational Dynamics of Employment." Canadian Cities in Transition: New Directions in the TwentyFirst Century. Eds. Trudi Bunting, Pierre Filion, Ryan Walker. Toronto: Oxford University Press, 2010. 110-130.

Huyssen, Andreas. Other Cities, Other Worlds: Urban Imaginaries in a Globalizing Age. Durham: Duke University Press, 2008.

Isurin, Ludmila, Donald Winford, Kees de Bot (eds.). Multidisciplinary Approaches to Code Switching. Amsterdam, Philadelphia: John Benjamins, 2009.

Iyer, Pico. The Global Soul: Jet Lag, Shopping Malls, and the Search for Home. New York: Vintage Departures, 2001.

Jäger, Dietrich. Erzählte Räume. Studien zur Phänomenologie der epischen Geschehensumwelt. Würzburg: Königshausen \& Neumann, 1998.

Jansen, Clifford, Lawrence Lam. "Immigrants in the Greater Toronto Area: A Sociodemographic Overview." The World in a City. Eds. Paul Anisef, Michael Lanphier. Toronto: University of Toronto Press, 2003. 63-131.

Jillson, Calvin C. Pursuing the American Dream: Opportunity and Exclusion over Four Centuries. Lawrence: University Press of Kansas, 2004.

Johansen, Emily. "Streets are the Dwelling Place of the Collective: Public Space and Cosmopolitan Citizenship in Dionne Brand's What We All Long For." Canadian Literature. 196. (Spring 2008): 48-62.

Joyce, James. Ulysses. Paris: Sylvia Beach, 1922.

Kaplan, Amy, Donald E. Pease (eds.). Cultures of United States Imperialism. Durham: Duke University Press,1993.

Kaufmann, Karen M. "The Mayoral Politics of New York and Los Angeles." Ed. David Halle. New York \& Los Angeles: Politics, Society, and Culture. A Comparative View. Chicago: The University of Chicago Press, 2003. 314340.

Keil, Roger, Gene Desfor. "Ecological Modernisation in Los Angeles and Toronto." Local Environment. 8.1. (2003): 27-44.

Keil, Roger. Los Angeles. Globalization, Urbanization and Social Struggles. Chichester: John Wiley \& Sons, 1998.

Kellman, Steven G. (ed.). Switching Languages: Translingual Writers Reflect on Their Craft. Lincoln: University of Nebraska Press, 2003. 
Keunen, Bart. "The Plurality of Chronotopes in the Modernist City Novel: The Case of Manhattan Transfer." English Studies. 5. (2001): 420-436.

Khaled, Nidhal. At Home and in Exile: Muslim Queer Community in Toronto. Lambert Academic Publishing, 2009.

Kich, Martin. "Chang-rae Lee." Asian American Novelists: A BioBibliographical Critical Sourcebook. Ed. Emmanuel Sampath Nelson. Westport: Greenwood Press, 2000. 175-179.

Kiel, L. Douglas, Euel W. Elliott (eds.). Chaos Theory in the Social Sciences: Foundations and Applications. Ann Arbor: University of Michigan Press, 1996.

Kim, Daniel Y. "Do I, too, Sing America? Vernacular Representations and Chang-rae Lee's Native Speaker." Journal of Asian American Studies. 6.7. (2003): 231-260.

Kim, Daniel Y. Writing Manhood in Black and Yellow: Ralph Ellison, Frank Chin, and the Literary Politics of Identity. Stanford: Stanford University Press, 2005.

Kingsley, Malarney Shaun. Culture, Ritual and Revolution in Vietnam. University of Hawaii Press, 2002.

Kingston, Maxine Hong. The Woman Warrior: Memoirs of a Girlhood Among Ghosts. New York: Knopf, 1976.

Kley, Antje. "“Beyond Control, but not Beyond Accomodation': Anmerkungen zu Homi K. Bhabhas Unterscheidung zwischen Cultural Diversity und Cultural Difference." Räume der Hybridität: Postkoloniale Konzepte in Theorie und Literatur. Ed. Christof Hamann et al. Hildesheim: Georg olms Verlag, 2002. 53-66.

Klimasmith, Betsy. At Home in the City: Urban Domesticity in American Literature and Culture, 1850 - 1930. Durham: University of New Hampshire Press, 2005.

Koman, Rita G. "Ellis Island: The Immigrants' Experience." OAH Magazine of History. (Summer 1999): 31-37.

Kortenaar, Neil Ten. "Multiculturalism and Globalization." The Cambridge History of Canadian Literature. Eds. Coral Ann Howells, Eva-Marie Kröller. Cambridge: Cambridge University Press, 2009. 556-579.

Kraidy, Marwan M. "Hybridity in Cultural Globalization." Communication Theory. 12.3. (2002): 316-339.

Kraidy, Marwan M. Hybridity: Or the Cultural Logic of Globalization. Philadelphia: Temple, 2005.

Kulyk Keefer, Janice. "Writing, Reading, Teaching Transcultural Canada." Multiculturalism in North America and Europe: Social Practices - Literary Vi- 
sions. Eds. Hans Braun, Wolfgang Kloos. Trier: Wissenschaftlicher Verlag

Trier: 1995. 180-197.

Kymlicka, Will. Finding Our Way: Rethinking Ethnocultural Relations in Canada. Oxford: Oxford University Press, 1998.

Lacan, Jacques-Marie Émile. "The Line and Light." The Four Fundamental

Concepts of Psychoanalysis. Trans. Alan Sheriden. Ed. Jacques-Alain Miller. New York: Norton, 1978.

Lach, William (ed.). New York, New York: The City in Art and Literature. New York: Metropolitan Museum of Art, 2000.

Langbaum, Robert. The Mysteries of Identity: A Theme in Modern Literature. New York: Oxford University Press, 1977.

Langlois, Paul. "Selected Data on Canada's Census Metropolitan Areas." Canadian Cities in Transition: New Directions in the Twenty-First Century. Eds. Trudi Bunting, Pierre Filion, Ryan Walker. Toronto: Oxford University Press, 2010. 448-449.

Lash, Scott, John Urry. Economies of Signs and Space: Theory, Culture \& Society. London: Sage, 1994.

Latouche, Serge. The Westernization of the World. Cambridge: Polity Press, 1996.

Lee, Chang-rae. "The Faintest Echo of Our Language." New England Review. 15.3. (Summer 1993): 85-92.

Lee, Chang-rae. A Gesture Life. London: Granta Books, 1999.

Lee, Chang-rae. Aloft. New York: Riverhead, 2004.

Lee, Chang-rae. Native Speaker. London: Granta Books, 1995.

Lee, Chang-rae. The Surrendered. New York: Riverhead, 2010.

Lee, James Kyung-Jin. "Where the Talented Tenth Meets the Model Minority: The Price of Privilege in Wideman's Philadelphia Fire and Lee's Native Speaker.” Novel. 35.2-3. (Spring/Summer 2002): 231-257.

Lee, Rachel C. "Reading Contests and Contesting Reading: Chang-rae Lee's $\mathrm{Na}$ tive Speaker and Ethnic New York." MELUS. 29.3-4. (Fall/Winter 2004): 341-352.

Lee, Richard, Sheila Pelizzon. "Hegemonic Cities in the Modern WorldSystem." Cities in the World-System. Ed. Resat Kasaba. New York: Greenwood, 1991. 43-54.

Lee, Sue-Im. "“We are not the World': Global Village, Universalism, and Karen Tei Yamashita's Tropic of Orange." Literature and Globalization: A Reader. Eds. Liam Connell, Nicky Marsh. London: Routledge, 2011. 315-331.

Lee, Wendy Ann. "Passing as Korean American." Relocating Postcolonialism. Ed. David Theo Goldberg, Ato Quayson. Oxford: Blackwell, 2002. 282-293. 
Lee, Young-Oak. "Language and Identity: An Interview with Chang-rae Lee." Amerasia Journal. 30.1. (2004). 215-227.

Lefebvre, Henri. The Production of Space. Oxford: Blackwell, 1991 [1974].

Lehan, Richard. The City in Literature: An Intellectual and Cultural History. Berkeley: University of California Press, 1998.

Levitt, Theodore: "The Globalization of Markets." Harvard Business Review. 61.3. (1983): 92-102.

Ley, David, Roman Cybriwsky. "Urban Graffiti as Territorial Markers." Annals of the Association of American Geographers. 64.4. (December 1974): 491505 .

Li, Wei. "Los Angeles' Chinese Ethnoburbs: From Ethnic Service Center to Global Economy Outpost." Urban Geography. 19.6. (1998): 502-517.

Liebes, Tamar, Elihu Katz. The Export of Meaning: Cross-Cultural Readings of Dallas. Cambridge: Polity Press, 1993.

Lim, Shirley Geok-Lin, John Blair Gamber, Stephen Hong Sohn, Gina Valentino (eds.). Transnational Asian American Literature: Sites and Transits. Philadelphia: Temple University Press, 2006.

Lindstrom-Best, Varpu. The Finnish Immigrant Community in Toronto: 18871913. Toronto: Multicultural History Society of Ontario, 1979.

Ling, Jinqi. Across Meridians: History and Figuration in Karen Tei Yamashita's Transnational Novels. Stanford: Stanford University Press, 2012.

Liu, Eric. The Accidental Asian: Notes of a Native Speaker. New York: Random House, 1998.

Lo, Lucia. "DiverCity Toronto: Canada's Premier Gateway City." Migrants to the Metropolis: The Rise of Immigrant Gateway Cities. Eds. Marie Price, Lisa Benton-Short. Syracuse: Syracuse University Press, 2008. 97-127.

Löbbermann, Dorothea. "Mapping Transculturation: Spatial Metaphor in Karen Tei Yamashita's Tropic of Orange." Transcultural Visions of Identities in Images and Texts. Transatlantic American Studies. Eds. Wilfried Raussert, Günter H. Lenz. Heidelberg: Winter, 2008. 263-279.

Löchte, Anne. Johann Gottfried Herder: Kulturtheorie und Humanitätsidee der Ideen, Humanitätsbriefe und Adrastea. Würzburg: Königshausen \& Neumann, 2005.

Lowe, Lisa, David Lloyd (eds.). The Politics of Culture in the Shadow of Capital. Durham: Duke University Press, 1997.

Lowry, Glen. “The Representation of 'Race' in Ondaatje's In the Skin of a Lion." Comparative Cultural Studies and Michael Ondaatje's Writing. Ed. Steven Tötösy de Zepetnek. West Lafayette: Purdue University Press, 2005. $62-72$. 
Ludwig, Sämi. "Ethnicity as Cognitive Identity: Private and Public Negotiations in Chang-rae Lee's Native Speaker." Journal of Asian American Studies. 10.3. (2007): 221-242.

Lurie, Alison. The Nowhere City. New York; Coward, 1965.

Lynch, Nicholas, David Ley. "The Changing Meaning of Urban Places" Canadian Cities in Transition: New Directions in the Twenty-First Century. Eds. Trudi Bunting, Pierre Filion, Ryan Walker. Toronto: Oxford University Press, 2010. 325-341.

Mall, Ram Adhar. "Interkulturalität, Intertextualität und Globalisierung." Literatur im Zeitalter der Globalisierung. Eds. Manfred Schmeling, Monika Schmitz-Emans, Kerst Walstra. Würzburg: Königshausen \& Neumann, 2000. 49-66.

Manzanas Calvo, Ana $\mathrm{M}^{\mathrm{a}}$, Jesús Benito Sánchez. Cities, Borders and Spaces in Intercultural American Literature and Film. New York: Routledge, 2011.

Marx, Karl, Frederich Engels. The Communist Manifesto. Harmondsworth: Penguin Books, 1967 [1848].

Marx, Karl. Grundrisse. Harmondsworth: Pelican, 1973.

Marzio, Peter C. (ed.). A Nation of Nations. New York: Harper and Row, 1976.

Massey, Doreen. Space, Place and Gender. Cambridge, Polity Press: 1994.

Maurer, Kathrin. "Im Zwischenraum der Sprachen: Globalität in den Texten Yoko Tawadas." Globalisierung und Gegenwartsliteratur: Konstellationen Konzepte - Perspektiven. Eds. Wilhelm Amann, Georg Mein, Rolf Parr. Heidelberg: Synchron, 2010. 323-332.

Maxwell, Thomas Robert. The Invisible French: The French in Metropolitan Toronto. Waterloo: Wilfrid Laurier University Press, 1977.

Mayo, Morrow. Los Angeles. New York: Knopf, 1933.

McGrew, Anthony G. “A Global Society?” Modernity and its Futures. Ed. Stuart Hall et al. Cambridge: Polity Press, 1992.

Meckseper, Cord, Elisabeth Schraut. Die Stadt in der Literatur. Göttingen: Vandenhoeck \& Ruprecht, 1983.

Melville, Herman. "Bartleby, the Scrivener: A Story of Wall Street." Putnam's Monthly. A Magazine of Literature, Science, and Art. 2.11. (November 1853). 546-557.

Melville, Herman. "Bartleby, the Scrivener: A Story of Wall Street." Putnam's Monthly. A Magazine of Literature, Science, and Art. 2.12 (December 1853). 609-615.

Melville, Herman. Moby-Dick; or, the Whale. New York: Harper \& Brothers, 1851. 
Michaels, Walter Benn. The Trouble with Diversity: How We Learned to Love Identity and Ignore Inequality. New York: Metropolitan Books, 2006.

Miles, Malcolm. Cities and Cultures. London: Routledge, 2007.

Miller, David, Douglas Arrowsmith. Witness to a City: David Miller's Toronto. Toronto: Cormorant Books, 2010.

Monahan, Torin. "Los Angeles Studies: The Emergence of a Specialty Field." City \& Society. 14.2. (2002): 155-184.

Moraru, Christian. "Speakers and Sleepers: Chang-rae Lee's Native Speaker, Whitman, and the Performance of Americanness." College Literature. 36.3. (Summer 2009): 66-91.

Morawska, Ewa T., Benedykt Heydenkorn, K. Kogler. Poles in Toronto: In Their Own Perception. Toronto: Canadian-Polish Congress, Canadian-Polish Research Institute, 1982.

Morrison, Toni. Jazz. London: Chatto \& Windus, 1992.

Murashige, Michael. "Karen Tei Yamashita." The Heath Anthology of American Literature. Eds. Paul Lauter et al. New York: Houghton Mifflin, 2006. 323.

Murdie, Robert, Carlos Teixeira. "Towards a Comfortable Neighbourhood and Appropriate Housing: Immigrant Experiences in Toronto.” Eds. Paul Anisef, Michael Lanphier. The World in a City. Toronto: University of Toronto Press, 2003. 132-191.

Myers-Scotton, Carol. "Codeswitching with English: Types of Switching, Types of Communities.” World Englishes. 8.3. (Winter 1989): 333-346.

Myers-Scotton, Carol. "The Possibility of Code-Switching: Motivation for Maintaining Multilingualism.” Anthropological Linguistics. 24.4. (Winter 1982): 432-444.

Nadig, Maya. "Transculturality in Process: Theoretical and Methodological Aspects Drawn from Cultural Studies and Psychoanalysis." Transculturality, Epistemology, Ethics, and Politics. Eds. Hans Jörg Sandkühler, Hong-Bin Lim. Frankfurt: Lang, 2004. 9-21.

Naipaul, V. S. The Mimic Men. London: Penguin, 1967.

Nassehi, Armin. Geschlossenheit und Offenheit: Studien zur Theorie der modernen Gesellschaft. Frankfurt: Suhrkamp, 2003.

Nederveen Pieterse, Jan. "Globalization as Hybridization." Global Modernities. Eds. Mike Featherstone et al. London: Sage, 1995.

Nederveen Pieterse, Jan. Globalization and Culture: Global Mélange. Oxford: Rowman \& Littlefield, 2004.

Nünning, Ansgar. "Formen und Funktionen literarischer Raumdarstellung: Grundlagen, Ansätze, narratologische Kategorien und neue Perspektiven." Raum und Bewegung in der Literatur: Die Literaturwissenschaften und der 
Spatial Turn. Eds. Wolfgang Hallet, Birgit Neumann. Bielefeld: transcript, 2009. 33-52.

O'Connell, Shaun. Remarkable, Unspeakable New York: A Literary History. Boston: Beacon Press, 1995.

Ohmae, Kenichi. The Borderless World: Power and Strategy in the Global Marketplace. London: HarperCollins, 1992.

Ohmae, Kenichi. The End of the Nation State: The Rise and Fall of Regional Economies. London: HarperCollins, 1995.

Olds, Kris, Henry Wai-Chung Yeung. "Pathways to Global City Formation: A View from the Developmental City-state of Singapore." Review of International Political Economy. 11.1. (2004): 389-402.

Ondaatje, Michael. In the Skin of a Lion. Toronto: McClelland \& Stewart, 1987.

Opoku-Dapaah, Edward. Somali Refugees in Toronto: A Profile. Toronto: York Lanes Press, 1995.

Ortiz, Fernando. Contrapunto Cubano (1947-1963). Caracas: Biblioteca Ayacucho, 1978.

Ortiz, Fernando. Cuban Counterpoint: Tobacco and Sugar. Durham, London: Duke University Press, 1995.

Ortiz, Vilma. "The Mexican-Origin Population: Permanent Working Class or Emerging Middle Class?" Ethnic Los Angeles. Eds. Roger David Waldinger, Mehdi Bozorgmehr. New York: Russell Sage Foundation, 1996. 247-278.

Pacione, Michael. Urban Geography: A Global Perspective. London: Routledge, 2009.

Padolsky, Enoch. "Cultural Diversity and Canadian Literature: A Pluralistic Approach to Majority and Minority Writing in Canada." New Contexts of $\mathrm{Ca}$ nadian Criticism. Eds. Ajay Heble, Donna Palmateer Pennee, J. R. (Tim) Struthers. Peterborough: Broadview Press, 1996. 24-42.

Paikeday, Thomas. The Native Speaker is Dead! Toronto: Paikeday Publishing, 1985.

Parekh, Bhikhu C. Rethinking Multiculturalism: Cultural Diversity and Political Theory. Basingstoke: Macmillan, 2000.

Park, Kyeyoung. "Korean Americans." Multiculturalism in the United States. A Comparative Guide to Acculturation and Ethnicity. Westport: Greenwood Press, 2005. 281-299.

Parker, Simon. Urban Theory and the Urban Experience: Encountering the City. London: Routledge, 2004.

Paxson, James J. "Personification's Gender." Rhetorica: A Journal of the History of Rhetoric. 16.2. (Spring 1998): 149-179. 
Perl, Anthony, Jeffrey Kenworthy. "The Canadian City at a Crossroads between 'Passage' and 'Place'." Canadian Cities in Transition: New Directions in the Twenty-First Century. Eds. Trudi Bunting, Pierre Filion, Ryan Walker. Oxford: Oxford University Press, 2010. 191-209.

Pickering, James H. (ed.). The City in American Literature. New York: Harper \& Row, 1977.

Pike, Burton. The Image of the City in Modern Literature. Princeton: Princeton University Press, 1981.

Pitkin, Thomas M. Keepers of the Gate: A History of Ellis Island. New York: New York University Press, 1975.

Polanski, Roman. Chinatown. 1974.

Porter, John Arthur. The Vertical Mosaic: An Analysis of Social Class and Power in Canada. Toronto: University of Toronto Press, 1965.

Powers, Richard. Gain. New York: Farrar, Straus \& Giroux, 1998.

Pratt, Mary Louise. Imperial Eyes: Travel Writing and Transculturation. London: Routledge, 1992.

Pynchon, Thomas. The Crying of Lot 49. Philadelphia: J. B. Lippincott, 1966.

Quan, Kenneth. Interview with Chang-rae Lee. http://www.international.ucla. edu/asia/article/11432, published May 21, 2004.

Quigley, Ellen. "Picking the Deadlock of Legitimacy: Dionne Brand's 'Noise like the World Cracking'." Canadian Literature. 186. (2005): 48-67.

Raleigh, John Henry. "The Novel and the City: England and America in the Nineteenth Century." Victorian Studies. 11.3. (March 1968): 291-328.

Rauch, Molly E. "Fruit Salad.” The Nation. 266.7. (March 1998): 28-30.

Raussert, Wilfried. "Global Cities and Cosmopolitanism Revisited: InterAmerican Mobility in Karen Tei Yamashita's Tropic of Orange." Cityscapes in the Americas and Beyond: Representations of Urban Complexity in Literature and Film. Eds. Jens Martin Gurr, Wilfried Raussert. Trier: Wissenschaftlicher Verlag Trier, 2011. 99-116.

Reckwitz, Erhard. "Postcolonially Ever After: Bemerkungen zum Stand der Postkolonialismustheorie." Anglia. 118.1. (2000): 1-40.

Reichardt, Ulfried. Globalisierung: Literaturen und Kulturen des Globalen. Berlin: Akademie Verlag, 2010.

Reif, Heinz. "Metropolises: History, Concepts, Methodologies." Thick Space: Approaches to Metropolitanism. Eds. Dorothee Brantz, Sasha Disko, Georg Wagner-Kyora. Bielefeld: transcript, 2010. 31-47.

Rhee, Michelle Young-Mee. “'Greater Lore': Metafiction in Chang-rae Lee's Native Speaker.” MELUS. 36.1. (Spring 2011): 157-176. 
Rhodes, Chip. Politics, Desire, and the Hollywood Novel. Iowa City: University of Iowa Press, 2008.

Rieff, David. Los Angeles: Capital of the Third World. New York: Simon and Schuster, 1991.

Ritzer, George. The McDonaldization of Society. Newbury Park: Pine Forge Press, 1993.

Robertson, Roland. Globalization: Social Theory and Global Culture. London: Sage, 1992.

Rodger, Richard. "The Significance of the Metropolis." Thick Space: Approaches to Metropolitanism. Eds. Dorothee Brantz, Sasha Disko, Georg WagnerKyora. Bielefeld: transcript, 2010. 85-103.

Rodriguez, Nestor, Joe R. Feagin. "Urban Specialization in the World System: An Investigation of Historical Cases." The Global Cities Reader. Eds. Neil Brenner, Roger Keil. London: Routledge, 2006. 32-41.

Rody, Caroline. The Interethnic Imagination: Roots and Passages in Contemporary Asian American Fiction. Oxford: Oxford University Press, 2009.

Roh-Spaulding, Carol. "Beyond Biraciality: 'Race' as Process in Work of Edith Eaton / Sui Sin Far and Winnifred Eaton / Onoto Watanna." Asian American Literature in the International Context. Ed. Rocio G. Davis et al. Hamburg: Lit, 2002. 21-35.

Rosaldo, Renato. "Foreword." Hybrid Cultures: Strategies for Entering and Leaving Modernity. Ed. Néstor García Canclini. Minneapolis: University of Minnesota, 1995. xi-xvii.

Rosaldo, Renato. Culture and Truth. New York: Beacon Press, 1989.

Rosenberg, Mark W., Dana H. Wilson. "Younger Cities, Older Cities, and Cities in the Balance: Spaces and Places of the Younger and Older Population." Canadian Cities in Transition: New Directions in the Twenty-First Century. Eds. Trudi Bunting, Pierre Filion, Ryan Walker. Toronto: Oxford University Press, 2010. 357-374.

Rosenthal, Caroline. New York and Toronto Novels after Postmodernism: Explorations of the Urban. Rochester, New York: Camden House, 2011.

Rotheram-Borus, Mary J. “Adolescents' Reference-group Choices, Self-esteem, and Adjustment." Journal of Personality and Social Psychology. 59.5. (Nov 1990): 1075-1081.

Ruscha, Ed. Thirtyfour Parking Lots. Los Angeles: Ed Ruscha, 1967.

Ruscha, Ed. Twentysix Gasoline Stations. Hollywood: National Excelsior Press, 1962.

Rushdie, Salman. Imaginary Homelands. London: Granta, 1991. 
Sabagh, Georges, Mehdi Bozorgmehr. "From 'Give Me Your Poor' to 'Save Our State': New York and Los Angeles as Immigrant Cities and Regions." New York \& Los Angeles: Politics, Society, and Culture. A Comparative View. Ed. David Halle. Chicago: The University of Chicago Press, 2003. 99-123.

Sachs, Jeffrey D. The End of Poverty. New York: The Penguin Press, 2005.

Sadowski-Smith, Claudia. Border Fictions: Globalization, Empire, and Writing at the Boundaries of the United States. Charlottesville: University of Virginia Press, 2008.

Said, Edward. Culture and Imperialism. London: Vintage, 1994.

Said, Edward. Orientalism. New York: Vintage 1978.

Sassen, Saskia. "Analytic Borderlands: Race, Gender and Representation in the New City." Re-Presenting the City: Ethnicity, Capital and Culture in the Twenty-First Century Metropolis. Ed. Anthony D. King. New York: New York University Press, 1996. 183-202.

Sassen, Saskia. "The Global City: Introducing a Concept." XI.2. (Winter/Spring 2005): 27-43.

Sassen, Saskia. "The Global City: Strategic Site/New Frontier." American Studies. 41.2-3. (Summer/Fall 2000): 79-95.

Sassen, Saskia. The Global City: New York, London, Tokyo. Princeton: Princeton University Press, 1991.

Sawhney, Deepak Narang, ed. Unmasking LA: Third Worlds and the City. New York: Palgrave Macmillan, 2002.

Schmeling, Manfred, Monika Schmitz-Emans, Kerst Walstra (eds.). Literatur im Zeitalter der Globalisierung. Würzburg: Königshausen \& Neumann, 2000.

Schmitz-Emans, Monika. "Globalisierung im Spiegel literarischer Reaktionen und Prozesse." Literatur im Zeitalter der Globalisierung. Ed. Manfred Schmeling et al. Würzburg: Königshausen \& Neumann, 2000. 285-315.

Schnell, Ralf (ed.) Metzler Lexikon Kultur der Gegenwart: Themen und Theorien, Formen und Institutionen seit 1945. Stuttgart, Weimar: J. B. Metzler, 2000.

Scholte, Jan Art. Globalization: A Critical Introduction. London: Macmillan, 2000 .

Schulze-Engler, Frank, Sissy Helff (eds.). Transcultural English Studies: Theories, Fictions, Realities. ASNEL Papers 12. Amsterdam, New York: Rodopi, 2009.

Schulze-Engler, Frank. "Von 'Inter' zu 'Trans': Gesellschaftliche, kulturelle und literarische Übergänge." Inter- und Transkulturelle Studien: Theoretische Grundlagen und interdisziplinäre Praxis. Ed. Heinz Antor. Heidelberg: Winter, 2006. 41-53. 
Scott, Allen John (ed.). The City: Los Angeles and Urban Theory at the End of the Twentieth Century. Berkeley: University of California Press, 1998.

Sennett, Richard. The Conscience of the Eye: The Design and Social Life of Cities. New York: Norton, 1990.

Shaw, Rhonda. "Border Crossing Between Sociology and Bioethics." New Zealand Sociology. 21.2. (2006): 173-195.

Shevtsova, Maria. "Dialogism in the Novel and Bakhtin's Theory of Culture." New Literary History. 23.3. History, Politics, and Culture. (Summer 1992): 747-763.

Shiel, Mark (ed.). Cinema and the City: Film and Urban Societies in a Global Context. Oxford: Blackwell, 2001.

Short, John Rennie. "Urban Imagineers: Boosterism and the Representation of Cities." The Urban Growth Machine: Critical Perspectives Two Decades Later. Eds. Andrew E. G. Jonas, David Wilson. Albany: State University of New York Press, 1999. 37-54.

Sieg, Christian. "Von Alfred Döblin zu Terézia Mora: Stadt, Roman und Autorschaft im Zeitalter der Globalisierung." Globalisierung und Gegenwartsliteratur: Konstellationen - Konzepte - Perspektiven. Eds. Wilhelm Amann, Georg Mein, Rolf Parr. Heidelberg: Synchron, 2010. 193-208.

Siemiatycki, Myer, Tim Rees, Roxana Ng, Khan Rahi. Integrating Community Diversity in Toronto: On Whose Terms? CERIS Working Paper Series No. 14. Toronto: Joint Centre of Excellence for Research on Immigration and Settlement, 2001.

Singh, Rajendra (ed.). The Native Speaker: Multilingual Perspectives. New Delhi: Sage, 1998.

Siskind, Mariano. "The Globalization of the Novel and the Novelization of the Global: A Critique of World Literature." Comparative Literature. 62.4. (2010): 336-360.

Slethaug, Gordon E. The Play of the Double in Postmodern American Fiction: The History of the Double. Traditional and Postmodern Versions. Southern Illinois University: Southern Illinois University Press, 1993.

Smith, David, Michael Timberlake. "Hierarchies of Dominance Among World Cities: A Network Approach." Global Networks, Linked Cities. Ed. Saskia Sassen. New York: Routledge, 2002.

Smith, Michael Peter, Joe R. Feagin. The Capitalist City. Oxford: Blackwell, 1987.

Smith, William. "Fluid Translations: Counter Torontos in David Bezmozgis's Natusha and Other Stories and Dionne Brand's What We All Long For." 
Canada Exposed: Canadian Studies. Eds. Pierre Anctil, André Loiselle, Christopher Rolfe. Brussels: P.I.E. Peter Lang, 2009. 243-253.

Soja, Edward W, Allen J. Scott. "Introduction to Los Angeles: City and Region."

The City: Los Angeles and Urban Theory at the End of the Twentieth Century. Ed. Allen J. Scott. Berkeley: University of California Press, 1998, 1-21.

Soja, Edward W. "Taking Space Personally." The Spatial Turn: Interdisciplinary

Perspectives. Ed. Barney Warf et al. London: Routledge, 2009. 11-35.

Soja, Edward W. "The Stimulus of a Little Confusion: A Contemporary Comparison of Amsterdam and Los Angles." The Global Cities Reader. Eds. Neil Brenner, Roger Keil. Oxon: Routledge, 2006.

Soja, Edward W. Postmetropolis: Critical Studies of Cities and Regions. Oxford: Blackwell, 2000.

Soja, Edward W. Postmodern Geographies: The Reassertion of Space in Critical Social Theory. London: Verso, 1989.

Song, Min Hyoung. Strange Future: Pessimism and the 1992 Los Angeles Riots.

Durham: Duke University Press, 2005.

Sorapure, Madeleine. "The Detective and the Author: City of Glass." Beyond the Red Notebook: Essays on Paul Auster. Ed. Dennis Barone. Philadelphia: University of Pennsylvania Press, 1995. 71-87.

Sorkin, Michael. "Explaining Los Angeles." California Counterpoint: New West Coast Architecture 1982. San Francisco: San Francisco Art Institute, 1982.

Spivak, Gayatri Chakravorty. Death of a Discipline. New York: Columbia University Press, 2003.

Steinmetz, Horst. "Globalisierung und Literatur(geschichte)." Literatur im Zeitalter der Globalisierung. Eds. Manfred Schmeling, Monika Schmitz-Emans, Kerst Walstra. Würzburg: Königshausen \& Neumann, 2000. 189-201.

Stockhammer, Robert. "und: Globalisierung, sprachig - Literatur (Gegenwart?, deutsch?)." Globalisierung und Gegenwartsliteratur: Konstellationen - Konzepte - Perspektiven. Eds. Wilhelm Amann, Georg Mein, Rolf Parr. Heidelberg: Synchron, 2010. 333-352.

Sturm-Trigonakis, Elke. Global Playing in der Literatur: Ein Versuch über die neue Weltliteratur. Würzburg: Königshausen und Neumann, 2007.

Sudjic, Deyan. The 100-mile City. San Diego: Harcourt Brace, 1992.

Tawada, Yoko. Überseezungen. Tübingen: konkursbuch, 2002.

Taylor, John Russell. Strangers in Paradise: The Hollywood Émigrés 19331950. London: Faber \& Faber, 1983.

Taylor, Peter J. "Leading World Cities: Empirical Evaluation of Urban Nodes in Multiple Networks." Urban Studies. 42.9. (2005): 1593-1608. 
Taylor, Peter J. World City Network: A Global Urban Analysis. London: Routledge, 2004.

Taylor, Peter J., David R. F. Walker, Gilda Catalano, Michael Hoyler. "Diversity and Power in the World City Network." Cities. 19. (2002): 231-241.

Thompson, Richard H. Toronto's Chinatown: The Changing Social Organization of an Ethnic Community. New York: AMS Press, 1989.

Tomlinson, John. Globalization and Culture. Cambridge: Polity Press, 2001.

Torczyner, James L., Shari L. Brotman, Jay Brodbar. Rapid Growth and Transformation: Demographic Challenges Facing the Jewish Community of Greater Toronto. Montreal: McGill Consortium for Ethnicity \& Strategic Social Planning, in conjunction with: Council of Jewish Federations-Canada, Jewish Federation of Greater Toronto, Statistics Canada, 1995.

Troper, Harold. "Becoming an Immigrant City: A History of Immigration into Toronto since the Second World War." The World in a City. Eds. Paul Anisef, Michael Lanphier. Toronto: University of Toronto Press, 2003. 19-62.

Troper, Harold. History of Immigration since the Second World War: From Toronto "The Good" to Toronto "The World in a City." CERIS Working Paper No.12. Toronto: Joint Centre of Excellence for Research on Immigration and Settlement, 2000.

Ty, Eleanor, Donald C. Goellnicht. "Introduction to Asian North American Identities: Beyond the Hyphen." Asian-American Writers. Ed. Harold Bloom. New York: Bloom's Literary Criticism. 2009. 123-137.

Ulin, David L. Writing Los Angeles: A Literary Anthology. Los Angeles: Library of America, 2002.

Vanderwerken, David L. "Manhattan Transfer: Dos Passos' Babel Story.” American Literature. 49.2. (May 1977): 253-267.

Vasconcelos, José. La Raza Cósmica. Barcelona: Agencia Mundial de Librería, 1925.

Veronis, Luisa. Rethinking Transnationalism: Latin Americans' Experiences of Migration and Participation in Toronto. Toronto: CERIS - The Ontario Metropolis Centre, 2006.

Vinodrai, Tara. "The Dynamics of Economic Change in Canadian Cities: Innovation, Culture, and the Emergence of a Knowledge-Based Economy." Canadian Cities in Transition: New Directions in the Twenty-First Century. Eds. Trudi Bunting, Pierre Filion, Ryan Walker. Toronto: Oxford University Press, 2010. 87-109.

Walcott, Rinaldo. "Against Institution: Established Law, Custom, or Purpose." Trans.can.lit.: Resituating the Study of Canadian Literature. Ed. Smaro Kamboureli. Waterloo: Wilfrid Laurier University Press, 2007. 17-24. 
Walcott, Rinaldo. "Toronto: A Many-Textured Thing." Revision of What We All Long For by Dionne Brand. Globe and Mail [Toronto] 22 Jan. 2005: D6.

Waldinger, Roger. "From Ellis Island to LAX: Immigrant Prospects in the American City." International Migration Review. 30.4. (Winter, 1996): 1078-1086.

Walks, R. Alan, Larry S. Bourne. "Ghettos in Canada's Cities? Racial Segregation, Ethnic Enclaves and Poverty Concentration in Canadian Urban Areas." The Canadian Geographer. 50.3. (2006): 273-297.

Wallace, Molly. "Tropics of Globalization: Reading the New North America." Symploke. 9.1. (2001): 145-160.

Watt, Ian. The Rise of the Novel: Studies in Defoe, Richardson and Fielding. London: Chatto \& Windus, 1974 [1959].

Wei, Li (ed.). The Bilingualism Reader. London: Routledge, 2000.

Weidtmann, Nils. "Postkoloniale Identitätssuche: Die innerkulturellen Krisen und der interkulturelle Dialog." Räume der Hybridität: Postkoloniale Konzepte in Theorie und Literatur. Ed. Christof Hamann et al. Hildesheim: Georg Olms Verlag, 2002. 109-124.

Weigel, Sigrid. “Zum 'topographical turn': Kartographie, Topographie und Raumkonzepte in den Kulturwissenschaften." KulturPoetik. 2.2. (2002): 151165.

Welsch, Wolfgang. "On the Acquisition and Possession of Commonalities." Transcultural English Studies. Theories, Fictions, Realities. Eds. Frank Schulze-Engler, Sissy Helff. ASNEL Papers 12. Amsterdam, New York: Rodopi, 2009. 3-36.

Welsch, Wolfgang. "Transculturality - the Puzzling Form of Cultures Today." Spaces of Culture: City, Nation, World. Ed. Mike Featherstone et al. London: Sage, 1999. 194-213.

Welsch, Wolfgang. "Transkulturalität: Zur veränderten Verfassung heutiger Kulturen.“ Hybridkultur: Medien, Netze, Künste. Eds. Irmela Schneider, Christian W. Thompson. Köln: Wienand, 1997. 67-88.

Werbner, Pnina. "Introduction: The Dialectics of Cultural Hybridity." Debating Cultural Hybridity: Multi-Cultural Identities and the Politics of Anti-Racism. Ed. Pnina Werbner et al. London: Zed Books, 1997. 1-26.

West, Nathaniel. The Day of the Locust. New York: Signet Classics, 1983 [1939].

Wharton, Edith. The Age of Innocence. New York: D. Appleton \& Company, 1920. 
Whelan, Carol Zapata. “'Do I Contradict Myself?': Progression through Contraries in Walt Whitman's 'The Sleepers'." Walt Whitman Quarterly Review. 10.1. (Summer 1992): 25-39.

Whitman, Walt. Leaves of Grass. Boston: Thayer and Eldridge, 1855.

Williams, Hugo. No Particular Place to Go. London: Jonathan Cape, 1981.

Wilson, Elizabeth. The Sphinx in the City: Urban Life, the Control of Disorder, and Women. Virago: London, 1991.

Wilson, Rita. "Cultural Mediation through Translingual Narrative." Target. 23.2. (2011): 235-250.

Wilson, Sarah. Melting-Pot Modernism. London: Cornell University Press, 2010. Winland, Daphne Naomi. We are Now a Nation: Croats between 'Home' and 'Homeland'. Toronto: University of Toronto Press, 2007.

Wirth-Nesher, Hana. City Codes: Reading the Modern Urban Novel. Cambridge: Cambridge University Press, 1996.

Wolf, Werner. "Description as a Transmedial Mode of Representation: General Features and Possibilities of Realization in Painting, Diction and Music." Description in Literature and Other Media. Eds. Werner Wolf, Walter Bernhart. Amsterdam: Rodopi, 2007. 1-87.

Wong, Paul, Chienping Faith Lai, Richard Nagasawa, Tieming Lin. "Asian Americans as a Model Minority: Self-Perceptions and Perceptions by Other Racial Groups.” Sociological Perspectives. 41.1. (1998): 95-118.

Wright, Chantal. "Exophony and Literary Translation: What it Means for the Translator when a Writer Adopts a New Language.” Target. 22.1. (2010): 22-39.

Wu, Frank H. Yellow: Race in America beyond Black and White. New York: Basic Books, 2002.

Wu, William F. The Yellow Peril: Chinese Americans in American Fiction. 1850-1940. Hamden: Archon Books, 1982.

Wunderli, Peter. Ferdinand de Saussure und die Anagramme: Linguistik und Literatur. Tübingen, Niemeyer, 1972.

Wyler, William (dir., prod.). Detective Story. Paramount Pictures, 1951.

Xiaojing, Zhou, Samina Najmi (eds.). Form and Transformation in Asian American Literature. Seattle: University of Washington Press, 2005.

Yamashita, Karen Tei, Ryuta Imafuku. "The Latitude of the Fiction Writer: A Dialogue.” 22 Feb 1999 Visions of Archipelago. Café Creole. 13 March 2008 $<$ http://www.cafecreole.net/archipelago/Karen_Dialogue.html $>$.

Yamashita, Karen Tei. Brazil-Maru. Minneapolis: Coffee House Press, 1992. Yamashita, Karen Tei. Circle K Cycles. Minneapolis: Coffee House Press, 2001. Yamashita, Karen Tei. I Hotel. Minneapolis: Coffee House Press, 2010. 
Yamashita, Karen Tei. Through the Arc of the Rainforest. Minneapolis: Coffee House Press, 1990.

Yamashita, Karen Tei. Tropic of Orange. Minneapolis: Coffee House Press, 1997.

Yoo, Jane. "Book Review: Cultural Alienation and the Asian American Changrae Lee, Native Speaker." Asian American Policy Review. 14. (January 2005): 57-59.

Young, Robert J. C. Colonial Desire. Hybridity in Theory, Culture and Race. London, New York: Routledge, 1995.

Zangwill, Israel. The Melting-pot: Drama in Four Acts. New York: Macmillan, 1916 [1909].

Zucchi, John E. Italians in Toronto: Development of a National Identity 18751935. Kingston: McGill-Queen's University Press, 1988.

Zukin, Sharon. The Cultures of Cities. Cambridge: Blackwell, 1995. 
